APAE No. 54

SUPPLEMENT 1

AEC Research and

Development Report

UC-81, Reactors-Power

(Special Distribution)

\title{
EXTENDED SM-2 CRITICAL EXPERIMENTS
}

$$
\text { CE-2 }
$$
W. J. McCool
By
R. A. Robinson
T. M. Raby
S. H. Weiss
E. W. Schrader
L. D. Walthousen

Approved by:

W. J. McCool, Supervisor, Critical Facility

Issued: June 30, 1961

Contract No. AT(30-3)-326

with U. S. Atomic Energy Commission

New York Operations Office

\author{
ALCO PRODUCTS, INC. \\ Nuclear Power Engineering Department \\ Post Office Box 414 \\ Schenectady 1, N.Y.
}




\section{ABSTRACT}

This report contains a description and results of a second series of critical experiments performed on the SM-2 core mockup, as additional to the first series of experiments reported in APAE No. 54. The SM-2 core mockup contains $36.4 \mathrm{~kg}$ U-235 and an estimated $67.9 \mathrm{gm} \mathrm{B-10}$. The equivalent dianeter and the active height are about 22 in. ; the metal-to-water volume ratio is 0.344 . Data is presented on activation, reactivity, and stuck rod measurements. All measurements were conducted on the open seven control rod array employing 38 stationary fuel elements.

Activation measurements consisted of neutron flux measurements using uranium fission foils for relative power distribution studies, the effect of fiux suppressors on reducing power peaks, blocked coolant channel measurements, and gamma ray dose distribution. Reactivity measurements were performed to determine the effect of flow divider, flux suppressors and simulated high temperature and pressure operation; B-10 loading in the SM-2 core; and core material coefficients. For the latter, the worth in cents per gm or cents per cc was determined at simulated temperature of $510^{\circ} \mathrm{F}$ for $\mathrm{B}-10, \mathrm{U}-235$, stainless steel, and void. Stuck rod measurements were made to obtain an indication of the criticality margin in the event one or more control rods should stick in the operating position.

\section{ACKNOWLEDGEMENT}

The authors gratefully acknowledge the contribution of F. L. Hess, Associated Nucleonics, Inc., in preparation of portions of this report. 


\section{TABLE OF CONTENTS}

\section{Page}

ABSTRACT

SUMMARY

INTRODUCTION

1.0 SYSTEM DESCRIPTION

1.1 Introduction

1.2 Experimental Assembly

1. 2.1 Core Support Assembly $1 . .+\ldots 5$

1.2. 2 Control Rod Assembly

1.2. 3 Fuel Element Structure

1.2. 4 Steel Reflector Assembly _...

1.2. 5 Flow Divider

1.2. 6 Neutron Source

1. 3 Experimental Techniques

1.3.1 Reactivity Measurements

1. 3.2 Boron Loading

1.4 Nomenclature and Explanations-......

1.4.1 Active Core-1. 1.5

1.4.2 Control Rod Withdrawal _........ 7

1.4. 3 Control Rod Position _...

1.4.4 Control Rod Array -............. 7

1.4.5 Data Point, Experimental _... 7

1.4. 6 Temperature -................. 7

2. 0 REACTIVITY MEASUREMENTS $\ldots \ldots \ldots \ldots$

2.1 introduction-...........

2. 2 B-10 Loading in the SM-2 Core Mockup from Core

Reactivity Measurements _........... 17

2. 2.1 Introduction- . . . .

2.2.2 Experimental Procedure and Results $\ldots . . . . . . .18$ 
2.3 Material Coefficients

2.3.1 Introduction- .

2. 3. 2 Procedure

2.3. 3 Heterogeneity Effect

2. 3.4 U-235 Worth

2. 3.5 B-10 Worth - . . . . . . 26

2. 3. 6 Stainless Steel Worth

2. 3. 7 Void Worth .................. 30

2.4 Reactivity Measurements Using Flow Divider . . . . . . . 31

2. 5 Suppressor Reactivity -

2.6 Additional Reactivity Measurements _..... $6 . \ldots \ldots \ldots . . . .33$

2.6.1 Effect of Mockup Control Rod Suppressors - . . . . . 33

2.6.2 Worth of Side Plates -................... 34

3. 0 ACTIVATION MEASUREMENTS -

3.1 Introduction $\ldots \ldots \ldots \ldots+\ldots 37$

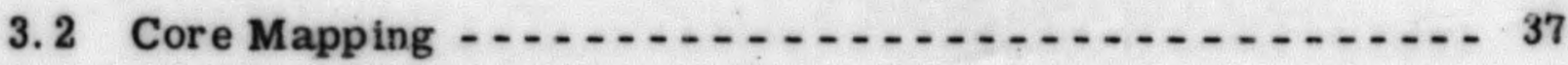

3.2. 1 introduction

3.2.2 Procedure-...

3.2. 3 Nomenclature

3.2.4 Data Processing- . . . . . . . . . . . . . 39

3.2. 5 Core Average . . . . . . . . . . . . . . . . . . 39

3.2. 6 Experimental Results Employing Laminated Steel Reflectors Without Flow Divider.(SM-2 Preliminary Mockup Core). ........... 40

3.2.7 Experimental Results Employing Laminated Steel Reflector, Flow Divider, and Flux Suppressors At the Top of the Active Meat of the Control Rod Fuel Elements (SM-2 Final Mockup Core) -........ 41

3.2. 8 Conclusions.......................... 91

3. 3 Flux Suppressor Measurements _...

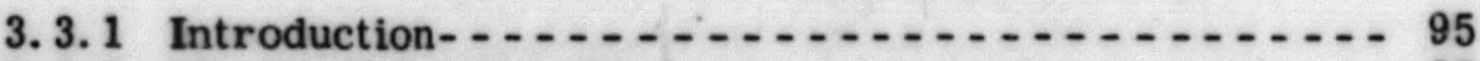

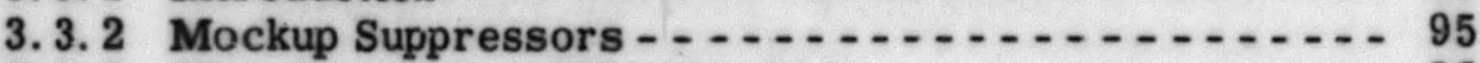

3. 3. 3 Flux Suppressor Effectiveness _... . . . . . . . . 96

3. 3.4 Integral Suppressors- ................. 96 


\section{TABLE OF CONTENTS (CONT'D)}

3. 4 Blocked Channel Measurements

3.4.1 Introduction-

3. 4.2 Experimental Method -................. 105

3. 4. 3 Water Reflected Core Measurements .......... 105

3.4.4 Steel Reflected Core Measurements-........... 105

4. 0 MISCELLANEOUS MEASUREMENTS - $\ldots \ldots \ldots \ldots \ldots$

4. 1 Gamma Ray Dose Measurements- 115

4.1.1 Experimental Techniques- _.

4.1.2 Experimental Results -.................. 121

4. 2 Seven Rod Bank Calibration at Simulated Elevated Temp-

erature and Pressure

4. 2.1 Introduction- . . . . .

4. 2.2 Calibration Technique - .

4. 2. 3 Simulation of Operating Conditions - .

4. 2. 4 Reactivity Change Due to Operation at $510^{\circ} \mathrm{F}$ and 2000 psi - . . .

4. 3 Stuck Rod Measurements - .

REFERENCES - . 135 APPENDCX A: Calculation Procedures Used to Determine B-10 Loading - A-1

A. 1 Calibration of Standard Tapes

A. 2 Intercalibration of Tapes

A. 3 Intercalibration of SM-2 Mockup Fuel Plates-....... A-2

A. 4 Intercalibration of Elements

A. 5 B-10 Worth Calculation of Assembled Mockup Element - .... A-4

A. 6 Comparison of BMI Reference and Mockup Element 


\section{TABLE OF CONTENTS (CONT'D)}

Page

APPENDIX B: Typical Calculation Procedure for Obtaining the

$$
\text { Core Average-........ B-1 }
$$

B. 1 Experimental Data Obtained Using Preliminary Mockup

as an Example -.................. B-1

B. 2 Calculation of Average Flux Across Plate "a" in Radial Direction Using Simpson's Rule .......... B-2

B. 3 Calculation of Average Power Along Plate "a" in an Axial Direction ............... B-3

B. 4 Calculation of Cell Average

B. 5 Calculation of Core Average

B. 6 Normalization of Data

APPENDLX C: Determination of B-10 Content of Boron Tapes - 


\section{LIST, OF FIGURES}

Figure

Title

- Page

1.1 Core Support Structure

1.2 Cross Section of SM-2 Core Mockup with Stainless Steel Reflector

1. 3

SM-2 Core in Reactor Tank

1.4

Control Rod Assembly

1. 5 Stationary Fuel Element

1.6 Control Rod Fuel Element

1. 7

Flow Divider Location

1.8 Boron Tape Applicator

2.1 Heterogeneity Factor, Uranium Worth vs. No. of Stainless Steel Bundles, Element in Position 33

3.1 Uranium Foil Locations on Element in Position 13

3.2 Fuel Plate Arrangement

3. 3 Location of Radial Planes Without Flow Divider, Section of Core Through Center of Elements in Positions $41,42,43$ and 44

3.4 Relative Power Distribution in SM-2 Preliminary Mockup Core, Normalized to Core Average

3. 5 Relative Power Distribution Along Axial Traverse on Centerline of Fuel Plate " $\mathrm{j}$ ", Elements in Positions 12, 13 and 14, SM-2 Preliminary Mockup Core

3. 6 Relative Power Distribution Along Axial Traverse on Centerline of Fuel Plate " $\mathrm{j}$ ", Elements in Positions 21, 22 and 23, SM-2 Preliminary Mockup Core

3. 7 Relative Power Distribution Along Axial Traverse on Centerline of Fuel Plate "j", Elements in Positions 31, 33 and 34, SM-2 Preliminary Mockup Core 


\section{LIST OF FIGURES (CONT'D)}

3.8 Relative Power Distribution Along Axial Traverse on Centerline of Fuel Plate "j",Elements in Positions 41, 42 and 43, SM-2 Preliminary Mockup Core

3.9 Relative Power Distribution Along Axial Traverse on Centerline of Fuel Plate "i" of Control Rods A, C and F, SM-2 Preliminary Mockup Core

Relative Power Distribution Along Radial Traverse 5 in. Above Bottom of Active Core, SM-2 Preliminary Mockup Core

3.11 Relative Power Distribution in the SM-2 Final Mockup Core, Normalized to Core Average

3.12 Relative Power Distribution Along Axial Traverse on Centerline of Fuel Plate "j", Elements in Positions 12, 13. and 14, SM-2 Final Mockup Core

3.13 Relative Power Distribution Along Axial Traverse on Centerline of Fuel Plate "j",Elements in Positions 21, 22 and 23, SM-2 Final Mockup Core

3.14 Relative Power Distribution Along Axial Traverse on Centerline of Fuel Plate " $\mathrm{j}$ ",Elements in Positions 31, 33 and 34, SM-2 Final Mockup Core

3.15 Relative Power Distribution Along Axial Traverse on Centerline of Fuel Plate "j",Elements in Positions 41, 42 and 43, SM-2 Final Mockup Core

3.16 Relative Power Distribution Along Axial Traverse on Centerline of Fuel Plate " $\mathrm{i}$ " of Control Rods A, C and F, SM-2 Final Mockup Core

3.17 Relative Power Distribution Along Radial Traverse 5 in. Above Bottom of Active Core, SM-2 Final Mockup Core

3.18 Relative Power Distribution Along Axial Traverse on Centerline of Fuel Plate "i", of Control Rod C, SM-2 Preliminary and Final Mockup Cores

3.19 Relative Power Distribution Along Radial Traverse at Top of the Active Core of Fuel Plate " $i$ " of Control Rods A, C and F, SM-2 Preliminary and Final Mockup Cores 


\section{LIST OF FIGURES (CONT'D)}

Figure

Title

Page

3.20 Relative Power Distribution Along Axial Traverse of Fuel Plate "j", Element in Position 41 Using Flux Suppressors, SM-2 Preliminary Mockup Core

3.21 Relative Power Distribution Along Axial Traverse of Fuel Plate "j", Element in Position 42 Using Flux

Suppressors, SM-2 Preliminary Mockup Core

3.22 Relative Power Distribution Along Axial Traverse of Fuel Plate "j", Element in Position 43 Using Flux

Suppressors, SM-2 Preliminary Mockup Core

3.23 Relative Power Distribution Along Axial Traverse at

1. 78 in. W.R.P. of Fuel Plate "r", Element in Position 43 Using Flux Suppressors, SM-2 Preliminary Mockup Core

Thermocouple Plate, SM-2 Critical Facility Test

3.25 Blocked Channel Filler Pọsition and Normal Fuel Plate Array

3. 26 Relative Power Distribution Along Axial Traverse on Centerline of Fuel Plates " $\mathrm{i}$ " and " $\mathrm{j}$ " Blocked Channel Measurements made in SM-2 Core Mockup with Water Reflector, Without Flow Divider

3. 27 Relative Power Distribution Along Axial Traverse on Centerline Between Fuel Plates " $\mathrm{c}$ " and " $\mathrm{j}$ ", Elements in Positions 42 and 46, Blocked Channel Measurements Made in SM-2 Core Mockup with Steel Reflector Without Flow Divider

Location of Film Badges on Fuel Elements and Steel

Reflector for Garnma Ray Dose Measurements

Location of Film Badges on Core
Gamma Ray Dose Measurements 


\section{LIST OF FIGURES (CONT'D)}

Figure

Title

Page

4. 5 Gamma Ray Dose Measurements, SM-2 Preliminary Mockup Core

4. 6 Sever: Rod Bank Calibration Curve at Simulated $510^{\circ} \mathrm{F}$ and 2000 psi Conditions, SM-2 Mockup Core with Steel Rellector and Flow Divider

4.7 Density of Water vs. Temperature at 2000 psi

4.8 No. of Aluminum Strips per Fuel Element Required to Simulate Operating Temperature of the SM-2 Reactor at 2000 psi

4. 9 Composite Seven Rod Bank Calibration Showing Calibration at $2000 \mathrm{psi}$ and $510^{\circ} \mathrm{F}$

A. 1 Control Rod E Calibration Curve

A-5

A. 2 B-10 Worth of Standards in Element Position

22 Plate "i"

A-6

A. 3

Log N Slope vs. Reactivity

A-7

B.1 Relative Power Distribution of Average Radial Power for Plate "a", Element in Position 12 


\section{LIST OF 'TABLES}

Table

Title

Page

2.1 B-10 Loading of Intercalibrated Tapes Tested in Element Position 22, Fuel Plate "i"

2.2 B-10 Lsading of 18 Intercalibrated Fuel Plates Tested in Element Position 22, Plate Position " $i$ "

2.3 B-10 Loading of 10 Intercalibrated SM-2 Mockup Fuel

Elements Tested in Element Position 22

Displacement Not Included)

2. $7 \quad$ Void Reactivity Coefficients

2.8 Reactivity Measurements Evaluating the Installation of Flow Divider

3.1 Relative Power Distribution Along Axial Traverses for Element in Position 12, SM-2 Preliminary Mockup Core

3. 3 Relative Power Distribution Along Axial Traverse for Element in Position 14, SM-2 Preliminary Mockup Core

3.4 Relative Power Distribution Along Axial Traverse for Element in Position 21, SM-2 Preliminary Mockup Core

3.5 Relative Power Distribution Along Axial Traverses for Element in Position 22, SM-2 Preliminary Mockup Core

3. 8 Relative Power Distribution Along Axial Traverses for Element in Position 33, SM-2 Preliminary Mockup Core 


\section{LIST OF-TABLES (CONT'D)}

Table

Title

Page

3.9 Relative Power Distribution Along Axial Traverses for Element in Position 34, SM-2 Preliminary Mockup Core

3. 10 Relative Power Distribution Along Axial Traverses for Element in Position 41, SM-2 Preliminary Mockup Core

Relative Power Distribution Along Axial Traverses for Element in Position 42, SM-2 Preliminary Mockup Core

Relative Power Distribution Along Axial Traverses for Element in Position 43, SM-2 Preliminary Mockup Core

Relative Power Distribution Along Axial Traverses for Element in Position 24 (Controi Rod A), SM-2 Preliminary Mockup Core

3.14 Relative Power Distribuciun Along Axial Traverses for Element in Position 44 (Control Rod C), SM-2 Preliminary Mockup Core

Relative Power Distribution Along Axial Traverses for Element in Position 32 (Control Rod F), SM-2 Preliminary Mockup Core

Relative Power Distribution Along Axial Traverses for Element in Position 12, SM-2 Final Mockup Core

Relative Power Distribution Along Axial Traverses for Element in Position 13, SM-2 Final Mockup Core

Relative Power Distribution Along Axial Traverses for Element in Position 14, SM-2 Final Mockup Core

Relative Power Distribution Along Axial Traverses for Element in Position 21, SM-2 Final Mockup Core

Relative Power Distribution Along Axial Traverses for Element in Position 22, SM-2 Final Mockup Core

Relative Power Distribution Along Axial Traverses for Element in Position 23, SM-2 Final Mockup Core 


\section{LIST OF TABLES (CONT'D)}

3.23 Relative Power Distribution Along Axial Traverses for Element in Position 33, SM-2 Final Mockup Core

3.25 Relative Power Distribution Along Axial Traverses for Element in Position 41, SM-2 Final Mockup Core

3.27 Relative Power Distribution Along Axial Traverses for Element in Position 43, SM-2 Final Mockup Core

3. 29 Relative Power Distribution Along Axial Traverses for Element in Position 44 (Control Rod C), SM-2 Final Mockup Core

Relative Power Distribution Along Axial Traverses for Element in Position 32 (Control Rod F), SM-2 Final Mockup Core

Relative Power Distribution Along Axial Traverses for Element in Position 41, SM-2 Preliminary Mockup Core with Suppressor Mockups

3. 32 Relative Power Distribution Along Axial Traverses for Element in Position 42, SM-2 Preliminary Mockup Core With Suppressor Mockups

Relative Power Distribution Along Axial Traverses for Element in Position 43, SM-2 Preliminary Mockup Core with Suppressor Mockups

Relative Power Distribution Along Axial Traverses for Element in Position 43, SM-2 Preliminary Mockup with Integral Suppressors in Element Position 43 


\section{LIST OF TABLES (CONT'D)}

Table

Title

Page

3.35 Relative Power Distribution Along Axial Traverses for Element in Position 42, Blocked Channel Measurements, SM-2 Mockup Core with Water Reflector, Without Flow Divider

3. 36 Relative Power Distribution Along Axial Traverses for Element in Position 42, Blocked Channel Measurements, SM-2 Preliminary Mockup Core

3. 37 Relative Power Distribution Along Axial Traverses for Element in Position 46, Clear Channel Measurements, SM-2 Preliminary Mockup Core

3. 38 Ratios of Clear Channel to Blocked Channel, Relative Power Measurements for Elements in Positions 46 and 42, SM-2 Preliminary Mockup Core

4.1 Gamma Ray Dose Measurements and Film Badge Locations

4. 2 Gamma Ray Dose Measurements and Film Badge Locations

4. 3 Calibration of Control Rod Bank Under Simulated Operating Conditions of $2000 \mathrm{psi}$ and $510^{\circ} \mathrm{F}$

4. 4 Critical Rod Configurations

B. 1

Experimental Foil Activation Data for Elenen 12

B. 2

Data for Obtaining the Average Power of the SM-2

Preliminary Mockup Core

C. 1

B-10 Analysis

C-1 


\section{SUMMARY}

A second series of critical experiments were performed on the final SM-2 mockup core to provide additional key data to that reported in APAE No. 54. * Measurements consisted of:

\section{A. REACTIVITY MEASUREMENTS}

The SM-2 mockup core contains an estimated $67.9 \mathrm{gm}$ of B-10 distributed uniformly, averaging $1.552 \mathrm{gm}$ per stationary fuel element and $1.282 \mathrm{gm}$ per control rod fuel element.

Core material coefficients were determined at simulated temperature of $510^{\circ} \mathrm{F}$ attained by inserting strips of aluminum between the fuel plates. The estimated average worths of materials in the core were 0.131 cents/gm for U-235, 3. 49 cents/gm for B-10, 0.0276 cents/cc for stainless steel and 0.0509 cents/ce for void.

The use of mockup flux suppressors at the bottom of the stationary fuel elements produced estimated reactivity changes for the entire core of $\mathbf{- 2 3 6}$ cents and -241 cents for $1 / 2$-in. and $3 / 4$-in. wide suppressors, respectively. The placing of $1 / 2$-in. wide mockup flux suppressors above the active meat of the fuel plates of the seven control rod fuel elements produced a negative reactivity change of 116.1 cents; the placing of these suppressors at the top of the active meat increased the negative reactivity change by 38.9 cents to 155.0 cents

Reactivity measurements conducted with a flow divider show a core reactivity loss of 165 cents when the flow divider is installed with stainless steel support plates; a loss of 143 cents results when it is attached to the reflector by support pins.

\section{B. ACTIVATION MEASUREMENTS}

The relative power distribution for two SM-2 mockup cores was obtained by foil activation. One mockup employed a laminated steel reflector without flow divider; the other employed a laminated steel reflector, flow divider, and flux suppressors at top of the active meat of control rod fuel elements. In each case an extensive number of data points (approximately 1700) were taken and reported for one quadrant of the core permitting the determination of an accurate core average and a detailed description of local effects.

* Noaks, J.W., et al, "SM-2 Critical Experiments - CE-1," APAE No. 54, November $30,1959$. 
For both mockups the highest power density was in the region surrounding the center of the core; the lowest along the outer ring of elements. Power peaks occurred in stationary fuel elements at the bottom of the active core and about 5-7 in. above the bottom of the active core, near the critical bank position. In control rod fuel elements without flux suppressors the power exhibited a small gradual increase until near the critical bank position when a very sharp rise occurred, due to the water gap between the absorber and control rod fuel element sections. The addition of flux suppressors to the top of the control rod fuel element sections eliminated this power spike and produced a noticeable reduction in power generation in the region of the interface between the suppressors and the meat. Other power spikes normally occurring at the bottom of the active core and at the radial core-reflector interface were effectively eliminated by placing flux suppressors at the bottom of stationary elements and a thick laminated steel reflector radially around the core. Peak power generation in the final mockup core was 4.6 times the core average and occurred within the central control rod fuel section. The minimum power generation of 0.1 of the core average occurred in element 21 at the edge of the core.

Blocked channel measurements were made to determine the effects on local power generation that result from blocking a fuel element coolant channel with various filler materials for purposes of in-core instrumentation. Results indicate that a coolant channel blocked with stainless steel or aluminum produces a slight flux suppressing effect. The aluminum was used as a mockup substitute for zirconium.

\section{MisCELLANEOUS MEASUREMENTS}

Gamma ray dose measurements indicate that the center of the core support plate will receive a gamma dose about 0.26 of the maximum of $7.8 \mathrm{R} / \mathrm{hr} / \mathrm{watt}$ received by the steel reflector; the top and bottom of the fuel elements receive about the same amount of gamma radiation.

Simulation of SM-2 operating conditions $\left(2000 \mathrm{psi}\right.$ and $\left.510^{\circ} \mathrm{F}\right)$ resulted in a $4.747 \mathrm{in.}$ increase in the seven rod critical bank position from 8.725 in. to 13. 472 in. and a corresponding shift in the calibration curve, with a core reactivity loss of about 7.7 dollars compared to measurements under room conditions.

Stuck rod measurements demonstrated that the reactor will remain subcritical upon full withdrawal of any two rods and certain three and four rod combinations. Criticality positions for other conditions were tabulated and reported. 


\section{INTRODUCTION}

The experiments described in this report were performed as part of the SM-2 core and vessel development program under AEC Contract No. AT(30-3)-326. These experiments were performed on mockups of the SM-2 core for the purpose of investigating the power distribution and control characteristics of the reactor, and to determine the core reactivity and power distribution effects that result from design modifications and/or additions such as reflectors, flow dividers and flux suppressors.

This report includes the balance of the experimental work performed since publication of APAE No. $54, \mathrm{CE}-1(1)$ and concludes the currently planned program on the SM-2 core. The experiments described include foil activation measurements for determination of relative power distribution in the core. Data is presented on element mapping, effect of flux suppressors, and blocked channel measurements. In addition, reactivity measurements were made to determine the burnable poison loading in the SM-2 fuel elements and to evaluate material coefficients in the core. Survey measurements on relative gamma flux and critical rod configurations are also reported.

Where possible all data is presented in both graphical and tabular form. All measurements were conducted at the Alco Products, Inc. Criticality Facility employing an open control rod array consisting of seven control rod assemblies and 38 stationary fuel elements. 


\subsection{SYSTEM DESCRIPTION.}

\subsection{INTRODUCTION}

A detailed description of the experimental assembly and its relationship to this Facility $(2)$ is presented in the Hazards Summary Report for the SM-2 Critical Experiments $(3)$ and the Hazards Summary Report on the Zero Power Experiments for the Army Package Power Reactor. (4)

The content of this chapter includes a general description of the experimental techniques and core assembly, and a definition of the system nomenclature used, to facilitate interpretation of the balance of the report.

\subsection{EXPERIMENTAL ASSEMBLY}

\subsubsection{Core Support Assembly}

The core support assembly consists of a three-tiered stainless steel table located over the center of the reactor tank floor at the Facility. Structural support, alignment and position of the assembly are assured by tie rods and spacers as shown in Fig. 1.1.

The core support has the potential of accommodating reactor cores with a total of 89 fuel elements and control rods, however, a maximum of 38 stationary fuel elements and seven control rod assemblies were utilized in the SM-2 tests. The elements were arranged in a $7 \times 7$ lattice utilizing an open seven control rod array as shown in Fig. 1.2. Figure 1. 3 illustrates the SM-2 core mockup, in place in the reactor tank, with a stainless steel reflector and with associated nuclear instrumentation.

\subsection{Control Rod Assembly}

Reactor control is maintained by the insertion and withdrawal of control rod assemblies which contain both nuclear fuel and box type boron absorbers in a stainless steel basket, Fig. 1.4. The control rod assemblies are driven by overhead drives and drop by gravity on scram. Guide rods and dashpot plungers to act as guides and decelerative devices respectively, are attached to the bottom of the control rod baskets.

\subsection{Fuel Element Structure}

Stationary fuel elemerits contain up to 18 stainless steel- $\mathrm{UO}_{2}$ matrix fuel plates, each loaded with $46.3 \mathrm{gm} \mathrm{U}-235$. Control rod fuel elements contain up to 16 similar fuel plates, each loaded with $42.2 \mathrm{gm} \mathrm{U}-235$. The individual fuel 
plates are composed of $26.5 \mathrm{w} / \mathrm{o}$ uranium oxide held in a 0.030 -in. thick matrix of stainless steel and clad with 0.005 -in. of stainless steel.

Flexibility of number and distribution of fuel plates in both stationary and control rod fuel elements is provided by extruded polystyrene grooves which hold the fuel plates erect and maintain a center-to-center fuel plate spacing of $0.163-$ in. Figures 1.5 and 1.6 show a stationary fuel element and control rod fuel element in the partially assembled state. The complete specifications for stationary fuel element, control rod fuel element, and absorber sections are reported in APAE No. 54. (1)

\section{2. 4 Steel Reflector Assembly}

The reflector assembly consists of a number of $1 / 2$-in. stainless steel sheets along the reactor sides and triangular bars along the corners (Fig. 1.1). Laminations of steel and water were obtained with the use of plexiglas spacers.

\subsubsection{Flow Divider}

The mockup flow divider is a 1/8-in. thick stainless steel plate inserted between the outer two rings of fuel elements, Fig. 1.7.

\section{2.6 Neutron Source}

A neutron source of encapsulated plutonium-beryllium with an emission rate of $8 \times 10^{6}$ neutrons/sec is used-during reactor operation at the Critical Facility. The source is inserted into and withdrawn from the reactor by means of a friction drive acting through an attached 1/4-in. rod.

\section{3 EXPERIMENTAL TECHNIQUES}

\section{3.1 Reactivity Measurenients}

All reactivity measurements were taken by measuring the difference in control rod position to achieve criticality between some reference condition and the condition under investigation. In order to establish the worth of moving a single rod or bank, it was necessary to obtain a series of rod or bank calibrations by the period method. The time rate of change on the $\log \mathrm{N}$ trace gives an indication of the reactor period which in turn is related to the change in reactivity through the in-hour formula. A relationship between the angle of the trace taken during a reactor period measurement and the corresponding reactivity change in cents is given in Fig. A. 3. The rod worth obtained from a specific period measurement is derived from Fig. A. 3 by dividing the reactivity change, in cents, by the difference in rod motion, in inches. Control rod or bank worth measurements were obtained at different rod or bank positions in order to establish a calibration curve such as shown in Fig. A. 1; for increased accuracy a least square fitting was obtained using an IBM-650 computer. Thus it is possible 
to obtain the total worth of a given reactivity measurement by obtaining the difference in the critical position of a calibrated control rod or bank.

\subsubsection{Boron Loading}

The SM -2 mockup fuel elements were loaded with boron impregnated tape cut into strips to fit over the uranium matrix of a fuel plate. The tapes are sections of adhesive-backed Mylar film loaded with boron carbide, of approximately 1-3 micron particle size, dispersed in ferrous oxide, thereby providing an ideal method of adding controlled amounts of B-10 to fuel plate surfaces. These boron strips were applied by means of a simple wringer type tape dispenser shown in Fig. 1.8.

\section{1,4 NOMENCLATURE AND EXPLANATIONS}

\subsubsection{Active Core}

That region defined by the upper and lower average limits of the U-235 distributions in the stationary fuel elements and the cell boundaries of the outer row of stationary elements.

\subsubsection{Control Rod Withdrawal}

Refers to the withdrawal of the absorber section of the control rod from the active core and the consequent simultaneous insertion of fuel.

\subsection{Control Rod Position}

Control rod positions are reported as the distance withdrawn from the position of deepest insertion measured in inches. Deepest insertion represents the nominal alignment of the bottom of the active core with the top limit of the U-235 distribution in the control rod fuel element, or the top limit of the flux suppressor if one is used. Bank positions result from the average position of the individual rods comprising the bank.

\subsection{Control Rod Array}

The open seven rod array referred to in this report is illustrated in Fig. 1.2.

\subsubsection{Data Point, Experimental}

All experimental data points are plotted as a point (circled, squared or other). Points derived from experimental data by cross plot or integration are represented by crosses.

\subsubsection{Temperature}

Unless otherwise noted, all measurements were taken at $68^{\circ} \mathrm{F}$. 


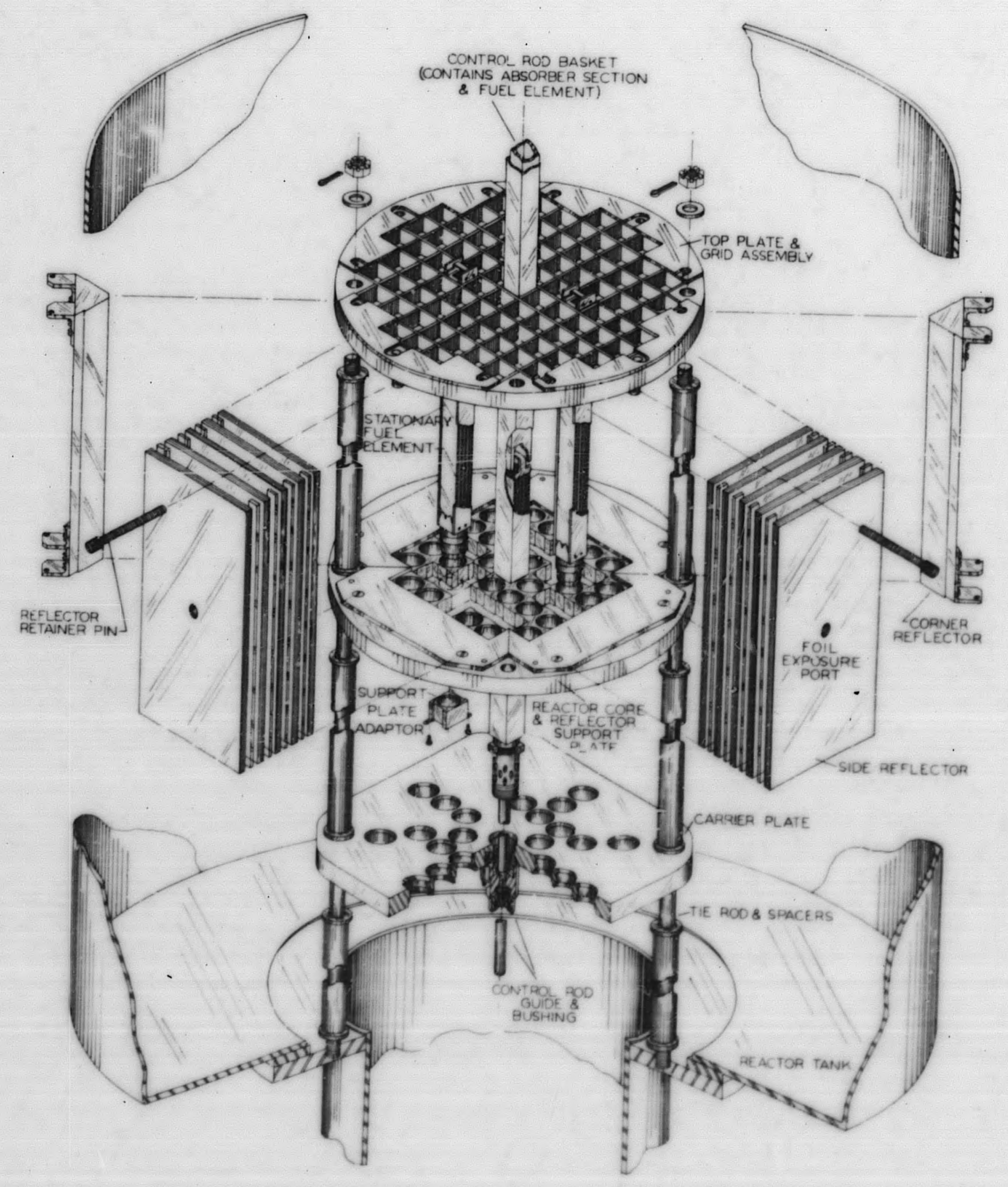

Figure 1.1. Core Support Structure 


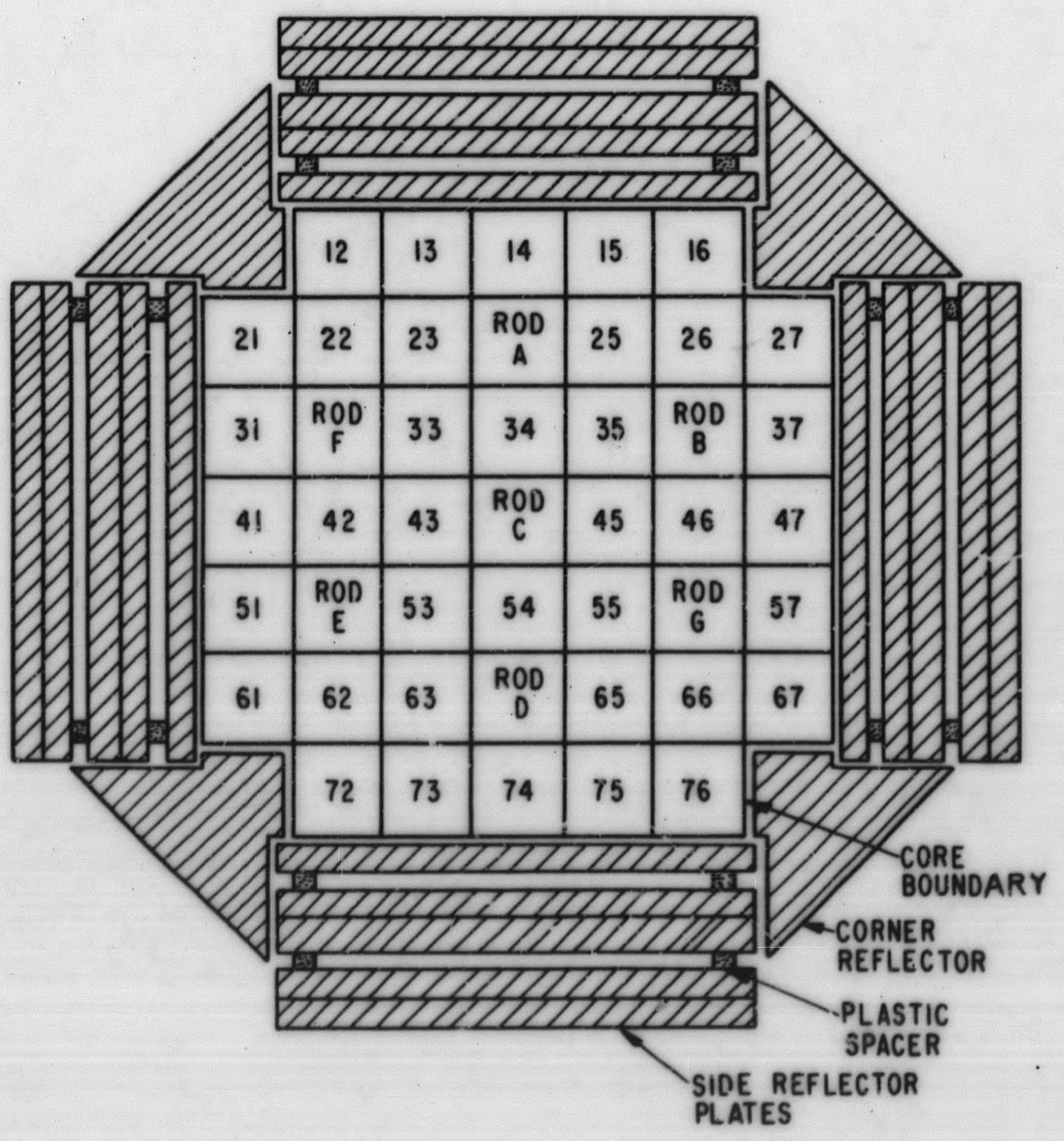

Figure 1.2 Cross Section of SM-2 Core Mockup with Stainless Steel Reflector 


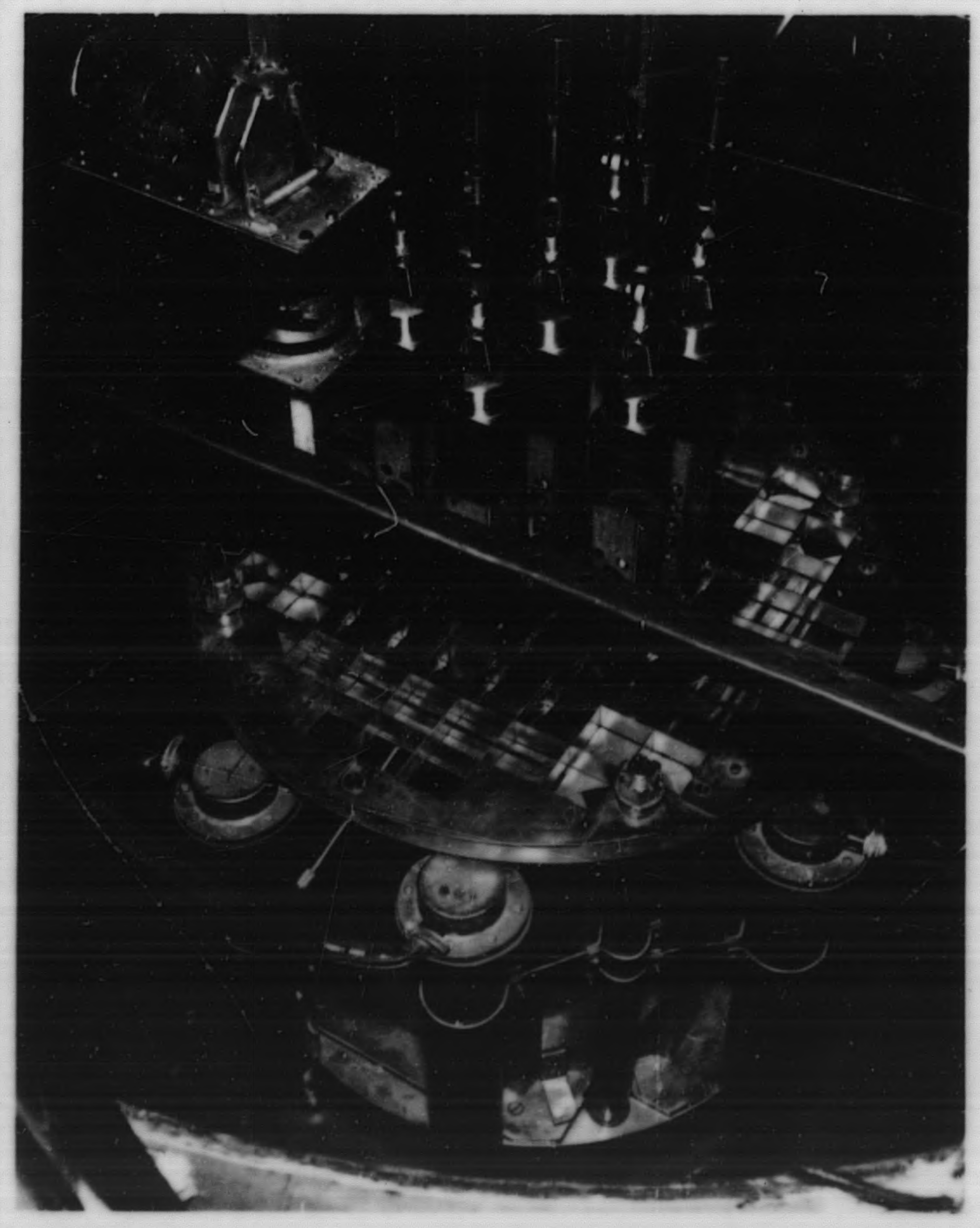

Figure 1.3 SM-2 Core in Reactor Tank 


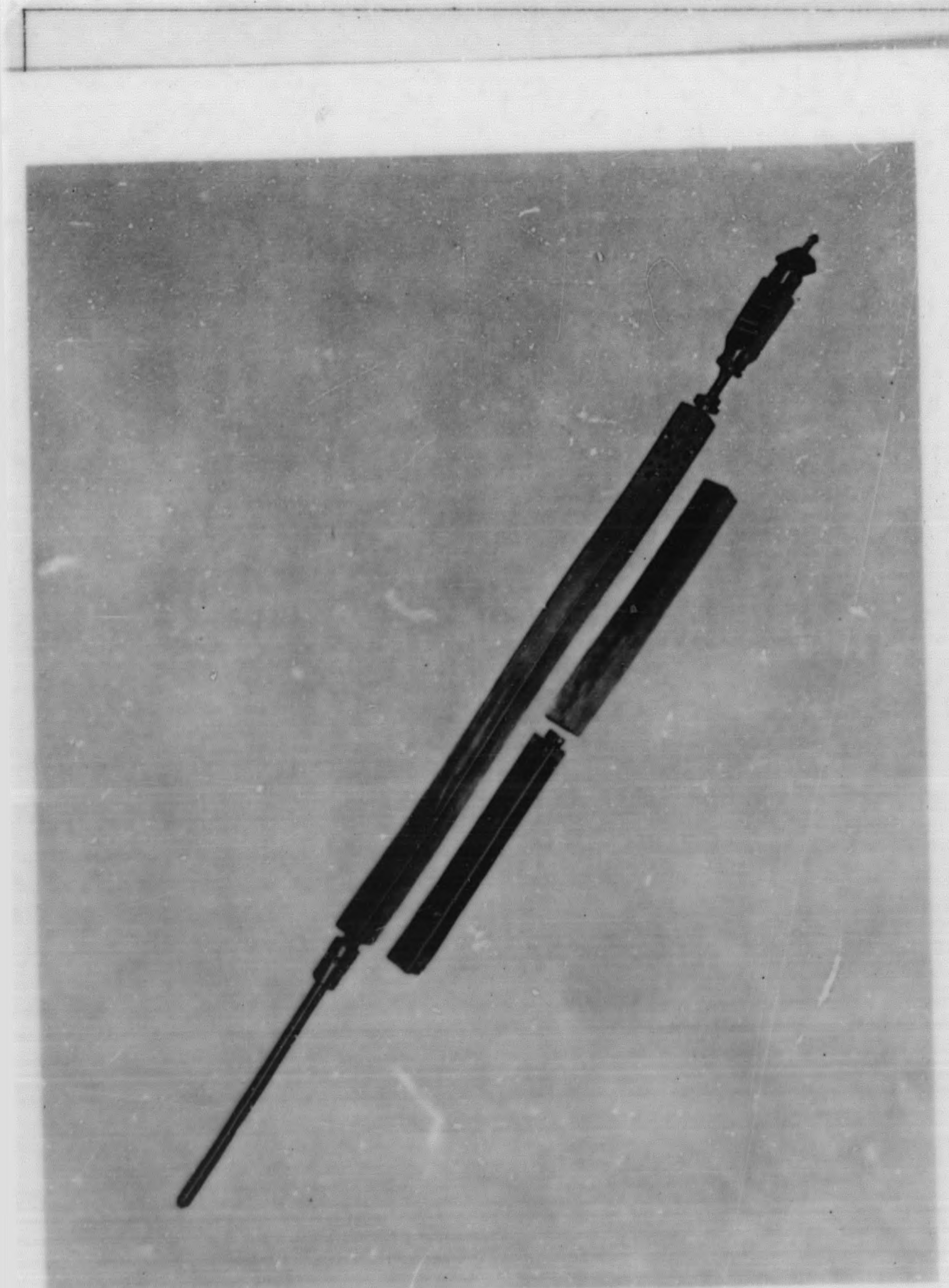

Figure 1. 4 Control Rod Assembly

12 


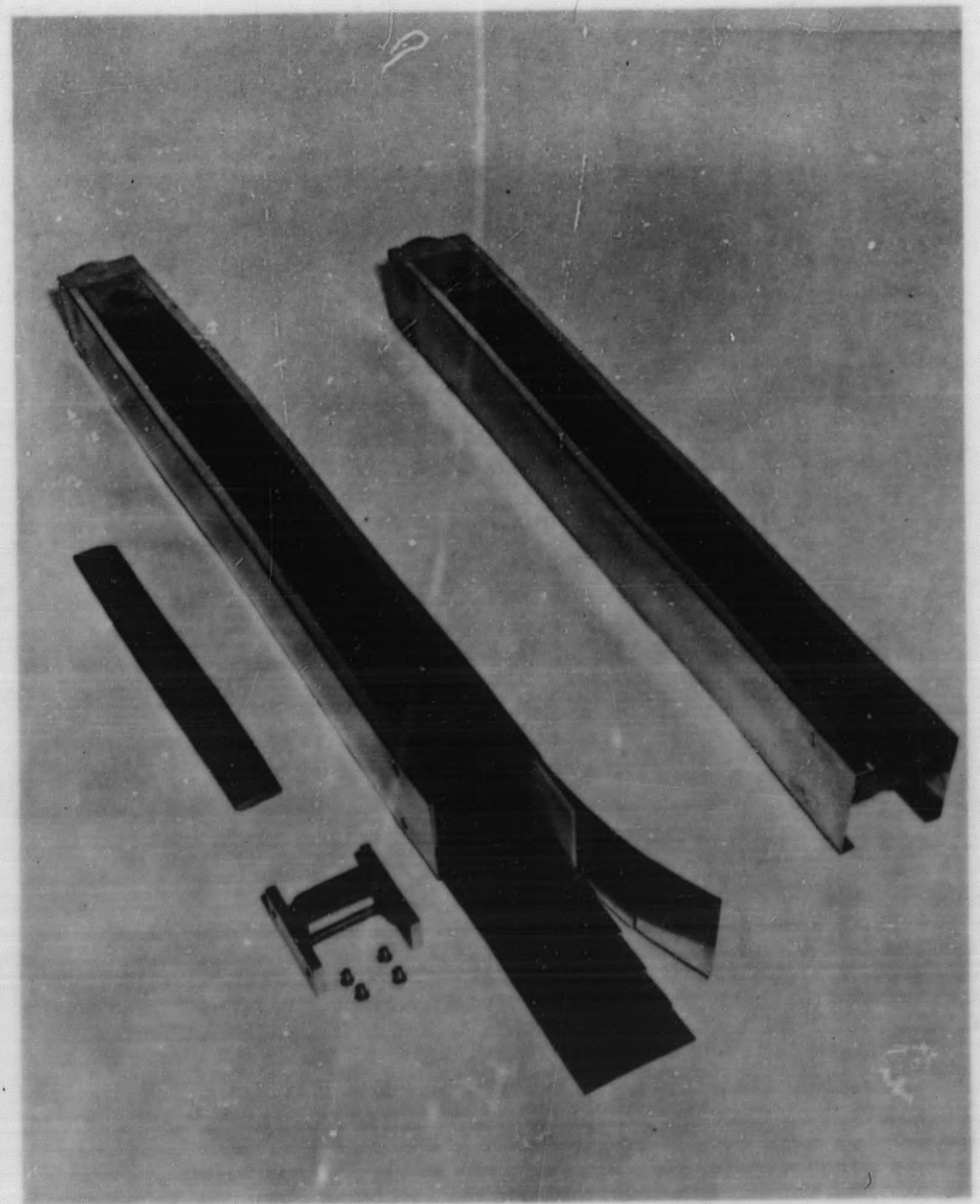

Figure 1.5 Stationary Fuel Element 


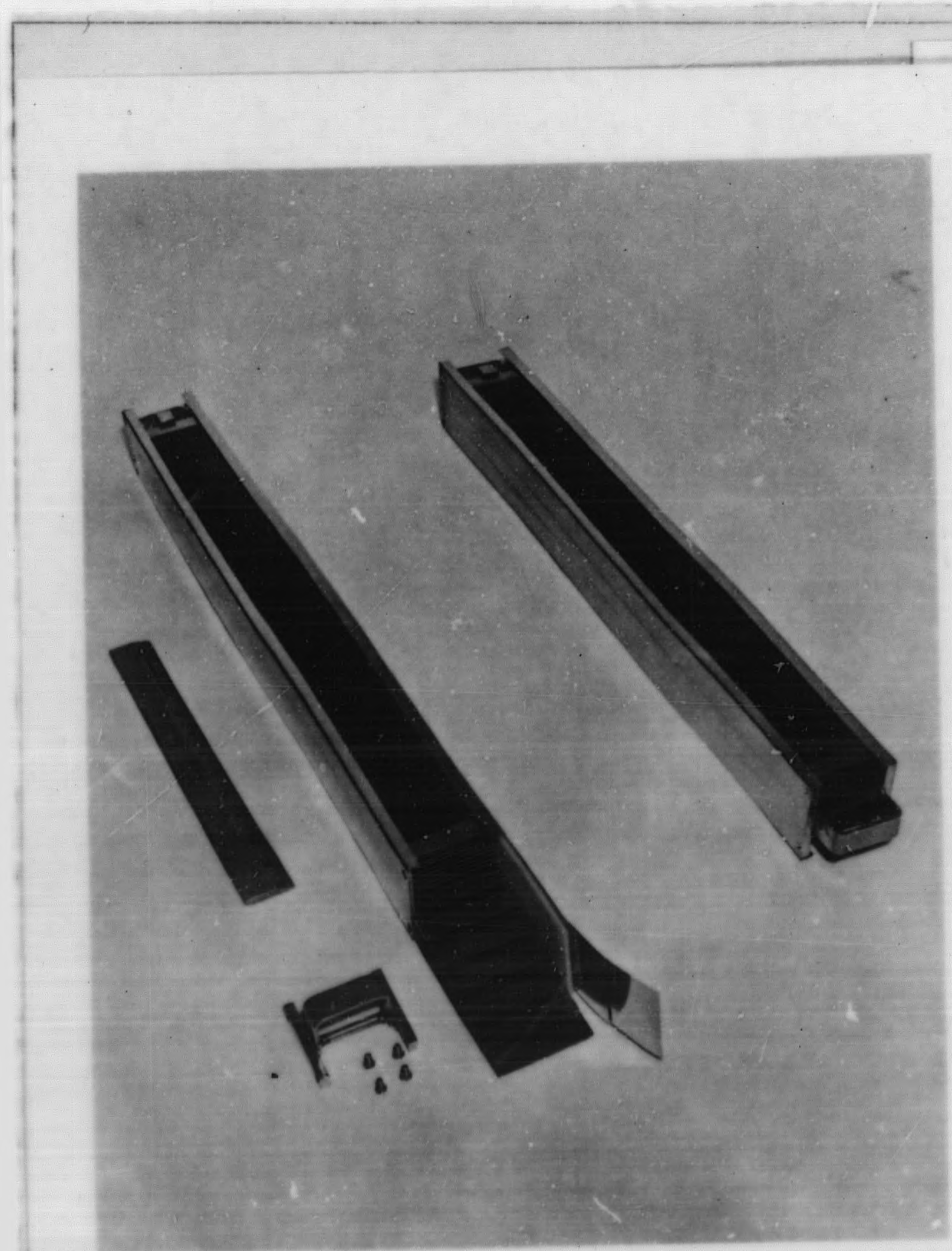

Figure 1.6 Control Rod Fuel Element 
(FLOW DIVIDER SHOWN BY DASHED LINES)

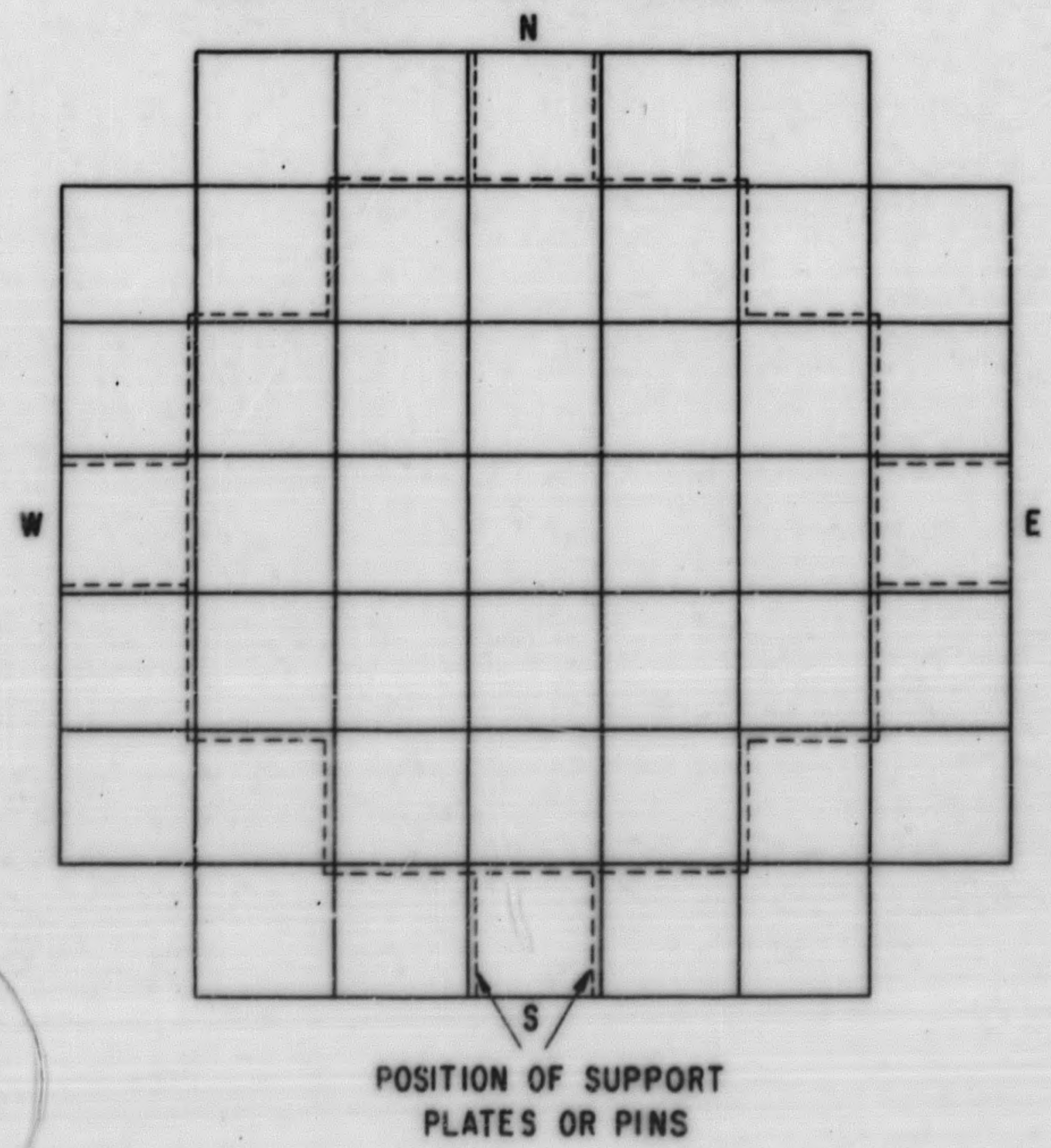

Figure 1. 7 Flow Divider Location 


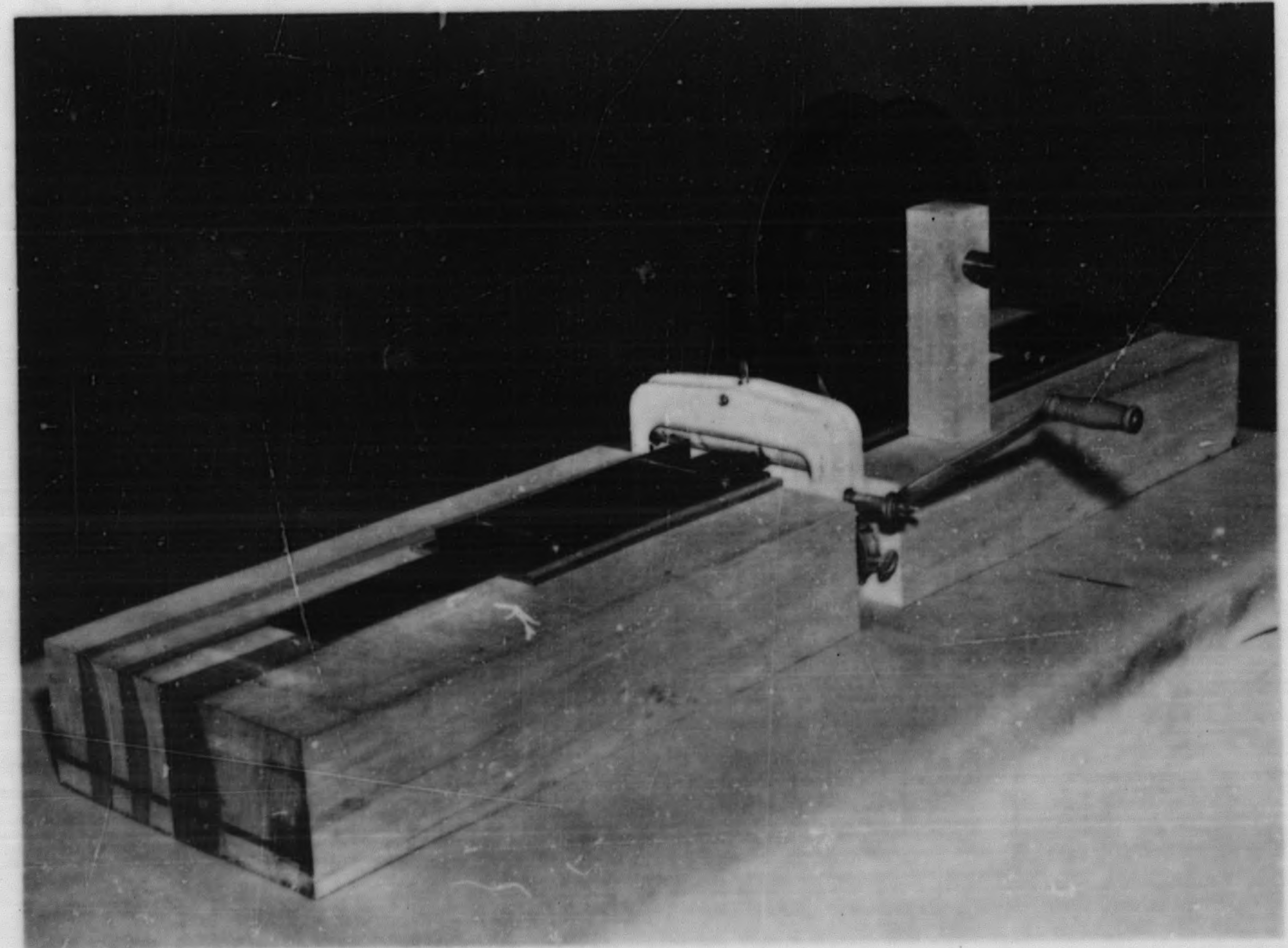

Figure 1.8 Boron Tape Applicator 


\subsection{REACTIVITY MEASUREMENTS}

\subsection{INTRODUCTION}

In order to properly evaluate the effects on SM-2 core reactivity resulting from subsequent small changes in the core design or specifications, certain reactivity measurements were performed using the SM-2 core mockup. A detailed description of the core and individual fuel element compositions are provided in APAE No. 54, (1) Appendix A, reference loading number 53.

Using the SM-2 core mockup, reactivity measurements were performed under both room temperature and simulated SM-2 operating temperature conditions of $510^{\circ} \mathrm{F}$. Reactivity measurements performed under room temperature conditions included: (1) B-10 loading determinations in selected fuel plates and fully assembled SM-2 mockup fuel elements, (2) reactivity comparisons between SM-2 mockup fuel plates and actual first-run SM-2 fuel plates, (3) reactivity worth of flux suppressors, (4) flow divider worth, and (5) worth of fuel element side plates. Reactivity measurements under simulated conditions of operating temperature included worth measurements for B-10, U-235, stainless steel, and voids.

In general these reactivity worth measurements for various materials were obtained for small variations in core materials about the final SM-2 core design point.

\subsection{B-10 LOADING IN THE SM-2 CORE MOCKUP FROM CORE REACTIVITY MEASUREMENTS}

\section{2, 1 Introduction}

Control of excess core reactivity in the SM-2 is maintained at any time during core life by means of movable control rods. In addition burnable nuclear poison B-10 is added to the fuel matrix of each fuel plate during fuel plate fabrication process for the purpose of extending core life expectancy. The amount of excess reactivity controllable by the movable control rods is fixed by the number, type, and distribution of control rods employed in the basic core design and cannot be easily changed after reactor startup. The burnable poison, on the other hand, is depleted from the core more rapidly than the fuel and results in a maximum control demand upon the movable rods near the core midlife. Considering these plus other control demands resulting from temperature and xenon reactivity effects, it becomes very important to specify to the closest possible tolerance the burnable poison loading in the reactor core, if one is to be assured that adequate system control is to be maintained over the core lifetime. 
A series of experiments were conducted at the Alco Critical Facility with the objective of obtaining a more precise determination of the boron-10 loading in the SM-2 core mockup than that previously reported. These measurements were based on physical methods of mass spectroscopy and core reactivity changes; a comparison with the results from chemical analysis is presented.

\section{2.2 Experimental Procedures and Results}

The experimental procedures employed in these tests were basically that of the standard sample technique in which a series of standard samples containing known and varying amounts of B-10 were prepared and inserted, in succession, into the reactor to generate a curve relating core reactivity change to $\mathrm{B}-10$ loading. A second series of samples containing an unknown amount of B-10 were then intercalibrated with the standards by inserting them into the reactor under test conditions identical with those employed for the standards. The core reactivity change was noted for each of the second series of samples and the B-10 loading cbtained for each sample by reference to the curve of reactivity vs. B-10 loading. Having obtained the B-10 loadings, the second series of intercalibrated samples were employed in the various experiments described below.

\subsection{1 Preparation of the Standard Samples}

Boron carbide obtained from the base material used in the manufacture of the Mylar film was utilized in the standard sample preparation. Four samples of $\mathrm{B}_{4} \mathrm{C}$ were weighed on an analytical balance and the amount of $\mathrm{B}-10$ in each sample calculated using the total boron weight percent as obtained by chemical analysis from Lucius Pitkin, Inc. and the AEC's New Brunswick laboratory, and the a/o B-10 as obtained from mass spectrograph isotopic analysis by the New Brunswick laboratory. These analyses of the base material have been reported previousiy $(1)$ and were in good agreement on the composition of the base material.

The four weighed samples of $\mathrm{B}_{4} \mathrm{C}$ were combined with a lacquer-tisinner binder and applied uniformly over the surface of a polystyrcne sheet of essentially the same wichth, thickness, and length as an SM-2 fuel plate. The ratio of thinner to lacquer was approximately 10 to 1 and complete transfer of material was insured by standard chemical techniques of muitiple washing and policing. The surface covered by the $\mathrm{B}_{4} \mathrm{C}$ on the polystyrene sheets was held to the nominal fuel matrix length and width specified for the SM-2 flexible critical experiments fuel plates in order to maintain consistency of poison geometry in these and subsequent intercalibrations with Mylar film. One blank sample of lacquer and thinner on poiystyrene was prepared as a zero reference piece; however, subsequent tests demonstrated that this blank reference produced no measurable reactivity change between it and the water which it displaced. 


\subsubsection{Calibration of the Standard Samples}

Using the four standard samples and the zero reference piece a curve was generated of reactivity change, $\Delta \mathrm{K}_{\mathrm{E}}$ vs. B-10 loading of the samples (Fig. A. 2) in the following manner:

1. The blank was inserted in the center of element position No. 22 (plate position "i"). All the fuel plates were removed from this element position to increase the thermal flux peaking and hence the sensitivity of the method.

2. The reactor was brought critical on calibrated control rod $\mathbf{E}$, five rod bank at 5.75 in. withdrawn, and with control rod $F$ fully withdrawn.

3. The four standard samples mounted in an identical manner were then substituted for the blank, one at a time and critical positions for each obtained on calibrated rod $\mathbf{E}$.

4. Control rod $\mathrm{E}$ was calibrated by taking period measurements during the above and subsequent operations.

5. The reactivity differences obtained from measurements (4) and (5) were plotted vs. the known B-10 content of the standards and thus Fig. A. 2 was generated.

The results of the above experiments (Fig. A. 2) were used as a basis for the following B-10 determinations.

\section{2. 2. 3 Intercalibration of Tapes}

A series of similar calibration runs were made with strips of boron impregnated tapes mounted on polystyrene sheets in a manner identical with that of the standard samples. The B-10 content of these tapes was determined from reactivity differences measured on calibrated control rod $\mathrm{E}$, utilizing, $\Delta \mathrm{K}_{\mathrm{E}}$ vs. B-10 loading curve, Fig. A. 2. After calibration these tapes were carefully stripped from the plastic to prevent boron losses. Two tapes, with the approximate B-10 content of an SM-2 reference fuel plate, were placed in layers on one side of a mockup fuel plate of element No. 22 for the purpose of intercalibrating additional fuel plates. Five others were used for B-10 worth determination, and four were sent for chemical analysis.

The B-10 loading of these tapes is given in Table 2. 1 together with the four obtained by chenical analysis. To simplify identification of tapes the following nomenclature is used, for example: 1-2 \#2 mdicates: order 1, batch 2, tape labeled \#2. 
TABLE 2.1

B-10 LOADING OF INTERCALIBRATED

TAPES TESTED IN ELEMENT POSITION 22, FUEL PLATE "i"

\begin{tabular}{cl}
$\begin{array}{c}\text { B-10 Loading by Inter-- } \\
\text { comparison with Standard Tapes }\end{array}$ & $\begin{array}{l}\text { B-10 Loading by } \\
\text { Chemical Analysis }\end{array}$ \\
\hline
\end{tabular}

Tape No.

$\underline{\mathrm{mg} / \mathrm{cm}^{2}}$

$\underline{m g}$

$\underline{\mathrm{mg} / \mathrm{cm}^{2}}$

\section{1-2 \#2}

0. 1560

54.4

$0.1717^{+}$

1-2 \#3*

0. 1590

55.4

1-2 \#4

0.1585

55.2

$0.140 \rho^{++}$

2-1 \#1

0.0770

26. 8

2-1 \#3**

0.0745

25.9

2-1 *5**

0.0745

25.9

$2 \cdot 1$ \#6

0.0717

25.0

$0.0551^{+}$

2-1 \#7**

0.0725

25. 3

2-1 *10**

0.0799

27.8

2-1 \#11

0.0735

25. 6

$0.0709^{++}$

2-1 औ12*

0.0755

26. 3

2-1 \#1 3**

0.0781

27.2

* Tapes applied to mockup fuel plate 139-S-3 to provide reference plate of known B-10 loading.

** Tapes applied to mockup fuel plates in plate positions $a, e, j, n$, and $r$ of element No. 22 for B-10 worth determination.

+ Chemical analysis by Lucius Pitkin.

++ Chemical analysis by BMI. 


\section{2. 2.4 Intercalibration of Mockup Fuel Plates}

Calibrated tapes 1-2 \#3 and 2-1 \#12 were placed on plate 139S-3 in position "i" of element No. 22 for the purpose of establishing a reference fuel plate. These two tapes were chosen because they have about the same B-10 loading as the SM-2 mockup fuel plates. The calibrated tapes were placed one at a time on the fuel plate and the net reactivity change produced by each was measured in order to obtain B-10 worth as a function of B-10 loading. The addition of calibrated tape 1-2 \#3 with $55.4 \mathrm{mg}$ B-10 produced a reactivity change equal to 197.9 cents per $\mathrm{gm}$ B-10. The further addition of calibrated tape 2-1 \#12 brought the total B-10 content to $81.7 \mathrm{mg}$ and lowered the B-10 worth to 178.1 cents per $\mathrm{gm} \mathrm{B-10}$ for the two tapes and to 136.4 cents per gm B-10 for the second added tape 2-1 \#12. This change in boron worth is attributed mainly to boron self-shielding, flux depression effects, and a slight hardening of the local neutron energy spectrum.

The remaining 17 fuel plates were loaded successively in position " $\mathrm{i}$ " of element No. 22 and their B-10 loadings were determined from individual reactivity changes between them and the reference fuel plate and utilizing the established B-10 loading and worth in the reference.

B-10 loading for each of the fuel plates is given in Table 2. 2. The average B-10 content amounted to $0.0828 \mathrm{gm}$ per: fuel plate for a total of $1.4905 \mathrm{gm}$ for 18 plates comprising stationary fuel element No. 22.

B-10 worth for element 22 was determined by applying tapes 2-1 \#3, 2-1 \#5, 2-1 \#7, 2-1 \#10 and 2-1 \#13 to plates $a, e, j, n$, and $r$ respectively. The measured reactivity difference rendered a B-10 worth of 56.62 cents per gm for element No. 22 in position 22.

\section{2. 2. 5 Intercalibration of Mockup Fuel Elements}

The B-10 loading of nine fuel elements was determined by intercalibrating them with the element in position 22. Eachelement was placed in turn in lattice position 22; the difference in reactivity between the element under test and the zero position established by element No. 22 was assumed to be a measure of the difference in B-10 loading. Any variations in fuel contents were assumed to be negligible; the B-10 loadings are given in Table 2.3.

The B-10 loadings of control rod fuel elements were calculated by ratioing the average stationary fuel element B-10 loading by the differences in the number of fuel plates and cross-sectional areas of the tapes applied. The average B-10 loading thus obtained was $1.278 \mathrm{gm}$ per control rod fuel element and the estimated total B-10 content of the SM-2 mockup core was $67.9 \mathrm{gm}$. 
TABLE 2.2

B-10 LOADING OF 18 INTERCALIBRATED FUEL PLATES TESTED IN ELEMENT POSITION 22, PLATE POSITION "i".

Plate Position

In Element 22**

a

b

c

d

e

f

g

h

i

j

l

m

n

o

p

q

r
Plate No.

$57-S-6$
$138-S-1$
$105-S-1$
$139-S-3$
$137-S-1$
$138-S-4$
$156-S-6$
$139-S-6$
$137-S-3$
$139-S-1$
$137-S-6$
$139-S-4$
$138-S-6$
$111-S-1$
$137-S-5$
$160-S-2$
$162-S-4$
$156-S-2$

B-10 Loading, gm

0.0867

0.0851

0.0817

0.0842

0.0803

0.0828

0.0840

0.0819

0.0812

0.0849

0.0778

0.0790

0.0833

0.0849

0.0856

0. 0828

0.0842

Total

$\overline{1.4905}$

0.0828

\section{Average}

* Reference fuel plate, containing intercalibrated tape Nos. 1-2 \#3 and 2-1 \#12 used to intercalibrate the other 17 fuel plates.

** After intercalibration, fuel plates were placed in positions indicated for the purpose of obtaining a standard mockup fuel element. 


\section{TABLE 2.3}

\section{B-10 LOADING OF 10 INTERCALIBRATED SM-2 MOCKUP FUEL ELEMENTS TESTED IN ELEMENT POSITION 22}

Fuel Element No.

12

$22^{*}$

27

37

47

57

67

74

75

76

B-10 Loading, gm

1.498

1. 491

1.583

1.522

1.548

1.520

1.590

1.659

1. 549

1. 551

Average

1.551

* Average reference fuel element used to intercalibrate the other nine fuel elements

\subsection{6 Comparison Between BMI Reference Element and Mockup Element}

Fuel element No. 22 was assembled with the 18 intercalibrated mockup fuel plates and the critical position of calibrated control rod $\mathbf{E}$ determined. The mockup plates were then removed and $18 \mathrm{SM}-2$, BMI manufactured reference fuel plates substituted, and the new critical position determined. The change in reactivity was calculated from the difference in the critical positions.' This change represented the additional amount of B-10 required on the mockup fuel elements to match the worth of the integral B-10 of the reference fuel element; if the reactivity change due to slight fuel loading difference was assumed to be negligible. This required additional B-10 was calculated to be $0.262 \mathrm{gm}$ based on an experimentally determined B-10 worth of 56.62 cents/gm for mockup element No. 22. Since the 18 mockup fuel plates contained a total of $1.491 \mathrm{gm} \mathrm{B-10}$, therefore total B-10 required on mockup plates to have the same reactivily effect as BMI reference plates is $1.753 \mathrm{gm}$ for an average B-10 loading of $0.0974 \mathrm{gm}$ per mockup fuel plate. This compares with the value of $0.0911 \mathrm{gm} / \mathrm{plate}$ reported by BMI for the reference plates.

Further interpretation of these data are complicated due to the larger fuel matrix dimensions of the $\mathrm{BMI}$ reference fuel plates compared to those of the SM-2 mockup plates. (1)(6). 


\subsubsection{Conclusions}

In carrying out the preceding experiments, reactivity differences were measured, then converted to equivalent grams of B-10. However, reactivity differences are not all caused by differences in B-10 loadings. Other sources contribute in varying degrees as follows:

1. Contribution of fuel loading difference to reactivity differences was assumed to be negligible since U-235 loadings can be accurately assayed and the difference in U-235 loadings were less than $0.2 \%$.

2. Method of applying burnable poison; in BMI reference plates it was incorporated in the fuel matrix as spherical particles of zirconium diboride, while in the mockup it was applied to the surface of the fuel plates as boron carbide coated Mylar tape.

3. Effect due to difference in particle size; the boron carbide in the Mylar tapes has a diameter of one to three microns, whereas zirconium diboride particles average about 100 microns. Also during manufacture, mockup fuel plates were reduced about 12 to 1 , thus containing uranium oxide particles with an average diameter of 66 microns; the BMI reference plates were reduced only about 6 to 1 with an average uranium oxide diameter of 112 microns.

4. Self-shielding of B-10 particles; in applying burnable poison in layers, the B-10 particles tend to shield each other and hence they become less effective as neutron absorbers. This is demonstrated by the chasige in B-10 worth from 197.9 cents when one tape is applied to a fuel plate to 136.4 cents when two are applied. The self-shielding effect on the worth of B-10 when it is integrated into the fuel matrix was not determined.

5. Difference in B-10 worth due to external and internal loading.

6. Difference in fuel matrix size between the reference and the mockup fuel plates.

After the above experiments were completed, additional chemical analyses were made on tapes taken from the same orders and batches. The results show the boron loading on the tapes to be very uniform; however, the results obtained from the two independent laboratories differed by about $12 \%$ for the order 1 batch 2 tape and by about $2 \%$ for the order 2 batch 1 tape. The results of the chemical analyses are given in Appendix C. 


\section{3 MATERIAL COEFFICIENTS}

\subsubsection{Introduction}

Reactivity worth measurements were made at a simulated operating temperature of $510^{\circ} \mathrm{F}$. The operating temperature was simulated by inserting aluminum strips in the stationary and control rod fuel elements. A detailed discussion of the temperature mockup is given in Section 4.2.3. The worth in cents per $\mathrm{gm}$ or cents per cc was determined for B-10, U-235, stainless steel, and void throughout one quadrant of the core, excepting the control rod fuel elements where only B-10 worths were measured. To obtain an estimate of the average worth of U-235, stainless steel and void in the whole core, the average for stationary elements was multiplied by the ratio of the average B-10 worth in the core to that in stationary elements only. This is justified since they were all measured in the same core under exactly the same conditions.

Prior to the worth measurements, a short heterogeneity experiment was performed to establish the adequacy of the experimental method, since usually it is not feasible to add a given material to a fuel element without introducing some heterogeneity.

\section{3. 2 Procedure}

Reactivity differences were measured using calibrated control rods $\mathrm{D}$ and $\mathrm{G}$ as a two rod bank. The five rod bank (A, B, C, E, F) was placed at 12.600 in. withdrawn. This choice allows for measurements to be made in a quadrant of the core that is least perturbed by rod motion. Also preiliminary measurements have inciicated that the calibration curve for control rods D \& G is smooth and essentially linear. A two rod calibrated bank was chosen instead of a single calibrated rod because the reactivity differences are large for B-10 measurements. All measurements were made relative to a zero position defined as the critical position with SM-1 standard element in position No. 76 and SM-2 mockup element 76 in position No. 22. This procedure leaves element No. 22 free for substitution measurements into the other positions of the quadrant. The zero position was takes at the beginning and end of each day to nullify effect.of temperature change.

\section{3. 3 Heterogeneity Measurements}

Since it is not usually feasible to add a given material to a fuel element without introducing some heterogeneity, a short experiment was made to determine the size of this heterogeneity factor. The experiment was performed by replacing six fuel plates (each 40 mils thick) by six $\mathbf{4 0 - m i l ~ t h i c k ~ p l a t e s ~ ( 4 - 1 0 ~}$ mil pieces) of stainless steel clad of essentially the same width and length. The size of the heterogeneity factor was determined by arranging the stainless steel plates in 6,3,2 and 1 discrete bundles and measuring the reactivity difference for each arrangement in element position No. 33. Reactivity differences obtained in this manner were converted into cents per gram of U-235 since the difference 
between the fuel plates and the stainless steel plates was U-235 (neglecting the U-238 and difference in particle size). This was done so that these results could be directly compared with the U-235 material coefficient later obtained using heavily loaded fuel plates. Figure 2.1 presents the data. The curve was linearly extrapolated to 13 bundles (the number of fuel plates in an element). The heterogeneity effect is seen to be small after about 5 bundles. The uranium worth obtained using 18 heavily loaded fuel plates is in good agreement with the value predicted from the extrapolated data.

\subsubsection{U-235 Worth}

Uranium worth measurements were made using 18 heavily loaded fuel plates to avoid the possibility of heterogeneity effects. First, element No. 22 was substituted into each element position of one quadrant of the core and the critical position determined on calibrated rods $D$ and $G$ with the five rod bank $(A, B, C, E, F)$ at 12. 600 in. Then, element No. 22 was loaded with 18 heavily loaded fuel plates and the same boron tapes and substituted through the same quacirant of the core in the same manner. The resulting reactivity differences determined the uranium worth for the quadrant.

Table 2. 4 lists the worths thus obtained together with those previously obtained at room temperature.

It is noted that the average U-235 worth at simulated temperature $\left(510^{\circ} \mathrm{F}\right)$ is approximately $24 \%$ less than the average $\mathrm{U}-235$ worth at room temperature.

\section{3. 5 B-10 Worth}

The boron impregnated Mylar tape was stripped off fuel plates a, e,j, n, and $r$ of element No. 22. Then element No. 22 was substituted into the other stationary fuel element positions of the quadrant. For the control rods the boron tape was stripped off fuel plates a, d, i, $\mathrm{m}$ and $\mathrm{p}$. The critical position for each measurement was determined on the calibrated two rod bank $D$ \& $G$ with the five rod bank (A, B, C, E, F) at 12.600 in. The B-10 worth was calculated from reactivity differences using B-10 loadings determined in the previous section and APAE 54. (1)

Table 2. 5 presents the B-10 worth data obtained at simulated temperature and that previously obtained at room temperature.

The average B-10 worth at simulated temperature $\left(510^{\circ} \mathrm{F}\right)$ is about $24 \%$ less than the average B-10 worth at room temperature which is the same amount the U-235 worth was decreased. This is the expected result since both U-235 and $\mathrm{B}-10$ are essentially $1 / \mathrm{v}$ absorbers. 


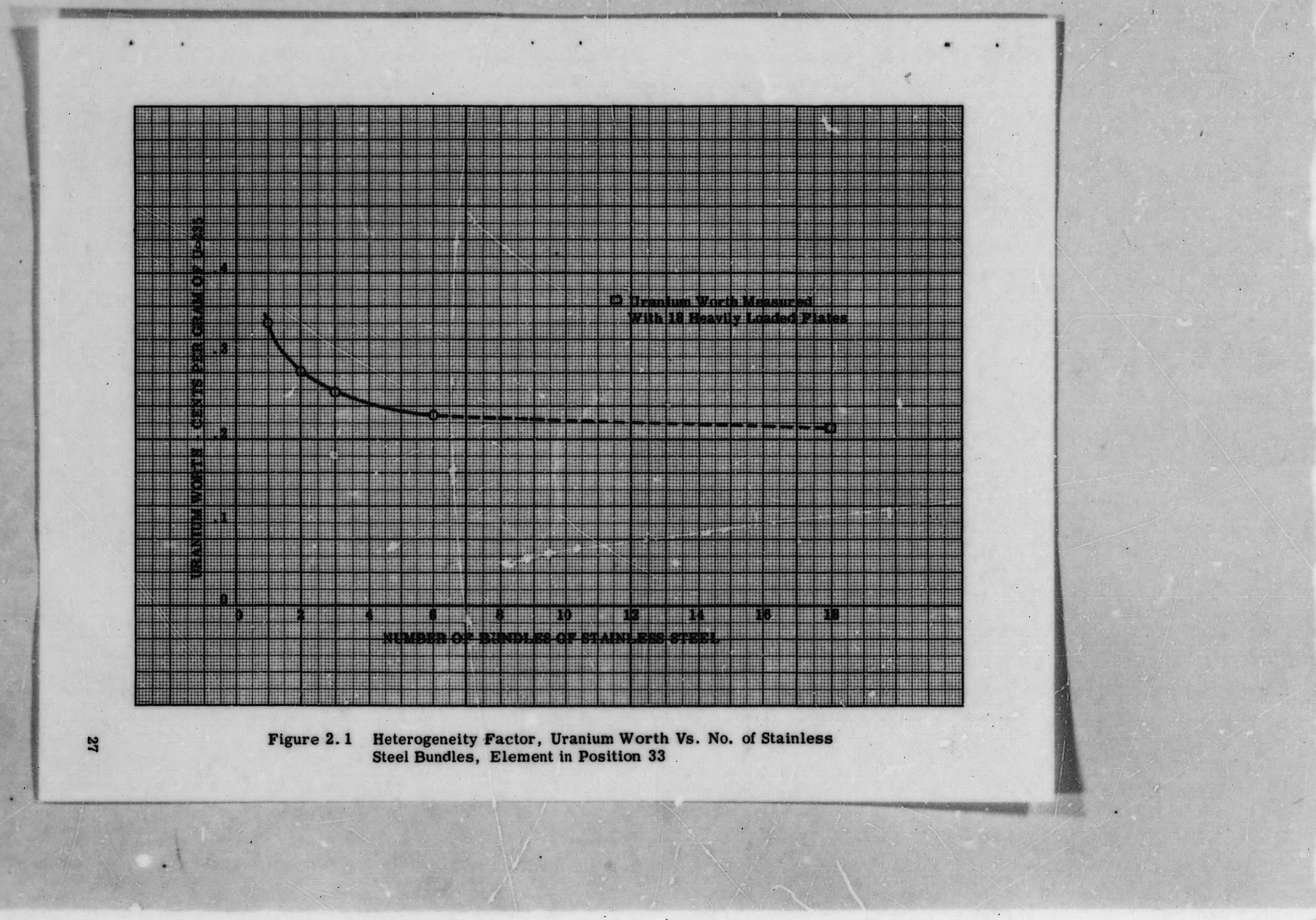


TABLE 2.4

U-235 REACTIVITY COEFFICIENTS

\section{Element \\ Position}

12

13

14

21

22

23

31

33

34

41

42

43

Average for stationary

fuel elements

Estimated Core Average

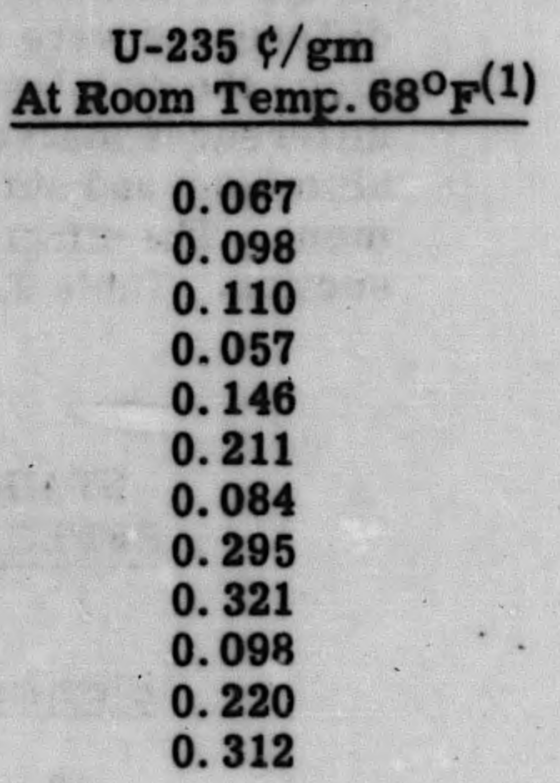

0.067

0.052

0.065

0.091

0.048

0.115

0.189

0.057

0.213

0.264

0.063

0.143

0.242

0.120

0.157

\section{B-10 REACTIVITY COEFFICIENTS}

\section{Element}

Position

12

13

14

21

22

23

31

33

34

41

42

43

Control Rod A

Control Rod $\mathbf{F}$

Control Rod C

Average for stationary

fuel elements

Estimated Core Average
B-10 Worth in $\mathrm{c} / \mathrm{gm}$

At Simulated Temp. $510^{\circ} \mathrm{F}$

8. 4 .

21. 7

22.5

7,2

29. 1

45. 5

16. 3

59.8

74. 6

20.4

42.4

71.8

50.0

41.2

88. 4

32.0

34.9
B-10 Worth in $\mathrm{c} / \mathrm{gm}$ AtRoom Temp. $68^{0} \mathrm{~F}(t)$

17. 0

25. 6

28. 0

14. 6

38. 6

57. 0

22. 6

79. 5

87. 7

25. 5

58.9

87.5

$\because$

-

42. 0 . 


\section{3. 6 Stainless Steel Worth}

Stainless steel worth or coefficient was determined by replacing the aluminum strips in element No. 22 by an equivalent volume of stainless steel clad. Reactivity differences were measured in the same manner as for other worth measurements. Since the stainless steel replaced an equal volume of the aluminum the reactivity differences measured were due to the differences in nuclear cross sections of aluminum and stainless steel only and dtd not include the effect of water displacement. The effect of water displacement or void worth is discussed in the next section. Table 2.6 lists the stainless worth at simulated temperature $\left(510^{\circ} \mathrm{F}\right)$.

\begin{tabular}{|c|c|}
\hline Element No. & $\begin{array}{l}\text { Stainless Steel Worth } \mathrm{C} / \mathrm{cc} \\
\text { at Simulated Temp. } 510^{\circ} \mathrm{F} \text {. }\end{array}$ \\
\hline $\begin{array}{l}12 \\
13 \\
14 \\
21 \\
22 \\
23 \\
31 \\
33 \\
34 \\
41 \\
42 \\
43\end{array}$ & $\begin{array}{l}0.0064 \\
0.0083 \\
0.0121 \\
0.0068 \\
0.0157 \\
0.0312 \\
0.0102 \\
0.0593 \\
0.0683 \\
0.0128 \\
0.0422 \\
0.0686\end{array}$ \\
\hline $\begin{array}{l}\text { Average for stationary } \\
\text { fuel elements }\end{array}$ & 0.0253 \\
\hline Estimated Core Average & 0.0276 \\
\hline
\end{tabular}

\subsection{Void Worth}

The void coefficient or worth was obtained by removing the aluminum strips from element No. 22 and substituting it in the element positions of the quadrant of the core being measured. The reactivity differences were measured on calibrated rods $D$ and $G$ with the five rod bank (A, B, C, E, F) at 12.600 in. In calculating the void coefficient the cross section of aluminum was assumed negligible. Table 2.7 lists the coefficients obtained at simulated temperature, $510^{\circ} \mathrm{F}$. 
TABLE 2.7

VOW REACTIVITY COEFFICIENTS

\begin{tabular}{cc} 
Element No. & Void Worth $\mathrm{f} / \mathrm{cc}$ \\
\cline { 2 - 2 } 12 & 0.0149 \\
13 & 0.0259 \\
14 & 0.0250 \\
21 & 0.0116 \\
22 & 0.0365 \\
23 & 0.0767 \\
31 & 0.0236 \\
33 & 0.0910 \\
34 & 0.1022 \\
41 & 0.0298 \\
42 & 0.0631 \\
43 & 0.1071
\end{tabular}

Average for stationary

fuel elements $\quad 0.0467$

Estimated Core

Average $\quad 0.0509$

The average void coefficient for the stationary fuel elements is $\mathbf{0 . 0 4 6 7}$ cents per cc. This value obtained by a series of individual measurements compares very well with the average value of about 0.04 cents/cc obtained when the water was displaced from all of the fuel elements by inserting aluminum strips to simulate the operating conditions $\left(510^{\circ} \mathrm{F}\right.$ at $\left.2000 \mathrm{psi}\right)$. $^{*}$ The fact that the average value ( 0.0467 cents/cc) obtained by individual measurements is higher than the value obtained from one single perturbation is to be expected since the sum of a series of small perturbations is usually larger than if the perturbation was made in a single step, due to changes in the neutron flux spectrum.

It should be noted that the void coefficients given in Table 2.7 can be added to the stainless steel coefficients in Table 2.6 if the total stainless steel worth or coefficient is desired, including water displacement.

\subsection{REACTIVITY MEASUREMENTS USING FLOW DIVIDER}

The basic SM-2 flow divider design has been reported previously. (6) This test provides data from which the reactivity effects resulting from the use of a flow divider and flow divider support structures may be evaluated. Flow divider reactivity evaluation was made by inserting $1 / 8$-in. stainless steel sheets

- Refer to Section 4.2 and APAE No. $54^{(1)}$. 
between the outer ring of elements as shown in Fig. 1. 7. The core was supported on a 1-in. thick plastic sheet placed on top of the existing stainless steel core support plate. The plastic insert was machined to accommodate the end boxes of the stationary fuel elements so that the proper spacing was achieved for the SM-2 core design with flow divider. Reactivity measurements were taken to evaluate:

1. The effect of raising the core upwards to accommodate the new plastic support plate.

2. The effect of spreading the outer ring of elements by the installation of the plastic support plate.

3. The effect of installing the flow divider between the outer ring of elements.

4. The effect of attaching flow divider to steel reflector by stainless steel support pins.

5. The effect of attaching flow divider to steel reflectors by stainless steel plates.

The results of these measurements are given in the following table.

TABLE 2.8

REACTIVTTY MEASUREMENTS EVALUATING THE INSTALLATION OF FLOW DIVIDER

Reactivity

Change (cents)

1. Effect of raising core 1-in. by means of plastic strips placed under fuel elements.

2. Effect of spreading spacing of elements

3. Effect of flow divider

4. Effect of using $\mathbf{3 2}$ pin supports for flow divider

5. Efftet of using 8 plate supports for flow divider

The first of these reactivity effects results from replacing the steel core support plate with an equivalent volume of water, and hence establishes the reactivity change resulting from the use of the lucite support plate. Since this 
reactivity change results from equipping the experiment it should not be attributed to effects introduced by the flow divider. However, the test data has potential application in the event significant changes are incorporated into the final $\mathbf{S M - 2}$ core support plate design which result in a significant change in the volume of steel in that region. Theremainder of these measurements indicate the effects on SM-2 core reactivity resulting from the use of a 1/8-in. flow divider inserted as shown in Fig. 1. 7. The individual reactivity effects result from increased effective core diameter by increasing the fuel element spacing in certain regions to accommodate the flow divider, insertion of the $1 / 8$-in. thick flow divider and the consequent displacement of some core moderator in that region, and the use of pin or plate type flow divider supports.

Table 2.8 shows that the effect of placing the flow divider in the core supported by pins results in a loss of 143 cents reactivity; the substitution of support plates for pins increases reactivity loss to 165 cents. The linear extrapolation of previous measurements $(1)$ renders a comparative estimated core reactivity change of $\mathbf{1 7 2}$ cents for a flow divider mockup, which did not provide for a mockup of the flow divider supports or increased fuel element spacing. The above measurements were carried out using the entire seven rod bank to measure reactivity changes; the worth of the bank at various positions is given in Fig. 2.2.

\section{5 SUPPRESSOR REACTIVITY}

The core reactivity change resulting from the use of mockup flux suppressors was determined by comparing the relative control rod banik positions at criticality to that obtained when testing "blank" suppressors which contained no neutron absorbing material. Elements Nos. 12, 13, 14, 21, 22, 23, 33, 34 and 41 were mocked up with Mylar tape as described later in Section 3.2; the reactivity calculated from these nine elements was ratioed to the total number of elements in the core. This produced estimated reactivity changes at room temperature for the entire core of $-\$ 2.36$ and $-\$ 2.41$ for the $1 / 2-i n$. and $3 / 4-i n$. wide mockup suppressors, respectively.

\section{6 ADDITIONAL REACTIVITY MEASUREMENTS}

The additional reactivity measurements discussed in this section were performed on the final SM-2 mockup with flow divider at room temperature.

\subsubsection{Effect of Mockup Control Rod Flux Suppressors}

The control rod flux suppressors were mocked up by applying 26 layers of boron impregnated Mylar tape to each side of the control rod fuel plates exactly as the stationary fuel element suppressors (refer to Section 3.2). Two separate measurements were made: (1) the $1 / 2-$ in. wide suppressors were placed directly 
above the top of the active meat of the fuel plates of the seven control rods; (2) the $1 / 2$-in. wide suppressors were placed on the upper $1 / 2-$ in. portion of the active meat of the fuel plates of the seven control rods.

The placing of the $1 / 2$-in. wide mockup flux suppressors above the active meat of the fuel plates of the seven control rods produced a negative reactivity change of 116.1 cents which changed the seven rod bank critical position from 7.845 in. to 8.352 in. The placing of the $1 / 2-$ in. wide suppressors on the upper $1 / 2$-in. portion of the active meat of the fuel plates of the seven control rods produced a negative reactivity change of 155.0 cents which corresponded to a final seven rod bank critical position of 8.531 in. The suppressors were left in this latter position when the final foil measurements were made. It is thought that this mockup is better than the first one as the spacing between the upper edge of the mockup suppressors and the bottom edge of the absorber sections is more nearly correct.

\subsection{Worth of Side Plates}

The SM-2 mockup has an equivalent side plate thickness of 0.0327 in. while the design side plate thickness is 0.040 in. Fifteen mils of stainless steel clad was added to each of 38 stationary fuel elements $(10$ mils on east side and 5 mils on west side) to bring the equivalent mockup side plate thickness to the $0.040 \mathrm{in}$. design thickness. The net reactivity change due to the additional clad in $\mathbf{3 8}$ elements was -23.5 cents. 


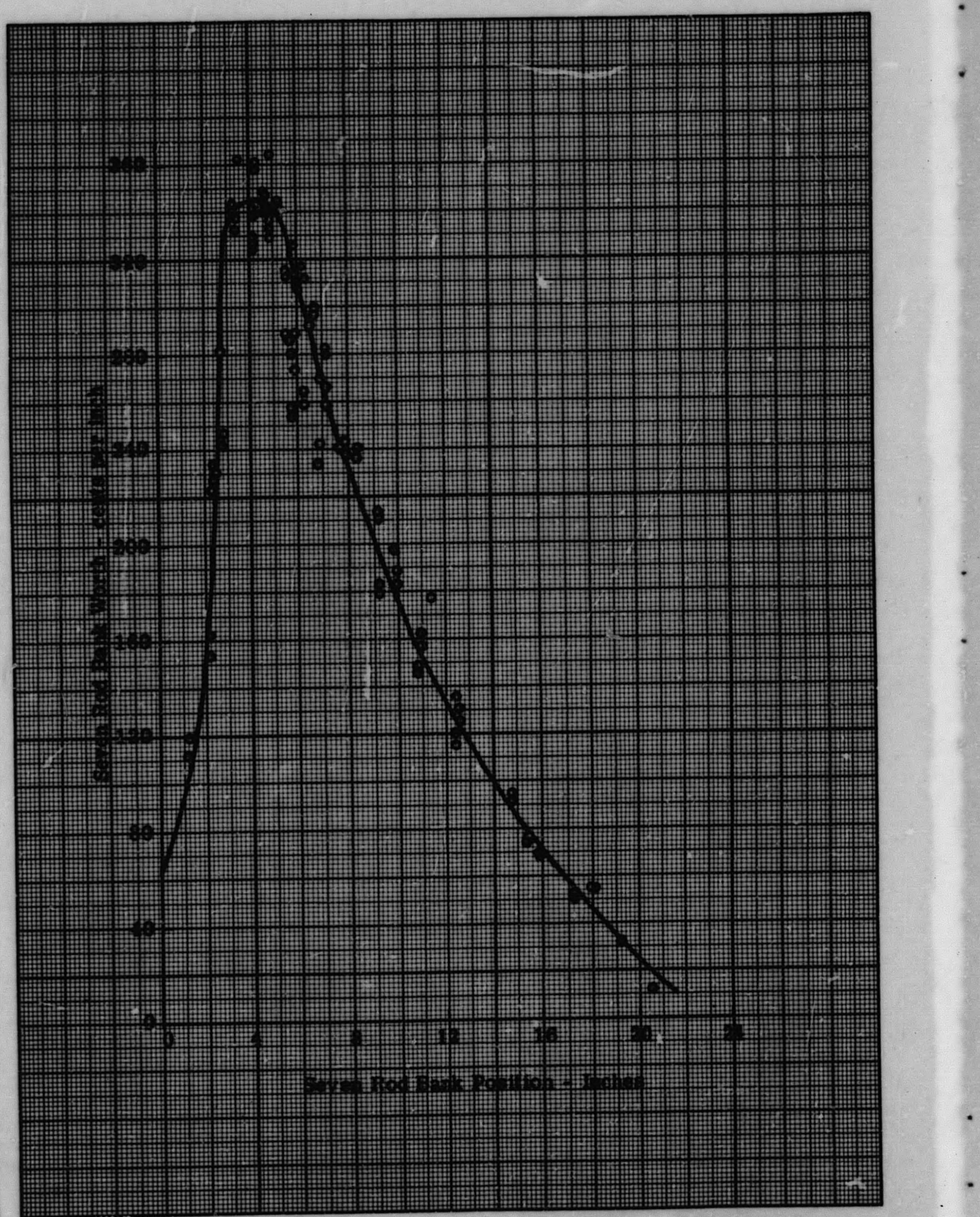

Figure 2.2 Composite Seven Rod Bank Calibration 


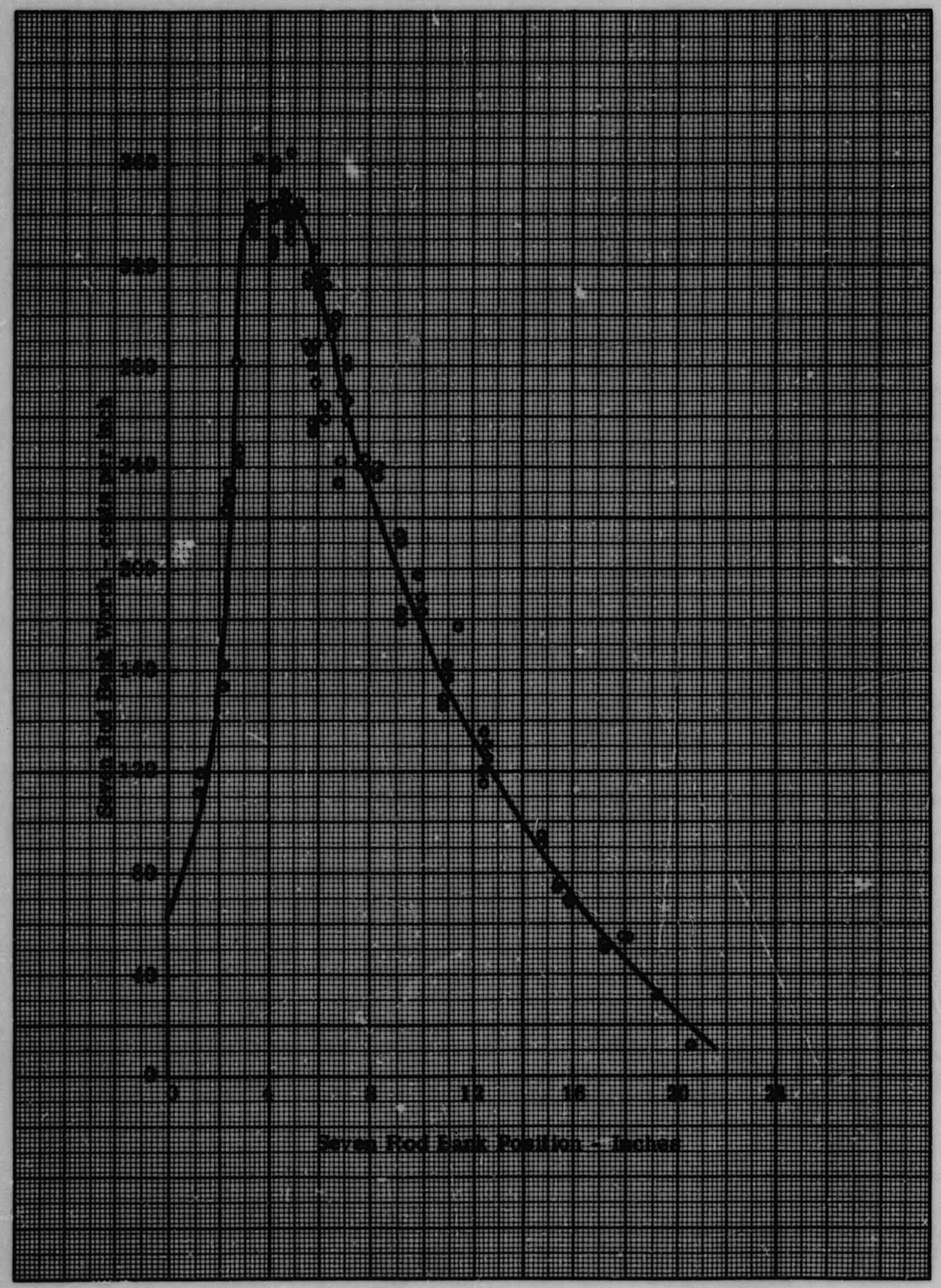

Figure 2.2 Composite Seven Rod Bank Calibration 


\section{0 ACTIVATION MEASUREMENTS}

\subsection{INTRODUCTION}

The relative power distribution in the SM-2 core was obtained by uranium foil activation measurements throughout one quadrant of the core for two separate SM-2 core mockups:

1. Preliminary mockup with laminated steel reflected core without flow divider.

2. Final mockup with laminated steel reflected core with $0.125-$ in. flow divider and $0.5-$ in. mockup flux suppressors at the top of the active meat of the control rod fuel elements.

The resulting data yielded the core average for each mockup and enabled a more definitive fine structure study to be made of the intercell power distribution and/or fission flux, than those previously reported. (1)

The effectiveness of both mockup and integral suppressors located at the lower boundary of the stationary fuel elements in reducing the high power spikes occurring near the bottom of the active meat was determined during a separate series of measurements. Blocked channel measurements were also performed to determine the effects on local power generation that result from blocking a fuel element coolant channel.

\subsection{CORE MAPPING}

\subsubsection{Introduction}

Activation measurements were performed using bare uranium foils taped directly to the fuel plates for the purpose of obtaining a ratio of measured activity to that of a reference. The reference foil for all activation measurements in this series was located at the centerline of the south side of fuel plate " $i$ " of element No. 34 at an axial elevation of 6 in. above the bottom of the active core.

Approximately 1700 data points were taken in one quadrant of the core to obtain an accurate core average based upon core symmetry and a detailed description of local effects. Each data point was then normalized to the average activation; thus, the core average becomes unity by definition.

\subsection{Procedure}

The fuel element to be mapped was instrumented with $19 \mathrm{w} / \mathrm{o}$ fully enriched uranium-aluminum alloy foils of approximately $12-14 \mathrm{mg}$ in weight and $0.25 \mathrm{in}$. diameter. The foils were taped to five fuel plates each of 12 stationary fuel ele- 
ments and three control rod fuel elements, representing a complete quadrant of the full core. The five fuel plates chosen included the two outside plates and the center plate which were mapped extensively, and two other intermediate fuel plates which were mapped as required and in varying degrèes.: This choice represents complete axial and radial traverses of the core. Since the core is symmetrical, mapping of only one quadrant was necessary to determine the core average. Typical foil locations for a stationary fuel element are shown in Fig. 3.1. The foils were activated in the SM-2 mockup core for 30 minutes at 30-40 watt power levels. The foils were then removed and counted with the aid of two scintillation counters.

\subsection{Nomenclature}

The following nomenclature is used in this chapter to define foil locations.

1. Position: Location of foil measured from the bottom of the active core in inches.

2. Axial plane: Plane perpendicular to the core axis and measured from the bottom of the active core in inches.

3. Central radial plane: Plane parallel to the north-south plane of the core and passing through the core centerline.

4. Radial plane: Plane parallel to the north-south plane of the core, distance measured from the central radial plane in inches.

5. Using the Tables: In the following tables all data points have been normalized to a core average power generation of unity (ref. par. 3. 2. 5). Data plots of relative power vs. location may be obtained in the following mánner.

Axial power distributions are obtained by reading the vertical columns in the appropriate tables. As an example, take the relative power distribution along the centerline of core position 42. Reierence to Fig. 3. $2,3.3$ and 3.4 indicates that these data points are located on fuel plate " $\mathrm{j} "$ and on the 5.88 -in. west radial plane of core position 42 . Thus, by referring to Table 3.11 for fuel element position 42, fuel plate " $j "$ at the 5.88 WRP and plotting down the vertical columns, the curve for Fig. 3.8 was generated where the foil position and relative power generation fall along the abscissa and ordinate respectively.

Radial power distribution may be obtained by reading the appropriate table entries in the horizontal direction. As an example, take the radial power distribution through fuel element positions $41,42,43$ and 44 (control rod C), and on an axial plane which is 5 in. above the bottom of the active core. Again by reference to Fig. 3.2, 3.3 and 3.4 it is established that these data points are located on fuel plate " $\mathrm{j}$ " for positions 
41,42 and 43 and on fuel plate " $i$ " for position 44 , which is a control rod and consequently has fewer fuel plates per element and a slightiy different plate identification. Reference to fuel plate " $\mathrm{j}$ " in Tables 3.10 , $3.11,3.12$ and fuel plate " $i "$ in Table 3.14 all at an axial position of 5 in. above the bottom of the active core renders the curve in Fig. 3.10 where the relative power generation has been plotted as a function of radial distance from the core centerline.

If a radial power distribution is desired in a direction which is normal to the plane of the fuel plates and at a specific axial elevation, then the following procedure applies. By reference to Fig. 3.3 and 3.4 the core position and fuel plates of interest are established. Then by reference to the appropriate tables the relative power generation in the selected plates at the selected axial elevation is obtained. As an example, if the radial power distribution through core positions 14 , 24 (control rod A), 34, and 44 (control rod C) is desired at an axial elevation of 5 in., the following procedure applies. By reference to Fig. 3.2, 3. 3 and 3.4 it is established that all data points are located along the central radial plane in core positions 14, 24, 34 and 44 at an axial position of 5 in., and all data points falling between plates " $\mathrm{i}$ " through " $p$ " for core position 44, "a" through " $r$ " for core position 34 , "a" through " $p$ " for core position 24 and " $a$ " through " $r$ " for core position 14 are desired. Then these data points may be obtained from Tables 3. 3, 3.9, 3.13 and 3.14, and a radial power distribution normal to the plane of the fuel plates constructed.

As indicated, Fig. 3.3 shows the locations of various radial planes in the west side of the core, these planes being perpendicular to the plane of the figure. In the following tables, C.R.P. stands for central radial plane; W.R.P. stands for west radial plane; E. R. P. stands for east radial plane.

\section{2. 4 Data Processing}

The data were processed in a manner identical to that described in AP Note 246. (5) This method yields the relative activity of the different foils to that of the reference, allowing corrections for weight, counter background, and radioactive decay. All of the data reported in this chapter were normalized to the core average thus permitting rapid inspection of high power areas.

\subsection{Core Average}

A useful relationship for purposes of core design is the local power generation related to that of the core average. Since all power measurements were related to an arbitrary reference in the core, the procedure described below was utilized in obtaining a core average that is unity by definition.

First, the relative power averages for each plate, then for each fuel element, and finally for the power generating core volume were obtained. Fuel 
plate averages relative to that of the reference point were obtained from measurements across the face of the fuel plates at several axial positions. These measurements were integrated by applying the 3-point or the 5-point Simpson's rule to obtain an average single set of values for the 3- and 5-point radial traverses measured along the fuel plate at various positions above the bottom of the active core. This procedure was followed for each of the five fuel plates selected to be mapped in each fuel element; the distances between radial traverse planes represented strips of equal width required for this integration.

Each set of average values obtained was plotted as a function of axial position for each fuel plate. The curves were integrated by determining the areas under them using a planimeter. These integrated values represented the average power along each fuel plate and within a fuel cell. The average activity of a complete fuel cell was obtained by plotting the average plate values obtained against the distances between the fuel plates selected. The curves were integrated by again employing Simpson's rule giving the average power for each fuel cell.

The core average power value was obtained by summing all the fuel cell power averages and dividing by the power generating volume of the core. This value was equated to 1.00 , and the experimental data points were normalized to this core average of unity. In determining the core average the cell averages for the control rod fuel elements have been weighted to include only the portion of the fuel plates actually inserted in the active core. A typical calculation for obtaining the core average is outlined in Appendix B.

\section{2. 6 Experimental Results Employing Laminated Steel Reflector Without Flow Divider (SM-2 Preliminary Mockup Core)}

Figure 3.4 gives the complete normalized power averages for each fuel element in the core. Of the $\mathbf{4 5}$ core positions, 14 stationary fuel elements clustered about the center of the core exceed the core average. The cell average for the control rod fuel elements are reported as less than the core average even though they have a higher than average power density over the region, since they were weighted to include only the portion of the fuel plates actually in the active core (ref. Table B-2), the seven rod critical bank position being 6.94 in.

Tables 3.1 through 3.15 present the normalized activity distribution along axial traverses of stationary fuel elements in positions $12,13,14,21,22,23,31$, $33,34,41,42,43$ and for control rod fuel elements $A, C$, and $F$ in positions 24, 44 , and 32 respectively. Plates $a, e, j, n$, and $\mathbf{r}$ were selected for these measurements for the stationary fuel elements; plates a, d, i, $m$ and $p$ for the control rod fuel elements. The data range from a normalized low of 0.06 of the core average for plate " $r$ " of stationary fuel element position 21 on the edge of the core to a. high of 7.88 of the core average for plate " $i$ " of control rod $C$ in position 44 in the middle of the core. 
The power traverses shown in Fig. 3.5 through 3.8 are typical of the power distribution axially along a fuel plate. Figures 3.5 and 3.6 show the power of the centerline traverses of plate " $\mathrm{j}$ " normalized to the core average for stationary fuel elements positions 12, 13, 14, and 21, 22, 23, respectively. Figures 3.7 and 3.8 show similar traverses for fuel element positions $31,33,34$, and 41,42 , 43, respectively. It may be concluded from the above that all stationary fuel elements exhibit a large power peak at the bottom of the active core when flux suppressors are not employed, and a smaller axial peak about 4-6 in. above the bottom of the active core. The power gradually diminishes as it approaches the top of the active meat. For example in element position 43 , along centerline of fuel plate " $\mathrm{j} "$ ", this power peaking is about 4.5 times the core average at the bottom of the active meat and 2.24 times the core average at an axial position 5 in. above it, while it is only 0.18 of the core average at the top of the active meat of the core.

Figure 3.9 shows the normalized power of the centerline traverses of fuel plate " $\mathrm{j}$ " of control rods $\mathrm{A}, \mathrm{C}$, and $\mathrm{F}$ for the portion of the fuel plates actually in the active core. There is a very small uniform increase in the normalized activity from the bottom of the active core to near the critical bank position of 6.94 in. at which point the power exhibits a very sharp increase shown by the almost vertical lines in Fig. 3.9.

Figure 3.10 shows a typical radial power traverse 5 in. above the bottom of the active core along the center of stationary fuel elements in positions 41 , 42,43 , and control rod $C$ in position 44 , indicating the overall rise in power upon approaching the center of the core and the power minima along the centerline of a fuel element in relation to its outer edges.

The measurements of this configuration show an overall maximum-toaverage power generation of $\mathbf{7 . 8 8}$ to 1 where the maximum is in the central control rod. The maximum-to-average considering the spike at the bottom of the core is $\mathbf{5 . 5 0}$ to $\mathbf{1}$. Ignoring both of these spikes the internal maximumto-average is 4 . 39 to 1 occurring within the central control rod fuel element. These measurements indicate the need for flux suppressors.

\section{2. 7 Experimental Results Employing Laminated Steel Reflector, Flow Divider and Flux Suppressors at the Top of the Active Meat of the Control Rod Fuel Elements(SM-2 Final Mockup Core)}

To the preliminary SM-2 mockup core was added a 0.125 -in. stainless steel flow divider inserted between the two outer rings of elements which were slightly displaced, as shown in Fig. 1.7 and described in Section 2.4. In addition, 0.5-in. mockup flux suppressors were placed at the top of the active meat of all control rod fuel elements. The relative power distribution for the final SM-2 core mockup was obtained in the same manner as that described in the preliminary tests. The critical bank position for these tests was 8.54 in. withdrawn. 


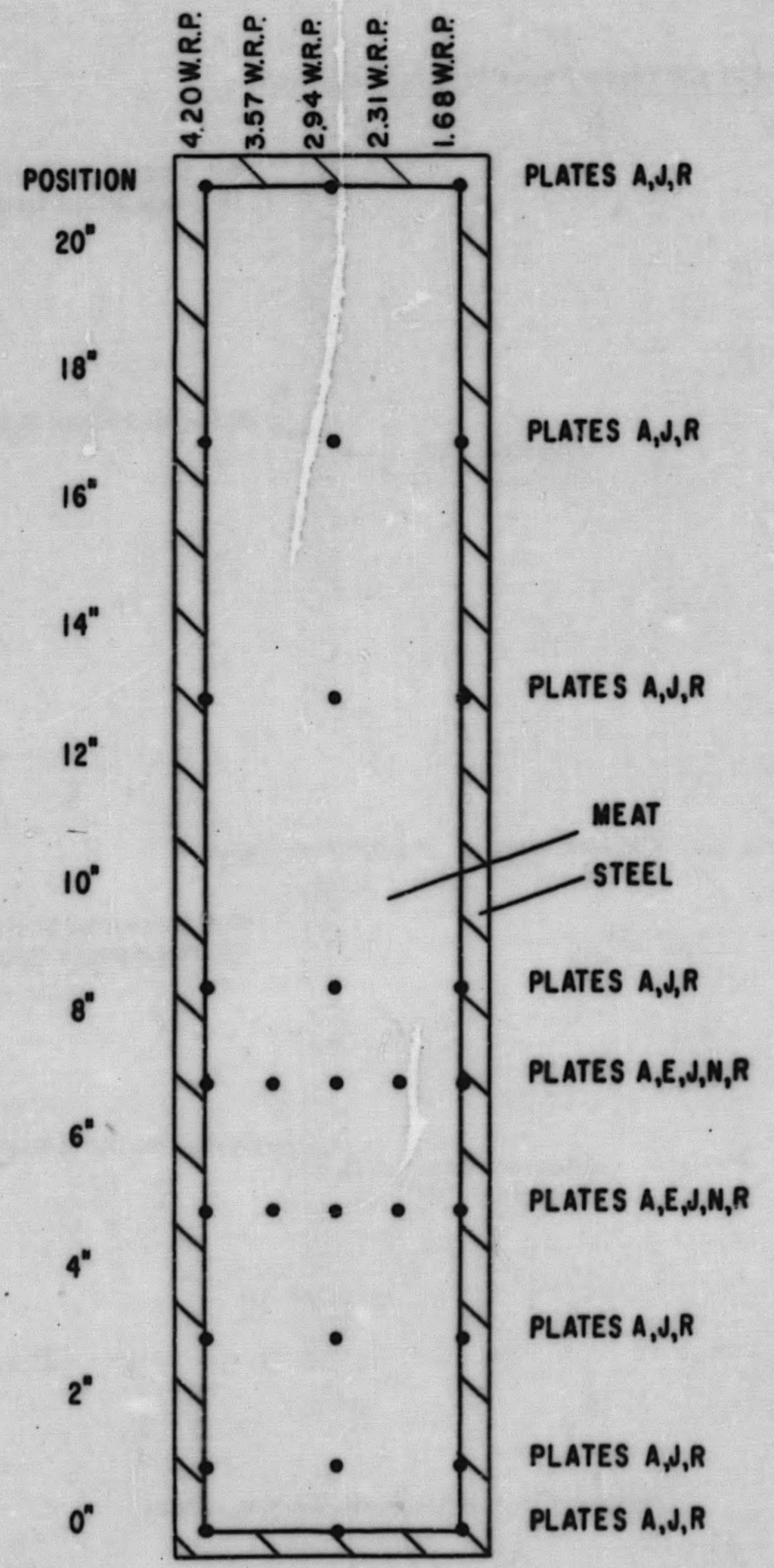

Figure 3.1 Uranium Foil Locations on Element in Position 13 
Stationary Element Fuel Plate Arrangement

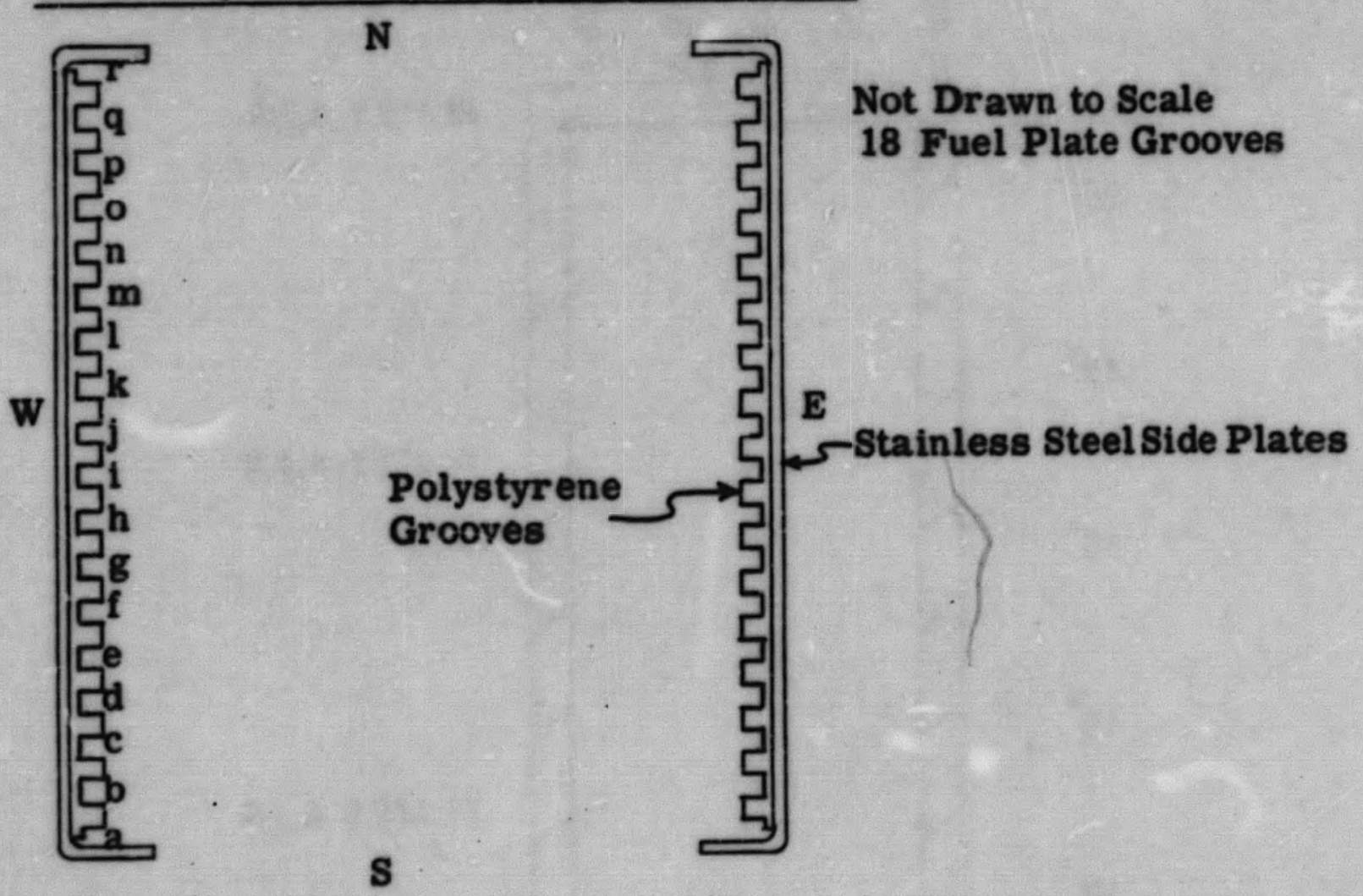

Control Rod Element Fuel Plate Arrangement

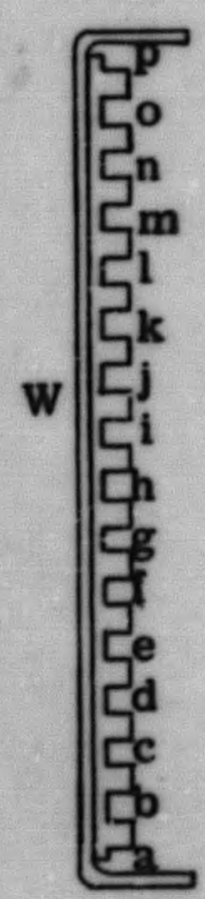

$\mathbf{N}$

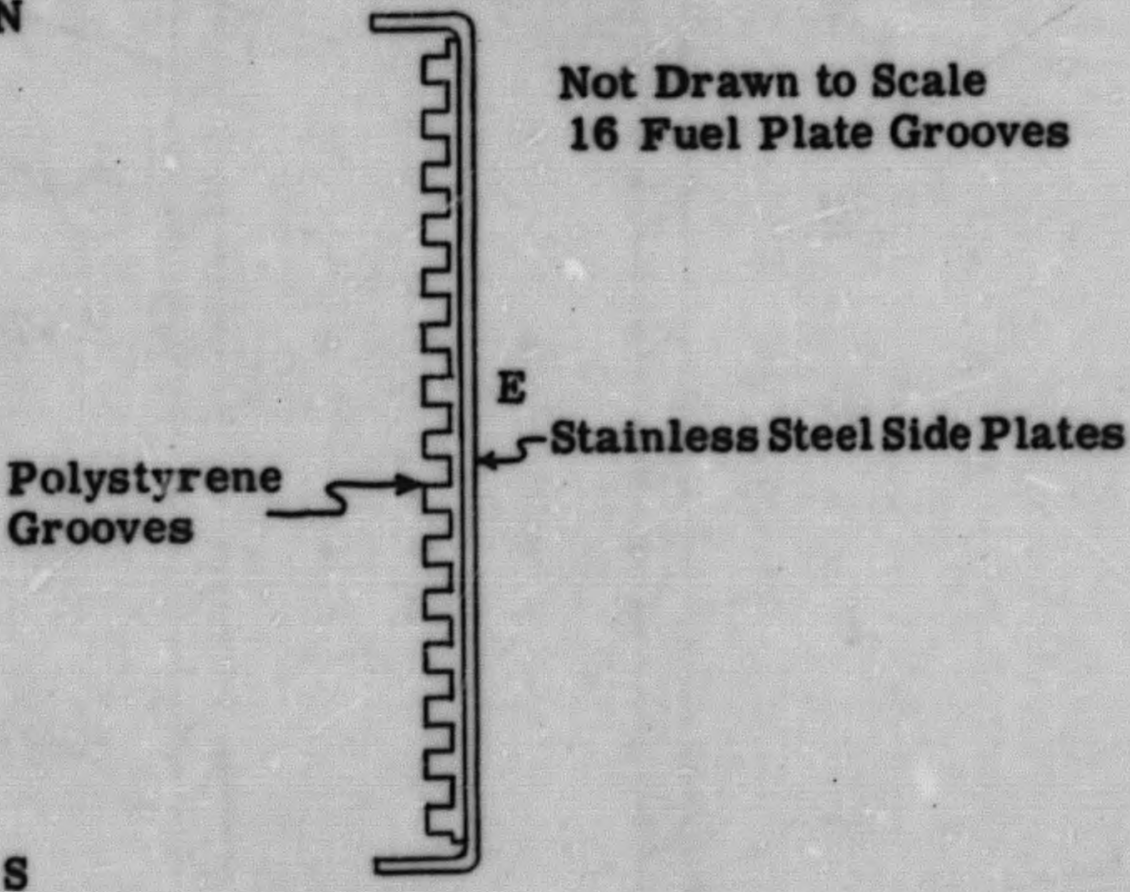

Figure 3.2 Fuel Plate Arrangement 


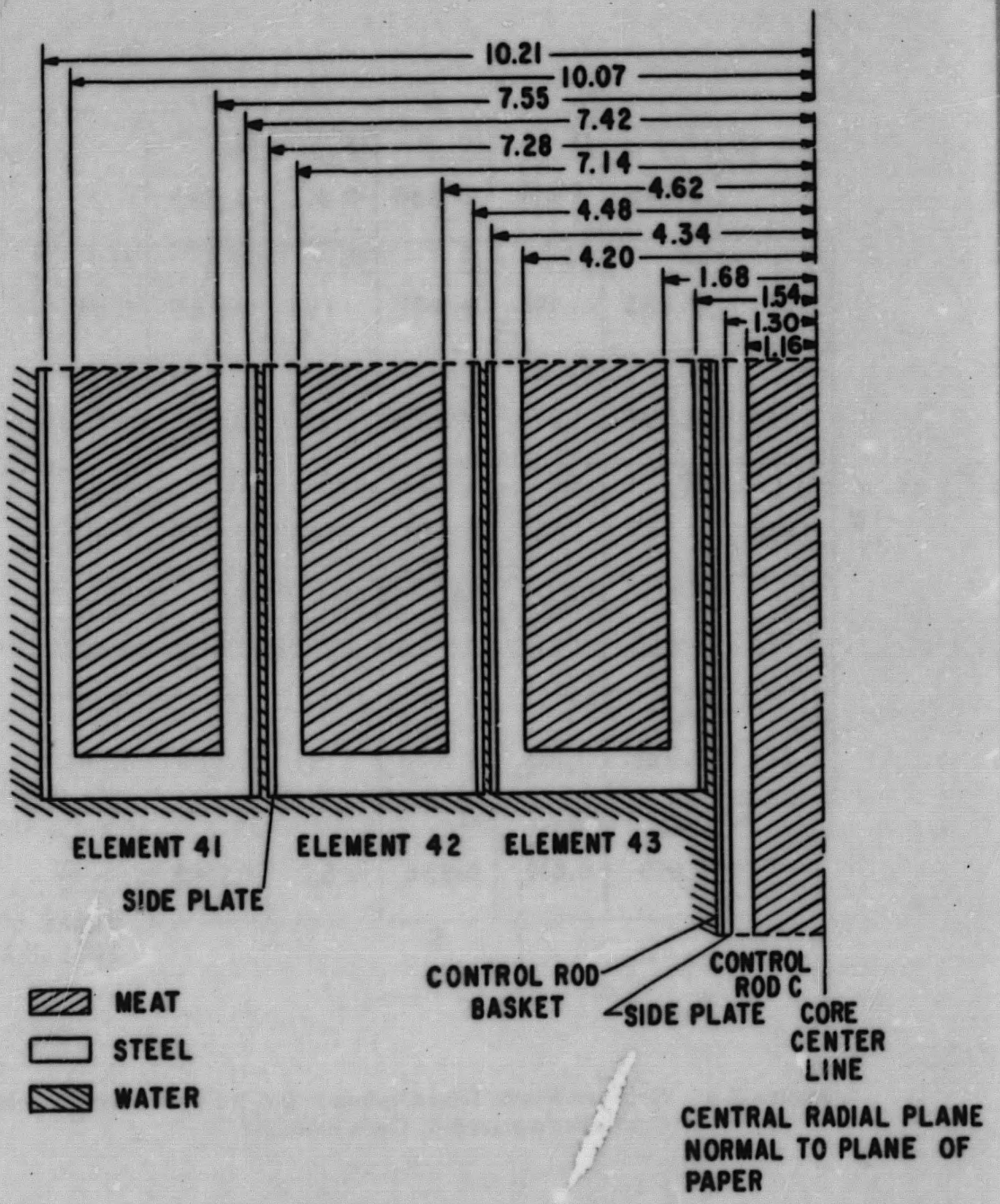

Figure 3.3 Location of Radial Planes Without Flow Divider, Section of Core Through Center of Elements in Positions 41, 42,43 and 44 


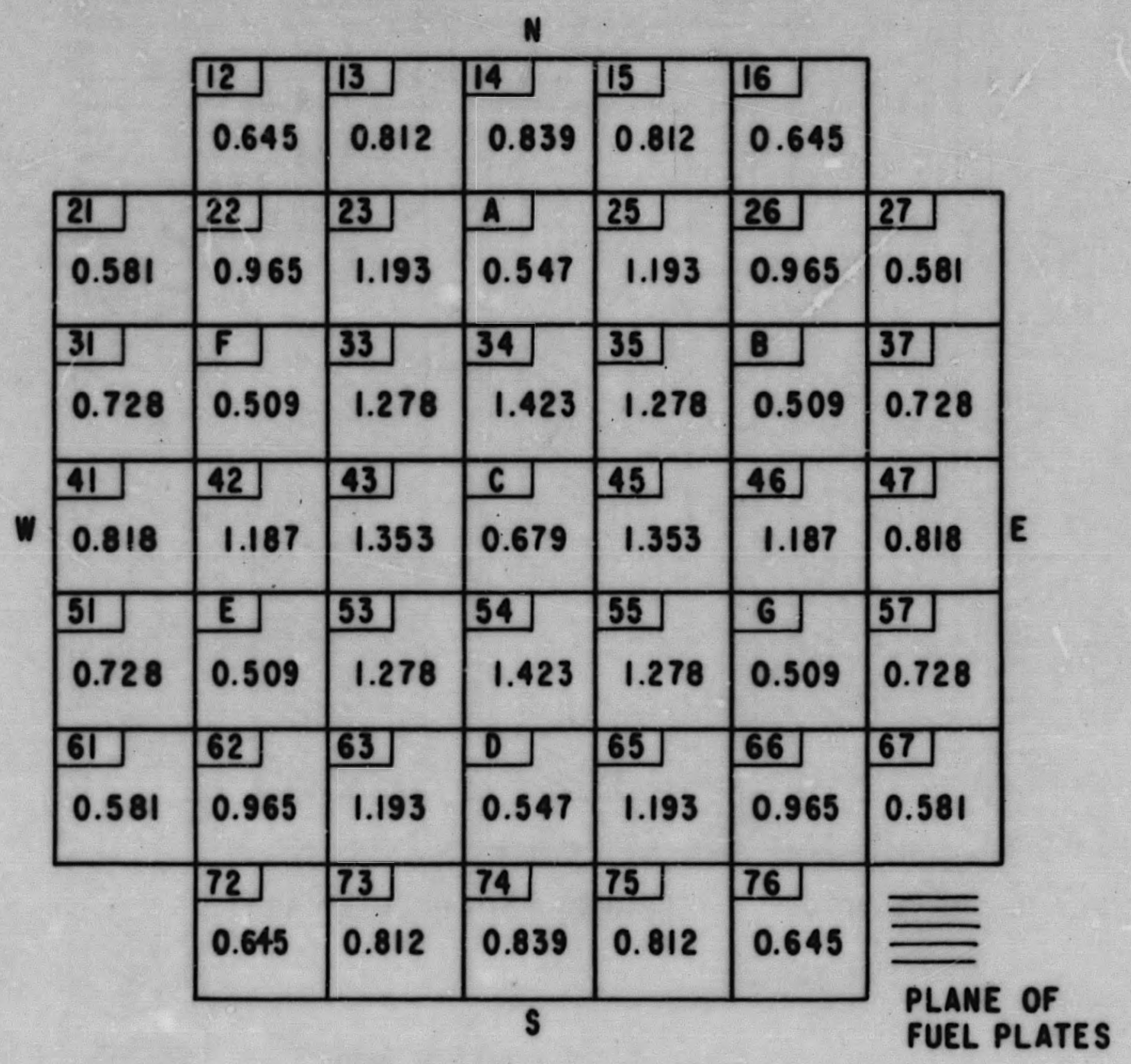

Figure 3.4 Relative Power Distribution in SM-2 Preliminary Mockup Core, Normalized to Core Average 
Table 3.1

Relative Power Distribution Along Axial Traverses For Element in Position 12

$$
\begin{gathered}
\text { DiM-2 Preliminary Mock } \\
\text { Plate "e" }
\end{gathered}
$$

Plate "j"

Position 7.14 WRP 6.51 WRP 5.88 WRP 5.25 WRP 4.62 WRP 7.14 WRP 6.51 WRP 5.88 WRP S.25 WRP 4.62 WRP T.14 WRP 6.51 WRP 5.88 WRP S.25 WRP 4.62 WRP

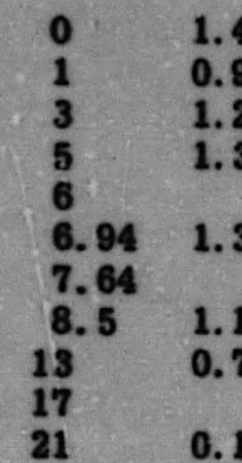

1.43
0.95
1.22
1.34
1.30
1.18
0.72
0.19

1.24

2.06
0.93
1.27

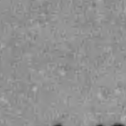

2.39

$1.22 \quad 1.30 \quad 1.46$

2. 11
2.36

1.13

1.11

1.06

1.50

2.11

0.87

0.95

1.13

1.22

2.03

2. 02

0.65
0.44

.27

(2)

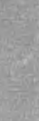

.

Blate "r"

Position 7.14 WRP 6.51 WRP 5.88 WRP 5.25 WRP 4.62 WRP 7.14 WRP 6.51 WRP 5.88 WRP 5.25 WRP 4.62 WRP

\begin{tabular}{|c|c|c|c|c|c|c|c|c|c|c|}
\hline $\begin{array}{l}0 \\
1 \\
3 \\
5\end{array}$ & 0.81 & 0.74 & 0.85 & 0.91 & 1.48 & $\begin{array}{l}0.56 \\
0.53 \\
0.56 \\
0.63\end{array}$ & 0.58 & $\begin{array}{l}0.74 \\
0.46 \\
0.63 \\
0.69\end{array}$ & 0.81 & $\begin{array}{l}1.04 \\
0.83 \\
1.02 \\
1.13\end{array}$ \\
\hline $\begin{array}{l}6.94 \\
7.64\end{array}$ & 0.76 & 0.67 & 0.72 & 0.87 & 1. 34 & 0.60 & 0.63 & 0.69 & 0.76 & 1.06 \\
\hline $\begin{array}{l}8.5 \\
13 \\
17\end{array}$ & & & & & & $\begin{array}{l}0.56 \\
0.37\end{array}$ & & $\begin{array}{l}0.58 \\
0.39 \\
0.21\end{array}$ & & $\begin{array}{l}1.06 \\
0.67\end{array}$ \\
\hline 21 & & & & & & 0.09 & & 0.10 & & 0.17 \\
\hline
\end{tabular}


Plate "a"

Plate "e"

Plate "j"

Position 4.20 WRP 3.57 WRP 2.94 WRP 2.31 WRP 1.68 WRP 4.20 WRP 3.57 WRP 2.94 WRP 2.31 WRP 1.68 WRP 4.20 WRP 3.57 WRP 2.94 WRP 2.31 WRP 1.68 WRP

$\begin{array}{cccc}0 & 2.56 & & 2.3 \\ 1 & 1.67 & & 1.20 \\ 3 & 2.24 & & 1.5 \\ 5 & 2.23 & 1.64 & 1.7 \\ 6 & & & \\ 6.94 & 2.13 & 1.28 & 1.52 \\ 7.64 & & & \\ 8.5 & 1.98 & & 1.32 \\ 13 & 1.13 & & 0.7 \\ 17 & & & 0.4 \\ 21 & 0.28 & & 0.1\end{array}$

2.31
1.20
1.55
1.76
1.52
1.32
0.76
0.41
0.19

$\begin{array}{ll}2.93 & \\ 2.08 & \\ 2.68 & \\ 2.87 & 2.20 \\ 2.73 & 2.02 \\ 1.99 & \\ 1.02 & \\ 0.25 & \end{array}$

\begin{tabular}{ll}
1.32 & 1.32 \\
1.30 & 1.22 \\
\hline & \\
\hline
\end{tabular}

$\begin{array}{ll}1.43 & 2.54 \\ 1.37 & 2.22 \\ & \\ & \end{array}$

$\begin{array}{ll}2.06 & \\ 1.27 & \\ 1.57 & \\ 1.69 & 1.13 \\ 1.65 & 1.18 \\ 1.52 & \\ 0.95 & \\ 0.24 & \end{array}$

2.08
0.76
1.02
1.15
1.06
0.97
0.56
0.30
0.16

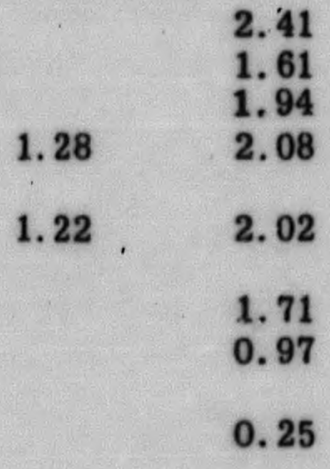

Plate " $\mathrm{n}$ "

Plate "r"

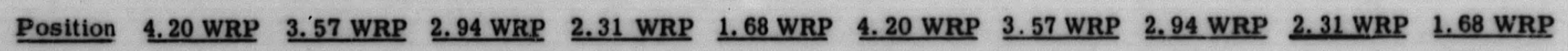

\begin{tabular}{|c|c|c|c|c|c|c|c|c|c|c|}
\hline $\begin{array}{l}0 \\
1 \\
3 \\
5 \\
0\end{array}$ & 1.65 & 1.00 & 0.95 & 1.13 & 1.65 & $\begin{array}{l}1.20 \\
0.87 \\
1.09 \\
1.30\end{array}$ & 0.85 & $\begin{array}{l}1.06 \\
0.63 \\
0.83 \\
0.90\end{array}$ & 0.95 & $\begin{array}{l}1.30 \\
1.02 \\
1.28 \\
1.32\end{array}$ \\
\hline $\begin{array}{l}6.94 \\
7.64\end{array}$ & 1.65 & 0.95 & 1.02 & 1.09 & 1.65 & 1. 11 & 0.87 & 0.81 & 0.91 & 1. 30 \\
\hline $\begin{array}{l}8.5 \\
13\end{array}$ & & - & & & & $\begin{array}{l}0.97 \\
0.58\end{array}$ & & $\begin{array}{l}0.83 \\
0.48\end{array}$ & & $\begin{array}{l}1.15 \\
0.67\end{array}$ \\
\hline $\begin{array}{l}17 \\
21\end{array}$ & & & & & & 0.15 & & 0.11 & & 0.19 \\
\hline
\end{tabular}


Table 3. 3

Relative Power Distribution Along Axial Traverses For Element in Position 14

Plate "a"

\begin{tabular}{clll} 
& \multicolumn{3}{c}{ Plate "a" } \\
\cline { 2 - 4 } Position & 1.20 WRP & 0.63 WRP & CR \\
0 & 2.89 & & 2. \\
1 & 2.12 & & 1. \\
3 & 2.68 & & 1.92 \\
5 & & 2.11 & 1.87 \\
6 & 2.86 & & 1.9 \\
6.94 & 2.92 & 2.37 & 2.8 \\
7.64 & 2.69 & & 2.59 \\
8.5 & 1.84 & & 1.1 \\
13 & 0.81 & & 0. \\
17 & 0.43 & & 0. \\
21 & 0.18 & & 0.0
\end{tabular}$$
\begin{gathered}
\text { Plate "e" } \\
\hline 1.26 \text { WRP } \\
0.63 \text { WRP CRP }
\end{gathered}
$$

2.35
1.43
1.92
1.97
1.93
2.86
2.59
1.18
0.40
0.20
0.09

$2.35 \quad 1.08 \quad 1.42$
SM-2 Preliminary Mockup Core
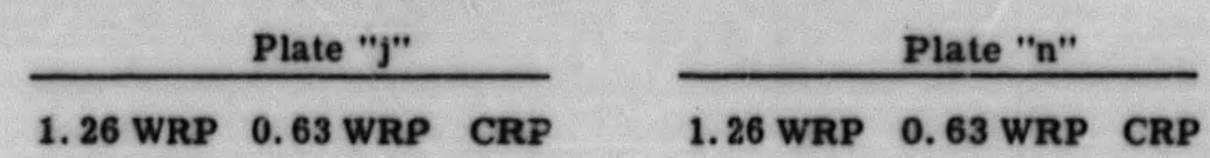

$2.62 \quad 2.17$

$\begin{array}{ll}2.17 & 2.28 \\ 0.94 & 0.94\end{array}$

$2.23 \quad 1.38 \quad 1.28$

1. 50

\begin{tabular}{l|l}
1.21 & 1.21 \\
1.36 & 1.28
\end{tabular}

1.28
21 $\quad 1.20$

$1.21 \quad 1.13$

$\begin{array}{ll}1.05 & 0.95 \\ 0.57 & 0.53\end{array}$

$\begin{array}{ll}0.57 & 0.53 \\ 0.27 & 0.29\end{array}$

$\begin{array}{ll}0.15 & 0.13\end{array}$

Plate " $r$ "

1. 26 WRP 0.65 WRP CRP

1. 32

$\begin{array}{lll}1.72 & 1.14 & 1.10\end{array}$

$\begin{array}{lll}1.68 & 1.05 & 1.04\end{array}$

.96
1. 19

1. 28

1. 29

1. 32

1. 29

0.65
0.40

0.90

1.29
0.68
0.89

0.86

0.94

0.90

0.90

0.81

0.81
0.27
0.27

0.27
0.11 
ยู

Table 3.4
$\frac{\text { Relative Power Distribution Along Axial Traverses For Element in Position } 21}{\text { SM-2 Preliminary Mockup Core }}$

Plate "a"

Plate "e"

Plate "j"

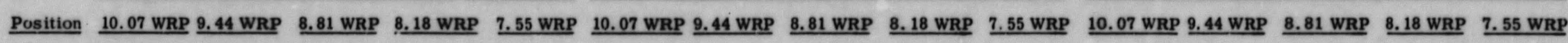

\begin{tabular}{|c|c|c|c|c|c|c|c|c|c|c|c|c|c|c|c|}
\hline $\begin{array}{l}0 \\
1 \\
3 \\
5 \\
6\end{array}$ & $\begin{array}{l}1.04 \\
0.72 \\
0.95 \\
1.10\end{array}$ & 1.00 & $\begin{array}{l}1.61 \\
0.87 \\
1.11 \\
1.18\end{array}$ & 1.41 & $\begin{array}{l}2.41 \\
2.20 \\
2.20\end{array}$ & 1.04 & 0.85 & 0.97 & 1.18 & 2.24 & $\begin{array}{l}0.97 \\
0.67 \\
0.85 \\
0.95\end{array}$ & 0.81 & $\begin{array}{l}1.52 \\
0.67 \\
0.83 \\
0.95\end{array}$ & 1.11 & $\begin{array}{l}2.41 \\
1.57 \\
1.85 \\
1.99\end{array}$ \\
\hline $\begin{array}{l}6.94 \\
7.64\end{array}$ & 1.00 & 1.04 & 1.10 & 1.24 & 2.11 & 0.97 & 0.87 & 0.91 & 1.09 & 2.11 & 0.97 & 0.69 & 0.85 & 1.04 & 1.83 \\
\hline $\begin{array}{l}8.5 \\
13 \\
17\end{array}$ & $\begin{array}{l}0.90 \\
0.53 \\
0.26\end{array}$ & & $\begin{array}{l}0.91 \\
0.50 \\
0.28\end{array}$ & & $\begin{array}{l}1.67 \\
0.72 \\
0.41\end{array}$ & & & & & & $\begin{array}{l}0.81 \\
0.50 \\
0.26\end{array}$ & 0.24 & $\begin{array}{l}0.74 \\
0.39 \\
0.24\end{array}$ & & $\begin{array}{l}1.61 \\
0.90\end{array}$ \\
\hline $\begin{array}{l}17 \\
21\end{array}$ & 0.13 & 0.12 & 0.10 & 0.10 & 0.18 & & & & & . & 0.10 & $\begin{array}{l}0.24 \\
0.08\end{array}$ & 0.10 & $\begin{array}{l}0.20 \\
0.12\end{array}$ & 0.21 \\
\hline
\end{tabular}

Plate "n"

Plate "r"

Position 10.07 WRP 9.44 WRP 8.81 WRP 8.18 WRP 7.55 WRP 10.07 WRP 9.44 WRP 18.81 WRP 8.18 WRP 7.55 WRP$$
\begin{gathered}
0 \\
1 \\
3 \\
5 \\
6 \\
6 . \\
7 . \\
8 . \\
13 \\
17 \\
21
\end{gathered}
$$

0.48

$\begin{array}{llllll}0.81 & 0.65 & 0.83 & 0.87 & 1.85\end{array}$

\begin{tabular}{|l|lllll}
\hline & 0.74 & 0.69 & 0.76 & 0.90 & 1.65
\end{tabular}

1. 65

0.56

0.55

0.53
0.30
0.18

0.18
0.06

$\begin{array}{ll} & 0.7 \\ & 0.44 \\ 0.55 & 0.5 \\ 0.50 & 0.6 \\ & 0.6 \\ & 0.5 \\ & 0.35 \\ 0.18 & 0.1 \\ 0.11 & 0.0\end{array}$

0.74
0.44
0.58

1.24
0.93

0.78

$0.74 \quad 1.37$

8.5

0.11

0.53

$\begin{array}{lll}0.53 & & 1.18 \\ .35 & & 0.67 \\ .19 & 0.24 & 0.39 \\ 0.08 & 0.12 & 0.18\end{array}$ 
Table 3.5

Fur Element in Position 22

Plate "a"

Plate " $\mathrm{e}$ "

Plate " 5 "

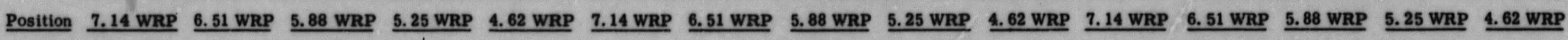
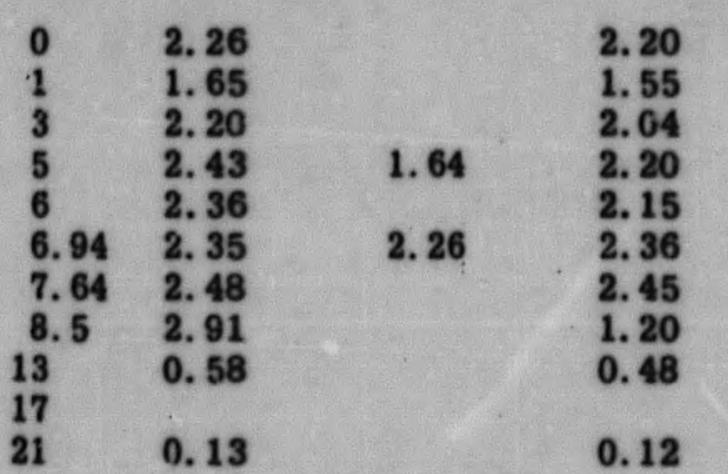

2. 45

3. 37

1.64

2.54

$2.26 \quad 1$.

$\begin{array}{lll}1.57 & 1.74 & 2.93\end{array}$

2. 39
1. 43
1.80

2. 26

$2.04 \quad 1.48$

$\begin{array}{llll}1.39 & 1.52 & 2.80\end{array}$

1.80
1.96
2.13
1.89

1. 34

2.28
1.09
1.32
1.43
1.41
1.27
1.20
1.20
0.63
0.35
0.17

3. 70

70.13

0.12

3. 39
2. 39
1.00
2. 48

Plate " $\mathrm{n}$ "

Plate " $\mathrm{r}$ "

Position 7.14 WRP 6.51 WRP 5.88 WRP 5.25 WRP 4.62 WRP 7.14 WRP 6.51 WRP 5.88 WRP 5.25 WRP 4.62 WRP

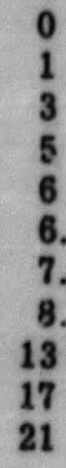

0
1
3
5
6
6.
7.
8.
13
17
21

$1.22 \quad 1.32$

$1.48 \quad 2.72$

1.67
1.18

$\begin{array}{lllllll}94 & 1.69 & 1.27 & 1.34 & 1.43 & 2.39\end{array}$

7. 54

2.

1.3
1.39
1.5
1.5
1.3
1.3
1.34
0.7

1.78
1.00
1.27
1.30
1.27
1.28
1.28
1.09
0.65
0.15

2. 77

1.34

2.28
2.48

1. 18

1.30
1.27

1. 39

2. 61

2. 33
2. 15

2.26

1.22

0.24

1. 69

1. 52

1.50
1.59
0.97
0.50
0.25

1. 30

2.72
2.82

2.84
2.56

2.54
2.26

1.2

0.65
0.27 
ูํ

Table 3.6
Relative Power Distribution Along Axial Traverses For Element in Position 23 SM-2 Preliminary Mockup Core

Plate "a"

Plate "e"

Plate "j"

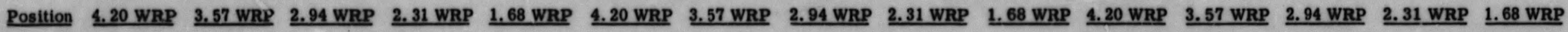

$\begin{array}{llll}\mathbf{0} & 3.82 & & 3.56 \\ 1 & 2.48 & & 1.65 \\ 3 & 3.08 & & 2.04 \\ 5 & 3.32 & 2.20 & 2.15 \\ 6 & 3.21 & & 2.20 \\ 6.94 & 3.02 & 1.92 & 1.96 \\ 7.64 & 2.80 & & 1.87 \\ 8.5 & 2.24 & & 0.7 \\ 13 & 1.02 & & 0.7 \\ 17 & & & 0.18 \\ 21 & 0.27 & & 0.18\end{array}$

$\begin{array}{lll}3.56 & & 4.00 \\ 1.65 & & 2.78 \\ 2.04 & & 3.52 \\ 2.15 & 2.45 & 3.76 \\ 2.20 & & 3.74 \\ 1.96 & 2.04 & 3.56 \\ 1.87 & & 3.19 \\ 0.78 & & 2.48 \\ 0.18 & & 1.06 \\ & & 0.25\end{array}$

3.67

$3.24 \quad 1.83$

$2.72 \quad 1.69$

1. 87

1.98

3. 58

2.63
2.96

1. 71

2.59
2. 52
2.31

2. 31
1. 34

1.34
0.72

0.39

Plate " $n$ "

Plate " $\mathrm{r}$ "

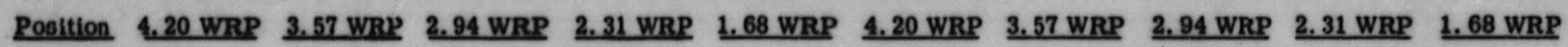

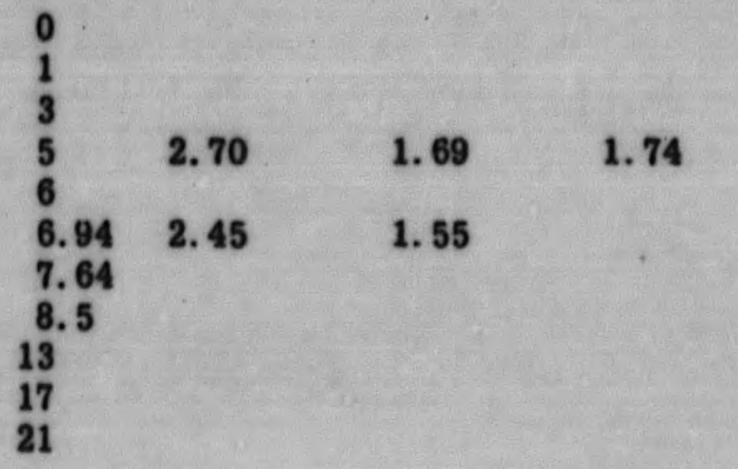

1. 71

2.96
1.74
2.28
2.36
2.43
2.36
2.26
1.99
1.24
0.32

2.80
1.22
1.50
1.69
1.59
1.50
1.48
1.32
0.72
0.18

3. 26

1.65

1.59

$\begin{array}{ll} & 3.26 \\ & 2.24 \\ 1.71 & 2.73 \\ 1.64 & 2.73 \\ & 2.93 \\ 2.82 \\ & 2.68 \\ & 2.02 \\ & 0.90 \\ & 0.20\end{array}$

\begin{tabular}{llll}
\hline 3.65 & & 3.42 \\
1.34 & & 2.62 \\
1.64 & & 3.05 \\
1.78 & & 1.94 & 3.27 \\
1.83 & & & \\
1.65 & 1.64 & 3.19 \\
1.61 & & 3.02 \\
1.50 & & 1.98 \\
0.76 & & 0.85 \\
0.48 & & 0.41 \\
0.20 & & 0.24
\end{tabular}


Table 3.7

Relative Power Distribution Along Axial Traverses For Element in Position 31

Plate "a"

Plate "e"

Plate " $\mathrm{j}$ "

Position 10.07 WRP 9.44 WRP 8.81 WRP 8.18 WRP 7.55 WRP 10.07 WRP 9.44 WRP 8.81 WRP 8.18 WRP 7.55 WRP 10.07 WRP 9.44 WRP 8.81 WRP 8.18 WRP 7.55 WRP

$\begin{array}{llll}0 & 1.32 & & 1.99 \\ 1 & 0.93 & & 0.9 \\ 3 & 1.15 & & 1.27 \\ 5 & 1.24 & 1.18 & 1.27 \\ 6 & 1.22 & 1.27 \\ 6.94 & 1.11 & 1.04 & 1.1 \\ 7.64 & 1.02 & & 1.09 \\ 8.5 & 0.95 & & 0.97 \\ 13 & 0.53 & & 0.5 \\ 17 & 0.15 & & 0.1 \\ 21 & 0.15 & & 0.1\end{array}$

1.99
0.95
1.27
1.27
1.22
1.18
1.09
0.97
0.53
0.13

2.65

1.52

1. 30

1.09

1.24

1.41
1.28

2. 59

1.46
.90

1.34

2.65
2.41
2.48

$1.11 \quad .91$

1.04

$\begin{array}{ll}1.28 & 2.52\end{array}$

0.17

Plate " $n$ "

Plate "r"

Position 10.07 WRP 9.44 WRP 8.81 WRP 8.18 WRP 7.55 WRP 10.07 WRP 9.44 WRP 8.81 WRP 8.18 WRP 7.55 WRP

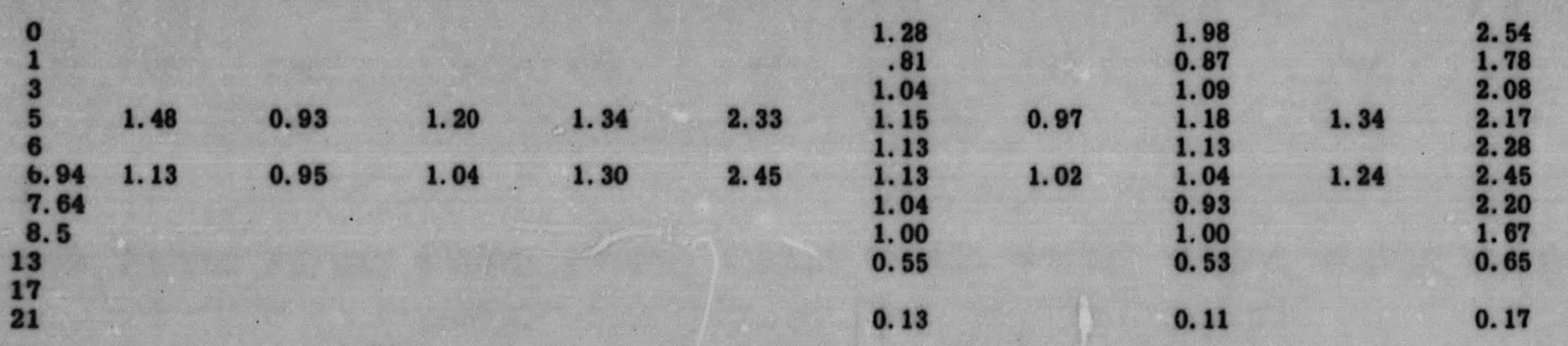


Table 3.8

Relative Power Distribution Along Axial Traverses for Elemert in Position 33

Plate "e"

Plate "j"

Position 4.20 WRP 3.57 WRP 2.94 WRP 2.31 WRP 1.88 WRP 4.20 WRP 3.57 WRP 2.94 WRP 2.31 WRP 1.68 WRP 4.20 WRP 3.57 WRP 2.94 WRP 2.31 WRP 1.68 WRP

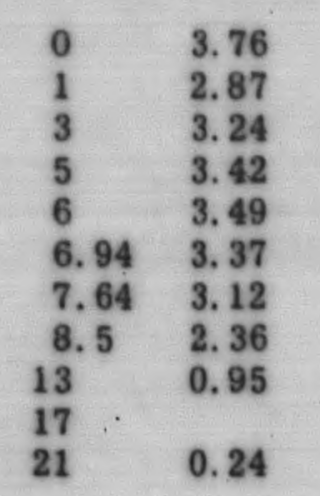

$\begin{array}{lll} & 3.81 & \\ & 1.85 & \\ 2.63 & 2.36 & \\ 2.15 & 2.48 & 2.69 \\ & 2.27 & \\ & 2.24 & 2.41 \\ & 1.87 & \\ & 1.74 & \\ & 0.85 & \\ & 0.17 & \end{array}$

4.32
2.91
3.76
4.04
3.93
3.45
3.58
2.91
1.41
0.27

$\begin{array}{ll}3.67 & 4.19 \\ 2.72 & 1.57\end{array}$

$\begin{array}{ll}2.89 & \\ 4.04 & 2.08\end{array}$

3. 28

$3.33 \quad 1.89$

Plate " $n$ "

Plate "r"

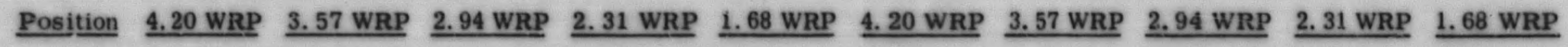

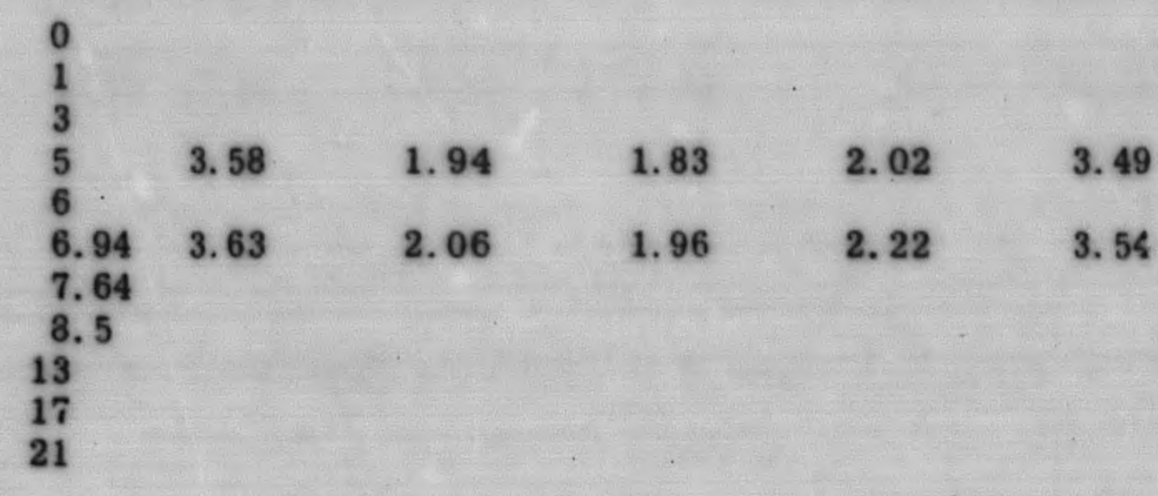

\begin{tabular}{ll} 
3. 70 & \\
2.54 & \\
2.82 & \\
3.19 & 2.08 \\
3.21 & \\
3.00 & 1.98 \\
3.00 & \\
2.31 & \\
0.91 & \\
0.26 & \\
\hline
\end{tabular}

3.81
1.57
2.02
2.11
2.02
1.89
1.71
1.52
0.76
0.17

$\begin{array}{ll} & 3.91 \\ & 2.56 \\ 2.22 & 3.19 \\ & 3.52 \\ 1.98 & 3.26 \\ & 3.26 \\ & 2.84 \\ & 2.48 \\ & 1.02 \\ & 0.25\end{array}$


able 3.9

Relative Power Distribution Along Axial Traverses For Element in Position 34

Plate "a"

\begin{tabular}{|c|c|c|c|}
\hline \multirow[b]{2}{*}{ Position } & \multicolumn{3}{|c|}{ Plate "a" } \\
\hline & 1.26 WRP & 0.63 WRP & CRP \\
\hline 0 & 4. 46 & & 3.21 \\
\hline 1 & 3. 63 & & 2.24 \\
\hline 3 & 4. 32 & & 2.70 \\
\hline 5 & 4. 32 & 3. 15 & 3.02 \\
\hline 6 & 4.23 & & 2.84 \\
\hline 6.94 & 4. 30 & 3.47 & 3. 37 \\
\hline 7.64 & 3. 93 & & 3. 63 \\
\hline 8.5 & 2. 73 & & 1.78 \\
\hline 13 & 1.09 & & 0.63 \\
\hline 17 & & & \\
\hline 21 & 0.28 & & 0.17 \\
\hline
\end{tabular}

\begin{tabular}{|c|c|c|}
\hline & Plate "e" & \\
\hline $1.26 \mathrm{WRP}$ & 0.63 WRP & CRP \\
\hline 5.22 & & 4. 39 \\
\hline 3. 10 & & 1. 67 \\
\hline 3. 70 & & 2. \\
\hline 3.89 & 2. 33 & 2. 36 \\
\hline 3.63 & & 2.13 \\
\hline 3.24 & 2. 20 & $2 .($ \\
\hline 3.24 & & 1.94 \\
\hline 2.82 & & 1.61 \\
\hline 1.22 & & 0.76 \\
\hline .35 & & 0.21 \\
\hline
\end{tabular}

Plate "j"

Plate " $\mathrm{n}$ "

\begin{tabular}{llll}
\hline 1.26 WRP & & 0.63 WRP & CRP \\
\cline { 1 - 1 } 5.50 & & 4.54 \\
2.78 & & 1.67 \\
3.33 & & & 2.15 \\
3.63 & & 2.20 & 2.20 \\
3.58 & & & 2.15 \\
3.47 & & 2.36 & 1.96 \\
3.02 & & & 1.89 \\
2.63 & & 1.50 \\
1.39 & & 0.85 \\
0.34 & & 0.44 \\
0.34 & & 0.35
\end{tabular}

\begin{tabular}{|c|c|c|}
\hline 1.26 WRP & $\underline{0.63 \text { WRP }}$ & $\underline{\text { CRP }}$ \\
\hline $\begin{array}{l}5.00 \\
2.96 \\
3.63 \\
3.67 \\
3.70 \\
3.21 \\
3.10 \\
2.28 \\
1.30\end{array}$ & $\begin{array}{l}2.28 \\
2.20\end{array}$ & $\begin{array}{l}4.14 \\
1.76 \\
2.13 \\
2.26 \\
2.11 \\
2.11 \\
1.87 \\
1.69 \\
0.87\end{array}$ \\
\hline
\end{tabular}

Plate " $\mathrm{r}$ "

1.26 WRP 0.63 WRP CRP

4. 14

$\begin{array}{ll}3.08 & 3.44 \\ 2.15 & 2.06\end{array}$

$\begin{array}{lll}2.15 & & 2.41 \\ 3.70 & 2.70 & 2.58\end{array}$

$\begin{array}{lll}3.84 & 2.54\end{array}$

2.70

3. 58

2. 39

0.34

raverses For Element in Position 41

SM-2 Preliminary Mockup Core

Plate "r"

Plate "a" Plate: "j"

Plate " $\mathrm{n}$ "

Position 8.81 WPR 10.07 WRP 9.44 WRP 8.81 WRP 8.18 WRP 7.55 WRP 10.07WRP 9.44 WRP 8.81 WRP 8.18 WRP 7.55 WRP

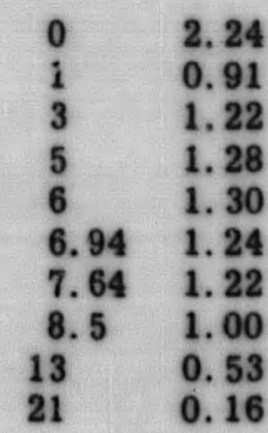

1.48
0.93
1.15
1.20
1.24
1.13
1.13
0.95
0.58
0.19

2.31
0.93
1.20
1.27
1.13
1.13
0.97
0.58
0.18

3.54
2.13
2.36
2.54
2.56
2.41
2.15
1.96
1.09
0.30

1.37
0.97
1.18
1.22
1.27
1.11
1.15
1.09
0.56
0.16

2. 36

.93
1.28

1. 15

1.28

3.49
2.17
2.59
2.63
2.63
2.43
2.22
1.96
0.95
0.25

10.07WRP 9.44WRP 8.81WRP 8.18WRP 7.55WRP

$\begin{array}{lllll}1.55 & & 2.35 & & 3.00 \\ 0.91 & & 0.97 & & 2.06 \\ 1.22 & & 1.27 & & 2.50 \\ 1.30 & 1.18 & 1.28 & 1.47 & 2.31 \\ 1.34 & & 1.37 & & 2.48 \\ 1.20 & 1.09 & 1.22 & 1.43 & 2.43 \\ 1.11 & & 1.22 & & 2.28 \\ 1.00 & & 1.00 & & 1.61 \\ 0.63 & & 0.63 & & 0.78 \\ 0.16 & & 0.16 & & 0.21\end{array}$


Table 3.11

Relative Power Distribution Along Axial Traverses For Element in Position 42

SM-2 Preliminary Mockup Core

Plate " $\mathrm{n}$ "

Plate " $\mathrm{r}$ "

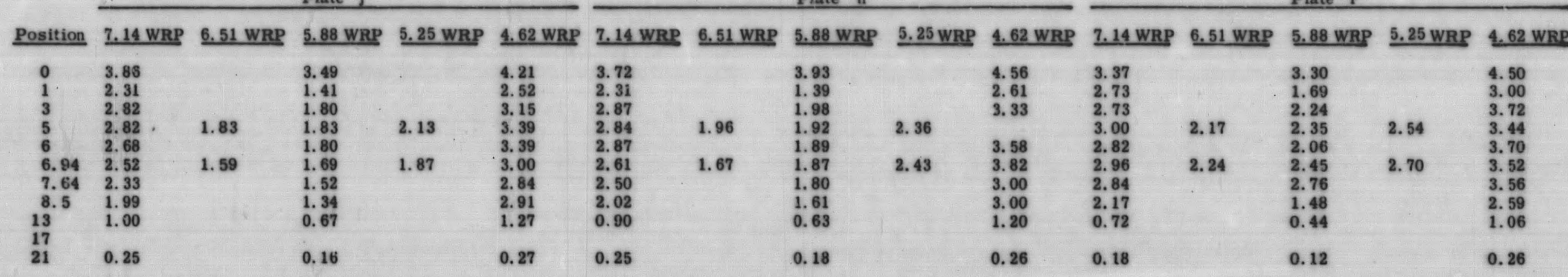

Table 3.12
$\frac{\text { Relative Power Distribution Along Axial Traverses For Element in Position } 43}{\text { SM-2 Preliminary Mockup Core }}$

Plate "j"

Plate " $\mathrm{n}$ "

Plate " $r$ "

Position 4.20 WRP 3.57 WRP 2.94 WRP 2.31 WRP 1.68 WRP 4.20 WRP 3.57 WRP 2.94 WRP 2.31 WRP 1.68 WRP 4.20 WRP 3.57 WRP 2.94 WRP 2.31 WRP 1.68 WRP

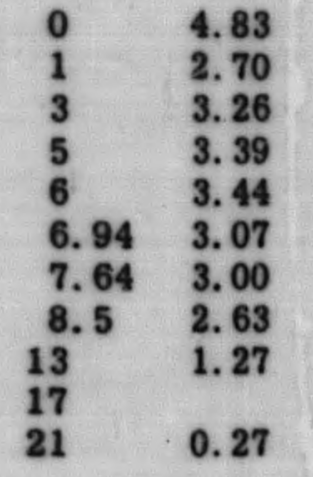

4.54
1.64
2.13
2.24
2.17
1.92
1.76
1.67
0.72
0.18

2.45

\begin{tabular}{l|l}
4.46 & 4.74 \\
3.28 & 2.59
\end{tabular}

2. 26

2. 20

3.28
4.02
4.09
4.04
4.54
4.13
2.48
0.90

4. 28

$\begin{array}{ll}4.28 & \\ 1.71 & \\ 2.17 & \\ 2.28 & 2.36 \\ 2.26 & \\ 1.98 & 2.17 \\ 1.80 & \\ 1.64 & \\ 0.78 & \\ 0.18 & \end{array}$

4.76
3.39
4.02
4.21
4.13
4.28
3.91
2.54
0.85
0.18

4.21
2.65

2. 28

3. $19 \quad 2.33$

4.44
1.65

1.65
2.70
2.39

2. 39
2.22

3. $35 \quad 2.13$

2.22
2. 15

3. 19

2. 39
1.02

2. 33

4. 46

3.63

0.21

0.26

0.26

1.96
1. 69
0.85

3. 98

3.91
3.89

3.89
3.67

2. 68
1.06

0.22 
Table 3.13

Relative Power Distribution Along Axial Traverses for Element in Position 24 (Control Rod A)

Plate "a"

Position 1.16 WRP 0.58 WRP CRP

$\begin{array}{lllll}0 & 2.89 & 1.99 & 1.92\end{array}$

$\begin{array}{lll}2.59 & 1.99 & 3 .\end{array}$

3.45

2. 59

\begin{tabular}{llll}
6.94 & 4.39 & 2.59 & 2.4 \\
\hline & 5.24 & 5.00
\end{tabular}

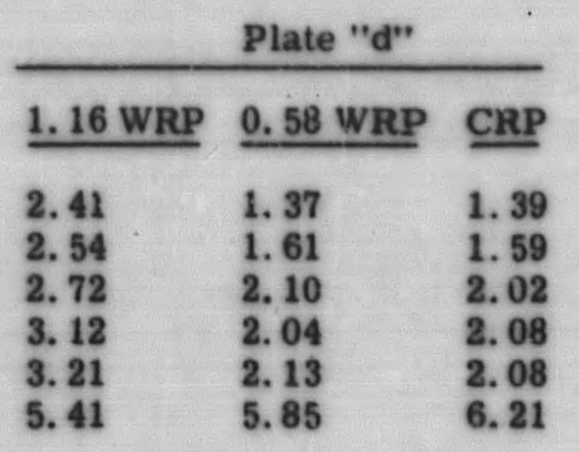

Plate "i"

\begin{tabular}{|c|c|c|c|c|c|}
\hline \multicolumn{3}{|c|}{ Plate "i" } & \multicolumn{3}{|c|}{ Plate "m" } \\
\hline .16 WRP & 0.58 WRP & CRP & 1.16 WRP & $0.58 \mathrm{WRP}$ & CRP \\
\hline $\begin{array}{l}2.31 \\
2.39 \\
3.08 \\
3.28 \\
3.43 \\
5.62\end{array}$ & $\begin{array}{l}1.24 \\
1.59 \\
1.92 \\
2.02 \\
1.99 \\
6.08\end{array}$ & $\begin{array}{l}1.18 \\
\text { 1. } 39 \\
\text { 1. } 88 \\
\text { 1. } 98 \\
\text { 2. } 04 \\
6.43\end{array}$ & $\begin{array}{l}1.99 \\
2.28 \\
2.95 \\
2.91 \\
2.95 \\
5.17\end{array}$ & $\begin{array}{l}1.27 \\
1.48 \\
1.78 \\
1.94 \\
2.13 \\
5.89\end{array}$ & $\begin{array}{l}1.18 \\
1.46 \\
1.83 \\
1.85 \\
1.89 \\
6.19\end{array}$ \\
\hline
\end{tabular}

Plate "p"

1.16 WRP 0.58 WRP CRP

$\begin{array}{lll}2.36 & 1.39 & 1.39\end{array}$

$2.17 \quad 1.64-1.55$

$\begin{array}{lll}2.84 & 2.04 & 2.04\end{array}$

$\begin{array}{lll}3.08 & 2.13 & 1.99\end{array}$


ย

\begin{tabular}{lll} 
& \multicolumn{1}{c}{ Plate "a" } & Plate "d" \\
Position CRP & CRP & CRP \\
\cline { 1 - 1 } 0 & 1.98 & 1.50 \\
1 & 2.15 & 1.92 \\
3 & 2.59 & 2.22 \\
5 & 2.76 & 2.41 \\
6 & 2.59 & 2.41 \\
6.94 & 5.52 & 6.80
\end{tabular}

Pusition

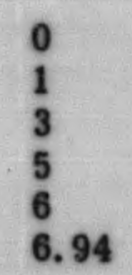

Table 3.14

For Element in Position 44 (Control Rod C)

\begin{tabular}{|c|c|c|c|c|}
\hline 1.16 WRP & 0.58 WRP & CRP & $0.58 \mathrm{ERP}$ & $1.16 \mathrm{ERP}$ \\
\hline $\begin{array}{l}2.82 \\
3.24 \\
3.82 \\
4.13 \\
3.91 \\
6.33\end{array}$ & $\begin{array}{l}1.59 \\
1.94 \\
2.45 \\
2.61 \\
2.54 \\
6.88\end{array}$ & $\begin{array}{l}1.50 \\
1.89 \\
2.31 \\
2.43 \\
2.48 \\
7.88\end{array}$ & $\begin{array}{l}1.59 \\
1.98 \\
2.36 \\
2.45 \\
2.52 \\
7.49\end{array}$ & $\begin{array}{l}3.21 \\
3.80 \\
4.02 \\
4.00\end{array}$ \\
\hline
\end{tabular}

Plate "p"

\begin{tabular}{|c|c|c|c|c|}
\hline 1.16 WRP & 0.58 WRP & CRP & 0.58 ERP & $1.16 \mathrm{ERP}$ \\
\hline $\begin{array}{l}3.21 \\
3.35 \\
3.89 \\
4.17 \\
4.32 \\
5.99\end{array}$ & $\begin{array}{l}2.22 \\
2.36 \\
2.20 \\
3.08 \\
3.00 \\
6.33\end{array}$ & $\begin{array}{l}2.15 \\
2.15 \\
2.68 \\
3.00 \\
2.82 \\
6.82\end{array}$ & $\begin{array}{l}1.98 \\
2.13 \\
2.68 \\
2.84 \\
2.89 \\
6.78\end{array}$ & $\begin{array}{l}3.17 \\
3.19 \\
4.00 \\
4.39 \\
4.16 \\
5.96\end{array}$ \\
\hline
\end{tabular}

Plate "m"

\begin{tabular}{|c|c|c|c|c|}
\hline 1.16 WRP & 0.58 WRP & CRP & 0.58 ERP & $1.16 \mathrm{ERP}$ \\
\hline $\begin{array}{l}2.96 \\
3.07 \\
3.74 \\
3.86 \\
3.82 \\
6.34\end{array}$ & $\begin{array}{l}1.59 \\
1.96 \\
2.35 \\
2.48 \\
2.33 \\
7.02\end{array}$ & $\begin{array}{l}1.48 \\
1.78 \\
2.31 \\
2.48 \\
2.33 \\
7.74\end{array}$ & $\begin{array}{l}1.52 \\
1.94 \\
2.31 \\
2.52 \\
2.43 \\
7.19\end{array}$ & $\begin{array}{l}2.91 \\
\text { 3. } 10\end{array}$ \\
\hline
\end{tabular}

4.04
6.28 
Table 3.15

Relative Power Distribution Along Axial Traverses For Element in Position 32 (Control Rod F) SM-2 Preliminary Mockup Core

\begin{tabular}{|c|c|c|c|c|c|c|c|c|c|c|c|c|c|c|c|}
\hline \multirow[b]{2}{*}{ Position } & \multicolumn{5}{|c|}{ Plate "a" } & \multicolumn{5}{|c|}{ Plate "d" } & \multicolumn{5}{|c|}{ Plate "i" } \\
\hline & 7.03 WRP & 6.46 WRP & 5.88 WRP & 5. $30 \mathrm{WRP}$ & 4. 73 WRP & 7.03 WRP & 6.46 WRP & 5.88 WRP & 5. $30 \mathrm{WRP}$ & 4.73 WRP & 7.03 WRP & $6.46 \mathrm{WRP}$ & $5.88 \mathrm{WRP}$ & 5. 30 WRP & $4.73 \mathrm{WF}$ \\
\hline $\begin{array}{l}0 \\
1 \\
3 \\
5 \\
6 \\
6.94\end{array}$ & $\begin{array}{l}1.96 \\
1.99 \\
2.39 \\
2.45 \\
2.54 \\
3.60\end{array}$ & 1.99 & $\begin{array}{l}1.61 \\
1.69 \\
2.35 \\
2.08 \\
4.69\end{array}$ & $\begin{array}{l}2.36 \\
4.91\end{array}$ & $\begin{array}{l}2.78 \\
2.73 \\
3.28 \\
3.37 \\
3.45 \\
4.65\end{array}$ & $\begin{array}{l}1.69 \\
1.80 \\
2.26 \\
2.45 \\
2.43 \\
4.13\end{array}$ & $\begin{array}{l}1.64 \\
4.93\end{array}$ & $\begin{array}{l}1.13 \\
1.39 \\
1.71 \\
1.65 \\
1.83 \\
5.80\end{array}$ & $\begin{array}{l}1.92 \\
5.85\end{array}$ & $\begin{array}{l}2.59 \\
2.61 \\
3.28 \\
3.47 \\
3.44 \\
5.61\end{array}$ & $\begin{array}{l}1.69 \\
1.85 \\
2.28 \\
2.45 \\
2.45 \\
4.21\end{array}$ & $\begin{array}{l}1.74 \\
5.36\end{array}$ & $\begin{array}{l}1.04 \\
1.34 \\
1.83 \\
1.83 \\
1.80 \\
5.96\end{array}$ & $\begin{array}{l}2.02 \\
5.80\end{array}$ & $\begin{array}{l}2.41 \\
2.63 \\
3.14 \\
3.21 \\
3.26 \\
5.32\end{array}$ \\
\hline
\end{tabular}

Plate " $m$ "

Plate " $\mathrm{p}$ "

Position 7.03 WRP 6.46 WRP 5.88 WRP 5.30 WRP 4.73 WRP 7.03 WRP 6.46 WRP 5.88 WRP 5.30 WRP 4.73 WRP

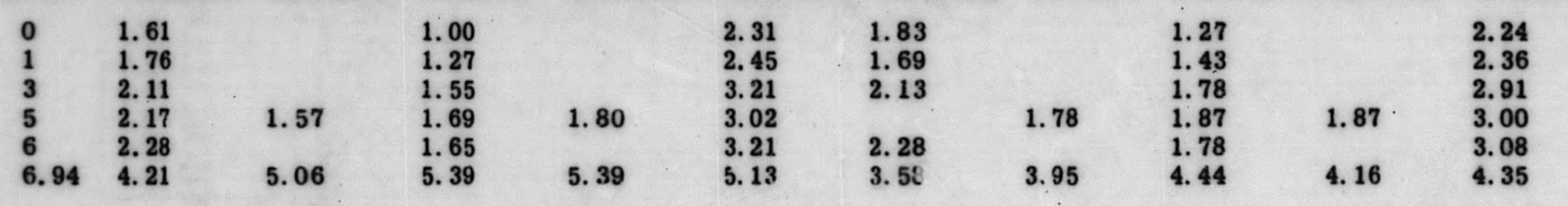




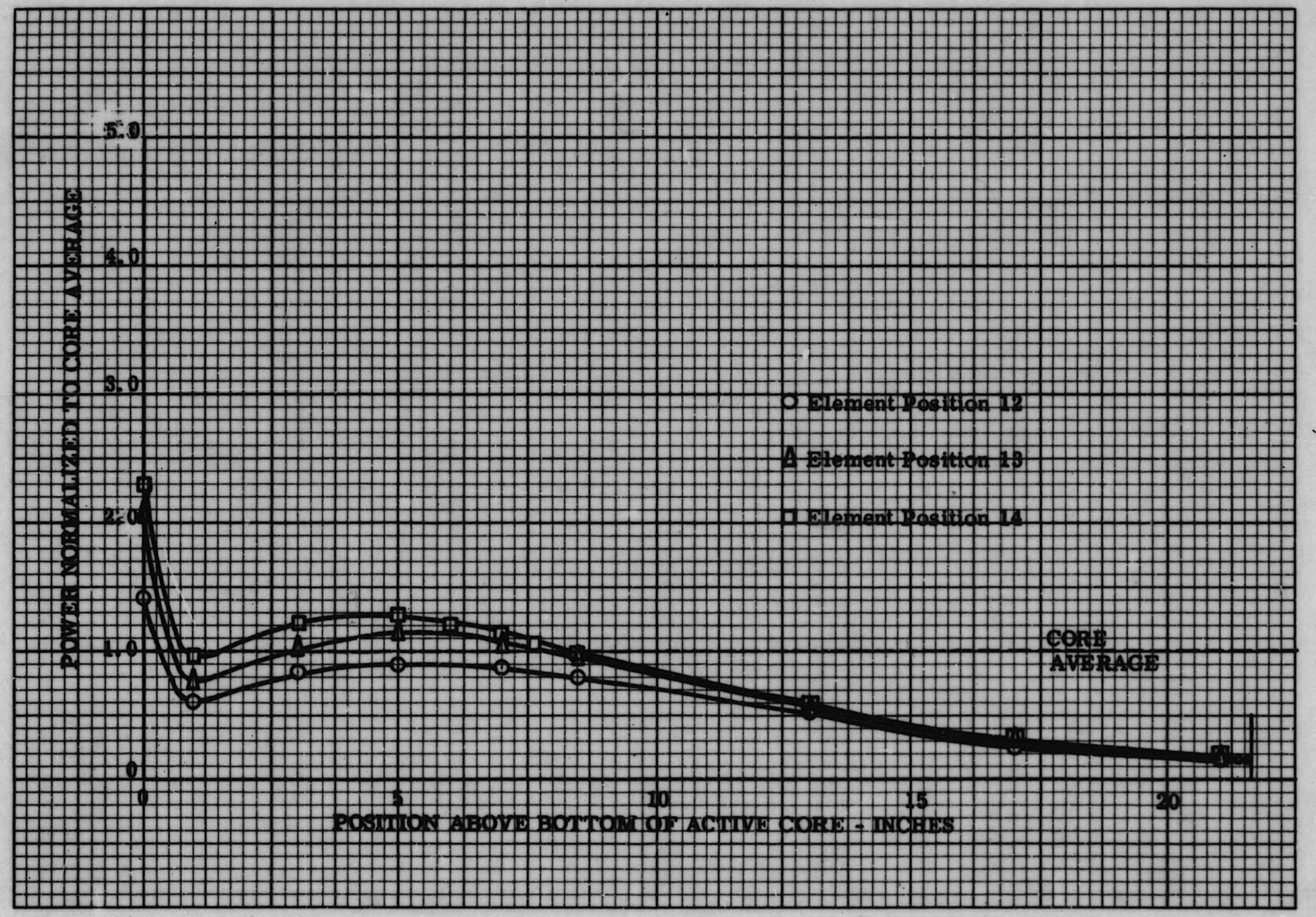

Figure 3.5 Relative Power Distribution Along Axial Traverse on Centerline of Fuel Plate "j", Elements in Positions 12, 13 and 14, SM-2 Preliminary Mockup Core 

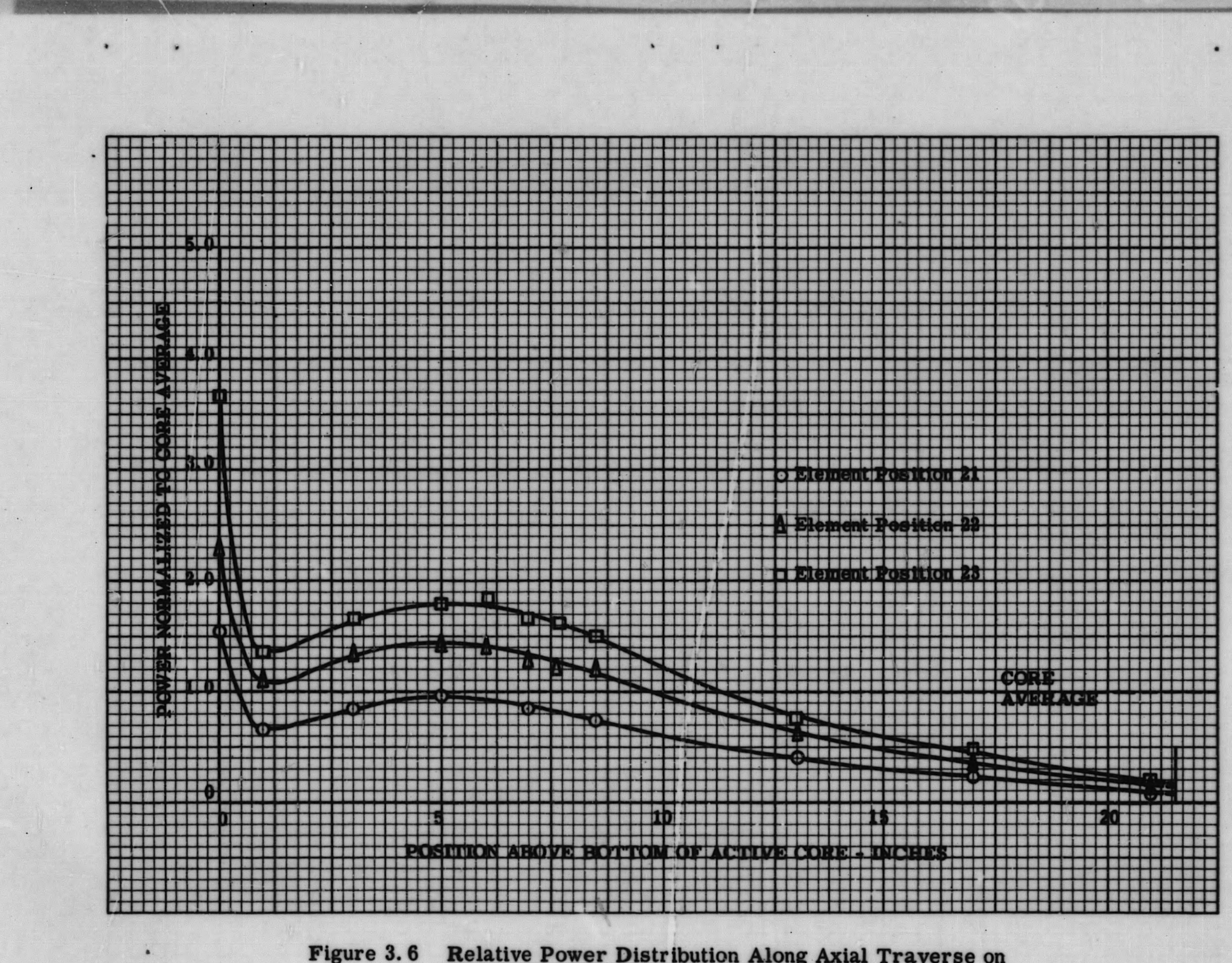

Figure 3.6 Relative Power Distribution Along Axial Traverse on 


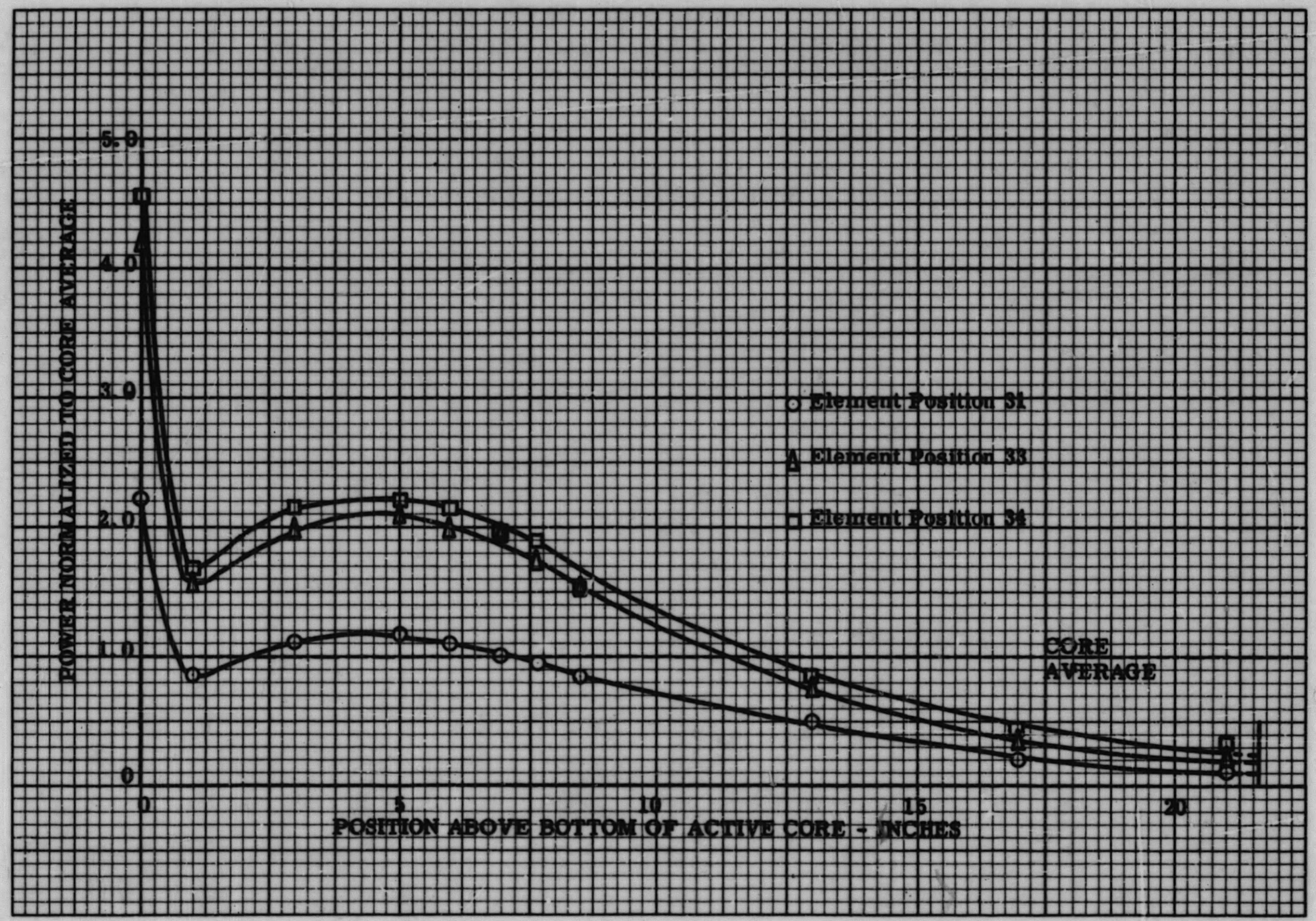

Figure 3.7 Relative Power Distribution Along Axial Traverse on Centerline of Fuel Plate "j", Elements in Positions 31, 33 and 34, SM-2 Preliminary Mockup Core 


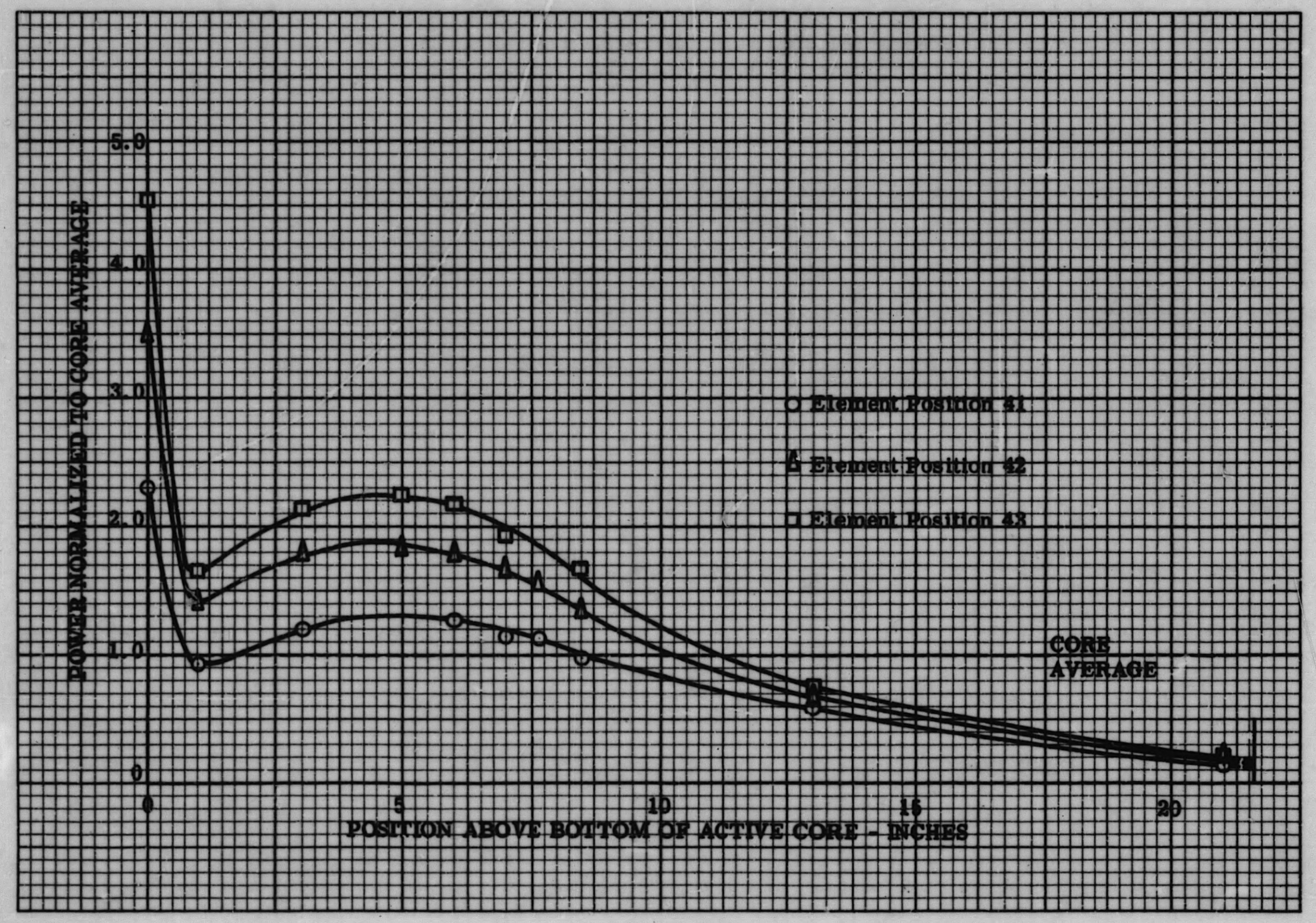

Figure 3.8 Relative Power Distribution Along Axial Traverse on 


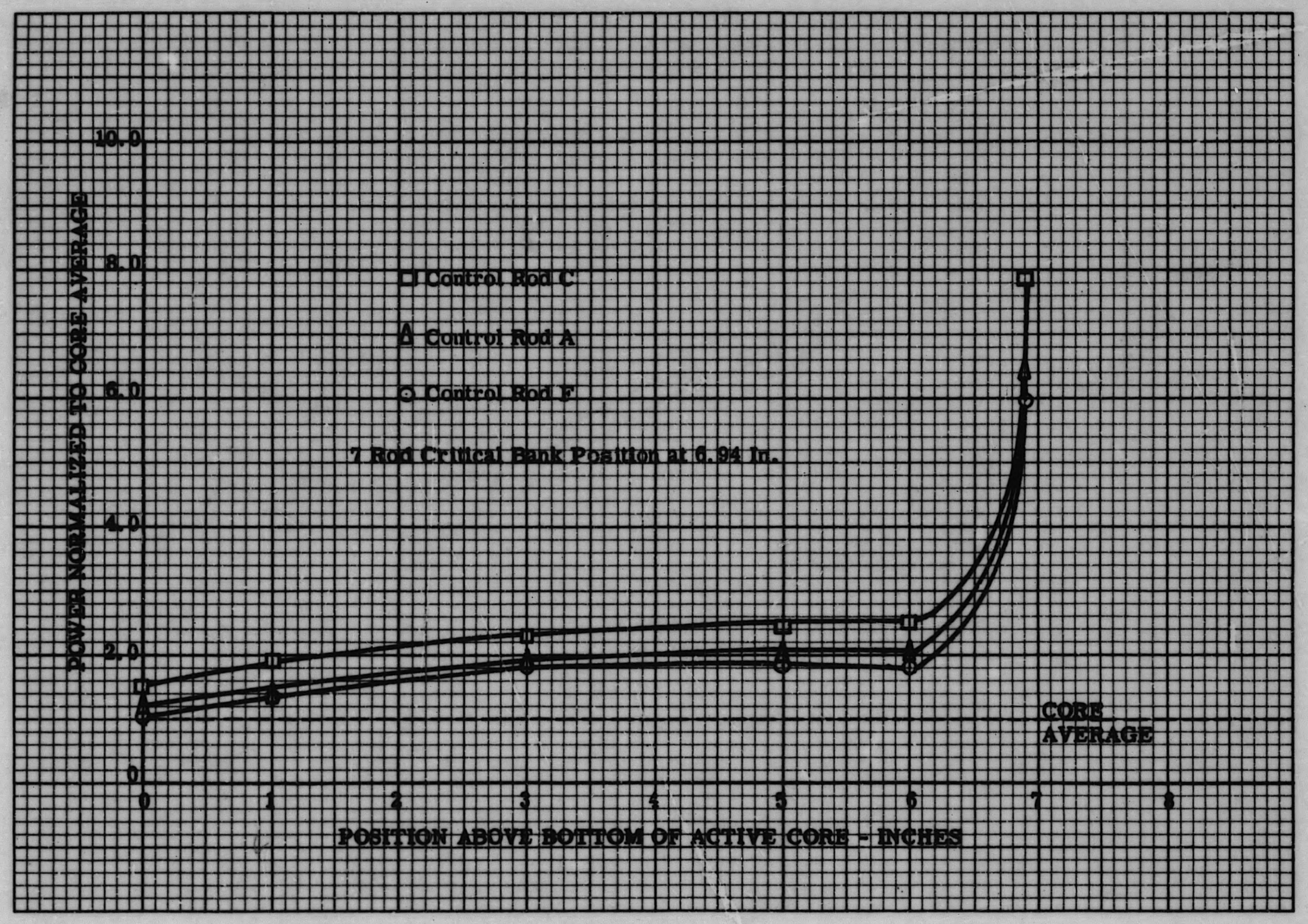

Figure 3.9 Relative Power Distribution Along Axial Traverse on Centerline of Fuel Plate " $\mathrm{i}$ " of Control Rods A, C and F, SM-2 Preliminary Mockup Core 

Figure 3.11 gives the complete normalized power averages in the core. Fourteen stationary fuel elements surrounding the center of the core exceed the core average, while all elements at the core boundary are less than the core average. The control rod fuel elements which have higher than average power density have been corrected to include only the portion of the fuel plates actually in the active core.

Tables 3.16 through 3.30 present the activity distributions normalized to a core average of unity along axial traverses of stationary fuel elements in positions $12,13,14,21,22,23,31,33,34,41,42,43$ and for fuel elements of control rods $A, C$, and $F$ in positions 24, 44, and 32, respectively. Again plates $a, e, j, n$ and $r$ were selected for mapping for stationary fuel elements and plates $\mathrm{a}, \mathrm{d}, \mathrm{i}, \mathrm{m}$, and $\mathrm{p}$ for the control rod fuel elements.

The use of the data tables is identical to that described previously (ref. par. 3. 2. 3); however due to the relocation of the outer fuel elements in order to accommodate the flow divider mockup, the data points in these fuel elements are slightly displaced relative to those recorded in the preliminary SM-2 core mockup.

The data ranged from normalized lows of 0.09 and 0.10 of the core average for plate " $r$ " of elements 21 and 12 at the outer edge of the core to highs of 4.74 for plate " $r$ " of element position 43, 4.62 for plate " $p$ " of control rod $C$, and 4. 57 for plate "a" of element position 34, all in the centet of the core. As expected the flux suppressors placed at the top of the active meat of fuel elements of control rods considerably reduced the power spikes (ref. Fig. 3.9) usually occurring in that region.

Figures 3.12 and 3.13 respectively show the activity of the centerline traverses of plate " $\mathrm{j}$ " for stationary fuel elements in positions 12, 13, 14 and $21,22,23$ normalized to the core average. Figures 3.14 and 3.15 show similar traverses for fuel elements in positions $31,33,34$ and $41,42,43$ respectively. Figure 3.16 shows the same traverses for plate " $i$ " of control rods A, C, and F.

For the stationary fuel elements again there is a large power peak at the bottom of the active core and a smaller axial peak about 5-7 in. above it. The power diminishes gradually until a low is reached at the top of the active core. As an example, along the centerline traverse of plate " $\mathrm{j}$ " of element position 43 the power peaking is about 4.3 times the core average at the bottom of the active core and 2.3 times at an axial position 5 in. above it. It is only 0.2 of the core average at the top of the active core. For the portion of the control rod fuel elements actually in the core, only one power peak is apparent at an axial position 5-6 in. above the bottom of the active core with a large dip at the bottom of the flux suppressors. Taking the centerline traverse along plate " $\mathrm{i}$ " of control rod $\mathrm{C}$, the highest normalized relative power of 2.47 occurs 6 in. above the bottom of the active core while it is only 0.95 at the bottom of the flux suppressor.

Figure 3.17 illustrates a radial power traverse 5 in. above the bottom of the active core along che center of stationary fuel elements in positions $41,42,43$ and control rod $C$ in position 44 . The rise in power operation is evident as the 
(HEAVY LINE INDICATES FLOW DIVIDER)

SUPPORTED BY PLATES

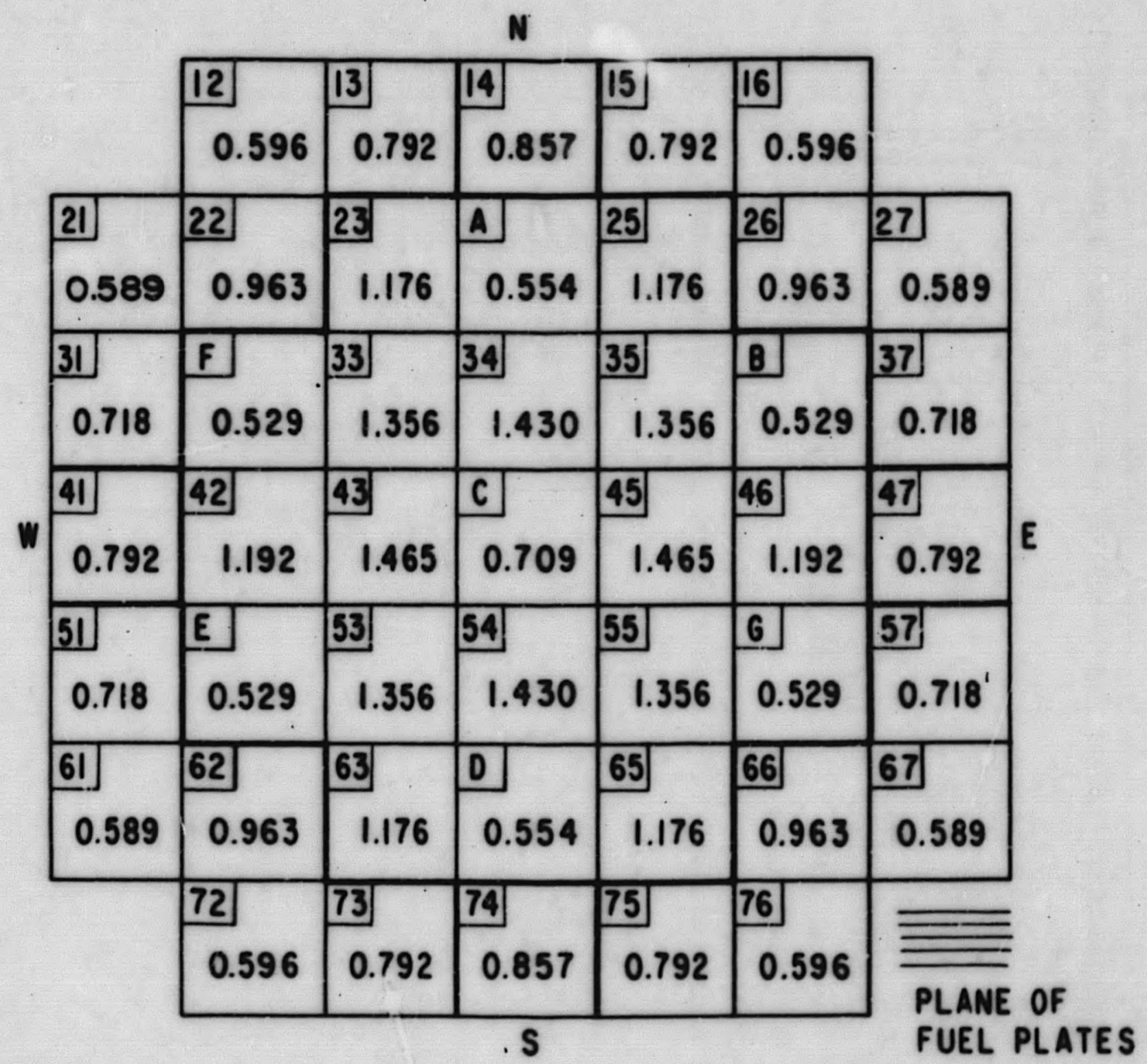

Figure 3.11 Relative Power Distribution in the SM-2 Final Mockup Core, Normalized to Core Average 
อ Table 3,16
Relative Power Distribution Along Axial Traverses for Element in Position 12
"SM-2 Final Mockup Core"

Plate "a" Plate "e"

Plate "j"

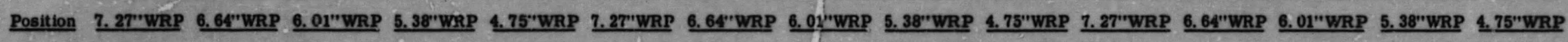
\begin{tabular}{lllllll}
\hline 0 & 1.32 & & 1.80 & & 2.14 \\
1 & 0.85 & & 0.83 & & 1.44 \\
3 & & & 1.12 & & 1.95 \\
5 & 1.22 & 1.17 & 1.29 & 1.44 & 2.22 \\
6 & 1.34 & 1.32 & 1.02 \\
6.94 & 1.29 & 1.12 & 1.22 & 1.41 & 2.05 \\
8.5 & 1.19 & & 1.10 & & 1.85 \\
13 & 0.76 & & 0.71 & & 1.12 \\
17 & 0.39 & & 0.37 & & 0.58 \\
21 & 0.19 & & 0.17 & & 0.27
\end{tabular} 0.99

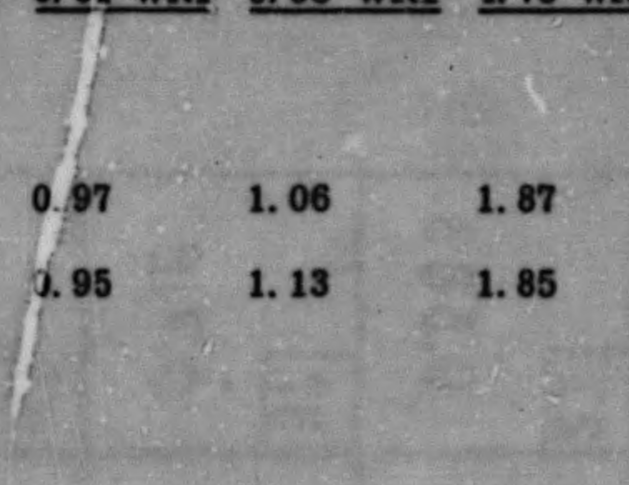

0.69
0.49
0.67
0.74
0.79
0.81
0.72
0.48
0.28
0.12

0.92

0.55

0.76

0.81

$\begin{array}{ll}0.88 & 0.92\end{array}$

1.66

Plate "r"

Plate "n"

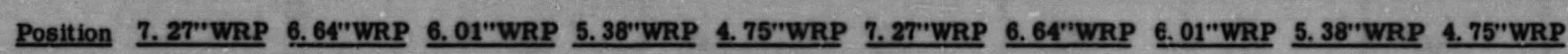

$$
\begin{array}{ll}
0 & \\
1 & \\
3 & \\
5 & 0.67 \\
6 & \\
6.94 & 0 \\
8.5 & \\
13 & \\
17 & \\
21 &
\end{array}
$$

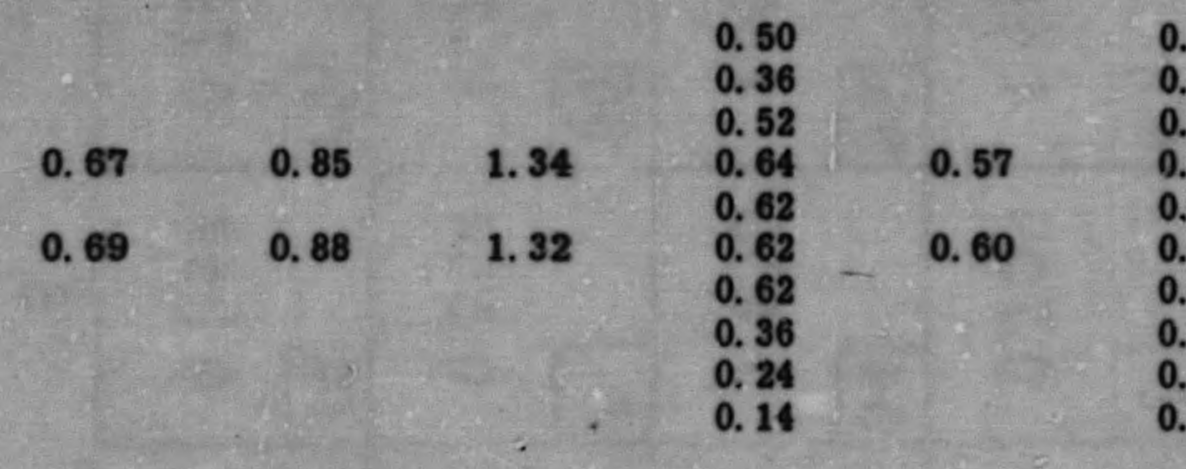

$\begin{array}{lll}0.76 & & 0 . \\ 0.43 & & 0 . \\ 0.52 & & 0 . \\ 0.64 & 0.74 & 0 . \\ 0.64 & 1 . \\ 0.62 & 0.69 & 1 . \\ 0.60 & & 0 . \\ 0.36 & & 0 \\ 0.21 & & 0 . \\ 0.10 & & 0 . \\ & & \end{array}$


Table 3. 17

$\frac{\text { Relative Power Distribution Along Axial Traverses for Element in Position } 13}{\text { "SM-2 Final Mockup Core" }}$

Plate "a"

Plate "e"

Plate "j"

Position 4.33"WRP 3.70"WRP 3.07"WRP 2.44"WRP 1.81"WRP 4.33"WRP 3.70"WRP 3.07"WRP 2.44"WRP 1.81"WRP 4.33"WRP 3.70"WRP 3.07"WRP 2.44"WRP 1.81"WRP

0 2.10

3. 1.85 1. 1.62

$6.54 \quad 2.36$

$\begin{array}{ll}13 & 1.16 \\ 17 & 0.62\end{array}$

1.64

1. 80

2.75

77

1.87

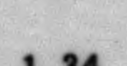

1.46

2. 59

1. $71 \quad 1.22$

1. 25

1.36

2. 45

1. 76

2.59
2. 26

2.26
1.04

0.55

2.61
0.44
0.18

Plate " $\mathrm{n}$ "

Plate " $r$ "

Position 4.33"WRP 3.70"WRP 3.07"WRP 2.44"WRP 1.81"WRP 4.33"WRP 3.70"WRP 3.07"WRP 2.44"WRP 1.81"WRP

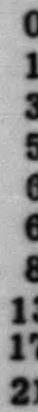

0
1
3
5
6
6.
8.5
13
17
21

$\begin{array}{lllll}1.27 & 0.97 & 1.04 & 1.11 & 1.87\end{array}$

0.92

0.90

$\begin{array}{lll}0.79 & & 0.62 \\ 0.95 & 0.79 \\ 1.06 & 0.88 & 0.90\end{array}$

$\begin{array}{llllll}94 & 1.27 & 0.95 & 0.95 & 1.06 & 1.87\end{array}$

8.5
17

0.83

0.90

0.92
0.83

0.83
0.55

0. 55

0.60
0.39

0.39
0.14

$\begin{array}{ll} & 1.39 \\ & 1.02 \\ & 1.27 \\ 0.95 & 1.43 \\ 0.88 & 1.46 \\ 0 & 1.41 \\ & 1.18 \\ & 0.67 \\ & 0.39 \\ & 0.14\end{array}$

$\begin{array}{lll}1.55 & & 1.99 \\ 0.76 & & 1.46 \\ 0.99 & & 1.66 \\ 1.13 & 1.34 & 2.15 \\ 1.06 & & 2.01 \\ 1.11 & 1.52 & 2.10 \\ 0.95 & & 1.99 \\ 0.65 & & 1.11 \\ 0.30 & & 0.51 \\ 0.16 & & 0.28\end{array}$


Table 3. 18
Relative Power Distribution Along Axial Traverses for Element in Position 14

\begin{tabular}{|c|c|c|c|c|c|c|c|c|c|c|c|c|c|c|c|}
\hline \multirow[b]{2}{*}{ Position } & \multicolumn{3}{|c|}{ Plate "a" } & \multicolumn{3}{|c|}{ Plate "e" } & \multicolumn{3}{|c|}{ Plate " $3 "$} & \multicolumn{3}{|c|}{ Plate "n" } & \multicolumn{3}{|c|}{ Plate " $r$ " } \\
\hline & 1. 26"WRP & 0.63"WRP & $\underline{\text { CRP }}$ & 1.26"WRP & 0. 63"WRP & CRP & $\underline{1.26^{\prime \prime} \text { WRP }}$ & $\underline{0.63^{\prime \prime} \text { WRP }}$ & $\underline{\text { CRP }}$ & 1.26"WRP & $\underline{0.63^{\prime \prime} \mathrm{WRP}}$ & $\underline{\text { CRP }}$ & 1. $26^{\prime \prime} \mathrm{WRP}$ & $0.63^{\prime \prime W R P}$ & CRP \\
\hline $\begin{array}{l}0 \\
1 \\
3 \\
5 \\
6 \\
6.94 \\
8.5 \\
13 \\
17 \\
21\end{array}$ & $\begin{array}{l}2.86 \\
2.17 \\
2.77 \\
2.97 \\
2.90 \\
2.80 \\
2.45 \\
1.08 \\
0.54 \\
0.24\end{array}$ & $\begin{array}{l}2.38 \\
1.99\end{array}$ & $\begin{array}{l}1.86 \\
1.45 \\
1.95 \\
2.10 \\
2.21 \\
1.99 \\
1.71 \\
0.59 \\
0.37 \\
0.15\end{array}$ & $\begin{array}{l}2.38 \\
1.84\end{array}$ & $\begin{array}{l}1.41 \\
1.24\end{array}$ & $\begin{array}{l}1.32 \\
1.34\end{array}$ & $\begin{array}{l}2.08 \\
1.46 \\
1.92 \\
1.92 \\
2.06 \\
1.80 \\
1.69 \\
0.85 \\
0.51 \\
0.23\end{array}$ & $\begin{array}{l}1.18 \\
1.18\end{array}$ & $\begin{array}{l}1.71 \\
0.83 \\
1.04 \\
1.18 \\
1.18 \\
1.13 \\
1.11 \\
0.60 \\
0.30 \\
0.14\end{array}$ & $\begin{array}{c}1.94 \\
-\end{array}$ & $\begin{array}{l}1.06 \\
1.06\end{array}$ & $\begin{array}{l}1.04 \\
0.92\end{array}$ & $\begin{array}{l}1.07 \\
0.71 \\
0.90 \\
1.37 \\
1.39 \\
1.18 \\
0.95 \\
0.61 \\
0.27 \\
0.13\end{array}$ & $\begin{array}{l}0.90 \\
0.88\end{array}$ & $\begin{array}{l}0.95 \\
0.55 \\
0.86 \\
0.86 \\
0.88 \\
0.80 \\
0.84 \\
0.40 \\
0.23 \\
0.15\end{array}$ \\
\hline
\end{tabular}


Table 3.19

Relative Power Distribution Along Axial Traverses for Element in Position 21

"SM-2 Final Mockup Core"

Plate "a"

Plate "e"

Plate " $\mathrm{j} "$

Position 10.20"WRP 9.57"WRP 8.94"WRP 8.31"WRP 7.68"WRP 10.20"WRP 9.57"WRP 8.94"WRP 8.31"WRP 7.68"WRP 10.20"WRP9.57"WRP 8.94"WRP 8.31"WRP 7.68"WRP

$\begin{array}{ll}0 & 1 . \\ 1 & 0 . \\ 3 & 1 . \\ 5 & 1 . \\ 6 & 1 . \\ 6.94 & 1 . \\ 8.5 & 1 . \\ 13 & 0 . \\ 17 & 0 . \\ 21 & 0 .\end{array}$

$\begin{array}{lll}1.78 & & 2.13 \\ 0.74 & & 1.46 \\ 0.97 & & 1.94 \\ 1.11 & 1.25 & 2.06 \\ 1.06 & & 2.01 \\ 0.99 & 1.16 & 1.82 \\ 0.88 & & 1.71 \\ 0.55 & & 0.79 \\ 0.28 & & 0.44 \\ 0.12 & & 0.21\end{array}$

1. 13

0.81

0.92

$1.09 \quad 1.94$

0.87

$\begin{array}{ll}11 & 0.95\end{array}$

0.92

1.13

0.83

0.90

1.09

1. 80

0.87
0.89

0.71

1. 00

0.62
0.78
0.87

0. 79

0.21

1.00
0.87
0.62
0.38
0.16

0.76

0.87
0.83
0.78

0.78
0.76

0.76
0.47

0.47
0.25
0.13

0.98

1.85
1.29
1.54

1.54
1.90

1.90
1.90
1.69

1.69
1.56

1. 96
0.49

Plate "n"

Plate "r"

Position 10.20"WRP9. 57"WRP 8.94"WRP 8.31"WRP 7.68"WRP 10.20"WRP 9.57"WRP 8.94"WRP 8.31"WRP 7.68"WRP

0
1
3
5
6
13
17
21

0.53

0.53

$\begin{array}{llllll}5 & 0.83 & 0.67 & 0.74 & 0.90 & 1.55\end{array}$

$\begin{array}{llllll}6.94 & 0.85 & 0.65 & 0.76 & 0.95 & 1.52\end{array}$

0.42
0.62
0.55

0.55
0.58
0.37

0.37

0.51

0.51

0.69
0.37
0.51
0.58
0.60
0.53
0.53
0.32
0.16
0.09

0. 69

0.67

1. 18

1. 18

1.16
1. 06

0.12

0.58
0.42
0.18

13
21

0.16
$-\quad 0.16$

$\begin{array}{ll}0.16 & 0.42 \\ 0.09 & 0.18\end{array}$ 


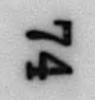

Table 3. 20

Relative Power Distribution Along Axial Traverses for Element in Position 22

Plate "e"

Plate " $\mathrm{j} "$

Plate "a"

Position 7.27"WRP 6.64"WRP 6.01"WRP 5.38"WRP 4.75"WRP 7.27"WRP 6.64"WRP 6.01"WRP 5. 38"WRP 4.75"WRP 7.27"WRP 6.64"WRP 6.01"WRP 5. 38"WRP 4.75"WRP

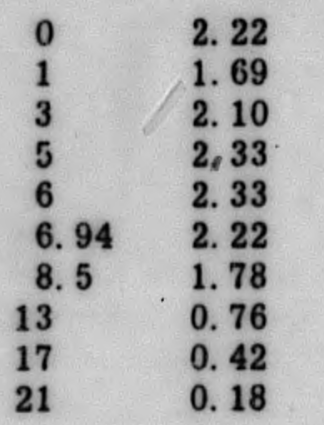

$\begin{array}{ll}2.06 & \\ 1.57 & \\ 1.96 & \\ 2.17 & 2.33 \\ 2.08 & \\ 2.10 & 2.22 \\ 1.66 & \\ 0.53 & \\ 0.30 & \\ 0.14 & \end{array}$

2.75
2.31
2.73
3.14
3.16
3.00
2.52
0.97
0.51
0.21

2. 03

1.41

1.57

1. 71 2. 01

$$
\text { 1. } 82
$$

0.14

1. 92

1. 39

1. 43

1. 57

2. 86

2. 70

$\begin{array}{ll}2.17 & \\ 1.32 & \\ 1.52 & \\ 2.01 & 1.25 \\ 1.87 & \\ 1.87 & 1.20 \\ 1.66 & \\ 1.02 & \\ 0.44 & \\ 0.23 & \end{array}$

1. 80
1. 02
1.22
1.34
1.32
1.18
1.18
0.62
0.37
0.18

$\begin{array}{ll} & 2.47 \\ & 1.82 \\ 1.48 & 2.31 \\ 1.43 & 2.54 \\ 1.43 & 2.49 \\ & 2.38 \\ & 2.10 \\ & 1.20 \\ & 0.62 \\ & 0.25\end{array}$

Plate " $\mathrm{n}$ "

Plate " $r$ "

Position 7.27"WRP 6.64"WRP 6.01"WRP 5.38"WRP 4.75"WRP 7.27"WRP 6.64"WRP 6.01"WRP 5.38"WRP 4.75"WRP

$\begin{array}{lllll}1.69 & 1.20 & 1.25 & 1.36 & 2.54\end{array}$

1. 32
0.97
1.27
1.48
1.43
1.39
1.32
0.74
0.49
0.18

1.39
0.88
1.13
1.25
1.25
1.22
1.06
0.62
0.37
0.14

1. 96

1. 99

3. 5

17
21

1. 20

2. 24

$\begin{array}{lll}0.18 & 0.14 & 0.53 \\ & & 0.23\end{array}$


Table 3. 21

Relative Power Distribution Along Axial Traverses for Element in Position 23

Plate "e"

Plate "j"

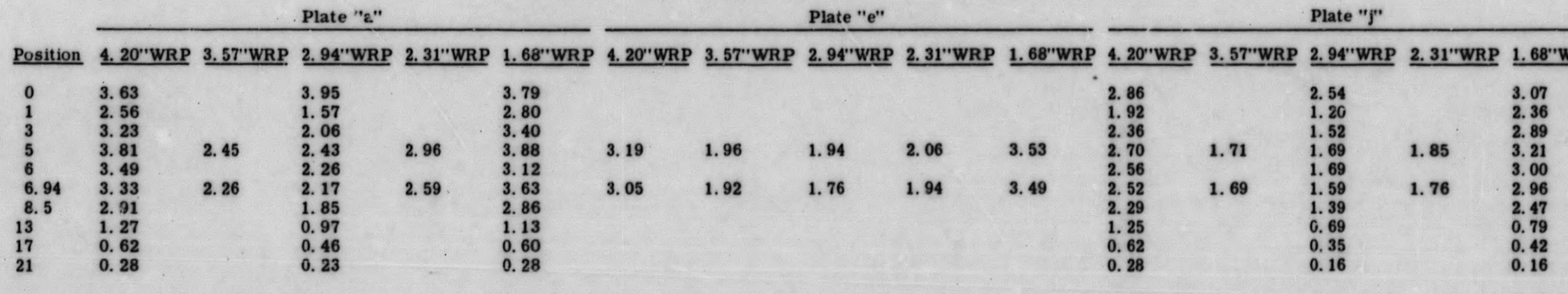

Plate "n"

Plate "r"

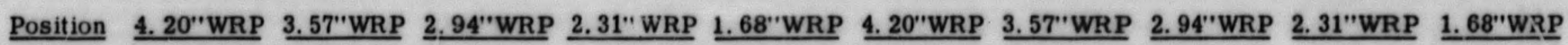

$\begin{array}{llllll}0 & & & & & \\ 1 & & & & & \\ 3 & 2.70 & 1.59 & 1.64 & 1.82 & 3.16 \\ 5 & 2.70 & . & & & \\ 6 & & & & \\ 6.94 & 2.56 & 1.62 & 1.57 & 1.73 & 3.03 \\ 8.5 & & & & & \\ 13 & & & & & \\ 17 & & & & & \\ 21 & & & & \end{array}$

$\begin{array}{ll}\begin{array}{l}2.45 \\ 1.78\end{array} & \\ 2.10 & \\ 2.40 & 1.66 \\ 2.26 & \\ 2.36 & 1.69 \\ 1.92 & \\ 1.11 & \\ 0.60 & \\ 0.28 & \end{array}$

$\begin{array}{lll}2.31 & & 2.86 \\ 1.32 & & 2.03 \\ 1.43 & & 2.56 \\ 1.69 & 1.64 & 2.80 \\ 1.64 & & 2.52 \\ 1.64 & 1.85 & 2.59 \\ 1.36 & & 2.08 \\ 0.79 & & 0.95 \\ 0.42 & & \\ 0.16 & & 0.44 \\ 0.23\end{array}$


ฝี

Table 3.22
$\frac{\text { Relative Power Distribution Along Axial Traverses for Element in Position } 31}{\text { "SM-2 Final Mockup Core" }}$

Plate "a"

Plate "e"

Plate " $j$ "

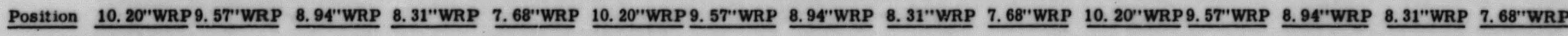

\begin{tabular}{lll}
0 & 1. \\
1 & 1 \\
3 & 1.3 \\
5 & 1 \\
6 & 1. \\
6.94 & 1 \\
8.5 & 1 \\
13 & 0 \\
17 & 0.4 \\
21 & 0. \\
\hline
\end{tabular}

1.62
0.95
1.34
1.59
1.52
1.48
1.27
0.72
0.35
0.14

2. 15

2. 77

1.92

2. 19

1. 29

1.39

2. 56

0. 95

1.06

1. 43

2. 10

1. 76

1. 20

0. 95

1.06

1. 25

2. 36

0.90
1.52

1. 36

2. 66
2. 24
0.85
0.37

0.37

1.16

0.74
0.97

1. 27

2. 15

$\begin{array}{ll}1.27 & 0.88\end{array}$

1. 06

1. 20

2. 36
2. 29

1. 29

0.65
0.58

0.83

0.49
0.30

0.14

1. 85

0.62

Plate "n"

Plate "r"

Position 10.20"WRP 9.57"WRP 8.94"WRP 8.31"WRP 7.68"WRP 10.20"WRP 9.57"WRP 8.94"WRP 8. 31"WRP 7.68"WRP

17

0. 90

1.

1.41

1.250 .90

$0.97 \quad 1.16$

2. 36

1. 27

1. 11

0.90
1.02

6. 941.

0.95

0. 95

1. 13

2. 29

1.18
0.88

0.35
0.21

0.90

1.04
1.02

1.02
0.95
0.49
0.25

0.49
0.25
0.14

1.25

1. 99
1. 66

2. 15

7

2. 24
2. 29

0.74

0.39
0.18 
Table 3. 23

Relative Power Distribution Along Axial Traverses for Element in Position 33

Plate "e"

Plate " $\mathrm{j}$ "

Position 4.20'WRP 3.57"WRP 2.94"WRP 2.31"WRP 1.68"WRP 4.20"WRP 3.57"WRP 2.94"WRP 2.31"WRP 1.68'WRP 4.20"WRP 3.57"WRP 2.94"WRP 2.31"WRP 1.68"WRP

0
1
3
5
6
6.94
8.5
13
17
21

$\begin{array}{lll}3.97 & & 3.79 \\ 2.68 & & 1.71 \\ 3.56 & & 2.24 \\ 3.79 & 2.47 & 2.47 \\ 3.60 & & 2.47 \\ 3.53 & 2.33 & 2.17 \\ 2.86 & & 1.94 \\ 1.13 & & 0.92 \\ 0.49 & & 0.39 \\ 0.23 & & 0.16\end{array}$

\begin{tabular}{ll}
\hline .00 & \\
2.77 & \\
3.74 & \\
4.09 & 3.77 \\
3.72 & \\
3.44 & 3. \\
3.12 & \\
1.20 & \\
0.60 & \\
0.30 &
\end{tabular}

3.86

$$
\text { 2. } 70
$$

$\begin{array}{ll}77 & 2.17\end{array}$

2. 19

2. 29

3. 97

2.73
3.67
3.56

2. 26

3.83
1.57

1.57
2.08
2.22

2. 45

2.82
3.87
3.60
3.28
3.16
3.14
1.32
0.58
0.30

Plate "n"

Plate " $r$ "

Position 4.20'WRP 3.57"WRP 2.94'WRP 2.31"WRP 1.68"WRP 4.20'WRP 3.57'WRP 2.94"WRP 2.31"WRP 1.68"WRP

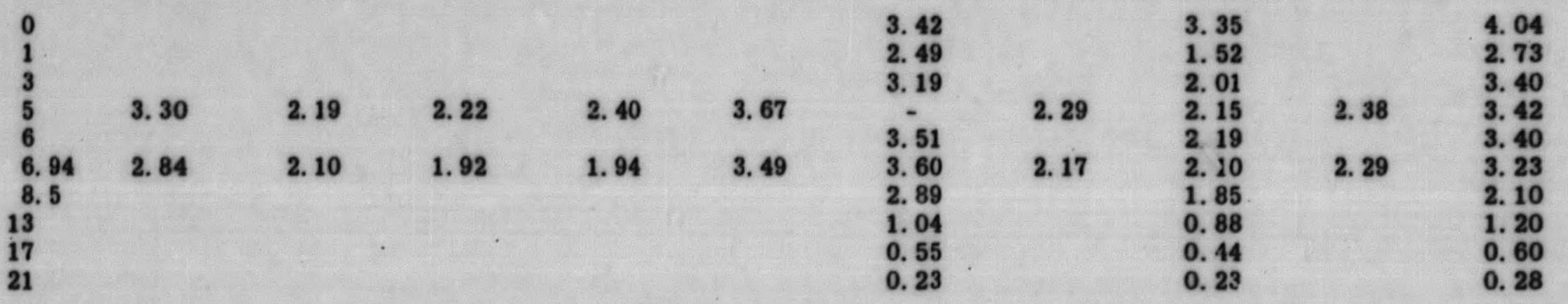


Plate "a"

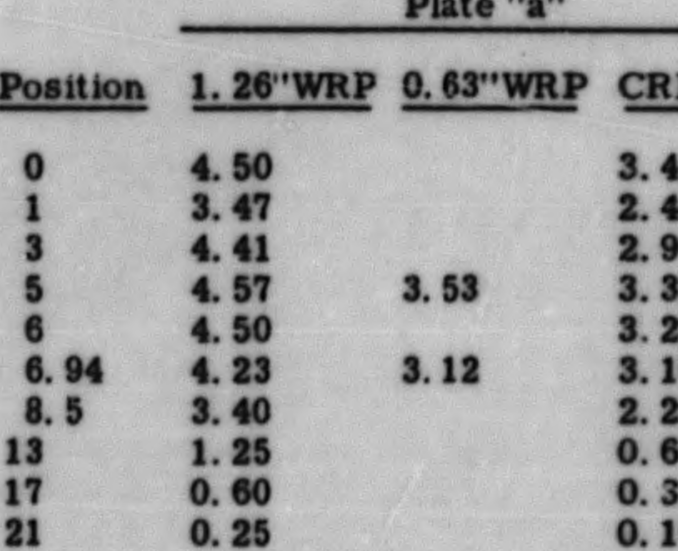

Plate "e"

1.26"WRP 0.63"WRP CRP 1.26"WRP 0.63"WRP CRP

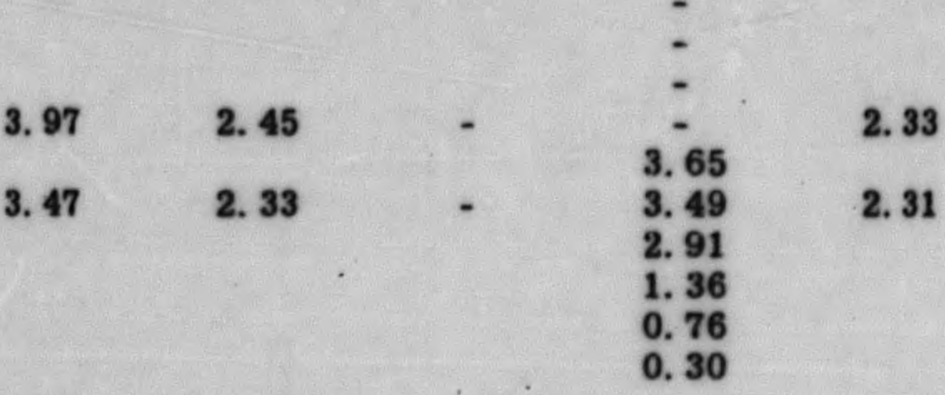

Plate "n"

1. 26"WRP 0.63"WRP CRP

1.64

2. 08

2.29
2.22

2.10

1. 82

0.83
Plate "r"

1. 26"WRP 0.63"WRP CRP

$\begin{array}{ll}3.42 & 2.49 \\ 2.59 & 1.69\end{array}$

$\begin{array}{llllll}3.44 & 2.31 & 2.24 & 3.47 & & 2.26 \\ & & & 3.86 & 2.73 & 2.45\end{array}$

$\begin{array}{lllllll}3.53 & 2.22 & 2.01 & 3.86 & 3.40 & 2.49 & 2.40 \\ & & & 2.89 & & \end{array}$

$\begin{array}{ll}2.82 & 1.69 \\ 1.13 & 0.51\end{array}$

$\begin{array}{ll}1.13 & 0.51 \\ 0.60 & 0.25 \\ 0.28 & 0.18\end{array}$ 
Table 3. 25

Relative Power Distribution Along Axial Traverses for Element in Position 41

Plate "j"

Plate " $\mathrm{n}$ "

Plate " $\mathrm{r}$ "

Position 10.20"WRP 9.57"WRP 8.94"WRP 8.31"WRP 7.68"WRP 10.20"WRP 9.57'WRP 8.94"WRP 8.31"WRP 7.68"WRP 10.20"WRP 9.57"WRP 8.94"WRP 8.31"WRP 7.68"WRP

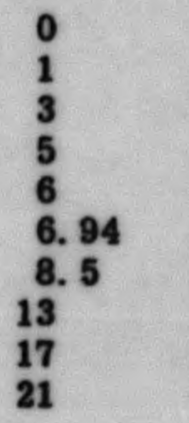

\begin{tabular}{ll}
\hline 1.36 & \\
0.95 & \\
1.18 & \\
1.18 & 1.04 \\
1.43 & 1.04 \\
1.34 & 1.04 \\
1.22 & \\
0.76 & \\
0.37 & \\
0.18 & \\
\hline &
\end{tabular}

2.22

0.83

$1.18 \quad 1.3$

2. 84

2. 29

1. 29

$\begin{array}{ll}1.09 & 1.18\end{array}$

1. 48

1. 34

$1.13 \quad 1.4$

2. 66

1. 29

$1.04 \quad 1.18$

1. 34

2. 70

1. 13

1.25

2. 19

0.99
1.18
1.32
1.39

1.29
1.13

1. 13

0.49

0.28
0.12

0.58
0.25

1. 22

1.39
1.29

$\begin{array}{r}1.11 \\ 0.65 \\ \hline\end{array}$

0.32

0.32
0.14

1. 57

2.52

2. 38

43

. 96

0.92

0.49 
Relative Power Distribution Along Axial Traverses for Element in Position 48

"SM-2 Final Mockup Core"

Plate "j"

Plate "n"

Plate " $\mathbf{r}$

Position 7.14"WRP 6.51"WRP 5.88"WRP 5.25"WRP 4.62"WRP 7.14"WRP 6.51"WRP 5.88"WRP 5.25"WRP 4.62"WRP 7.14"WRP 6.51"WRP 5.88"WRP 5. 25"WRP 4.62"WRP

$\begin{array}{ll}0 & 3.05 \\ 1 & 2.01 \\ 3 & 2.45 \\ 5 & 2.75 \\ 6 & 2.61 \\ 6.94 & 2.61 \\ 8.5 & 2.03 \\ 13 & 1.06 \\ 17 & 0.53 \\ 21 & 0.23\end{array}$

2.68
1.41
1.78
1.94
1.92
1.88
1.46
0.72
0.35
0.1

3.88

3. 16

$2.06 \quad 3.40$

1. 94

2. 19

3. 86

2. 22

1. 78

. 2.06

$2.49 \quad 1.78$

1.82

2. 08

3. 44

2. 56

3.00
1.41

$\begin{array}{ll}.72 & 1.41 \\ .35 & 0.74\end{array}$

0.230 .14

30

$\begin{array}{ll} & 1.96 \\ & 1.55 \\ 2.10 & 1.59 \\ 1.82 & 2.19 \\ & 2.15 \\ & 2.01 \\ & 1.59 \\ & 0.42 \\ & 0.25 \\ & 0.12\end{array}$

2. 33
2. 10

3. 72

3. 60
4.13 
Table 3.27
Relative Power Distribution Along Axial Traverses for Element in Position 43 'SM-2 Final Mockup Core"

Plate "j" Plate " $n$ "

Plate " $\mathrm{r}$ "

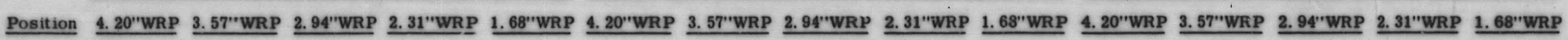

$0 \quad 3.58$

3. 58 4. 32

3. $40 \quad 2.79$
3.49

$\begin{array}{lllll}5 & 3.47 & 2.40 & 2.29 & 2 .\end{array}$

$\begin{array}{lllll}6 & 3.58 & & 2.1 .9 & \\ 6.94 & 3.40 & 2.19 & 2.13 & 2.33\end{array}$

4.16

3. 12

8. $5 \quad 2.66$

$\begin{array}{ll}13 & 1.29 \\ 17 & 0.65 \\ 31 & 0.23\end{array}$

2.13
1.87
0.81

0.21

3. 70

2. 33

2. 33

2. 61

4. 20

3. $79 \quad 3.40$

2. 19

2. 13

2. 36

3.86

0.88

0.44

$\begin{array}{ll}3.79 & 4.74 \\ 1.78 & 3.00\end{array}$

$\begin{array}{lll}1.78 & & 3.00 \\ 2.24 & 4.04\end{array}$

$\begin{array}{lll}2.45 & 2.59 & 4.07 \\ 2.38 & & \end{array}$

$\begin{array}{lll}2.38 & & 3.95 \\ 2.29 & 2.38 & 3.86\end{array}$

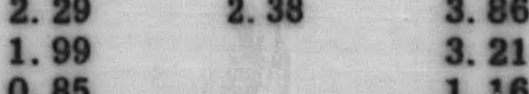

1.16
-1.58

0.58
0.23 
Table 3.28

Relative Power Distribution Along Axial Traverses for Element in Position 24 (Control Rod A)

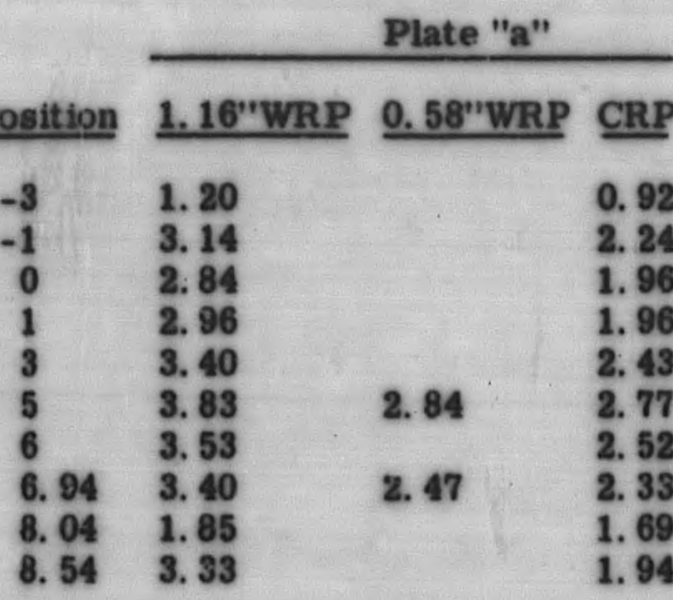

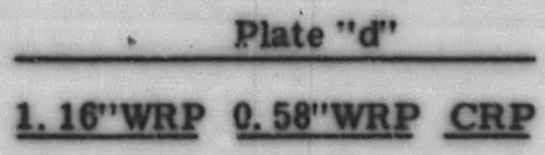

3. 47

2. 03

$3.42 \quad 1.85$
2. 06

1. 78
Plate "i"

1.16"WRP 0.58"WRP CRP

0.88

2. 2.03

2. 2.24

2. 91

3.23
3.42
1.87

2.89

0.42
0.85
1.06
1.32
1.69
1.89
1.85
1.71
0.74
1.94

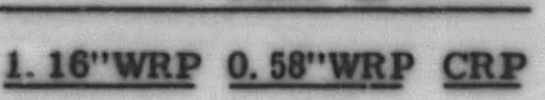

Plate " $\mathrm{p}$ "

1.16"WRP 0.58"WRP CRP

0.83

0.55

2. 19 1. 25

$\begin{array}{ll}\text { 2. } 08 & 1.22 \\ 2.66 & 1.69\end{array}$

$\begin{array}{llllll}2.89 & 1.76 & 1.69 & 2.89 & 2.10 & 2.13\end{array}$

$\begin{array}{lllllll}2.63 & 1.62 & 1.62 & 2.98 & 2.66 & 1.87 & 2.03 \\ & & & 5.85 & & 0.85\end{array}$

$\begin{array}{lll}2.66 & 1.87 & 1.85 \\ 1.89 & & 0.81\end{array}$ 
Table 3.29

Relative Power Distribution Along Axial Traverses for Element in Position 44 (Control R.od C)

Plate "i"

1.16" WRP 0.58" WRP CRP

$1.20 \quad 0.58$

$2.47 \quad 1.18$

$\begin{array}{ll}2.52 & 1.43 \\ 2.52 & 1.87\end{array}$

$\begin{array}{ll}3.23 & 1.87 \\ 4 & 2.38\end{array}$

$\begin{array}{lll}4.02 & 2.61 & 2.40 \\ 4.02 & & \end{array}$

$\begin{array}{lll}4.02 & & 2.47 \\ 3.70 & 2.36 & 2.29\end{array}$

$\begin{array}{llll}6.94 & 3.70 & 2.36 & 2.29 \\ 8.04 & 2.33 & & 0.95 \\ 8.54 & 3.00 & & 2.08\end{array}$

Plate " $\mathrm{m}$ "

1.16" WRP 0.58"WRP CRP

\begin{tabular}{l|ll}
4.02 & 2.49 & 2.33 \\
2.82 & 2.29 & 2.03
\end{tabular}

Plate "p"

1.16" WRP $0.58^{\text {"WRP CRP }}$

$1.43 \quad 0.99$

$\begin{array}{ll}3.47 & 2.08 \\ 3.33 & 2.15\end{array}$

3.51
4.13

$3.37 \quad 2.77$

$\begin{array}{ll}4.09 & 3.07\end{array}$

$\begin{array}{lll}3.60 & 2.80-2.56 \\ 3 & & 2.13\end{array}$ 
\$

Table 3.30
Relative Power Distribution Along Axial Traverses for Element in Position 32 (Control Rod $\mathbf{Y}$ )

\begin{tabular}{|c|c|c|c|c|c|c|c|c|c|c|c|c|c|c|c|}
\hline \multirow[b]{2}{*}{ Position } & \multicolumn{5}{|c|}{ Plate "a" } & \multicolumn{5}{|c|}{ Piate "d" } & \multicolumn{5}{|c|}{ Plate " $\mathrm{j}$ " } \\
\hline & 7.04"WRP & $6.46^{\prime \prime W R P}$ & 5. 88"WRP & 5. $30^{\prime \prime} \mathrm{WRP}$ & 4. 72"WRP & 7.04'WRP & 6. $46^{\prime \prime} \mathrm{WRP}$ & 5.88'WRP & 5. $30^{\prime \prime}$ WRP & 4. 72'WRP & 7.04"WRP & 6. 46"WRP & 5. $88^{\prime \prime W R P}$ & 5. 30"WRP & 4. 72"WRP \\
\hline $\begin{array}{l}-3 \\
-1 \\
0 \\
1 \\
3 \\
5 \\
5 \\
6 \\
6.94 \\
8.04 \\
8.54\end{array}$ & $\begin{array}{l}0.85 \\
2.82 \\
2.03 \\
2.08 \\
2.61 \\
2.86 \\
2.77 \\
2.56 \\
1.69 \\
1.92\end{array}$ & $\begin{array}{l}2.29 \\
2.10\end{array}$ & $\begin{array}{l}0.83 \\
1.71 \\
1.59 \\
1.52 \\
2.01 \\
2.26 \\
2.22 \\
2.13 \\
1.22 \\
1.64\end{array}$ & $\begin{array}{l}\text { 2. } 66 \\
\text { 2. } 31\end{array}$ & $\begin{array}{l}1.16 \\
3.19 \\
2.80 \\
2.56 \\
3.30 \\
3.70 \\
3.28 \\
3.26 \\
2.29 \\
2.43\end{array}$ & $\begin{array}{l}2.59 \\
\text { 2. } 22\end{array}$ & $\begin{array}{l}1.71 \\
1.55\end{array}$ & $\begin{array}{l}1.89 \\
1.62\end{array}$ & $\begin{array}{l}1.94 \\
1.76\end{array}$ & $\begin{array}{l}3.30 \\
\text { 2. } 96\end{array}$ & $\begin{array}{l}0.65 \\
1.43 \\
1.64 \\
1.87 \\
2.54 \\
2.68 \\
2.47 \\
1.80 \\
1.06 \\
1.66\end{array}$ & $\begin{array}{l}1.78 \\
1.59\end{array}$ & $\begin{array}{l}0.42 \\
0.92 \\
1.22 \\
1.69 \\
1.79 \\
1.79 \\
1.66 \\
0.65 \\
1.20\end{array}$ & $\begin{array}{l}2.01 \\
1.78\end{array}$ & $\begin{array}{l}0.99 \\
2.43 \\
2.45 \\
2.63 \\
2.89 \\
3.33 \\
3.28 \\
2.98 \\
1.69 \\
2.03\end{array}$ \\
\hline & & & Plate "m" & & & & & Plate "p" & & & & & & & \\
\hline Position & 7.04"WRP & 6.16"WRP & 5. $88^{\prime \prime}$ WRP & 5. $30^{\circ}$ WRP & 4. 72"WhP & $7.04^{\prime \prime W R P}$ & 6. $46^{\prime \prime W R P}$ & 5.88'WRP & 5. $30^{\prime} \mathrm{WRP}$ & 4.72"WRP & & & & & \\
\hline $\begin{array}{c}-3 \\
-1 \\
0 \\
1 \\
3 \\
5 \\
5 \\
6 \\
6.94 \\
8.04 \\
8.54\end{array}$ & $\begin{array}{l}2.77 \\
\text { 2. } 33\end{array}$ & $\begin{array}{l}1.69 \\
1.43\end{array}$ & $\begin{array}{l}1.69 \\
1.52\end{array}$ & $\begin{array}{l}1.92 \\
1.71\end{array}$ & $\begin{array}{l}3.40 \\
3.03\end{array}$ & $\begin{array}{l}0.76 \\
1.85 \\
1.76 \\
1.89 \\
3.05 \\
2.56 \\
2.56 \\
2.31 \\
1.32 \\
1.85\end{array}$ & $\begin{array}{l}1.99 \\
1.82\end{array}$ & $\begin{array}{l}0.53 \\
1.18 \\
1.48 \\
1.48 \\
1.96 \\
2.17 \\
1.92 \\
1.82 \\
0.90 \\
1.78\end{array}$ & $\begin{array}{l}\text { 2. } 31 \\
\text { 2. } 19\end{array}$ & $\begin{array}{l}\text { 1. } 06 \\
\text { 2. } 73 \\
2.40 \\
2.52 \\
3.23 \\
3.79 \\
3.42 \\
3.74 \\
2.10 \\
3.00\end{array}$ & ? & & & & \\
\hline
\end{tabular}




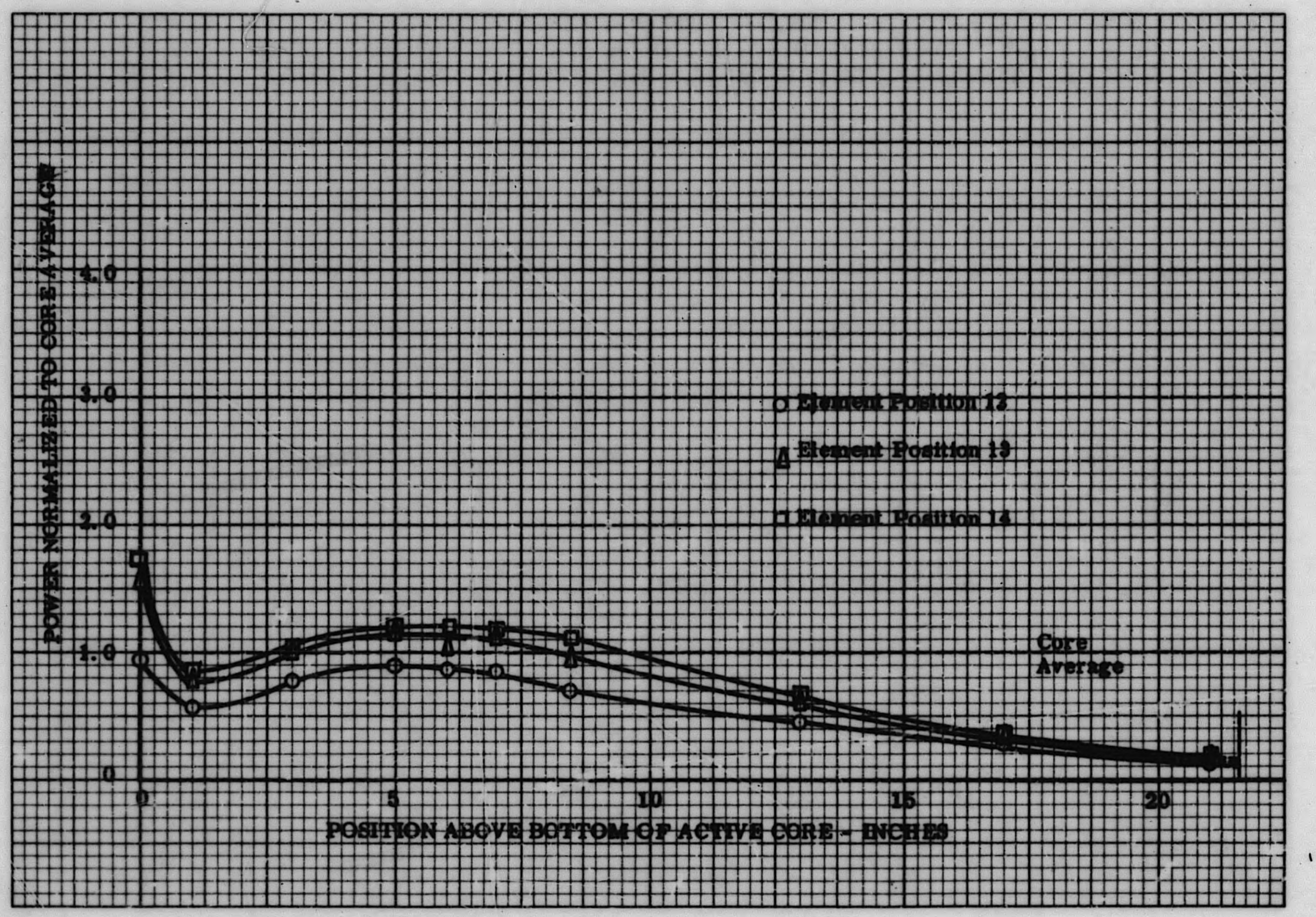

Figure 3.12 Relative Power Distribution Along Axial Traverse on Centerline of Fuel Plate " $\mathrm{j} "$, Elements in Positions 12,

13 and 14, SM-2 Final Mockup Core 


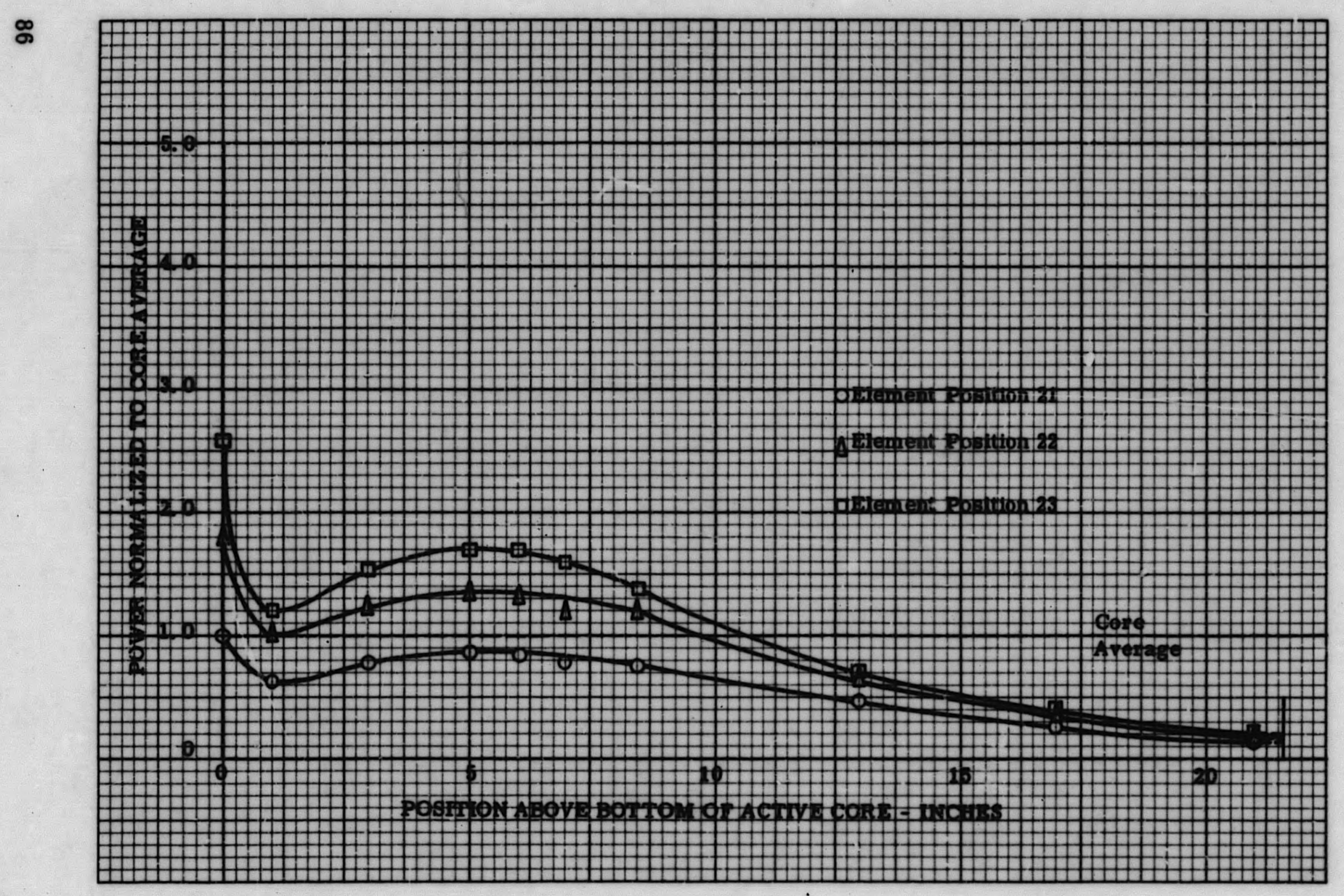

Figure 3.13 Relative Power Distribution Along Axial Traverse on Centerline of Fuel Plate "j", Elements in Positions 21, 22 and 23, SM-2 Final Mockup Core 


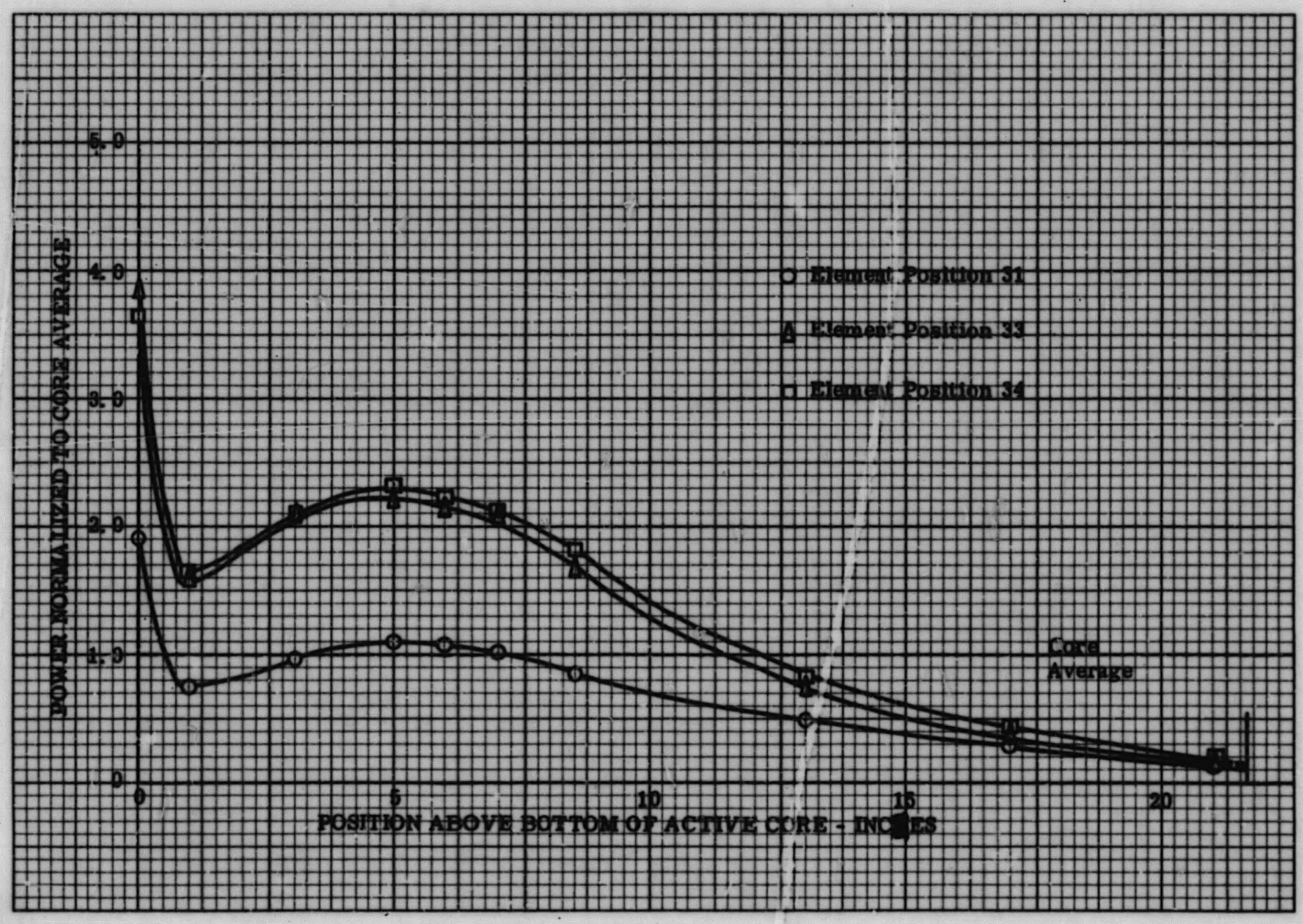

$\stackrel{9}{9}$

Figure 3.14 Relative Power Distribution Along Axial Traverse on

Centerline of Fuel Plate "j", Flements in Positions 31,
33 and 34, SM-2 Final Mockup Core

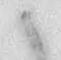




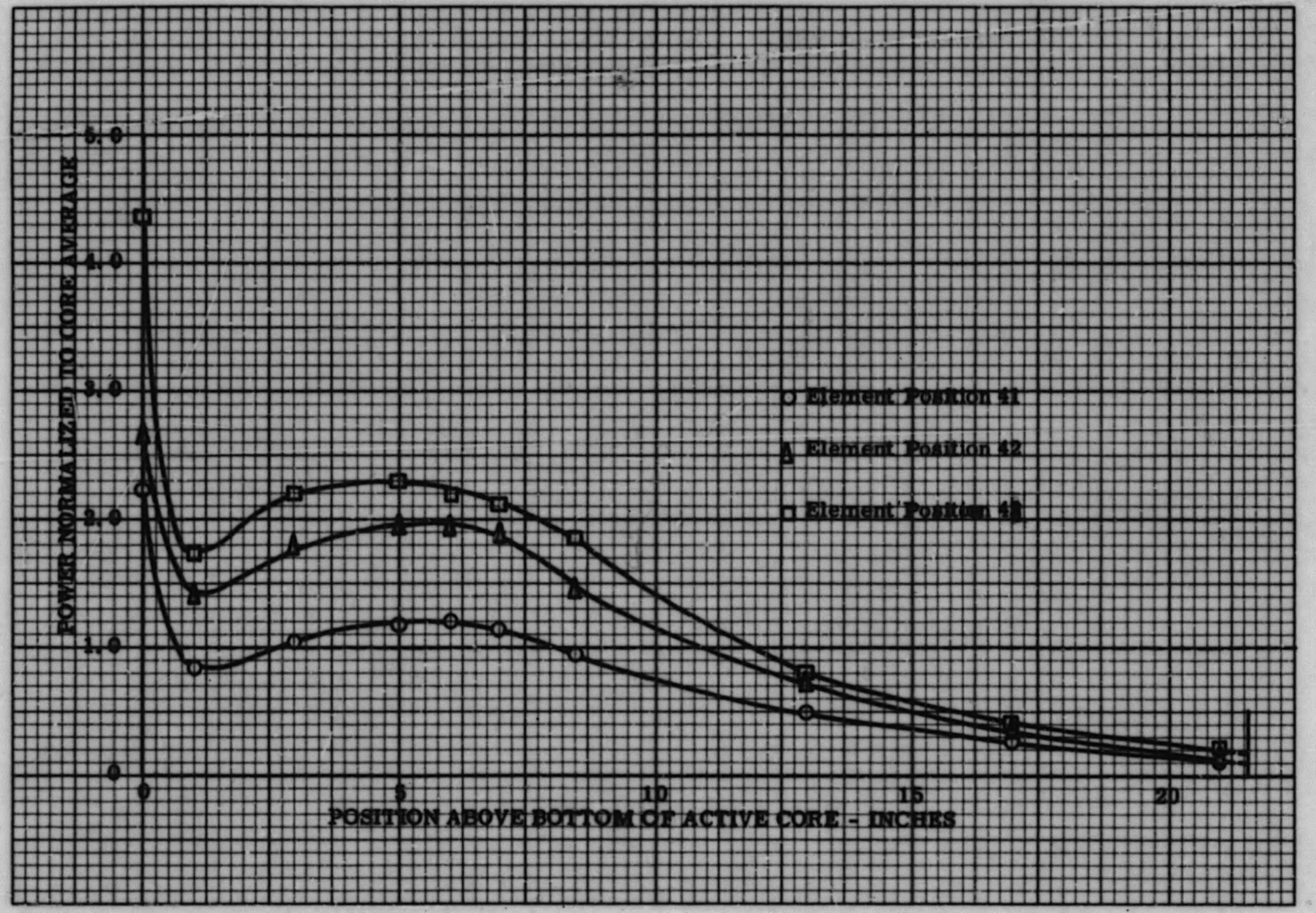

Figure 3.15 Relative Power Distribution Along Axial Traverse on Centerline of Fuel Plate "j", Elements in Positions 41,
42 and 43, SM-2 Final Mockup Core

. 


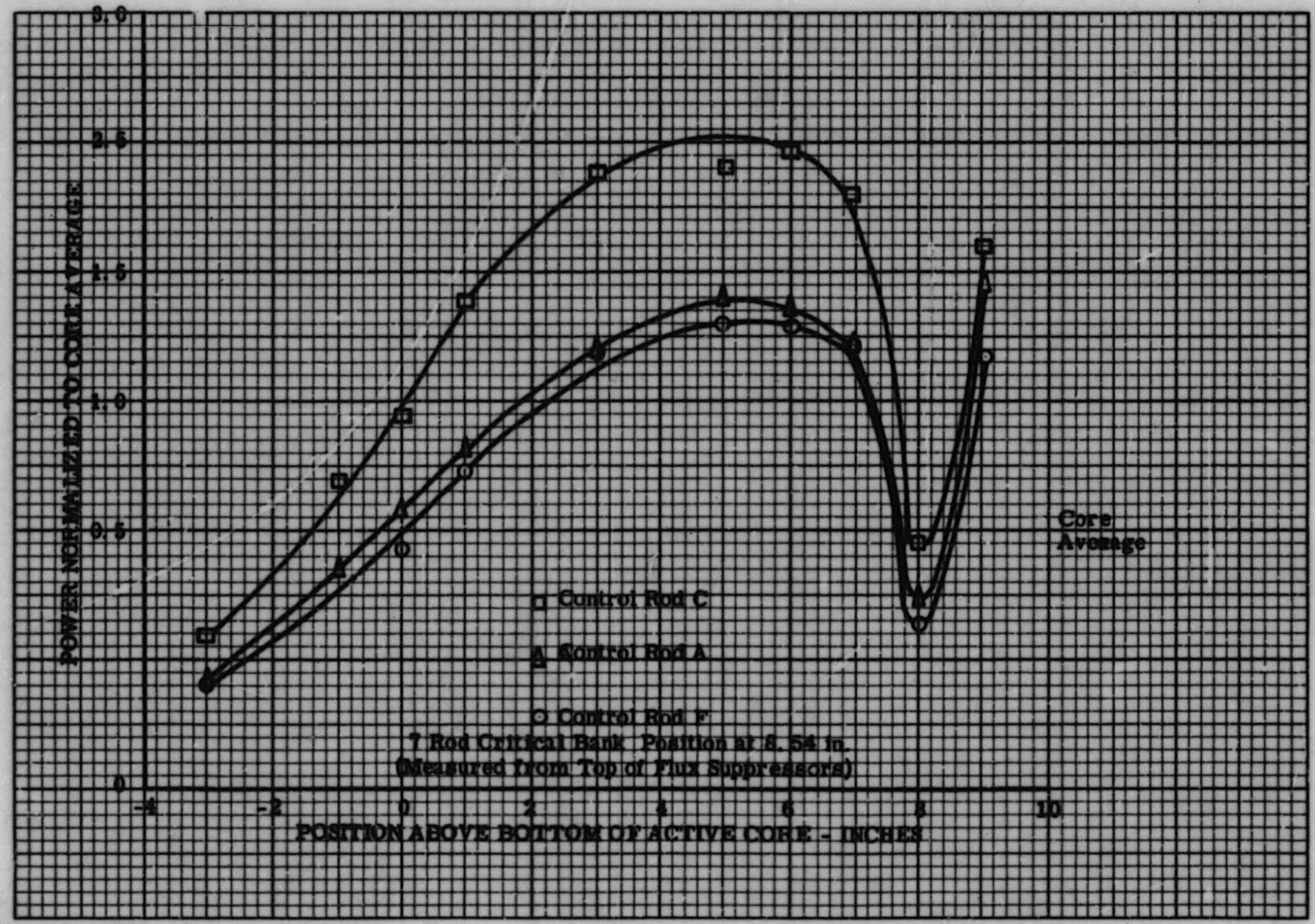

Figure 3.16 Relative Power Distribution Along Axial Traverse on Centerline of Fuel Plate " $\mathrm{i}$ " of Control Rods A, C and F, SM-2 Finai Mockup Core 
8

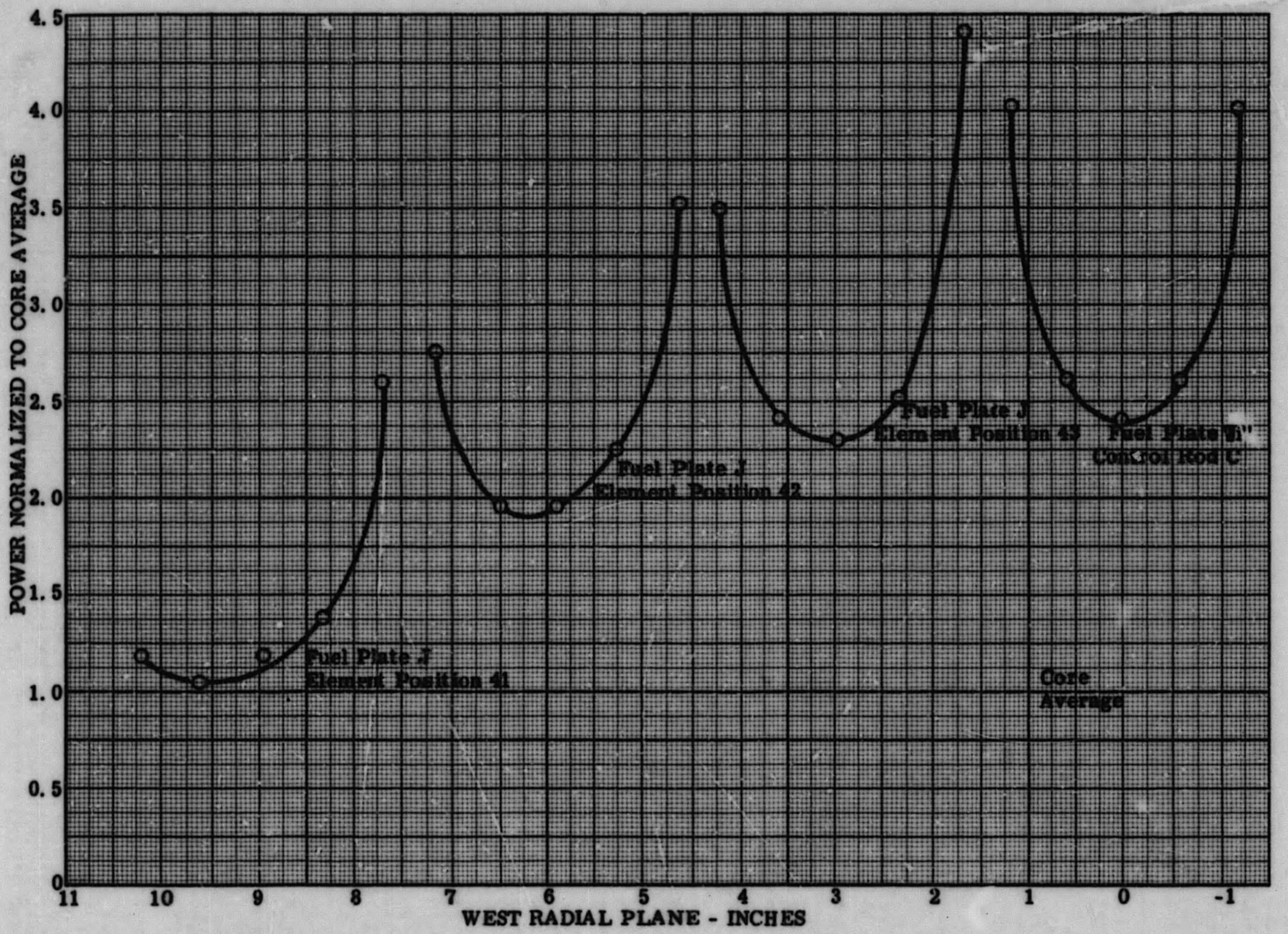

Figure 3.17 Relative Power Distribution Along Radial Traverse 5 In. Above Bottom of Active Core, SM-2 Final Mockup Core 
center of the core is approached. Power minimas occur as expected along the centerline with maximas along the edges. The overall maximum-to-average power generation in the core is 4.74 to 1 occurring as aispike at the bottom of fuel element in position 43. The internal maximum of 4.62 to 1 occurs within the central control rod fuel element.

\section{2.8 Conclusions}

A survey of the power producing characteristics of the SM-2 core was obtained from activation measurements. The highest power density was in the region surrounding the center of the core, the lowest along the outer ring of elements. In stationary fuel elements power peaks occurred at the bottom of the active core and 4-7 in. above it in the vicinity of the critical bank position, with power gradually diminishing as the top of the active core was reached. In general, minimum power generation occurred along the centerline of fuel elements and maximum at the edges. The data of Fig. 3.4 and 3.11 differ from that previously reported(1) since these data include the control rods in the core average; include more detailed mapping and in the latter case include a flow divider mockup.

In control rod fuel elements without flux suppressors, the power exhibited a small gradual increase until near the critical position where a very sharp rise occurred corresponding on the average to more than a threefold increase in power. The addition of flux suppressors at the top of the active meat eliminated this peak in power, dropping the power by as much as $90 \%$. Maximum suppressor effect of 9.2 to 1 occurred at the centerline of plate " $i$ " of control rod $F$ while it was 8.3 to 1 and 7.3 to 1 on the centerline of plate " $i$ " of control rod C and A, respectively. This demonstrates the usefulness and effectiveness of suppressors in eliminating sharp power spikes, thus permitting maximum power to be generated within an appreciable volume of the fuel element.

Figure 3.18 shows the relative power distribution along an axial traverse on centerline of plate " $\mathrm{i}$ " of control rod $\mathrm{C}$ with and without suppressors. Figure 3.19 illustrates radial traverses at the top limit of the active meat for plate " $i$ " of control rods $\mathbf{A} ; \mathbf{C}$ and $\mathbf{F}$ for the two mockups. Considerable reduction in power in the suppressor region is evident in the above two figures.

An examination of the power distribution in the vicinity of the flow divider and the resulting outward displacement of the outer ring of fuel elements indicates in general only a slight decline and a more even distribution of power in the flow divider region.

Among individual elements in the preliminary mockup core, a peak-toaverage power density of 2.6 to 1 occurred within the portion of the central control rod in the active core while average-to-minimum power density of 1.7 to 1 occurred in element position 21 at the corner of the core. The use of flow divider and control rod flux suppressors in the final mockup slightly changed the overall power distribution in the core allowing for a more even distribution and lesser power spikes. Again,peak and minimum power densities occurred 


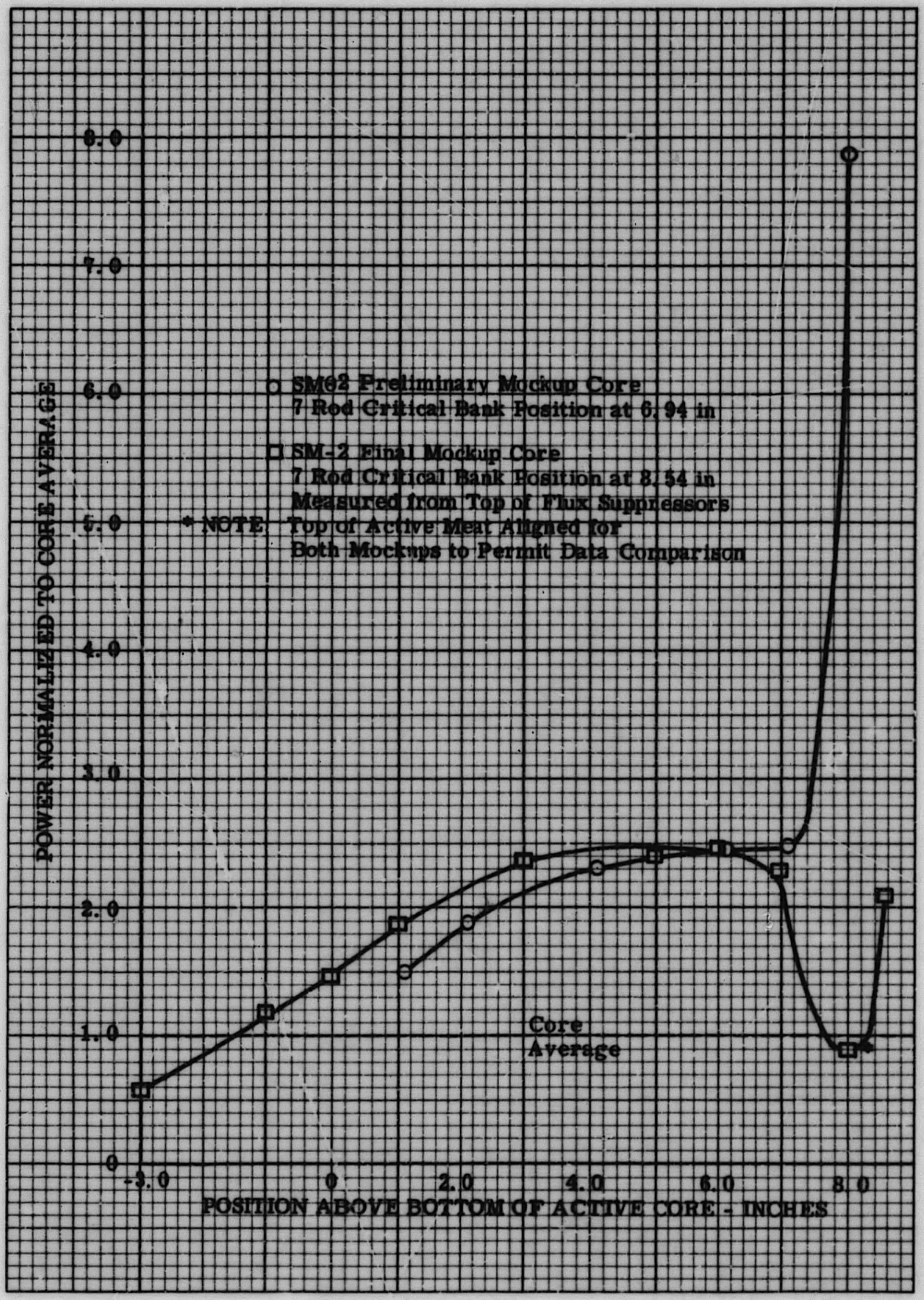

Figure 3.18 Relative Power Distribution Along Axial Traverse on Centerline oi Fuel Plate " $\mathrm{i}$ " of Control Rod C, SM-2 Preliminary and Final Mockup Cores 


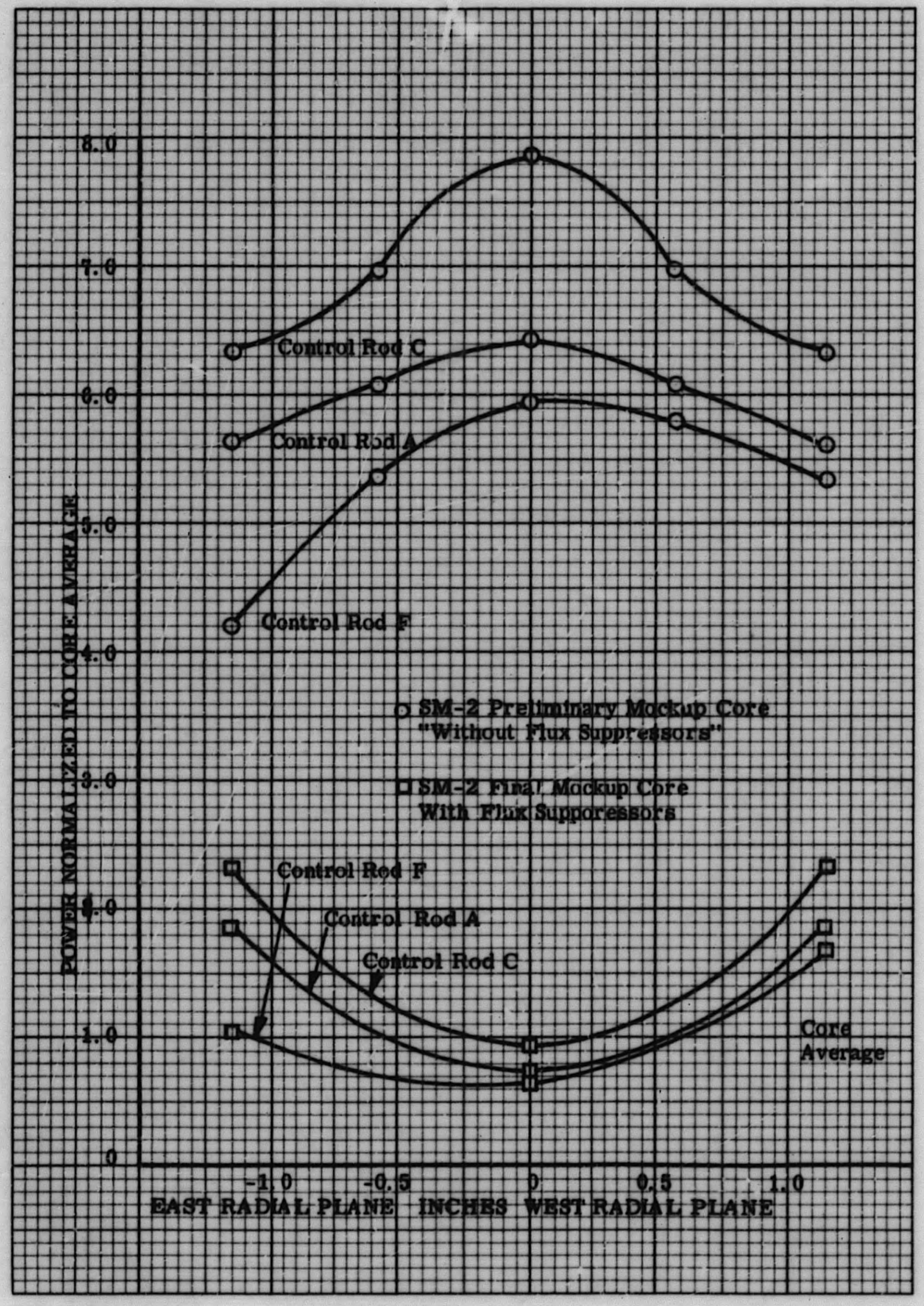

Figure 3.19 Relative Power Distribution Along Radial Traverse at Top of the Active Core of Fuel Plate "i" of Control Rods A, C and F, SM-2 Preliminary and Final Mockup Cores 
within the active portion of the central control rod and the corner element in position 21; the peak-to-average ratio was reduced to 2.3 to 1 while average-tominimum remained at 1.7 to 1 . An indication of the overall change in power distribution is given by the changes in the normalization factor which increased from 2.18 for the preliminary to 2.31 for the final mockup.

\section{3 FLUX SUPPRESSOR MEASUREMENTS}

\subsubsection{Introduction}

The effectiveness of both mockup and integral suppressors located at the lower boundary of stationary fuel elements, was demonstrated in reducing the high power peaks occurring at the bottom of the active core. The relative power measured in these regions with flux suppressors was reduced to approximately $1 / 8$ the value obtained without suppressors, bringing the local power well below the core average. Tables $3.31,3.32,3.33$ and 3.34 summarize the measurements, made on elements 41,42 , and 43 , respectively, using $1 / 2-$ and $3 / 4-$ in. long suppressors, normalized to a core average of unity. Comparison of foil activations with and without suppressors is given in Fig. 3.20, 3.21, and 3.22 through the centerline of plate " $j$ " of elements 41,42 , and 43 , respectively; Fig. 3.23 compares the effectiveness of mockup flux suppressors at the edge of fuel element 43 at plate "r".

The effectiveness of the suppressors: extend up to an axial position of about 2 to 3 in. from the lower boundary of the active core.

\section{3.2 Mockup Suppressors}

The mockup flux suppressors consist of multi-layers of Mylar film impregnated with boron. The Mylar film was applied to both sides of the fuel plates to an aerial density of $0.0045 \mathrm{gm} \mathrm{B-10}$ per $\mathrm{cm}^{2}$ on each side. This B-10 density was equivalent to the europium density of $1.529 \mathrm{gm} \mathrm{Eu} / \mathrm{cc}$ in the design europiur. flux suppressors. The width of the mockup suppressors was identical to the specified fuel matrix width and the upper suppressors boundary was at the lower active core limit.

The use of Mylar tape on the plate surface to mockup the suppressor fills $50 \%$ of the coolant channel between the plates. This would presuppose a reduction in neutron flux, thus tending to improve the apparent neutron absorption efficiency of the mockup suppressors over equivalent integral suppressors. How ever, subsequent data obtained with integral europium suppressors indicated that this effect was more apparent than real, and the foil activations with both types of suppressors were approximately the same (Fig. 3.22).

A comparison of runs using a "blank" suppressor, i. e., Mylar tape without boron impregnation, with those in which no tape at all was used, produced little differences in relative foil activations (Fig. 3.20-3.22). This indicates that the effect of placing the uranium foils farther out in the water gap is not readily discernable in the region directly below the active core boundary. 


\subsubsection{Flux Suppressor Effectiveness}

The use of $1 / 2$ in. long suppressors reduces the flux peaks near the bottom of the active core by a factor of approximately eight. However the $50 \%$ increase in suppressor length to $3 / 4$ in. did not produce a further flux suppression above the bottom of the active core nor extend the range of flux suppression beyond the 2 in. to 3 in. axial position, thus demonstrating essentially an equivalence between 1/2- and 3/4-in. long flux suppressors.

\subsubsection{Integral Suppressors}

Subsequent to the mockup suppressor tests, $18 \mathrm{SM}-2$ fuel plates containing integral suppressors were made available for testing. These fuel plates had an average $\mathrm{Eu}_{2} \mathrm{O}_{3}$ loading in the suppressor region of $0.780 \mathrm{gm}$. This was about $33 \%$ less europium than the design loading of $1 \mathrm{gm}$ of europium per plate or 1.529 $\mathrm{gm} \mathrm{Eu} / \mathrm{cc}$. The integral suppressors had an average length of $0.549 \mathrm{in}$. and an average width of 2.686 in.

Since only 18 plates containing flux suppressors were available, flux measurements could be made only with a single fuel element containing the suppressors. Hence, the environment was not quite identical to that obtained using Mylar tape mockups where the fuel elements surrounding the foil instrumented element all contained suppressors. Nevertheless, reasonable agreement between the mockup and integral suppressor measurements was obtained. Figure 3.22 shows that the integral flux suppressors were only slightly less effective than the $1 / 2$-in. long mockup suppressors. This is probably due to the combination of effects resulting from the slightly lower effective loading of the integral suppressors and the fact that integral suppressors did not extend into the coolant passage as che mockup suppressors did.

\section{4 BLOCKED CHANNEL MEASUREMENTS}

\subsubsection{Introduction}

The objective of these survey experiments was to determine the effects on local power generation that result from blocking a fuel element coolant channel with various filler materials. The blocked channel method is used for installation of thermocouples for fuel plate temperature profile measurements during reactor power operation. The experimental runs consisted of measuring the foil activations when blocking the central channel of element position No. 42 with a metal filler.

Measurements were made in the SM-2 core mockup both with a water reflector and with a stainless steel reflector. Stainless steel and aluminum fillers were used in the experiment. 
Table 3.31

Relative Power Distribution Along Axial Traverses For Element in Position 41;

SM-2 Preliminary Mockup Core with Suppressor Mockups

Plate "a"

Position

9.97 WRP 8.81 WRP 7.65 WRP

$\begin{array}{lll}1.96 & 3.47 & 3.86 \\ 1.28 & 2.33 & 3.05 \\ 0.83 & 0.93 & 1.65 \\ 1.02 & 1.18 & 2.06\end{array}$

$-1 / 2$
0
1
3

$-1 / 2$
0
1
3

0.50
0.33
0.56
0.91

0.66
0.30
0.74
1.08

1.00
0.58
1.24
1.71

$-1 / 2$
0
1
3

$\stackrel{0}{\mathbf{1}}$ $\begin{array}{lll}0.25 & 0.25 & 0.41 \\ 0.27 & 0.27 & 0.52 \\ 0.65 & 0.77 & 1.30 \\ 0.92 & 1.06 & 1.71\end{array}$

2.24
0.91

1.22
Plate " $j$ "

9.97 WRP 8.81 WRP 7.65 WRP

Operation With Blank Flux Suppressors

$\begin{array}{lll}2.33 & 3.60 & 4.58 \\ 1.34 & 1.85 & 2.82 \\ 0.76 & 0.85 & 1.69 \\ 1.00 & 1.09 & 1.96\end{array}$

Operation With Half Inch Flux Suppressors

$\begin{array}{lll}0.39 & 0.49 & 0.81 \\ 0.27 & 0.26 & 0.36 \\ 0.60 & 0.65 & 1.23 \\ 0.84 & 0.95 & 1.77\end{array}$

Operation With Three Quarter Inch Flux Suppressors

$\begin{array}{lll}0.22 & 0.21 & 0.43\end{array}$

\begin{tabular}{lll}
0.26 & 0.26 & 0.46 \\
0.71 & 0.76 & 1.34 \\
0.95 & 0.99 &. \\
\hline
\end{tabular}

Operation Without Flux Suppressors

$\underset{\substack{2,2.1 \\ \text { a.d } \\ \text { i.m }}}{2}$
Plate " $r$ "

9.97 WRP 8.81 WRP 7.65 WRP

$\begin{array}{lll}1.98 & 3.30 & 3.98 \\ 1.27 & 1.92 & 2.33 \\ 0.81 & 0.91 & 1.48 \\ 1.02 & 1.13 & 2.02\end{array}$

$\begin{array}{lll}0.43 & 0.53 & 0.56 \\ 0.22 & 0.26 & 0.41 \\ 0.64 & 0.74 & 1.21 \\ 0.94 & 1.03 & 1.58\end{array}$

$\begin{array}{lll}0.21 & - & 0.34 \\ 0.29 & 0.26 & 0.47 \\ 0.75 & 0.78 & 1.39\end{array}$

$\begin{array}{lll}0.75 & 0.78 & 1.33 \\ 1.02 & 1.01 & 1.72\end{array}$

2.35
0.97
1.27 


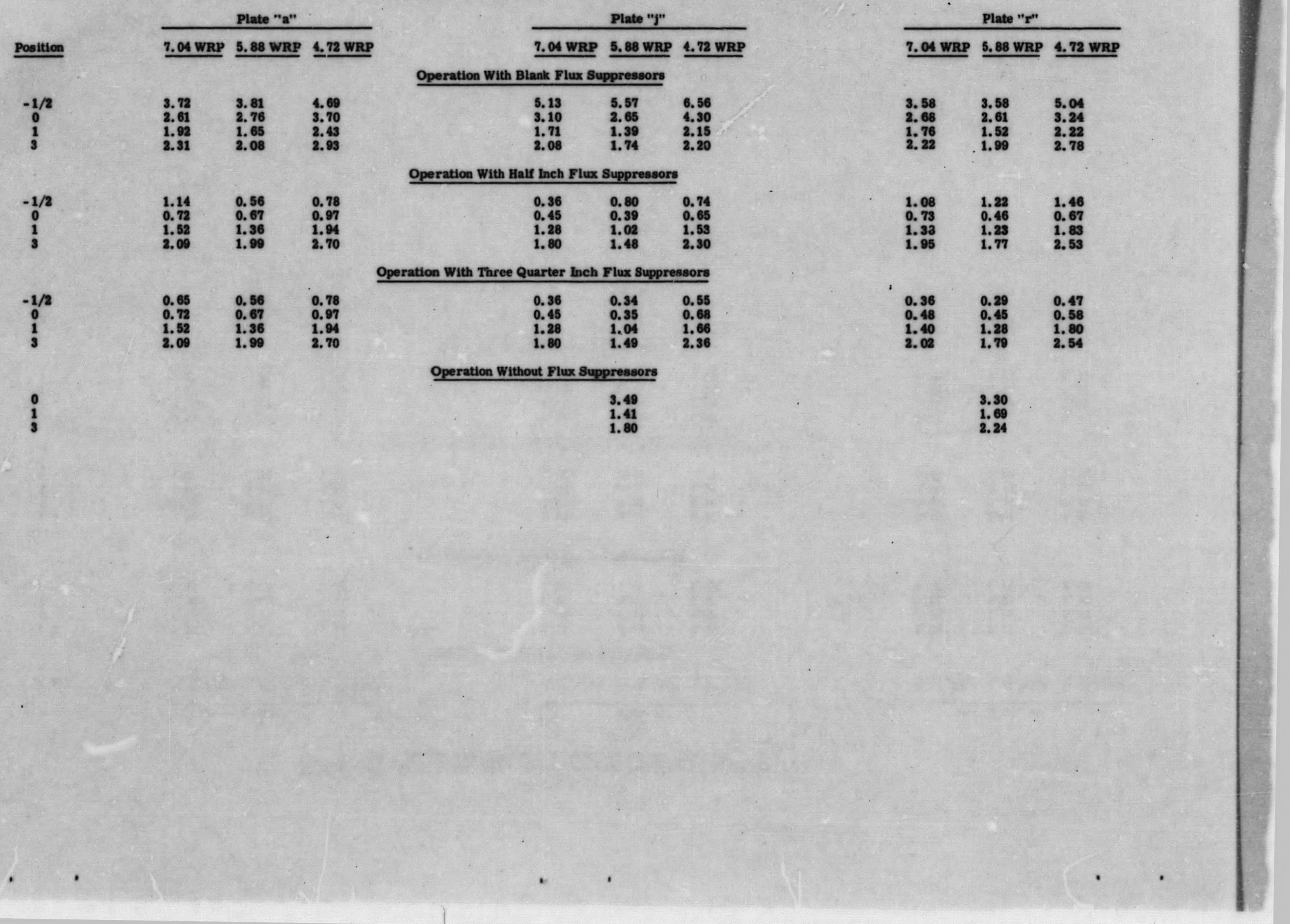


Table 3.33

Relative Power Distribution Along Axial Traverses For Element in Position 48

年

Plate "a"

Position

Active Core-inches $4.10^{\prime \prime}$ WRP 2.94" WRP 1.78" WRP

$-1 / 2$
0
1
3

$-1 / 2$
0
1
3

$-1 / 2$
0
1
3

0
1
3

$\begin{array}{lll}1.96 & 1.38 & 1.47 \\ 0.85 & 0.63 & 0.95 \\ 1.93 & 1.46 & 2.03 \\ 2.60 & 2.15 & 2.96\end{array}$

$\begin{array}{lll}0.67 & 0.54 & 0.78 \\ 0.77 & 0.53 & 0.76 \\ 1.93 & 1.56 & 2.08 \\ 2.71 & 2.20 & 2.88\end{array}$

Plate " $\mathrm{j}$

4.10" WRP 2.94" WRP 1.78" WRP

Operation with Blank Flux Suppressors

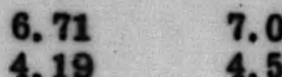

$\begin{array}{ll}4.19 & 4.50 \\ 2.24 & 1.57 \\ 2.89 & 2.08\end{array}$

6.65
4.63
2.36
3.05

Operation with Half Inch Flux Suppressors

$\begin{array}{lll}1.39 & 1.67 & 1.43 \\ 0.60 & 0.57 & 0.97 \\ 1.64 & 1.37 & 2.03 \\ 2.39 & 1.92 & 2.82\end{array}$

2.

1.37
1.92

.03

Operation With Three Quarter Inch Flux Suppressors

$\begin{array}{ll}0.38 & 0.67 \\ 0.44 & 0.84\end{array}$

0.57

2. 71

1.8

0.84
2.00
2.74

Operation Without Flux Suppressors

i:

Plate "r"

\subsection{0"WRP 2.94"WRP $1.78^{\prime \prime}$ WRP}

$\begin{array}{lll}6.01 & 6.63 & 5.96 \\ 3.89 & 4.19 & 4.37 \\ 2.13 & 1.69 & 2.33 \\ 2.52 & 2.24 & 2.96\end{array}$

$\begin{array}{lll}1.75 & 1.53 & 2.04 \\ 0.55 & 0.43 & 0.72 \\ 1.70 & 1.41 & 2.06 \\ 2.39 & 1.95 & 2.81\end{array}$

$\begin{array}{llc}0.39 & 0.26 & 0.48 \\ 0.52 & 0.44 & 0.64 \\ 1.66 & 1.34 & 2.06 \\ 2.22 & 1.92 & -\end{array}$

4.44
1.65
2.70 
Table 3.34

Relative Power Distribution Along Axial Traverses For Element in Position 43 ;

Plate "f"

Plate "j"

Plate "n"

Plate "r"

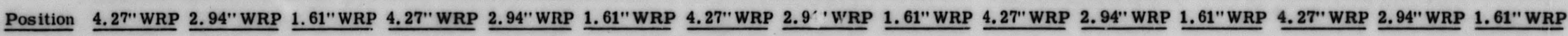
Operation With Integral Suppressors

\begin{tabular}{|c|c|c|c|c|c|c|c|c|c|c|c|c|c|c|}
\hline $\begin{array}{c}-1 / 2 \\
0 \\
1 \\
3 \\
5 \\
7\end{array}$ & $\begin{array}{l}2.67 \\
1.79 \\
2.12 \\
2.73\end{array}$ & $\begin{array}{l}3.10 \\
1.47 \\
1.62 \\
2.26 \\
2.37 \\
2.12\end{array}$ & $\begin{array}{l}3.60 \\
1.86 \\
2.41 \\
3.23\end{array}$ & $\begin{array}{l}2.07 \\
1.64 \\
1.94 \\
2.70\end{array}$ & $\begin{array}{l}1.41 \\
0.78 \\
1.44 \\
1.83 \\
2.15 \\
1.98\end{array}$ & $\begin{array}{l}2.13 \\
1.53 \\
2.27 \\
3.24\end{array}$ & $\begin{array}{l}3.11 \\
1.41 \\
1.99 \\
2.69\end{array}$ & $\begin{array}{l}2.26 \\
0.63 \\
1.51 \\
2.08 \\
2.22 \\
1.97\end{array}$ & $\begin{array}{l}2.43 \\
1.25 \\
2.32 \\
3.07\end{array}$ & $\begin{array}{l}2.33 \\
1.44 \\
2.02 \\
2.67\end{array}$ & $\begin{array}{l}1.87 \\
1.17 \\
1.57 \\
2.20 \\
2.26 \\
2.00\end{array}$ & $\begin{array}{l}1.68 \\
1.65 \\
2.51 \\
3.34\end{array}$ & $\begin{array}{l}2.74 \\
1.68 \\
1.97 \\
2.72\end{array}$ & $\begin{array}{l}2.74 \\
1.08 \\
1.60 \\
2.12 \\
2.32 \\
1.97\end{array}$ \\
\hline
\end{tabular}


rans

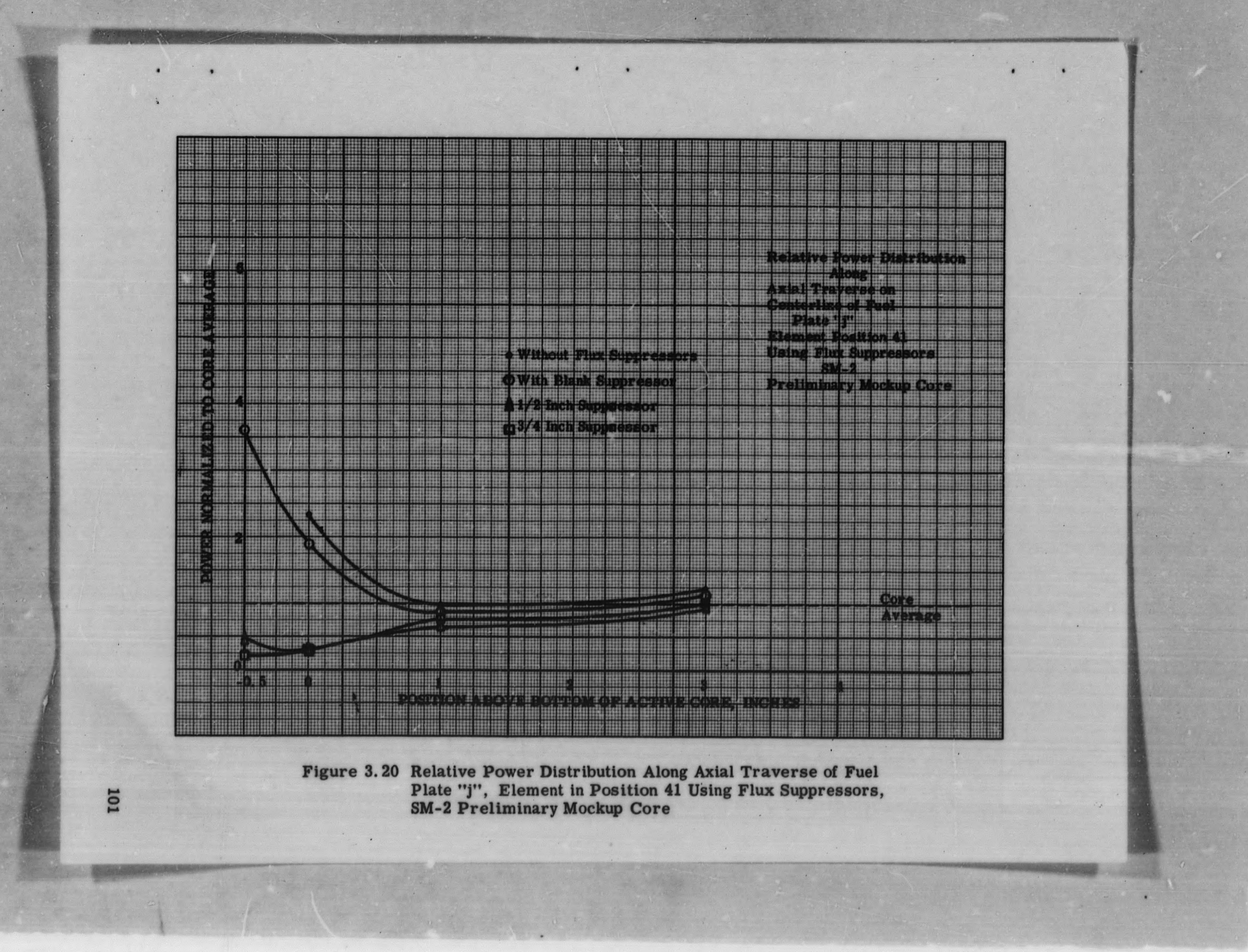




\section{总}

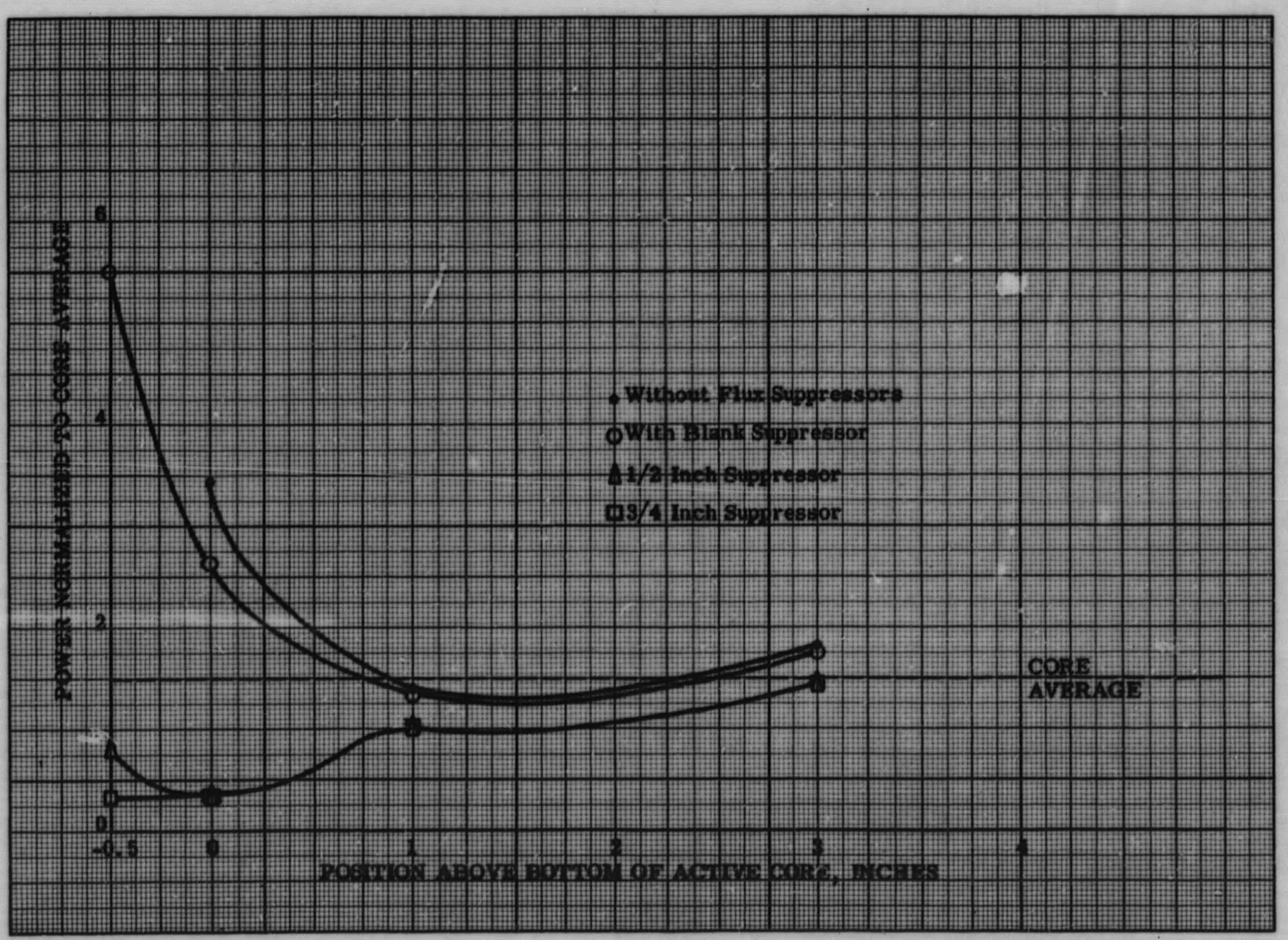

Figure 3.21 Relative Power Distribution Along Axial Traverse of Fuel Plate " $\mathrm{j}$ ", Element in Position 42 Using Flux Suppressors, SM-2 Preliminary Mockup Core 


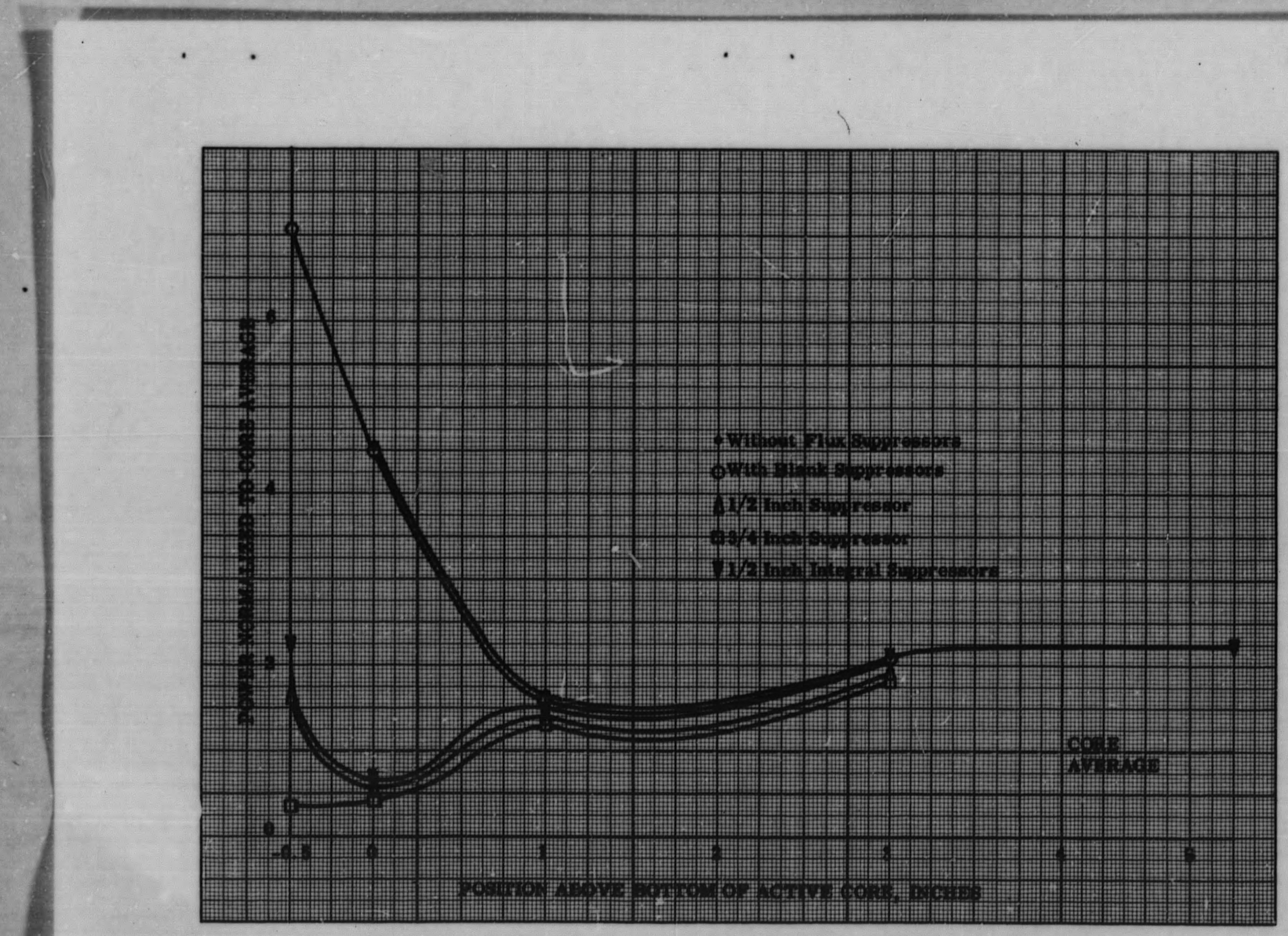

Figure 3.22 Relative Power Distribution Along Axial Traverse of Fuel Plate " $\mathrm{j}$ ", Element in Position 43 Using Flux Suppressors, SM-2 Preliminary Mockup Core 


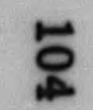

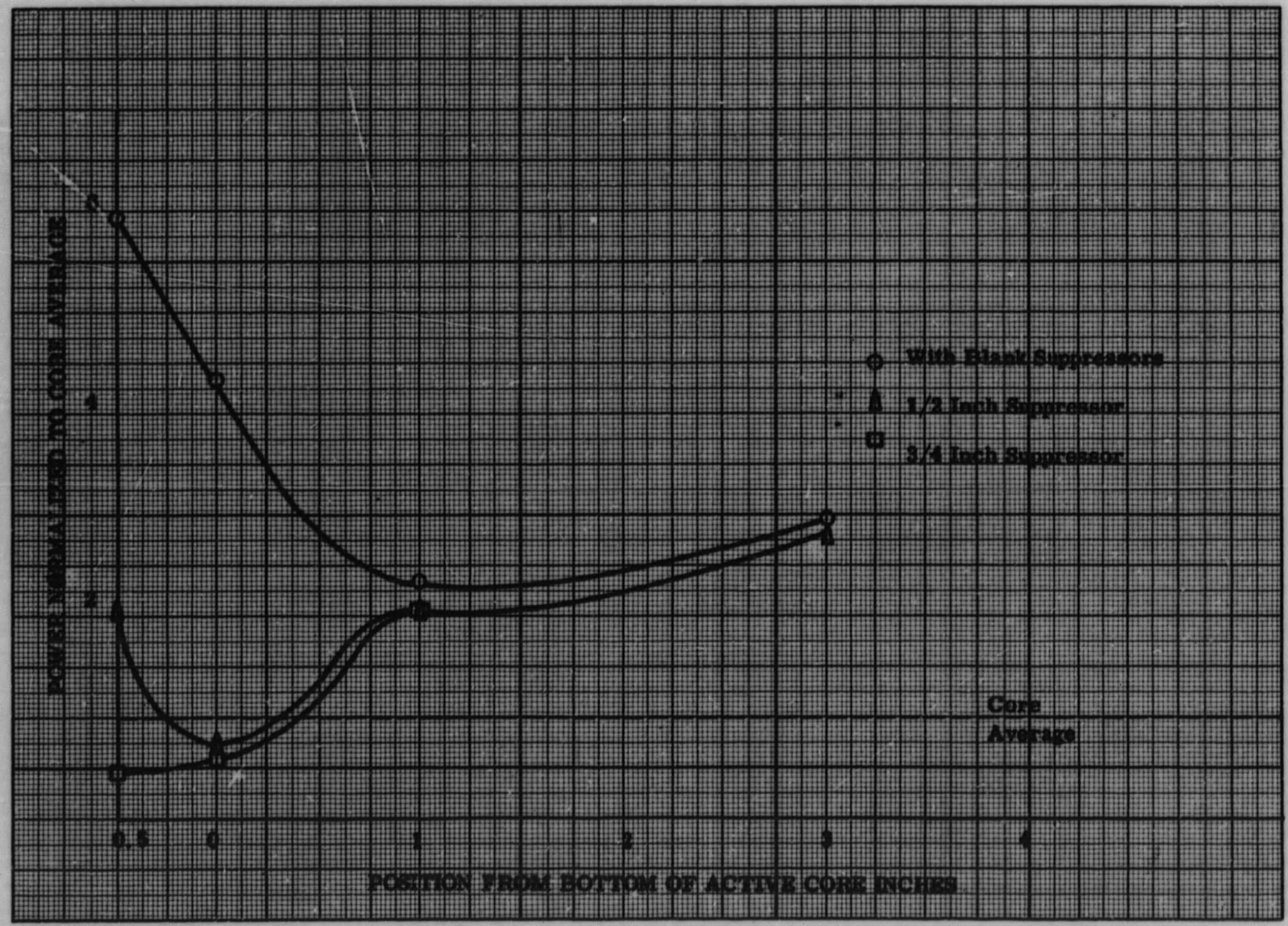

Figure 3.23 Relative Power Distribution Along Axial Traverse at 1.78 In. W.R.P. of Fuel Plate "r", Element in Position 43 Using Flux Suppressors, SM-2 Preliminary Mockup Core 


\subsubsection{Experimental Method}

Two stainless steel or aluminum filler plates were used to block the water channel between fuel plates " $\mathrm{i}$ " and " $\mathrm{j}$ " of the element in position 42 . Stainless steel sheathed chromelalumel thermocouples were inserted between the aluminum filler plates which were specially grooved for this purpose. It was felt that the cross section of the stainless steel filler satisfactorily approximated that of the thermocouples. The fillers were 0.063 in. thick and 22-15/16 in. long. Figure 3.24 is a.drawing from which the fillers or thermocouple plates were made. Figure 3.25 shows the cross section of the central portion of the fuel element with and without the blocked channel.

The center of the blocked channel plus the south sides of fuel plates " $n$ " and " $r$ " were instrumented with uranium foils. The foils were activated, counted, and the data processed as described in AP Note 246. (5)

\section{4. 3 Water Reflected Core Measurements}

Figure 3.26 shows that the blocked channel produces a flux suppressing effect. In addition, the relative foil activity measured in the run using stainless steel filler plates was less than the corresponding run with aluminum. It is estimated that a maximum flux reduction of $20 \%$ occurred between the unblocked and the aluminum blocked charnel; the foil activity measured in the run with stainless steel filler was about $9 \%$ less than that obtained when using the aluminum filler plates. Because of time limitations, a zero run mapping the flux in a clear channel was not performed. However, data was avallable from previous experiments to establish the unperturbed flux distribution along plate " $i$ ". To facilitate data comparison, all measurements were normalized to a core average of unity. Table 3. 35 lists the normalized foil activation for blocked channel measurements using aluminum and stainless steel filler material. It also presents earlier unblocked channel measurements.

\section{4. 4 Steel Reflected Core Measurements}

The blocked channel measurements using stainless steel fillers were repeated using a steel reflected core. To offset any variances in bank positioning, foil courting, etc., which must be allowed for when different runs are compared, it was decided that element 46, symmetrical in core geometry to element $\mathbf{4 2}$ which contained the blocked channel, be also instrumented with uranium foils. This permitted flux measurements for the same clear and blocked channel to be made simultaneously. Tables $3.36,3.37$ and 3.38 present the data. Figure 3.27 shows the axial flux traverses with and without the stainless steel blocking plates. A comparison of Fig. 3:26 and 3.27 shows that the effect of blocking one channel is similar in the water and steel reflected cores. The largest difference in the ratio between clear and steel blocked channel measurements is about 1.38 at the 5 in. axial location above the bottom of the active core (refer to Table 3.38). 
Table 3.35
Relative Power Distribution Along Axial Traverses For Element in Position 42 - Blocked Channel Measurements

Between Plates " $\mathrm{j}$ " and " $\mathrm{j}$ " Plate " $\mathrm{n}$ "

Plate " $r$ "

Position 7.14 WRP 6.51 WRP 5.88 WRP 5.25 WRP 4.62 WRP 7.14 WRP 6.51 WRP 5.88 WRP 5.25 WRP 4.62 WRP 7.14 WRP 6.51 WRP 5.88 WRP 5.25 WRP 4.62 WRP

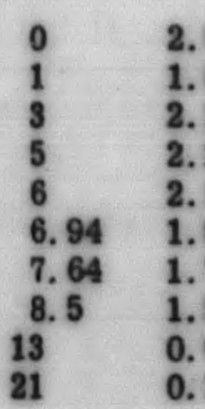

$\begin{array}{llllll}2.90 & & 2.87 & & 4.14 \\ 1.67 & & 1.03 & & 2.04 \\ 2.16 & & 1.34 & & 2.67 \\ 2.27 & 1.44 & 1.41 & 1.62 & 2.71 \\ 2.13 & & 1.36 & & 2.67 \\ 1.92 & 1.17 & 1.14 & 1.41 & 2.42 \\ 1.73 & & 1.07 & & 2.28 \\ 1.51 & & 0.95 & & 2.02 \\ 0.67 & & 0.45 & & 1.00 \\ 0.16 & & 0.12 & & 0.28\end{array}$
Blocking Material - Aluminum

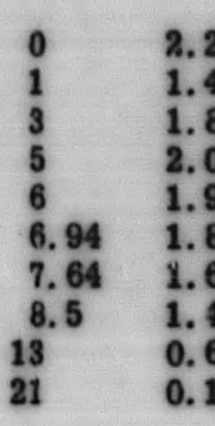

$\begin{array}{ll}2.27 & \\ 1.44 & \\ 1.87 & \\ 2.06 & 1.29 \\ 1.97 & 1.13 \\ 1.85 & 1.13 \\ 1.63 & \\ 1.47 & \\ 0.67 & \\ 0.17 & \end{array}$

2.17
0.92
1.20
1.26
1.22
1.10
1.03
0.91
0.41
0.09

1.42

3.27
1.98
2.46
2.67
2.46
2.35
2.23
1.97
0.81
0.19

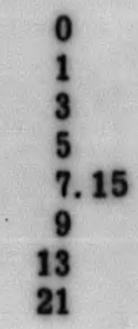

Plate "i"

3.01
1.92
2.28
2.42
2.42
2.23
2.09
1.67
0.77
0.20

Blocking Material - Staintess Stee

1. 75

1.48

2.62
1.36
1.66
1.71
1.60
1.61
1.44
1.19
0.59
0.14

4.34
2.61
3.17
3.55
3.62
3.18
3.04
2.59
1.15
0.22

$\begin{array}{ll}2.88 & \\ 2.14 & \\ 2.55 & \\ 2.73 & 1.96 \\ 2.73 & \\ 2.64 & 2.09 \\ 2.69 & \\ 1.86 & \\ 0.65 & \\ 0.14 & \end{array}$

2. 61

2. 03
2.04

2. 01

2.14

2.40
1.42

1.42
0.47
0.09

$\begin{array}{ll} & 3.96 \\ & 2.85 \\ & 3.41 \\ 2.27 & 3.63 \\ 2.45 & 3.45 \\ & 3.31 \\ & 3.28 \\ & 2.41 \\ & 0.94 \\ & 0.24\end{array}$

$\begin{array}{llll}3.57 & & 2.72 & \\ 1.90 & & \begin{array}{l}2.79 \\ 1.29\end{array} & \\ 1.78 & & 1.61 & \\ 2.26 & 1.60 & 1.66 & 1.94 \\ 2.21 & & 1.61 & 1.72 \\ 2.15 & 1.45 & 1.48 & 1.39 \\ 1.97 & & 1.39 & \\ 1.67 & & 1.12 & \\ 0.79 & & 0.56 & \\ 0.19 & & 0.14 & \end{array}$

4.05
2.55
3.24
2.87
3.33
3.27
2.98
2.59
1.17
0.28

2.96
2.24
2.72
2.69
2.63
2.92
2.56
1.90
0.66
0.15

2.54
1.58
1.90
2.05
2.04
2.23
2.40
1.25
0.45
0.10

2. 2

2.40

Blocking Material - None

$\begin{array}{lll}2.87 & & 3.81 \\ 1.32 & & 2.16 \\ 1.69 & & 3.05 \\ 1.80 & 1.99 & 3.03 \\ 1.59 & 1.76 & 2.44 \\ 1.18 & 1.33 & 1.95 \\ 0.60 & & 0.97 \\ 0.13 & & 0.26\end{array}$


$\bar{\Xi}$

\begin{tabular}{c} 
Table 3.36 \\
Relative Power Distribution Along Axial Traverses For Element in Position 42 - Blocked Channel Measurements \\
\hline SM-2 Prefliminats
\end{tabular} locking Material Stainless Stee

Retween Plate " $\mathrm{i}$ " and " $\mathrm{j}$ "

Plate " $\mathrm{n}$ "

Plate " $r$ "

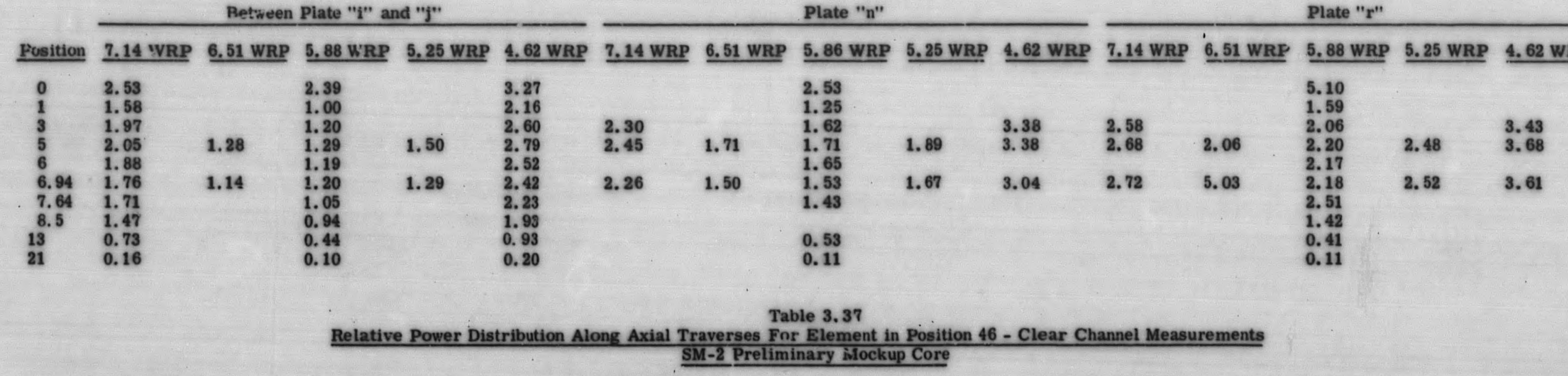

Plate "j"

Between
P1. "i" \&"j"

Plate " $n$ "

Plate " $r$ "

7.14 ERP 6.51 ERP 5.88 ERP 5.25 ERP 4.62 ERP 5.88 WRP 7.14 ERP 6.51 ERP 5.88 ERP 5.25 ERP 4.62 ERP T.14 ERP 6.51 ERP 5.88ERP 5.25ERP 4.62 ERP

$\begin{array}{ll}0 & 3.23 \\ 1 & 199 \\ 2 & \\ 3 & 2.55 \\ 4 & \\ 5 & 2.77 \\ 6 & 2.64 \\ 6.94 & 2.54 \\ 7.64 & 2.33 \\ 8.5 & 1.94 \\ 10 & 0.95 \\ 13 & 0.95 \\ 15 & \\ 20 & \\ 21 & 0.24\end{array}$

2.65

2. 26

1.71

$\begin{array}{ll}1.85 & 1.78\end{array}$

$1.62 \quad 1.65$

2. 05

3. 25

1.64

2.91
1.33

2.,88

$\begin{array}{lll}1.65 & 1.81 & 3.20 \\ & & 2.81\end{array}$

1.96

1.80

2.46

$2.50 \quad 1.81$

1.61

$2.35 \quad 1.62$

1.80

$\begin{array}{lll}3.23 & 2.68\end{array}$

2.02

3.34

$\begin{array}{lllll}1.77 & 2.05 & 3.35 & 2.28 & 2.09\end{array}$

$\begin{array}{lll}1.97 & 2.34 & 3.54\end{array}$

1.27

1.09

1.81

$\begin{array}{lll}3.00 & \text { 2. } 95 & 2.14\end{array}$

2. $39 \quad 3.51$

0.65

0.46
0.21

1.34

2.26
2.45
1.37

0.45

0.32

0.15

0.16 
Table 3. 38
Ratios of Clear Channel to Blocked Channel Relative Power Measurements for Elements in Positions 46 and 42 Blocking Material - Stainless Steel

Plate "j" and Between plates " $\mathrm{i}$ " and "j"

Plate " $n$ "

Plate "r"

7.14 ERP 6.51 ERP 5.88 ERP 5.25 ERP 4.62 ERP 7.14 ERP 6.51 ERP 5.88 ERP 5.25 ERP 4.62 ERP 7.14 ERP 6.51 ERP 5.88 ERP 5.25 ERP 4.62 ERP

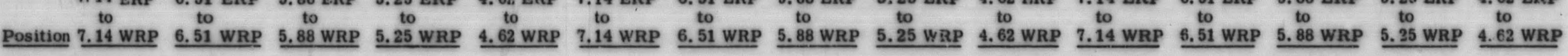

$\begin{array}{ll}0 & 1.27 \\ 1 & 1.26 \\ 3 & 1.30 \\ 5 & 1.35 \\ 6 & 1.40 \\ 6.94 & 1.45 \\ 7.64 & 1.36 \\ 8.5 & 1.32 \\ 13 & 1.31 \\ 21 & 1.50\end{array}$

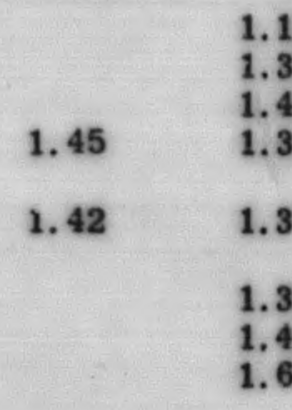

$\begin{array}{ll}1.11 & \\ 1.35 & \\ 1.42 & \\ 1.38 & 1.37 \\ 1.37 & 1.41 \\ 1.35 & \\ 1.49 & \\ 1.67 & \end{array}$

1.30

1.25

1.07
1.02
1.02

1.06

1.26 i.

1.04

1.08

1.03

1.32
1.53

1. 36

1.08

0.95

1.04

0.56

0.96

0.98

$\begin{array}{ll}0.95 & 0.97 \\ 0.96\end{array}$

$\begin{array}{llll}1.08 & 1.10 \quad 1.08 & 0.95 \\ & & 1.04\end{array}$

$0.95 \quad 0.97$

1.17
1.30 


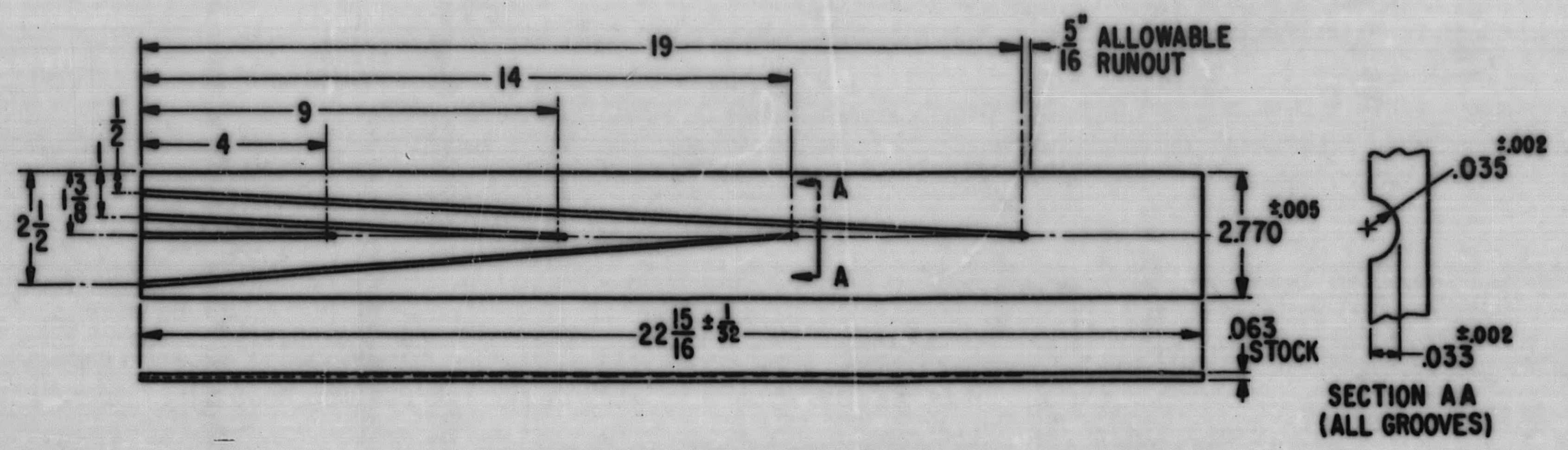

Figure 3.24 Thermocouple Plate, SM-2 Critical Facility Test

E 


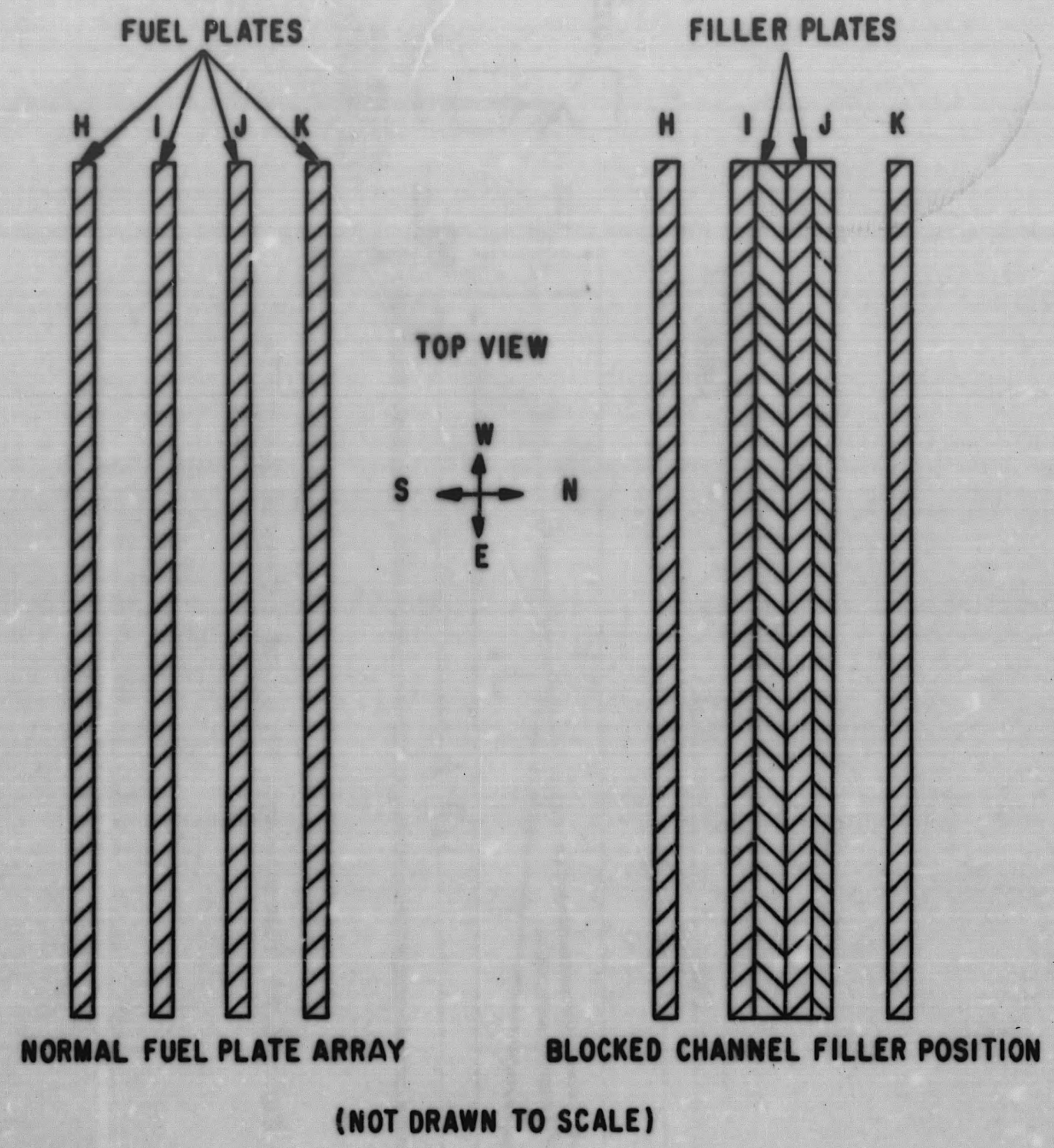

Figure 3.25 Blocked Channel Filler Position and Normal Fuel Plate Array 


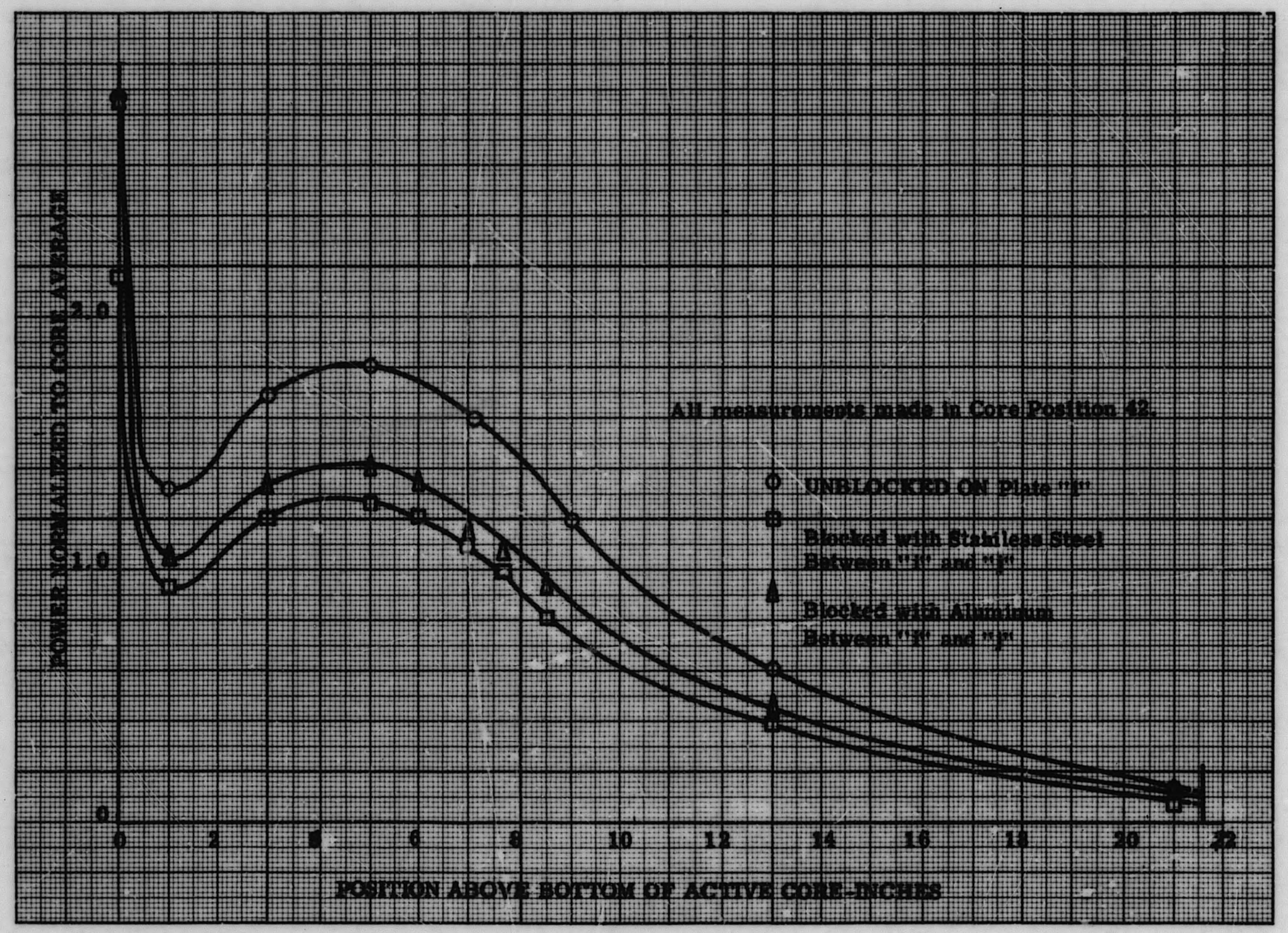

Figure 3.26 Relative Power Distri'jution Along Axial Traverse on Centerline of Fuel Plates " $\mathrm{i}$ " and " $\mathrm{j}$ " Blocked Channel Measurements Made in SM-2 Core Mockup with Water Reflector, Without Flow Divider 
E

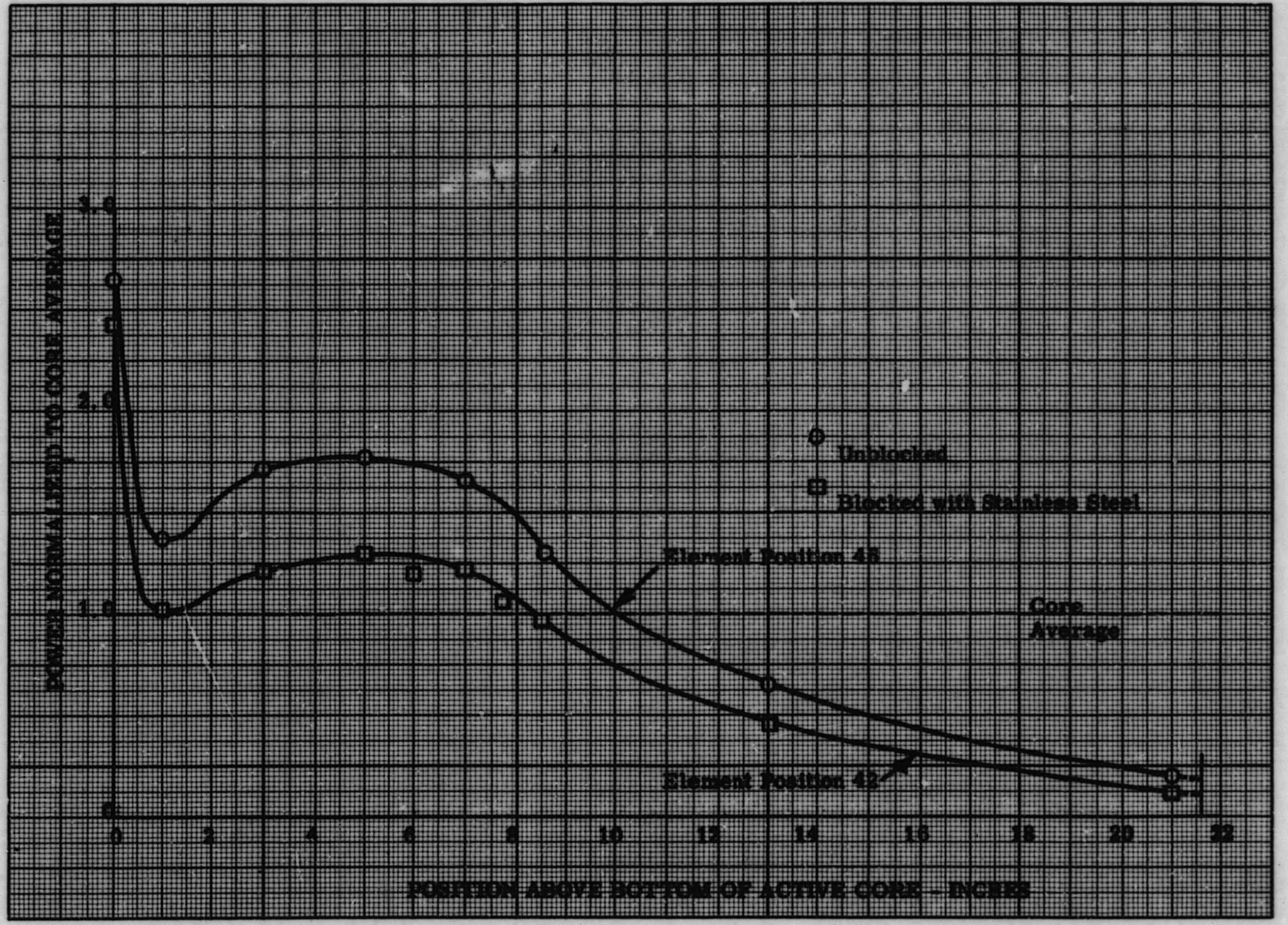

Figure 3.27 Relative Power Distribution Along Axial Traverse on Centerline Between Fuel Plates " $i$ " and " $j "$, Elements in Positions 42 and 46, Blocked Channel Measurements Made in SM-2 Core Mockup With Steel Reflector Without Flow Divider 


\section{0 MISCELLANEOUS MEASUREMENTS}

\section{1 GAMMA RAY DOSE MEASUREMENTS}

An indication of the gamma heating distribution expected in the SM-2 core and vessel was obtained by a survey using film badges as radiation dosimeters. The location of these film badges is shown in Fig. 4.1 and 4. 2 and Table 4. 1 and 4. 2. The reactor was operated for 10 minutes at a power level estimated at 10 watts and the badges removed within 30 minutes after shutdown. The integrated gamma dosage is given in Tables 4.1 and 4.2 and plotted in Fig. 4. 3, 4. 4 and 4. 5. As expected, the maximum gamma heating occurred in the steel reflector adjacent to the core with the flux dropping rapidly toward the outer ecige of the reflector.

\section{1. 1 Experimental Techniques}

The film badges were located so that symmetry would give duplication of data. Each film was encased in Mylar tape to prevent water contact, and attached in the following locktions:

1. Radially along the steel reflector midway between the top and core support plates.

2. Radially on the upper edge of elements $14,34,41,42$ and 43 just below the top plate.

3. Axially along the rod guide of control rod "C" which was kept fully withdrawn.

4. Radially in the water channels of the perforated core support plate just below elements $41,42,43,54,74$ and the reflector.

5. Other miscellaneous locations on the core support plate.

Tables 4. 1 and 4. 2 present the radiation dose rate in terms of $R / h r / w a t t$ for the run. These results are merely estimates and should be treated as such. For instance, the relationship between radiation dosage and power level could not be ascertained since absolute reactor power measurements had not been made, Hence, the estimate of 10 watt power operating level may. have a rather iarge uncertainty factor. Secondly, each of the film badges received additional radiation after reactor shutdown, which, while of lesser magnitude, would still contribute to the total reported gamma dosage. Furthermore, it should be appreciated that the film badge cannot differentiate between the types of radiation it receives the presence of other types of radiation which affect film exposure but whose 


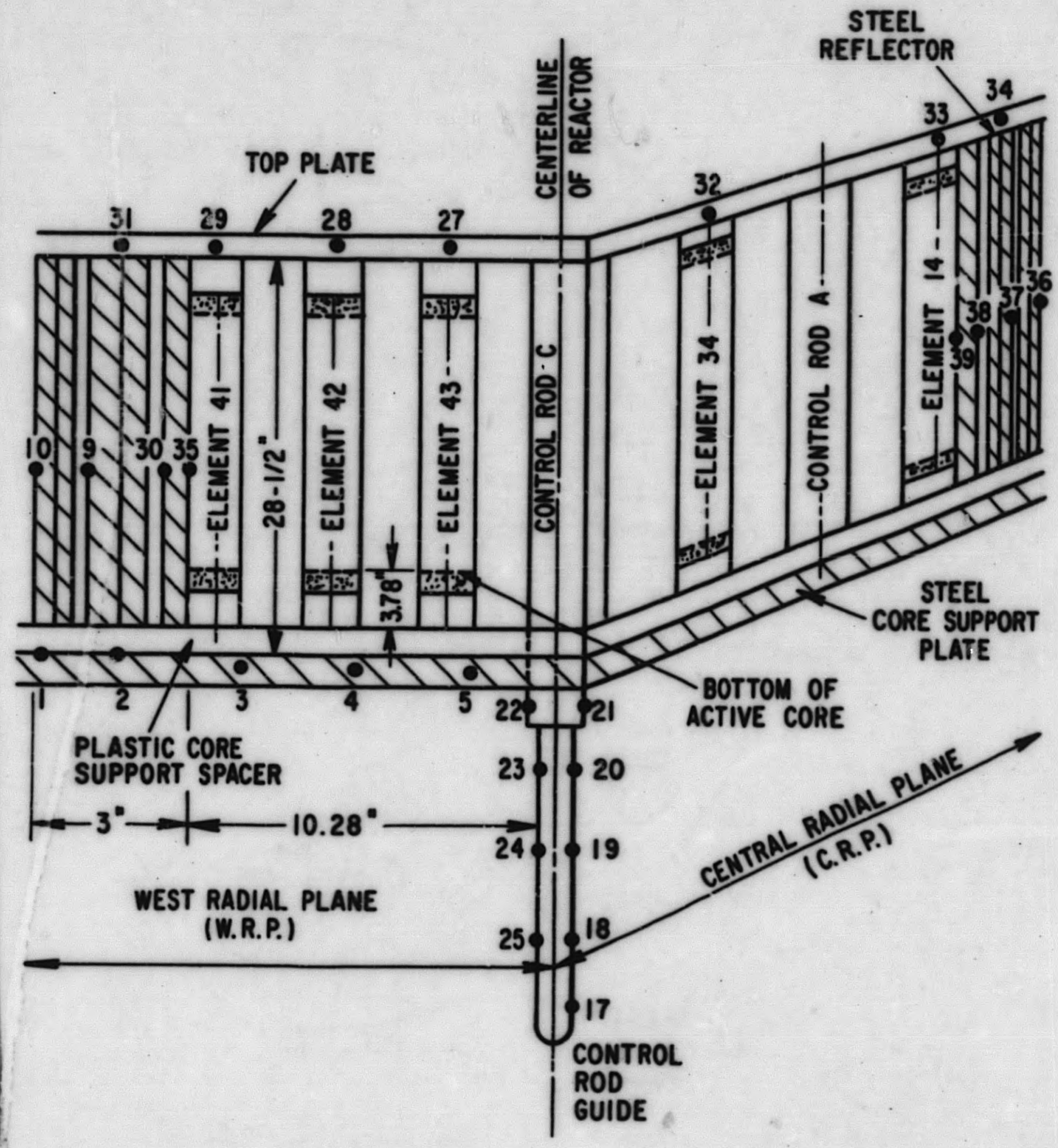

Figure 4.1 Location of Film Badges on Fuel Elements and Steel Reflector for Gamma Ray Dose Measurements 


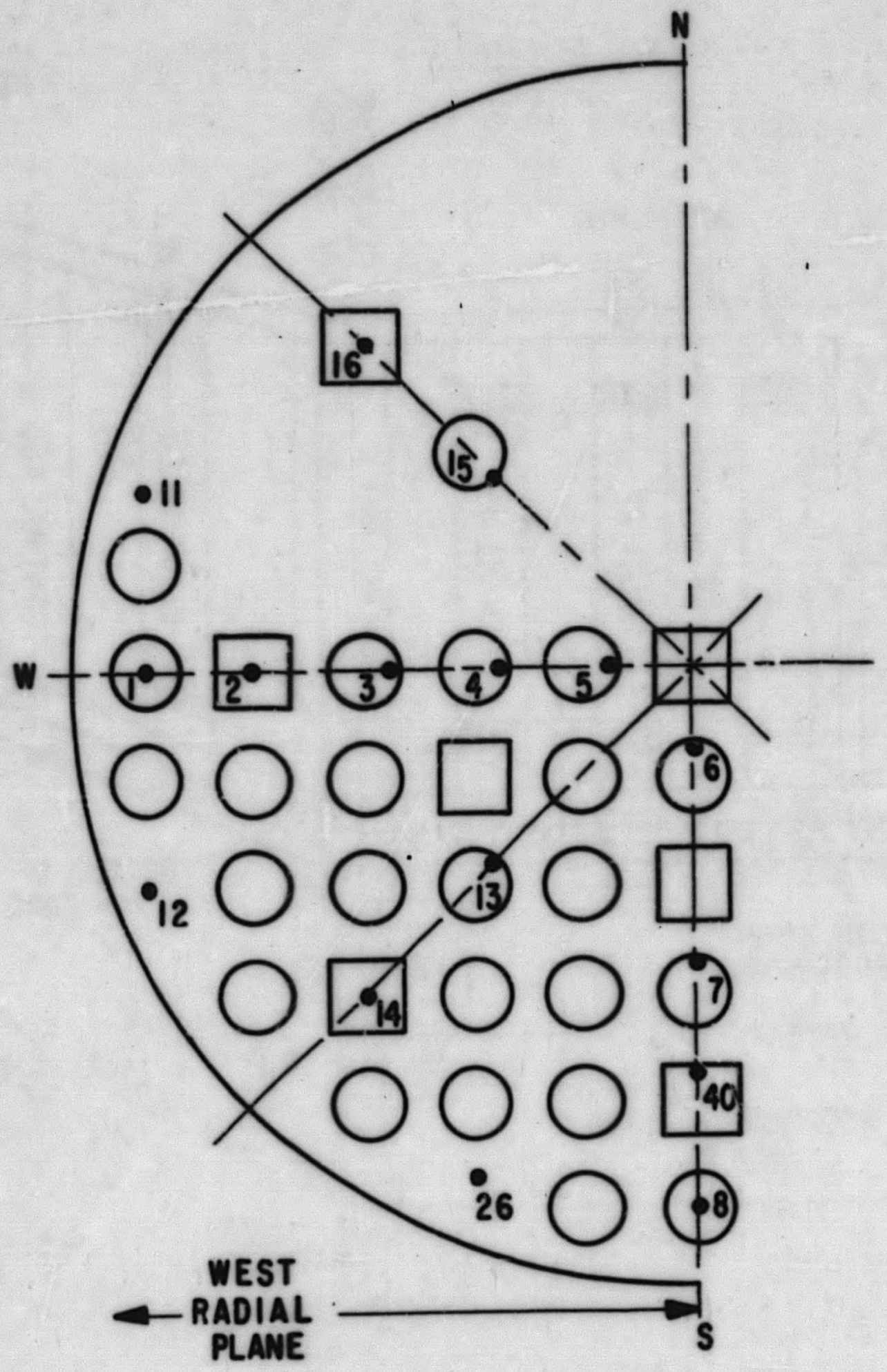

Figure 4.2 Location of Film Badges on Core Support Plate for Gamma Ray Dose Measurements 
TABLE 4.1

GAMMA RAY DOSE MEASUREMENTS AND FILM BADGE* LOCATIONS

Location Repbrted Dosage

Number Dosage, $\mathbf{R}$ R/hr/watt

$1 \quad 0.185$

0.11

0. 84

2. 3

3. 6

3. 0

3. 6

2. 4

0.51

0. 36

0. 29

2. 88

0.78

2. 76

C. 18

0. 30

1. 92

40

3.2

0.50

30

$-6.28$

$-5.53$

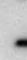

$-4.78$

$-5.53$

$-5.53$

$-5.53$

$-5.53$

$-5.53$

$-4.78$

$-6.28$

$-6.28$

$-5.53$

$-4.78$

$-5.53$
Axial Location Radial Location from from bottom of active core, Reactor Center, in. in. West North South $-4.78$ 14. 69

11. 75

7. 57

4. 63

1. 69

1. 69

7. 57

14. 69

14. 69 . 5. 88

14. 69

5. 88

4. 63

4. 63

8. 82

8. 82

4. 63

4. 63

8. 82

8. 82

5. 88

14. 69

10. 50

* Exposed at estimated 10 watt power level for 10 minutes. 
TABLE 4. 2

GAMMA RAY DOSE MEASUREMENTS AND FILM BADGE* LOCATIONS

\begin{tabular}{|c|c|c|c|c|c|c|}
\hline \multirow[b]{2}{*}{$\begin{array}{l}\text { Location } \\
\text { Number } \\
\end{array}$} & \multirow[b]{2}{*}{$\begin{array}{l}\text { Reported } \\
\text { Dosage, R } \\
\end{array}$} & \multirow[b]{2}{*}{$\begin{array}{l}\text { Dosage } \\
\mathrm{R} / \mathrm{hr} / \text { watt }\end{array}$} & \multirow{2}{*}{$\begin{array}{l}\text { Axial Location } \\
\text { from bottom of } \\
\text { active core, } \\
\text { in. } \\
\end{array}$} & \multicolumn{3}{|c|}{$\begin{array}{l}\text { Radial Location } \\
\text { from Reactor Center, in. }\end{array}$} \\
\hline & & & & West & North & South \\
\hline 9 & 4. 6 & 2. 76 & 9. 22 & 12.03 & & \\
\hline 10 & 3.2 & 1. 92 & 9. 22 & 13. 28 & & \\
\hline 17 & 0.058 & 0.035 & -26.78 & s. & & 0.63 \\
\hline 18 & 0.36 & 0. 216 & -21.28 & & & 0.63 \\
\hline 19 & 0.75 & 0.450 & -14.28 & & & 0.63 \\
\hline 20 & 1.2 & 0.72 & -10.28 & & & 0.63 \\
\hline 21 & 3.4 & 2. 04 & -7.28 & & & 1.4 \\
\hline 22 & 3.4 & 2. 04 & -7.28 & & 1.4 & \\
\hline 23 & 0.91 & 0.55 & -10.28 & : & 0.63 & \\
\hline 24 & 0.48 & 0.29 & -14.28 & & 0.63 & \\
\hline 25 & 0.30 & 0.18 & -21.28 & & 0.63 & \\
\hline 27 & 5.00 & 3. 0 & 22. 25 & 2. 94 & & \\
\hline 28 & 4.00 & 2. 4 & 22. 25 & 5. 88 & & \\
\hline 29 & 3.20 & 1. 92 & 22. 25 & 8. 81 & & re \\
\hline 30 & 8.50 & 5. 10 & 9. 22 & 10.78 & & \\
\hline 31 & 0.70 & 0.42 & 22. 25 & 11. 75 & & \\
\hline 32 & 5.50 & 3. 30 & 22. 25 & & 2. 94 & \\
\hline 33. & 3. 40 & 2. 04 & 22. 25 & & 8. 81 & \\
\hline 34 & 0.80 & 0.48 & 22. 25 & & 11. 75 & 6 \\
\hline 35 & 10.00 & 6. 00 & 9. 22 & 10.28 & & \\
\hline 36 & 3.60 & 2. 16 & 9. 22 & & 13. 28 & \\
\hline 37 & 4.80 & 2. 88 & 9.22 & & 12.03 & \\
\hline 38 & 8.50 & 5. 10 & 9.22 & & 10. 78 & \\
\hline 39 & 13. 00 & 7.80 & 9.22 & & 10. 28 & \\
\hline
\end{tabular}

* Exposed at estimated 10 watt power level for 10 minutes. 
contribution to the reported dosage cannot be distinguished from that produced solely by gamma rays. Thus, the results obtained in these measurements should be interpreted merely as an indication of the trend and order of magnitude of the gamma flux expected without attaching quantitative importance to the reported dosage values.

\section{1. 2 Experimental Results}

The experimental results have been plotted on Fig. 4. 3, 4. 4 and 4. 5 with the appropriate film badge location numbered for convenience. From the data it can be seen that the gamma dosage in the center of the reflector drops rapidly from a high of $13 \mathrm{R} / \mathrm{hr} /$ watt to a low of $2 \mathrm{R} / \mathrm{hr} /$ watt at its outer edge and that the axial measurements along the guide of control rod $\mathrm{C}$ showed the expected decrease in gamma flux as the distance from the bottom of the active core increased. The flux along the core support plate decreased from 3.6 R/hr/watt to $0.1 \mathrm{R} / \mathrm{hr} /$ watt on a center to core edge traverse. Dosage measurements made at either end of the stationary fuel plates appear to have the same gamma field, reading a maximum of $3 \mathrm{R} / \mathrm{hr} /$ watt on element No. 43 .

\section{2 SEVEN ROD BANK CALIBRATION AT SIMULATED ELEVATED TEMPERATURE AND PRESSURE}

\section{2. 1 Introduction}

Since it is not possible to operate the ALCO Critical Facility at the design operating conditions of the SM-2 reactor, it was necessary to simulate these effects in order to obtain an estimate of the characteristics of the control rod bank in this region. Operation at $2000 \mathrm{psi}$ and $510^{\circ} \mathrm{F}$ causes a loss of reactivity from operation at room conditions due to differences in moderator density; this results in a larger withdrawal of the control rod bank to achieve criticality. The experiments described below were run in order to calibrate the control rod bank in the desired SM-2 operating range with the flow divider in place. The calibration curve obtained is presented in Fig. 4. 6. The data were corrected by 1 in. dial displacement incurred due to use of a plastic core support plate required for mockup operation with flow divider.

\section{2. 2 Calibration Technique}

Operation of $2000 \mathrm{psi}$ and $510^{\circ} \mathrm{F}$ causes a change in the density of water from $62.3 \mathrm{lbs} / \mathrm{ft}^{3}$ at $70^{\circ} \mathrm{F}$ and 1 atmosphere to $48.9 \mathrm{lbs} / \mathrm{ft}^{3}$. To simulate the loss in moderator density, it was calculated that $\mathbf{4 0}$ aluminum strips were required to be placed in each stationary fuel element and 38 in each control rod fuel section to displace the proper amount of water. The resulting reactivity measurements indicated approximately a 5 in. shift in bank position. In order to obtain a complete calibration of the bank as a function of bank location, some of the fuel plates were removed and stainless steel strips of equal thickness substituted. These strips were covered with 2 layers of \#1-2 boron tape to replace the boron loading. These substitutions caused a further loss of reactivity; the effects of these additions to the mockup are given in Table 4.3. 


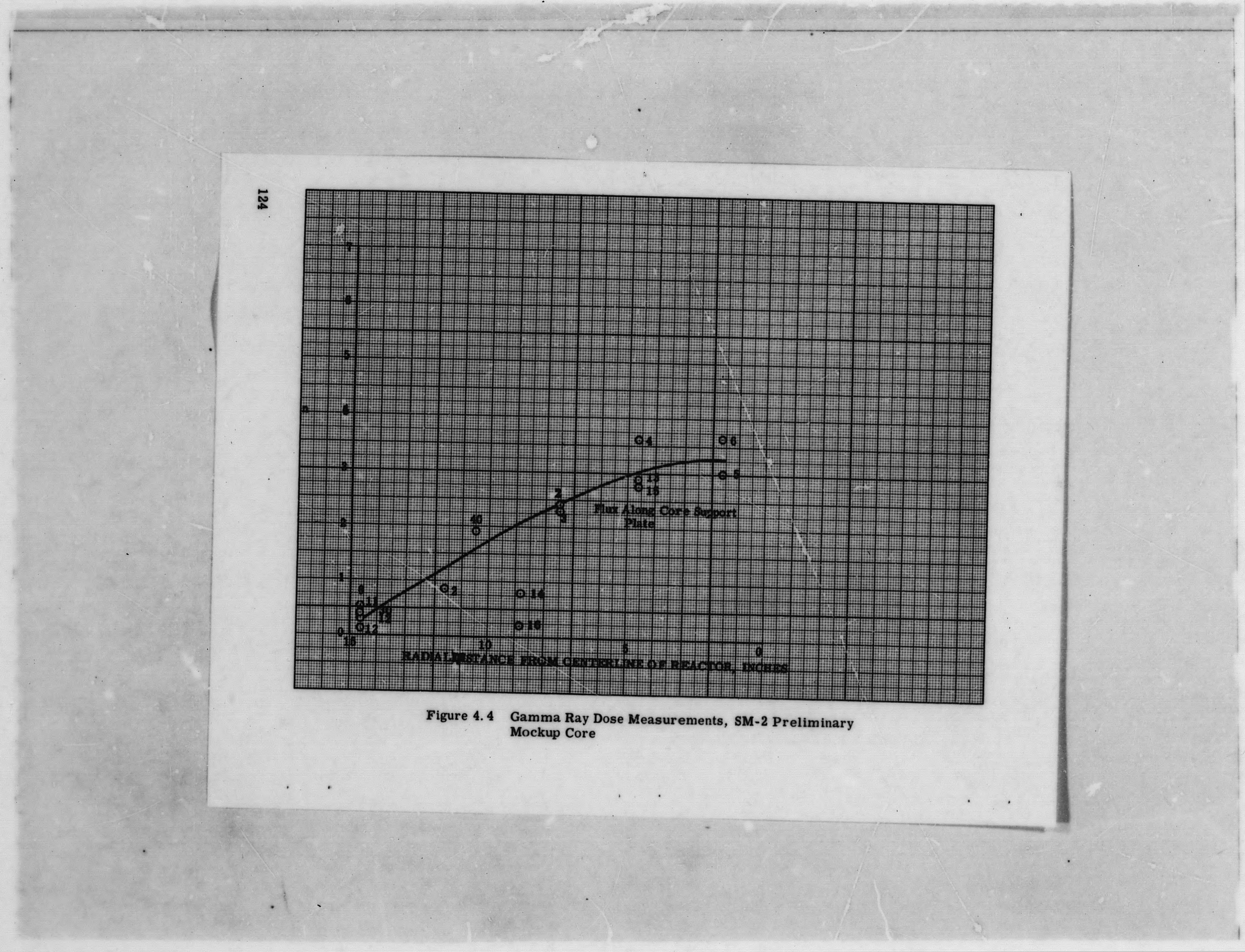




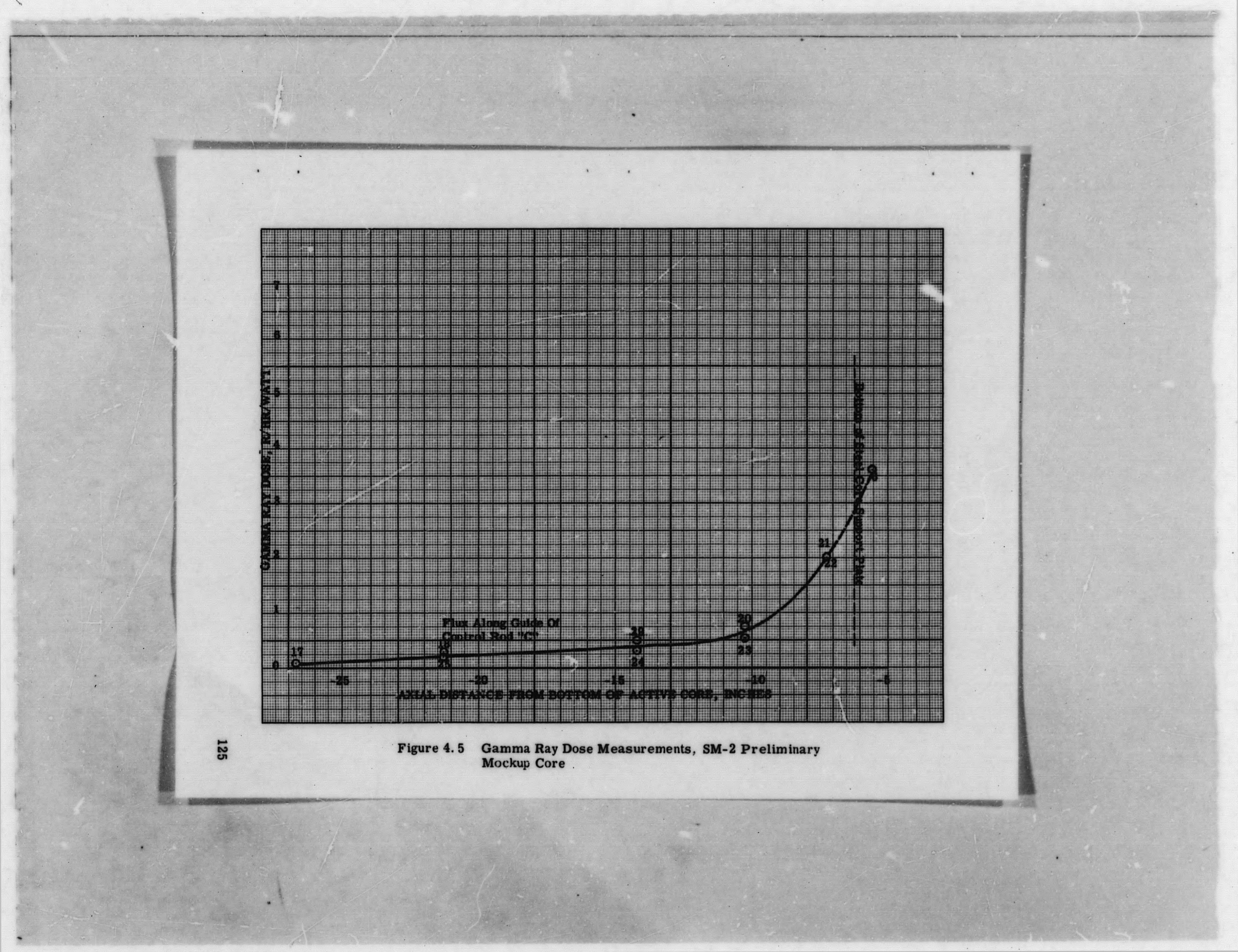




\section{TABLE 4.3}

\section{CA LIBRATION OF CONTROL ROD BANK UNDER SIMULATED OPERATING CONDITIONS \\ OF 2000 Psi and $510^{\circ} \mathrm{F}$}

\section{Simulation Technique}

(1) Initial Zero Run

(2) Addition of 40 strips of 15-mil thick aluminum to each stationary fuel element and 38 strips to each coutrol rod fuel section.
Average 7 Rod Bank Critical Position Dial Reading, Inches

\section{725}

13. 540

(3) Same as (2) but with the addition of 23 aluminum strips per reflector water gap for a total of $\mathbf{9 2}$ strips in the reflector region.

(4) Substitution of bundles of four 10-mil thick stainless steel strips in plate position $a, j$, and $r$ of elements 34,43 , 45 and 54 with appropriate boron loadings.

(5) Same as (4) above except that stainless steel bundles were also substituted in plates $e$ and $n$ in addition.

(6) Same as (4) above except that stainless steel bundles were also substituted in elements $33,35,53$ and 55 in addition.

(7) Same as (6) above except that stainless steel bundles were also substituted in elements 23, 25, 63 and 65 in addition.

(8) Same as (7) above except that stainless steel bundles were also substituted in element 46 in addition.

(9) Same as (8) above except that stainless steel bundles were also substituted in element 42 in addition. 


\section{2. 3 Simulation of Operating Conditions}

The relationship of moderator temperatures vs density is presented in Fig. 4. 7. The number of aluminum strips required to displace an amount of water equal to the moderation loss incurred at the operating conditions due to density difference was calculated from the following:

$$
\mathrm{N}=\left(\frac{\rho_{0}-\rho}{\rho_{0}}\right) \quad\left(\frac{A_{1}}{A_{2}}\right) F
$$

where $\mathbf{N}=$ No. of aluminum strips required

$$
\begin{aligned}
& \rho_{0}=\text { density at } 70^{\circ} \mathbf{F} \text { and } 1 \text { atmosphere } \\
& \rho=\text { density at the desired conditions } \\
& \mathbf{A}_{1}=\text { Cross-sectional area of fuel cell } \\
& \mathbf{A}_{2}=\text { Cross-sectional area of aluminum strip } \\
& \mathbf{F}=\text { Fraction of fuel cell cross section filled with water. }
\end{aligned}
$$

Using data presented in APAE No. 54 and Fig. 4. 7, calculations were performed to relate the number of aluminum strips to the water temperature as shown in Fig. 4. 8.

To illustrate the calculation at $510^{\circ} \mathrm{F}$, the number of strips " $N$ " required for a stationary element:

$$
\begin{aligned}
\frac{\rho_{0}-\rho}{\rho_{0}} & =\frac{62.3-48.9}{62.3}=0.215 \\
A_{1} & =(2.9375 \mathrm{in})^{2}=8.629 \mathrm{in}^{2} \\
A_{2} & =(0.0154)(2.266)=0.0349 \mathrm{in}^{2} \\
\mathrm{~F} & =\frac{A_{1}-(18 \times \text { plate area }+2 \times \text { side plate area })}{A_{1}} \\
& =\frac{8.629-(18 \times 2.77 \times 0.0408+2 \times 2.863 \times 0.0327)}{8.629} \\
& =0.742=(0.215)(8.629)(0.742)=39.4 \text { or } 40 \text { strips }
\end{aligned}
$$




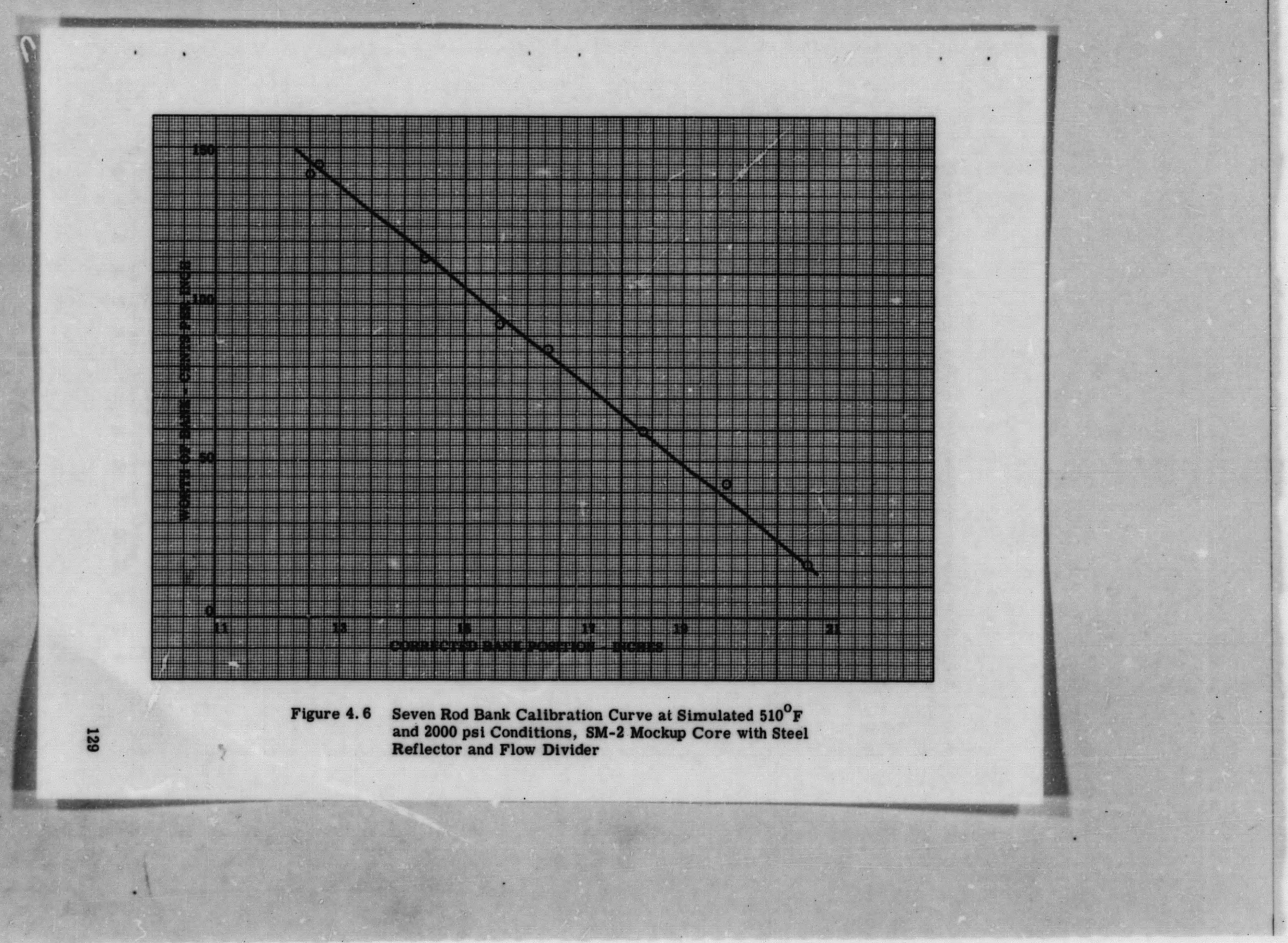




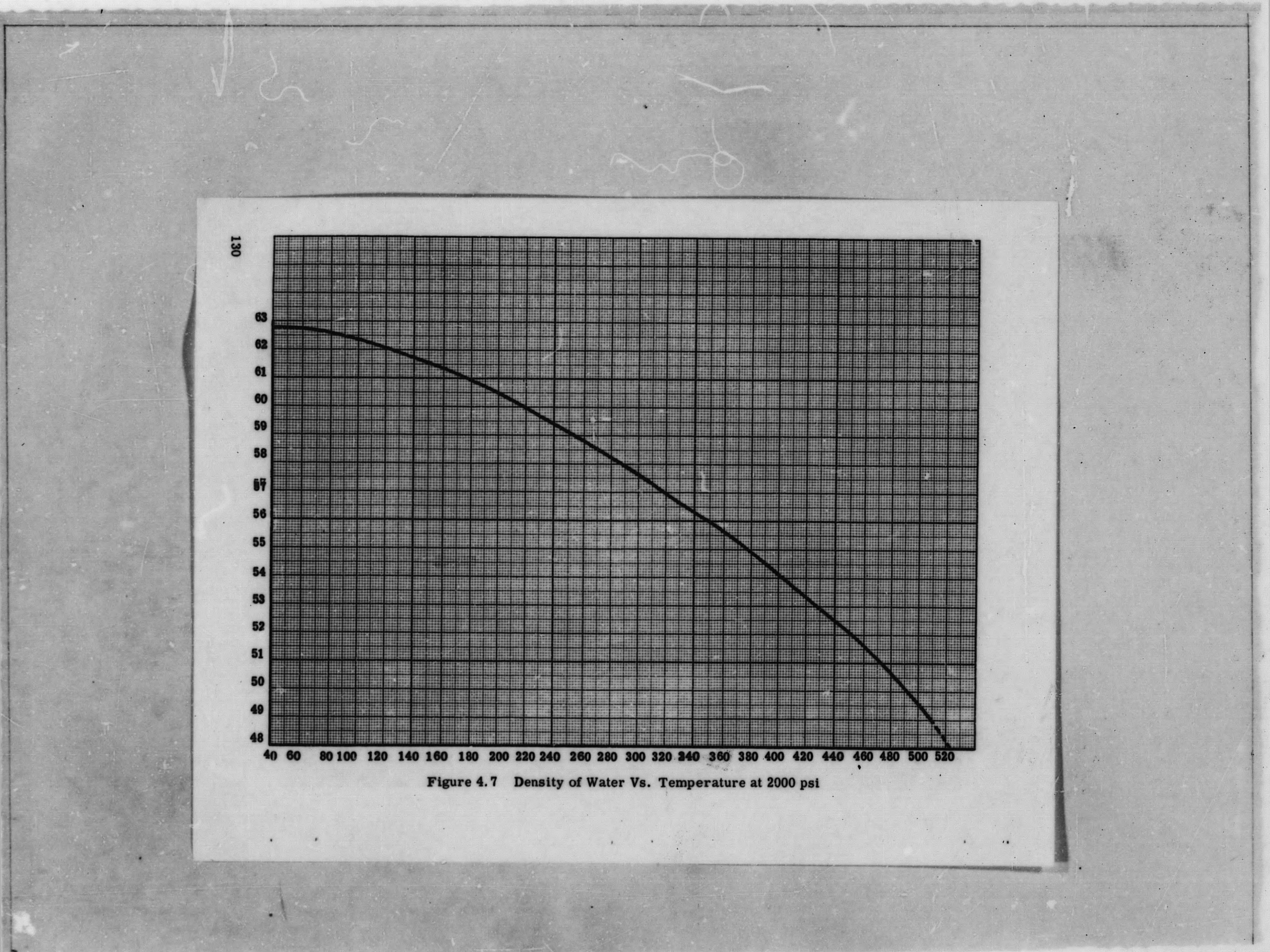




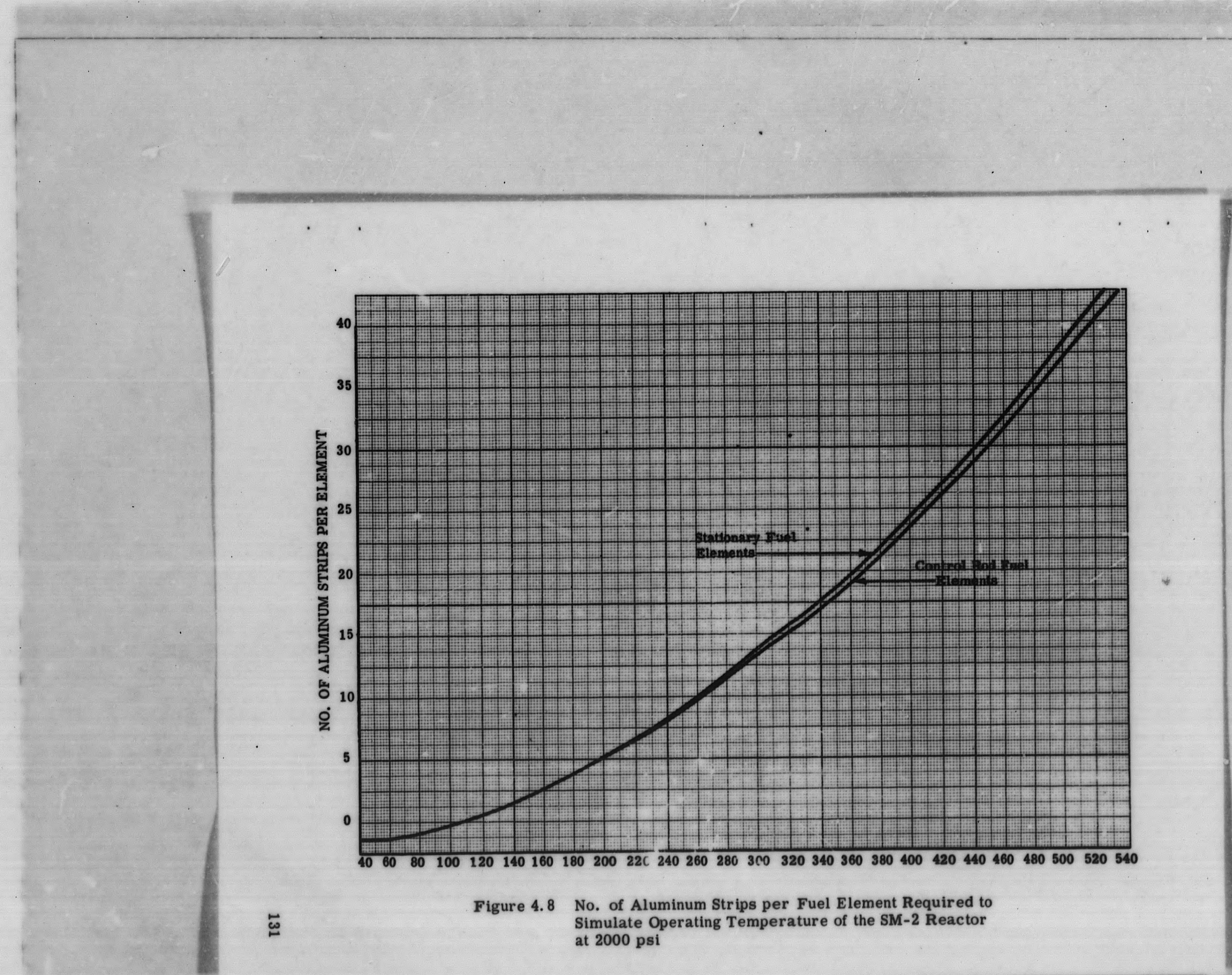




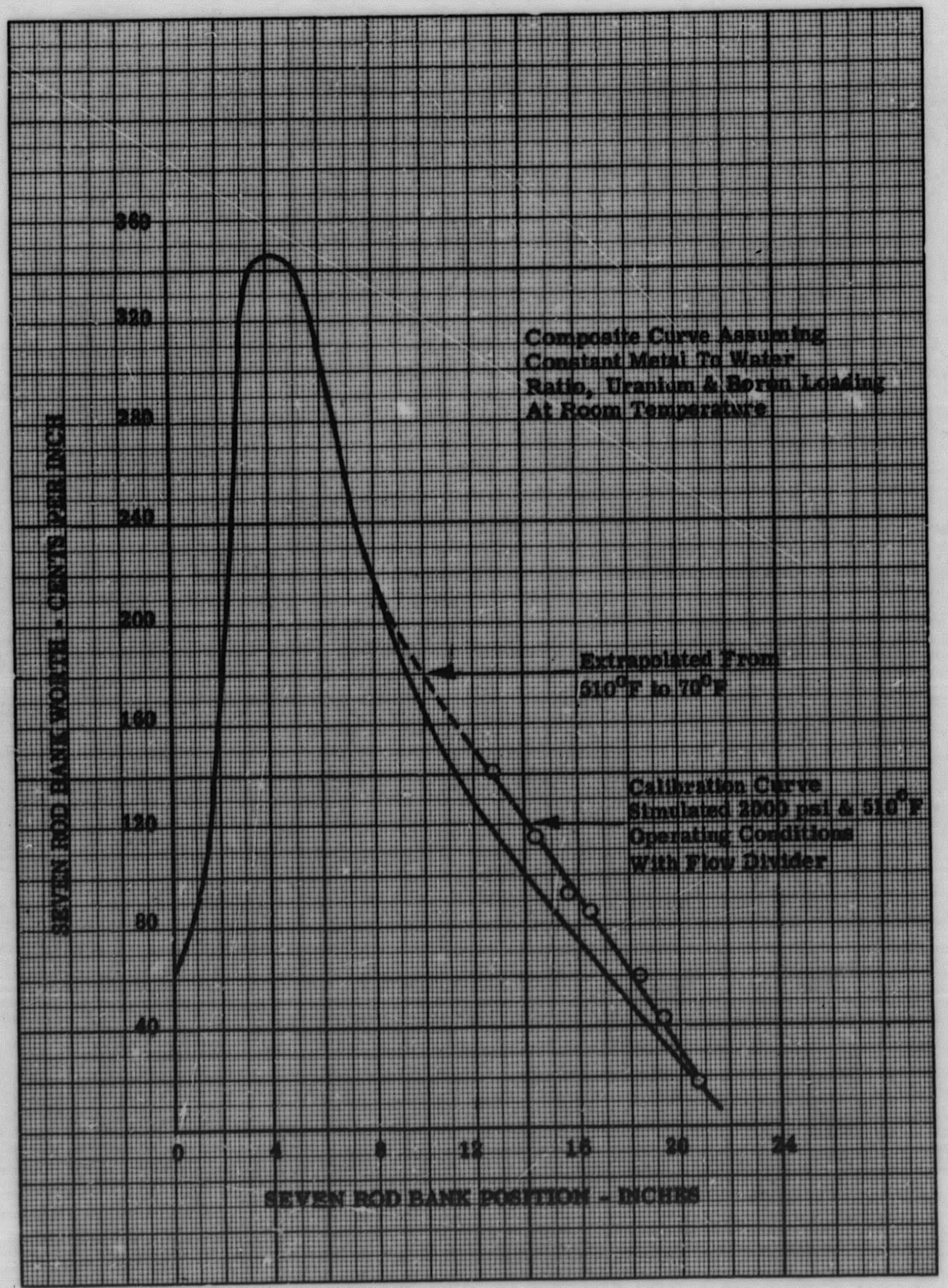

Figure 4.9 Composite Seven Rod Bank Calibration Showing Calibration at 2000 psi and $510^{\circ} \mathrm{F}$ 


\section{2. 4 Reactivity Change Due to Operation at $510^{\circ} \mathrm{F}$ and $2000 \mathrm{Psi}$}

The dashed portion of the seven rod bank position curve in Fig. 4. 9 represents the bank worth from $70^{\circ} \mathrm{F}$ to $510^{\circ} \mathrm{F}$, extrapolated to slope similarly to Fig. 4. 3 in APAE No. 54. (1) Although no measurements were taken in this region, integration by Simpson's rule produced an average bank worth of 162 cents per inch at 11.1 in. Thus, the determined $\Delta \mathrm{K}_{\mathrm{E}}$ due to increasing the core temperature is calculated from Table 4.3 as:

$$
\Delta \mathrm{K}_{\mathrm{E}}=162(8.725-13.472)=-769 \text { cents }
$$

\section{3 STUCK ROD MEASUREMENTS}

Stuck rod measurements were made using the open seven control rod array SM-2 final mockup core, utilizing a 2.5-in. laminated stainless steel reflector, and a 0.125 -in. stainless steel flow divider as shown in Fig. 1.2 and 1. 7. Table 4. 4 presents the critical control rod configurations and rod worth for various cases tested. Rods omitted in table were fully inserted and the reactor was brought critical on the critical $\operatorname{rod}(s)$ indicated for each case.

TABLE 4.4

\section{CRITICAL ROD CONFIGURATIONS}

\begin{tabular}{|c|c|c|c|c|}
\hline Case & $\begin{array}{l}\text { Rod (s) Fully } \\
\text { Withdrawn }\end{array}$ & $\begin{array}{l}\text { Critical } \\
\text { Rod(s) } \\
\end{array}$ & $\begin{array}{l}\text { Critical } \\
\text { Position(in.) }\end{array}$ & $\begin{array}{c}\text { Worth } \\
\text { cents/in. } \\
\end{array}$ \\
\hline 1 & C & A, D & 15. 616 & $42.4 @ 15.809$ in. \\
\hline 2 & C & $\mathbf{A}, \mathbf{F}$ & 13. 443 & $68.2 @ 13.587$ in. \\
\hline 3 & C & $A, G$ & 17. 282 & 30.0 @ 17.504 in. \\
\hline 4 & C & E, F & 14. 778 & 55.5 @ 14.964 in. \\
\hline 5 & C & $\mathbf{B}, \mathbf{D}, \mathbf{F}$ & 12. 481 & 75.9 @ 12, 609 in. \\
\hline 6 & A, D & C & 14.891 & $37.4 @ 15.155$ in. \\
\hline 7 & $\mathbf{A}, \mathbf{E}$ & $\mathbf{F}$ & 18. 482 & $11.9 @ 19.319$ in. \\
\hline 8 & $\mathbf{A}, \mathbf{D}, \mathbf{E}$ & B & 13. 704 & $19.1 @ 14.087$ in. \\
\hline 9 & $\mathbf{B}, \mathbf{C}, \mathbf{E}$ & D & 4. 959 & 32.7 @. 5.263 in. \\
\hline 10 & $\mathbf{B}, \mathbf{D}, \mathbf{E}$ & $\mathbf{F}$ & 12. 440 & $25.9 @ 12.781$ in. \\
\hline 11 & $\mathbf{B}, \mathbf{E}, \mathbf{F}, \mathbf{G}$ & C & 1.088 & $18.8 @ 1.775$ in. \\
\hline
\end{tabular}


The critical rod configurations reported above are much different from those in APA E No. 54(1) because of increase in B-10 loading and addition of flow divider and reflector. The following rod combinations were found to be subcritical when fully withdrawn: any two rods; three rod arrays ADE, BCE, BCF, BDE, EFG; and four rod array, BEFG. 


\section{REFERENCES}

1. Noaks, J. W., et al, "SM-2 Critical Experiments - CE-1," APA E No. 54, November 30, 1959.

2. Noaks, J. W., "The Alco Products, Inc., Criticality Facility - Description and Operation," APAE No. 36, July 16, 1958.

3. Noaks, J. W., "Hazards Summary Report for SM-2 Critical Experiments," APAE No. 36 Supplement 1, January, 1959.

4. Meem, J. L., "Hazards Summary Report on the Zero Power Experiments for the Army Package Power Reactor," APAE No. 5, January 27, 1956.

5. McCool, W. J. , et al, "Description of Fission Foil Counting and Data Processing Techniques Employed at Alco Criticality Facility," AP Note 246, April 22, 1960.

6. Hoover, H. L. , Project Engineer, "SM-2 Reactor Core and Vessel Review Report, December 15, 1959 to March 18, 1960, " APA E Memo No. 250, March 30, 1960. 


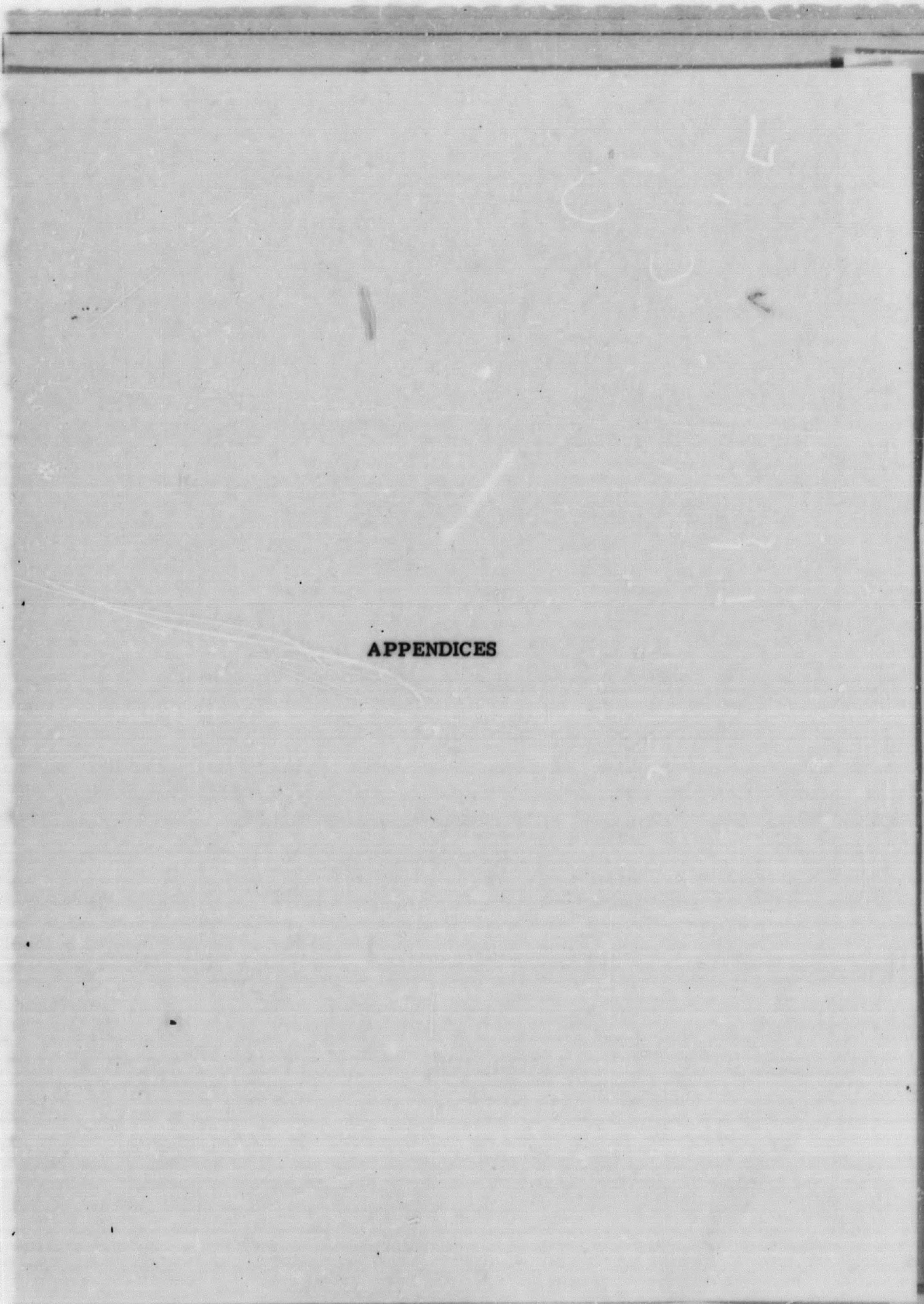




\section{APPENDIX A}

\section{CALCULATION PROCEDURES USED TO DETERMINE B-10 LOADINGS}

\section{A. 1 CALIBRATION OF BORON STANDARDS}

The repositioning of control rod $\mathbf{E}$ with the insertion of a standard sample in place of a "blank" establishes a method of relating boron loading to core reactivity change. The following presents a typical calculation used to calibrate standard samples in terms of reactivity.

Reactivity, $f=\left[1 / 2\left(W_{1}+W_{2}\right)\right]\left(P_{1}-P_{2}\right)$

where $\quad P_{1}=$ Position of control rod $\mathbf{E}$ with standard No. 1 placed in plate $i$ of element No. 22, i. e. , measuring position

$P_{2}=$ Position of control rod $\mathbf{E}$ with blank standard placed in plate $i$ of element No. 22 i. e., zero position.

$W_{1}=$ Worth of the $\operatorname{rod} E$ at $P_{1}$, in $\mathrm{c} /$ in.

$W_{2}=$ Worth of $\operatorname{rod} E$ at $P_{2}$ in $\varphi /$ in.

In the following computations several Rod $\mathbf{E}$ calibration curves were ssed because of change in the bank position for the different measurements. A typical curve is shown in Fig. A. 1 which represents a "least squares" average taken from data points obtained by period measurements. Figure A. 3 was used in period computations.

From Reactor Log Data Book, for runs No. 147 and 148:

$$
\begin{aligned}
& \text { B-10 Content of Tape } \\
& \text { Rod E Position } \\
& \mathrm{mg} / \mathrm{cm}^{2} \\
& \text { Rod E Worth } \\
& P_{1}=13.395 \text { in. } \\
& \text { 0. } 186 \\
& W_{1}=24.14 \\
& P_{2}=13.008 \text { in. } \\
& 0 \\
& W_{2}=25.47 \\
& \text { B-10 Worth }=[1 / 2(24.14+25.47)](13.395-13.008) \\
& =(24.81)(0.387)=9.60 \mathrm{f}
\end{aligned}
$$

Repeating these measurements for the other standard samples, B-10 worth vs. B-10 loading is plotted in Fig. A-2. 


\section{A. 2 INT ERCALIBRATION OF TAPES}

The B-10 loading of tape 2-1 \#6 (Ref. Table 2. 1), substituted in plate $i$ of element No. 22, for example, was similarly obtained from equation (1) and Fig. A-2.

From the reactor log book, runs No. 149 and 150:

\section{Rod E Position}

$P_{1}=13.146$

$P_{2}=12.994$

\section{Tape}

Tape 2-1 \#5

Blank Tape

\section{Rod E Worth}

$W_{1}=24.99$

$W_{2}=25.52$

\section{$\therefore$ B-10 Worth $=3.847$ \&}

From Fig. A-2 a core reactivity change of 3.847 \& under these test conditions corresponds to a boron loading of $0.0717 \mathrm{mg} \mathrm{B-10} / \mathrm{cm}^{2}$. In this fashion, data for the other intercalibrated tapes was calculated which is given in Table 2. 1.

\section{A. 3 INTERCALIBRATION OF SM-2 MOCKUP FUEL PLATES}

The substitution of fuel plate 139-S-3 in plate $i$ of element 22, with and without intercalibrated tape 1-2 \#3 resulted in the following:

Runs No. 166, 167

\section{Rod E Position}

$P_{1}=11.201$

$P_{2}=10.861$

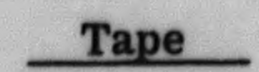

With Tape 1-2 \#3

No Boron on plate

\section{Rod E Worth}

$w_{1}=31.66$

$W_{2}=32.82$

$\therefore$ Reactivity by equation $(1)=10.962$ \&

B-10 Worth of tape on fuel plate, $\mathrm{C} / \mathrm{gm}=\frac{\mathrm{R}}{\mathrm{AG}}$

$R=$ reactivity, cents from equation (1)

$\mathbf{A}=$ area of boron tape applied, $\mathrm{cm}^{2}$

$\mathrm{G}=$ boron loading for tape, $\mathrm{mg} / \mathrm{cm}^{2}$

B-10 Worth $=10.962 /(348.4)(0.1590)=197.9 \mathrm{c} / \mathrm{gm}$

A-2 
A similar calculation for the addition of tape 2-1 \#12 produced a boron worth of $136.4 \mathrm{c} / \mathrm{gm}$. The total loading on plate $139 \mathrm{~S}-3$ is $55.4+26.3=81.7$ mg.

The substitution of fuel plate 156S-2 in place of reference plate 139S-3 (containing tapes 1-2 \#3 and 2-1 \#12) produced the following:

\section{Runs No, 168,169}

\section{Rod E Position}

$P_{2}=11.326$

$\mathbf{P}_{1}-11.315$
Plate No.

156s-2

139S-3

\section{Rod E Worth}

$w_{1}=31.23$

$W_{2}=31.27$

$\therefore$ Reactivity from equation $(1)=-0.344 \mathrm{C}$

The B-10 difference between plates $139 \mathrm{~S}-3$ and $156 \mathrm{~S}-2$ is found by:

B-10 Mass Difference $-0.344 /-136.4=+0.0025 \mathrm{gm}$

$\therefore$ Total loading on plate $156 \mathrm{~S}-2$ is then $=0.0817+0.0025=0.0842 \mathrm{gm}$.

The results of similar calculations for the other fuel plates of element 22 is given in Table 2. 2.

\section{A. 4 INT ERCALIBRATION OF ELEMENTS}

A similar calculation was performed to obta in the boron loadings of other elements. Instead of using $136.4 \mathrm{G} / \mathrm{gm}$, which is the boron worth of a single tape on a fuel plate in the center of an unloaded fuel element as described in paragraph 2. 2. 2. 4, the value of $56.62 \mathrm{c} / \mathrm{gm}$ was determined by the addition of 5 calibrated tapes on element No. 22 as the worth of uniformly distributed boron in a fully assembled fuel element. For element 47 , for example,

Reactivity $=\left[1 / 2\left(W_{1}+W_{2}\right)\right]\left(P_{1}-P_{2}\right)=(30.06(0.109)=3.28 \mathrm{f}$

Additional boron on element $\mathbf{4 7}$ over that on element 22:

Weight Diff. $=3.28 \mathrm{c} / 56.62 \mathrm{f} / \mathrm{gm}=+0.0579 \mathrm{gm}$

Total loading of element $47=1.4905 \mathrm{gm}+0.0579 \mathrm{gm}=1.5484 \mathrm{gm}$. Results for other elements are given in Table 2. 3. 
A. 5 B-10 WORTH CALCULATION OF ASSEMBLED MOCKUP ELEMENT

Runs No. 195, 199, 200

Rod E Position

$P_{1}=10.492 \quad$ Element 22 with 5 Tapes

Rod E Worth

$P_{2}=10.284 \quad$ Element 22 without these
5 Tapes

$\mathrm{w}_{1}=35.61$

$\mathrm{w}_{2}=36.35$

total loading of 5 tapes $=0.1321 \mathrm{gm} \mathrm{B}-10$

Reactivity from equation $(1)=7.48 \mathrm{c}$

$\therefore \mathrm{B}-10$ worth of tapes $=7.48 \mathrm{c} / 0.1321 \mathrm{gm}=56.62 \mathrm{c} / \mathrm{gm}$

A. 6 COMPARISON OF BMI REFERENCE AND MOCKUP ELEMENTS

Runs No. 195, 196, 199

Rod E Position

$P_{1}=10.701$

$P_{2}=10.284$
Rod E Worth

BMI Element

Element 22 $\mathrm{w}_{1}=34.92$

$\mathrm{w}_{2}=36.35$

Reactivity, from equation $(1)=14.86$ ६

$\therefore$ B-10 Loading of BMI Element $=1.4905+\frac{14.86 \mathrm{f}}{56.62 \mathrm{c} / \mathrm{gm}}=1.753 \mathrm{gm}$ 


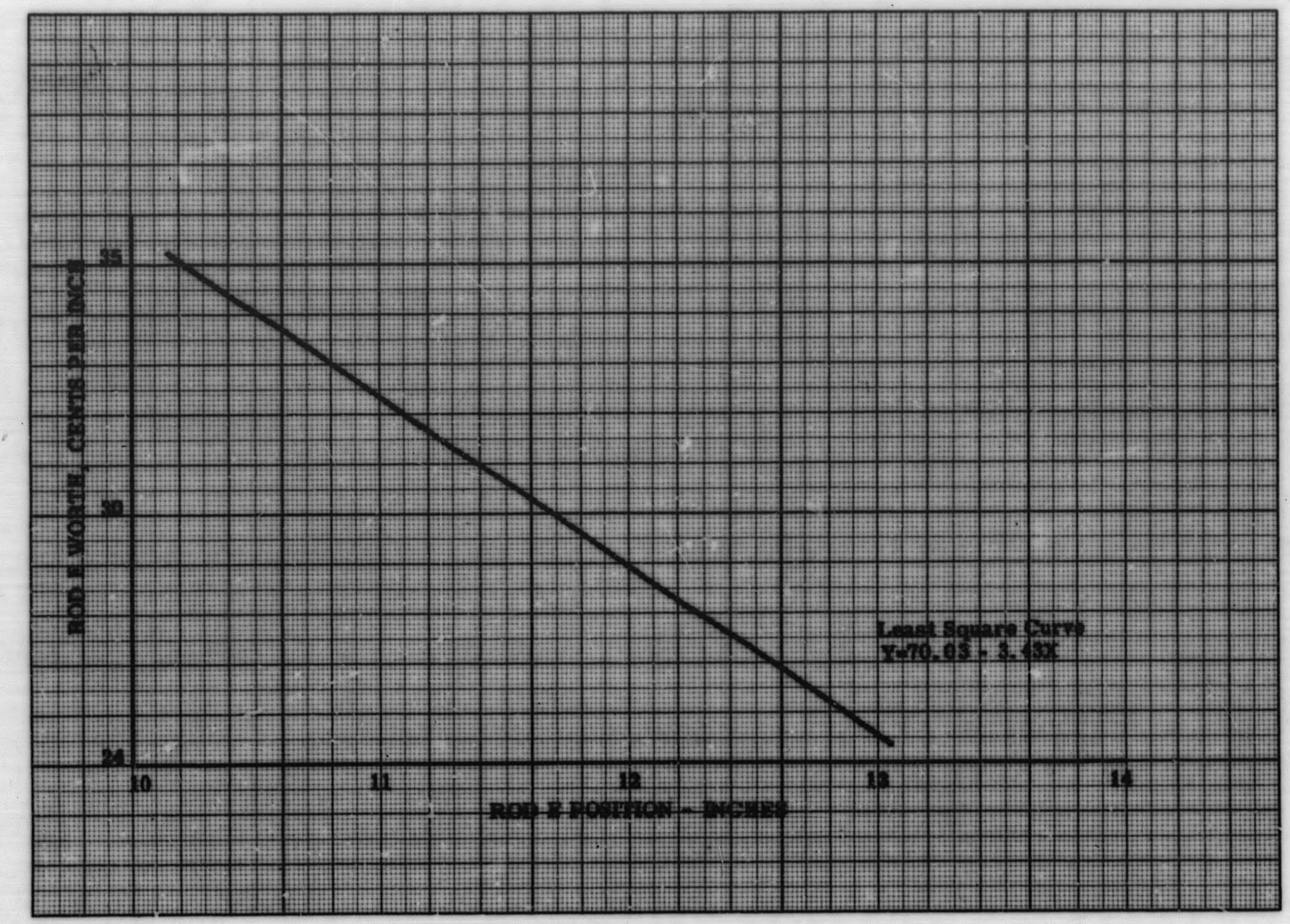

Figure A. 1 Control Rod E Calibration Curve 


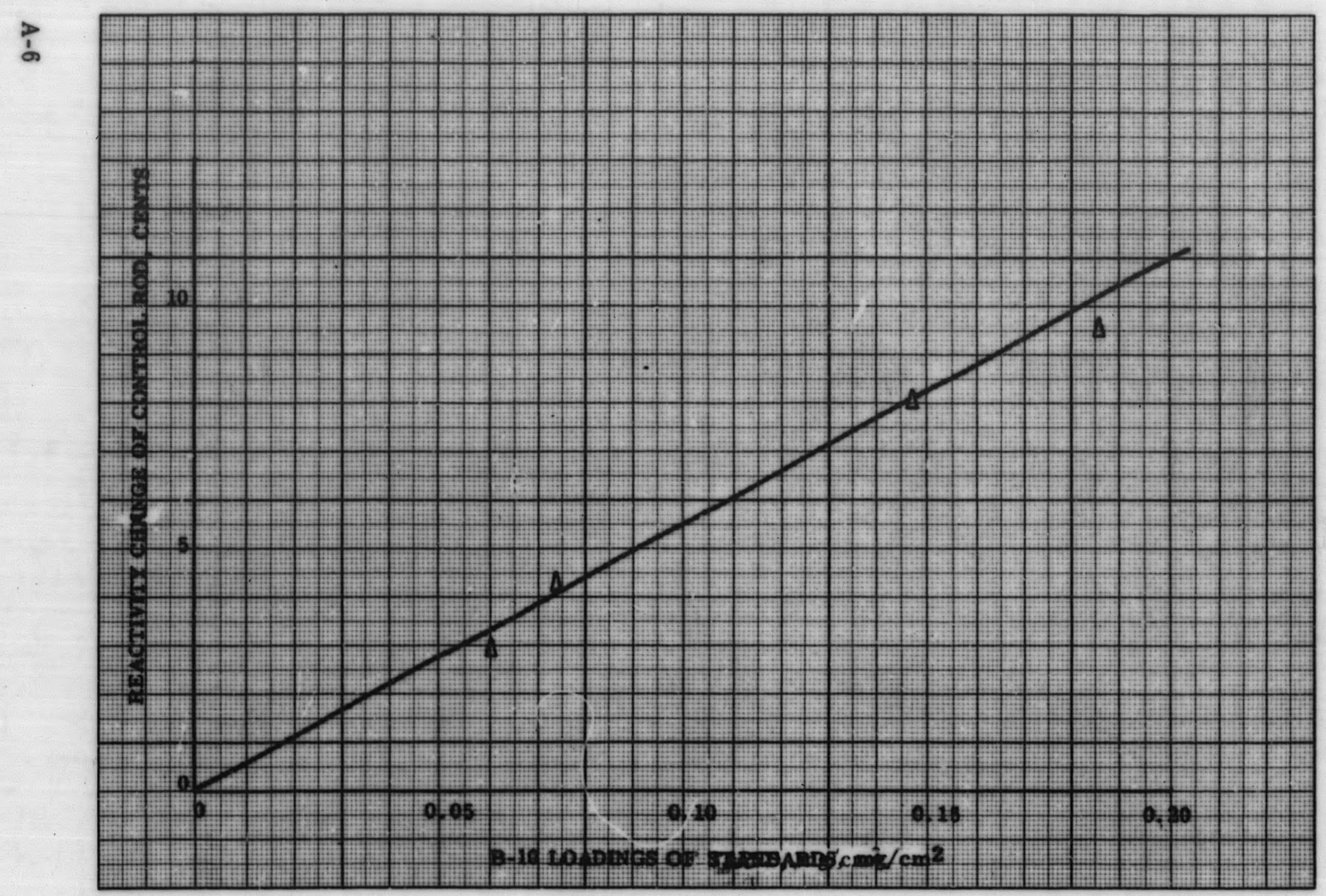

Figure A. 2 B-10 Worth of Stendards in Element Position

22 Plate " $\mathrm{i}$ " 


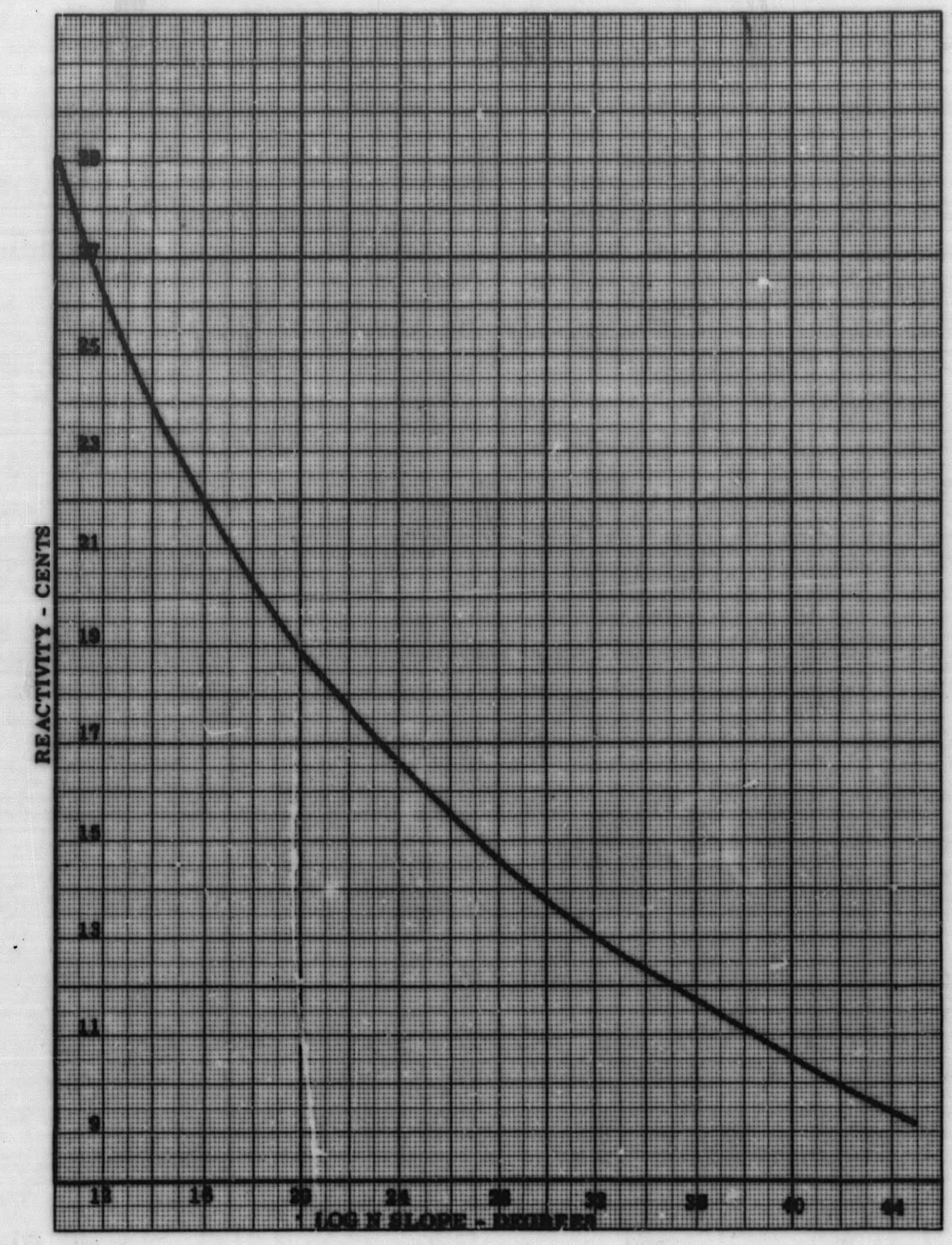

Figure A. 3 Log N Slope vs. Reactivity 


\section{APPENDLX B \\ TYPICAL CALCULATION PROCEDURE FOR OBTAINING THE CORE AVERAGE}

\section{B. 1 EXPERIMENTA L DATA OBTAINED USING PRELIMINARY MOCKUP AS AN EXAMPLE}

The relative foil activation data for element 12 , plate a is typical for these runs. Table B-1 below presents the relative flux data in raw form; these have been normalized by the procedure outlined below to form part of Table 3.1.

TABLE B. 1

EXPERIMENTAL FOIL ACTIVATION DATA FOR ELEMENT 12

\section{Axial}

Foil Location above bottom of active core, inches
0
0. 656
0.954
1. 111
1
0. 436
0.430
0.774
3
0. 559
0. 616
0. 574
0. 530
0.965

\section{5}
6. 94
0. 593
0. 556
0. 536
8. 50
0. 328
13. 0
17. 0
21. 0
0. 0863
0. 640
0. 684
1. 089
$0.600 \quad 0.673$
1. 011
0. 530
0. 929
0. 300
0. 515

* The relative power at a specific test point is established by the ratio of the induced activities of test foil to that of the reference foil (paragraph 3. 2. 1). 


\section{B. 2 CA LCULATION OF A VERAGE POWER ACROSS PLATE "a" IN RADIAL DIRECTION USING SIMPSON'S RULE:}

For axial positions 0, 1, 3, 8. 5, 13, and 21, the 3-point Simpson's rule was employed. ployed.

For axial positions 5 and 6.94, the 5-point Simpson's rule was em-

a. Using 3-point Simpson's rule of axial position 0 as a typical example of its application:

$$
A=1 / 3 h\left[y_{0}+y_{2}+4 y_{1}\right]
$$

where

$$
\begin{aligned}
y_{0} & =0.656, y_{2}=1.111, y_{1}=0.954 \\
1 / 3 h & =1 / 3\left(\frac{7.13 W R P-5.88 W R P}{7.13 W R P-4.63 W R P}\right)=1 / 3\left(\frac{1.25}{2.5}\right)=0.1667 \\
\therefore A & =0.931
\end{aligned}
$$

b. Using 5-point. Simpson' $\varepsilon$ rule at 5 -in. axial position as a typical example of its application:

$$
A=1 / 3 h\left[y_{0}+y_{4}+4\left(y_{1}+y_{3}\right)+2 y_{2}\right]
$$

where

$$
\begin{aligned}
y_{0} & =0.616, y_{4}=1.089, y_{1}=0.574, y_{3}=0.684, y_{2}=0.640 \\
1 / 3 h & \left.=1 / 3\left|\frac{7.13 W R P-6.51}{7.13 W R P} \frac{W R P}{W R P}\right|=1 / 3 \mid \frac{0.62}{2.50}\right)=0.0833 \\
\therefore A & =0.67
\end{aligned}
$$

In this fashion, the experimental data given in Table B-1 was reduced to the following: 
Axial location above bottom of active core, inches

$\begin{array}{rr}0 & 0.94 \\ 1 & 0.49 \\ 3 & 0.64 \\ 5 & 0.67 \\ 6.94 & 0.64 \\ 8.5 & 0.59 \\ 13.0 & 0.34 \\ 17.0 & 0.23 \\ 21.0 & 0.08\end{array}$

Average radial activity for plate a
04
0.64
0.67
59
0. 34
0.08

B. 3 CALCULATION OF AVERAGE POWER ALONG PLATE "a" IN AN AXIAL DIRECTION

A plot of the above data produced a curve shown in Fig. B-1. Using a planimeter, the area under the curve was obtained. This procedure was repeated for all the plates of element 12, giving the following:

\section{Plate \\ Position}

a

e

j

n

$r$

\section{Average Power Density}

0.427

0.383

0.300

0.260

0.216

A similar procedure was employed for all the stationary elements. The control rod curves, however, were plotted up to $7 \mathrm{in}$. instead of $21.6 \mathrm{in}$., since only 7 in. extended into the active core.

\section{B. 4 CALCUlation OF CELl A VERAGE}

The average power of element 12 was obtained by applying Simpson's 5 -point rule to the above data across the element in a north-south direction. This gave a cell average of 0.313. However, the use of the Simpson formula is only an approximation; the use of graphical integrations produces a cell average of about 5\% lower value. To compensate for the use of Simpson's approximation, all cell averages were multiplied by 0.946 . These cell averages for all elements and control rods are given in Table B-2. 


\section{B. 5 CALCULATION OF CORE AVERAGE}

The core average was obtained by weighting the cell average of each fuel element in the quadrant and dividing the sum of the weighted cell average by the weighting factor. The results, given in Table B-2, give a core average of 0.459 .

TABLE B-2

DATA FOR OBTAINING THE AVERAGE POWER OF THE SM-2 PRELIMINARY MOCKUP CORE

\begin{tabular}{|c|c|c|c|c|}
\hline $\begin{array}{c}\text { Element } \\
\text { No. } \\
\end{array}$ & $\begin{array}{l}\text { Cell * } \\
\text { Average } \\
\end{array}$ & $\begin{array}{l}\text { Weighting ** } \\
\text { Factor }\end{array}$ & $\begin{array}{c}\text { Weighted } \\
\text { Cell } \\
\text { Average } \\
\end{array}$ & $\begin{array}{l}\text { Fuel Element *** } \\
\text { Averages Normalized to } \\
\text { Core Average Equaı to One } \\
\text { (Relative Power) } \\
\end{array}$ \\
\hline 12 & 0. 296 & 1 & 0.296 & 0.645 \\
\hline 13 & 0.373 & $i$ & 0.373 & 0.812 \\
\hline 14 & 0.385 & $1 / 2$ & 0.192 & 0.839 \\
\hline 21 & 0.267 & 1 & 0.267 & 0.581 \\
\hline 22 & 0.443 & $i$ & 0.443 & 0.965 \\
\hline 23 & 0.548 & 1 & 0.548 & 1. 193 \\
\hline 31 & 0.334 & 1 & 0. 334 & 0.728 \\
\hline 33 & 0.587 & $i$ & 0.587 & 1. 278 \\
\hline 34 & 0.653 & $1 / 2$ & 0.326 & 1. 423 \\
\hline 41 & 0.376 & $1 / 2$ & 0.188 & 0.818 \\
\hline 42 & 0.545 & $1 / 2$ & 0.272 & 1. 187 \\
\hline 43 & 0.621 & $1 / 2$ & 0.310 & 1. 353 \\
\hline Rod A & 0.948 & $1 / 2 \times 0.265$ & 0.126 & 0.547 \\
\hline $\operatorname{Rod} \mathbf{F}$ & 0.883 & $1 \times 0.265$ & 0.234 & 0.509 \\
\hline \multirow[t]{2}{*}{ Rod C } & 1. 177 & $1 / 4 \times 0.265$ & $\underline{0.078}$ & 0.679 \\
\hline & & 9. 965 & 4. 574 & \\
\hline
\end{tabular}

* Average foil activation in element obtained by a combination of Simpson's rule averaging and graphical integration.

** Symmetry factor for the elements in one core quadrant. For control rods, this value is reduced by the ratio of the volume of uranium in a control rod actually inserted in the active core (a depth of $7 \mathrm{in}$.) to the volume of uranium in a stationary fuel element (length of 21.6 in. ). $\frac{\mathrm{V} \text { control rod }}{V \text { fuel element }}=\frac{16 \text { plates } \times 2.32^{\prime \prime} \text { wide } \times 0.03^{\prime \prime} \text { tk } \times 7.0^{\prime \prime} \text { in active core }}{18 \text { plates } \times 2.52^{\prime \prime} \text { wide } \times 0.03^{\prime \prime} \text { tk } \times 21.6^{\prime \prime} \text { long }}=0.265$

*** The core average is obtained from the following:

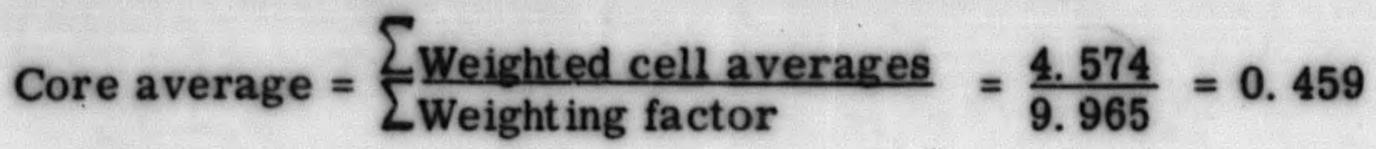


From this, the relative power of each element related to the core average is obtained by the following:

Relative power of stationary element $=\frac{\text { cell average for stationary element }}{\text { core average }}$

Relative power of control rod $=\frac{\text { cell average for control rod } \times 0.265}{\text { core average }}$

\section{B. 6 NORMALIZATION OF DATA}

Preliminary mockup data presented in this report have been normalized to this core average. Thus, for example, the activation data shown in Tables 3.1 to 3.15 are the raw data points divided by 0.459 to permit intercomparison to a common reference.

Final mockup data presented in Tables 3.16 to 3.30 were normalized to a final mockup core average of 0.432 obtained in a similar manner to that described in this Appendix. 


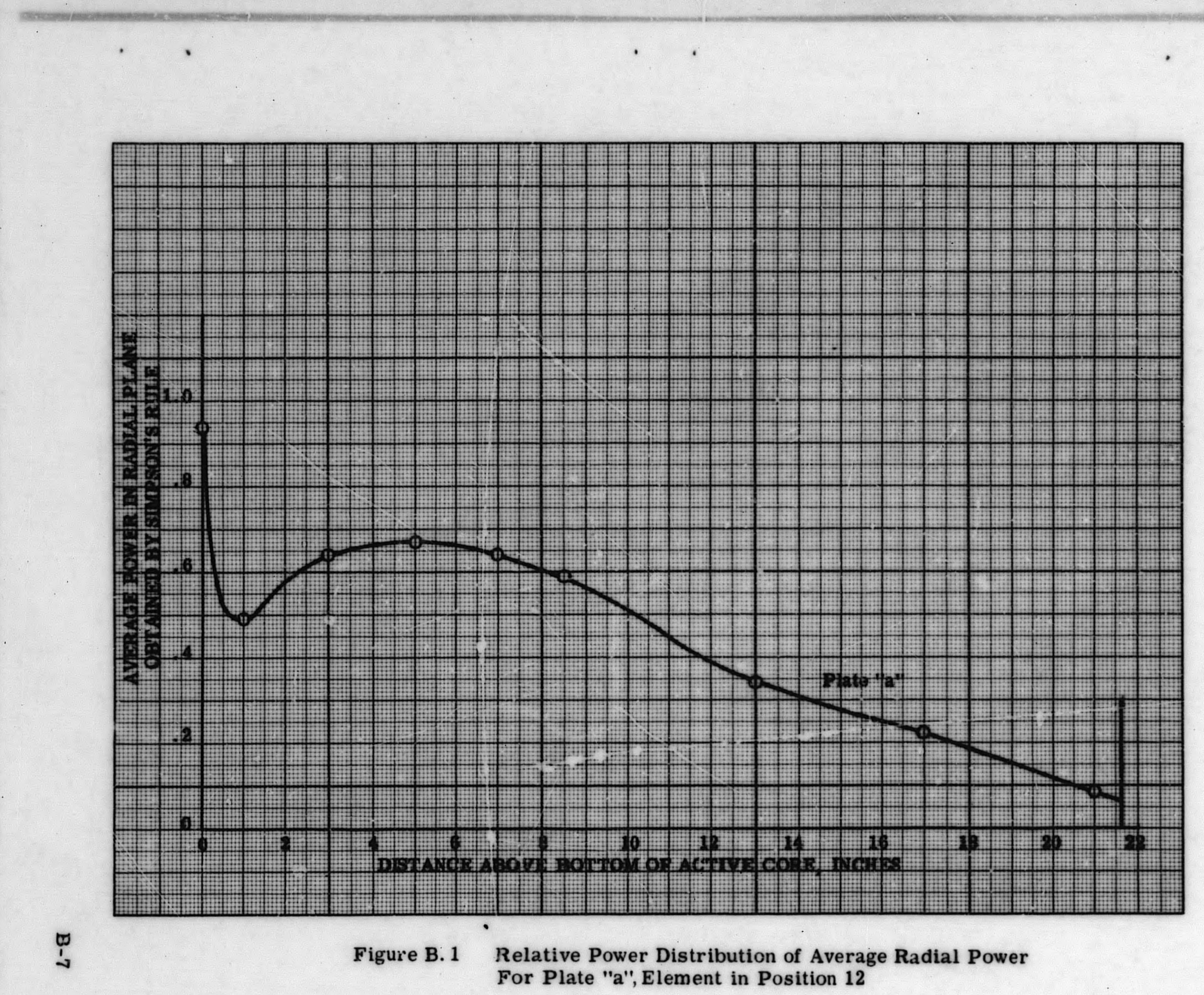

For Plate "a", Element in Position 12 


\section{APPENDIX C}

DETERMINATION OF B-10 CONTENT OF BORON TAPES

Table C. 1 lists the results of the B-10 determination obtained from reactivity measurements and from chemical analysis. The experiments and analysis were performed on two sets of boron impregnated Mylar tape, for reference: order one batch two (1-2), and order two batch one (2-1).

It should be noted that two separate chemical analyses were performed independently by Lucius Pitkin and by BMI.

\section{TABLE C. 1}

\section{B-10 ANALYSIS}

Method of B-10

Determination

Reactivity measurements

Chemical Analysis Lucius Pitkin (1).

Chemical Analysis Lucius Pitkin (2)

Chemical Analysis BMI

(2)

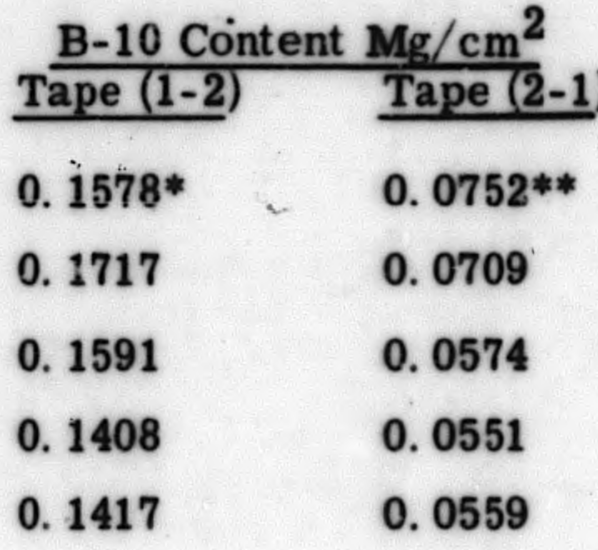

* Average of 3 measurements

** Average of 9 measurements

It is apparent that no clear and definite result could be derived from the above measurements because of the large variation among them. Although results obtained from reactivity measurements are in close agreement among themselves, thcy differ considerably from those obtained by chemical analysis. The same is true for the BMI results; they are consistent among themselves but inconsistent with the others. The Lucius Pitkin results are neither consistent among themselves nor fully agree with the other two. The method of manufacture of the boron tape precludes such large discrepancies. The choice of the reactivity measurements as the basis for estimating the B-10 content of the SM-2 mockup core was made because of their reproducibility.

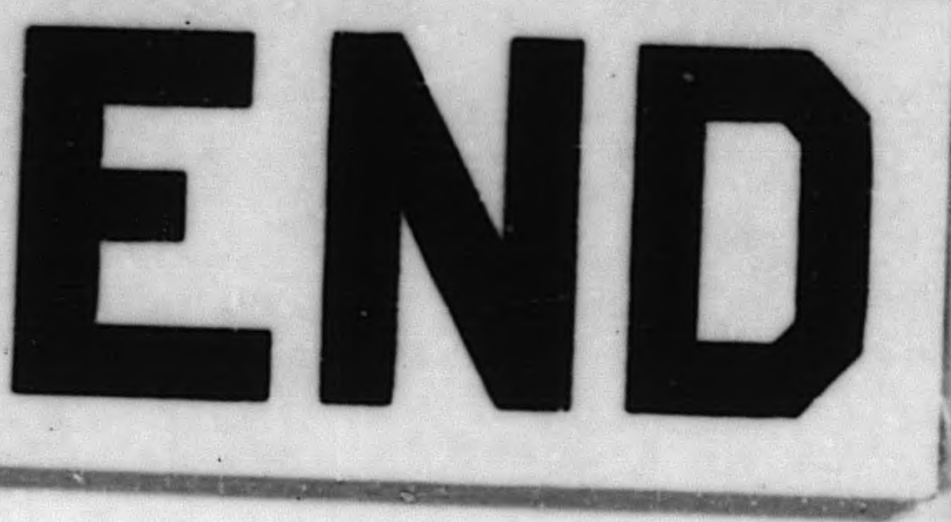

